\title{
Escalonamento \\ de \\ reservas de domínio
}

Maria do Carmo Garcia Noronha

\author{
DissertaÇÃo de Mestrado \\ APRESENTADA AO \\ Instituto de Matemática e Estatística \\ DA \\ Universidade de São Paulo \\ PARA \\ obtenção do GRAu de Mestre \\ EM \\ CiÊnCia da Computação
}

Curso: Mestrado em Ciência da Computação

Área de Concentração: Sistemas Operacionais

Orientadora: Prof. Dra. Dilma Menezes da Silva - IME - USP

Durante a elaboração deste trabalho, a autora recebeu apoio financeiro da UNISA

— São Paulo, maio de 2001 - 


\section{Escalonamento}

de

reservas de domínio

Este exemplar corresponde à redação final da dissertação devidamente corrigida e defendida por Maria do Carmo Garcia Noronha e aprovada pela comissão julgadora.

Banca examinadora:

- Profa. Dra. Dilma Menezes da Silva (orientadora) - IBM

- Prof. Dr. Carlos Eduardo Ferreira - IME-USP

- Profa. Dra. Liria Matsumoto Sato - EP-USP 
Às minhas filhas

Karina, Fernanda e Beatriz 


\section{Agradecimentos}

À minha orientadora Professora Dilma, pela paciência, incentivo, orientação e confiança depositada em meus estudos e neste trabalho.

Aos Professores Carlos Eduardo Ferreira e Liria Matsumoto Sato pela presença na comissão julgadora desta minha dissertação de Mestrado, pelas suas sugestões e críticas.

A todos do Instituto de Matemática e Estatística da USP, em especial aos colegas pela amizade; ao Professor Siang por me receber de volta com tanto carinho; ao Professor José Augusto pelas sugestões durante o desenvolvimento do programa de mestrado; aos Professores Marcelo Finger, Kunio e Ana Cristina pelas palavras de incentivo; ao Professor Leônidas pelas dicas na instalação do sistema operacional Linux; ao Professor Marco Dimas Gubitoso por sua participa, ao na banca de qualificação.

À Universidade de Santo Amaro, onde exerço a profissão de professora desde 1999, pelo apoio financeiro durante este tempo tornando possível a concretização deste trabalho.

À minha prima e Maria Elisa, por trazer-me de volta ao meio acadêmico, por acreditar em meu potencial, pelo apoio e incentivo.

Aos meus colegas e amigos Amarilis, Ana Paula, Ana Rosa, Arnaldo Mandel, Cao, Cibeli, Ediberto, Eugênio, Euler, Francisco Eloi, Franklin, Isabel, Jefferson, Jorge, Leandro, Liliane, Lucy Mari, Madson, Marquinhos, Milton, Myrthes, Mônica, Ricardo, Roberto, Said, Sirley, Uirá e tantos outros, pela força; aos meus estimados alunos, pela paciência e energia que recebi a cada dia.

Às minhas queridas amigas Eliana, Lorena, Marília e Verinha, pelo carinho e que sempre estiveram torcendo por mim.

Aos meus queridos irmãos Luiz Fernando e Mabel pelo apoio e incentivo constante, mesmo estando distante.

Ao meu esposo Ivan, que de sua maneira ajudou-me a recuperar minha coragem de seguir em frente nos meus ideais tão sonhados...

Às minhas filhas pelo carinho e compreensão que tiveram neste período difícil de nossas vidas.

À minha mãe pelo amor, por todo apoio e confiança durante toda a vida.

Ao meu pai,

Sua curiosidade em conhecer novas paisagens o fez caminhar para além desta vida.

... obrigada, por sempre me guiar e dar-me exemplos de conduta e sabedoria.

E a Deus pela força para superar os obstáculos e vencer desafios. 


\section{Resumo}

Pesquisas na área de Sistemas Operacionais indicam que os sistemas operacionais atuais não atendem adequadamente demandas específicas de aplicações de tempo real as quais apresentam comportamento definido segundo requisitos temporais, não oferecendo garantias de QoS. O desempenho de uma aplicação é, em parte, determinado pela carga do sistema. Oa parâmetros tradicionais de QoS incluem justiça, atraso e throughput.

Quando o objetivo é executar diversas aplicações de tempo real na mesma máquina, o sistema operacional precisa oferecer garantias de QoS tal que os recursos do sistema possam ser provisionados pelas aplicações tal que alcancem níveis desejados de desempenho previsível.

Sob esse contexto, dividimos nosso trabalho em três partes. Na primeira, discutimos o problema da alocação apropriada dos recursos para cada tipo de aplicação ser capaz de alcançar um nível específico de QoS e das limitações dos sistemas operacionais atuais. Apresentamos algumas soluções aplicáveis tratadas em suas soluções algorítmicas presentes na literatura, que utilizam esquemas de gerenciamento de recursos baseados em reserva de recurso e que oferecem algumas garantias de QoS.

Na segunda parte, nosso estudo está baseado em dois outros trabalhos de pesquisa.) (O primeiro diz respeito a um novo critério de QoS chamado serviço cumulativo. Discutimos a importância da garantia de serviço cumulativo para escalonadores tal que ofereça desempenho previsível para aplicações que requerem múltiplos recursos. O critério serviço cumulativo permite o relacionamento do total de serviço obtido por um processo sob uma política de escalonamento com o servico ideal que o processo teria acumulado executando em cada recurso se tivesse determinado uma fração de reserva de cada um destes. E refere-se também aos algoritmos de escalonamento: Move-to-Rear List Scheduling, Shortest Virtual Time First Round Robin e Weighted Round Robin Scheduling, que provêm as garantias de serviço cumulativo, justiça (compartilhamento do recurso proporcional) e atraso limitado. O segundo trabalho de pesquisa refere-se à introdução de um novo conceito em sistemas operacionais chamado reserva de domínios que permite um controle explícito sobre o provisionamento dos recursos do sistema pelas aplicações. Em geral, a cada reserva de domínio é designada uma certa fração de reserva de cada recurso (por exemplo, 25\%CPU, 50\%I/O). Apresentamos o sistema operacional experimental Eclipse que utiliza a abstração reserva de domínios e estes escalonadores.

$\mathrm{Na}$ terceira parte, estudamos as políticas de escalonamento acima, onde um quantum alocado para um domínio pode ser particionado, e suas propriedades. Desenvolvemos um ambiente para simulação baseado na proposta reserva de domínios, onde estas políticas foram implementadas com o intuito de analisarmos os efeitos dereserva de domínios sob um modelo de sistema e processos, o seu comportamento e eficácia diante de vários cenários. 


\begin{abstract}
The researches in the field of Operating Systems indicate that current general-purpose multiprogrammed operating systems do not support the specific demand for real-time applications, which have timing requirements, and not provide Quality of Service (QoS) guarantees since the performance of a single application is, in part, determined by the overall load on system. The traditional QoS parameters include fairness, delay, and throughput.

In order to support multiple real-time applications on a single platform, the operating system must provide QoS guarantees so that the system resources can be provisioned among applications to achieve desired levels of predictable performance.

Based on the context described, our work is divided into three parts. In the first, we discuss the problem of allocation appropriate resource capacity to achieve a specific level of QoS for an application based in its types and in current multiprogrammed operating systems limits. We present applicable solutions deals with algorithm solutions and present in literature, that use scheduling schemes in a resource allocation decision and offer some requirements of QoS.

In the second part, our work is based on two other specific researches. The first research is concerned a new criterion called cumulative service, hich complements other QoS parameters such as delay and fairness. We discuss the importance of cumulative service guarantee for ensuring predictable aggregate throughput for applications that require multiple resources. The cumulative service criterion relates the total service obtained by a process under a scheduling policy to the ideal service that the process would have accumulated by executing on each resource at a reserved rate. And it is concerned the following scheduling policies: Move-toRear List Scheduling, Shortest Virtual Time First Round Robin and Weighted Round Robin Scheduling. These scheduling policies provide a cumulative service guarantee as well as the traditional guarantees such as fairness (proportional sharing) and bounded delay. The second research deals of the introduction a new concept: the operating system abstration called reservation domains, which is intended to provide predictable QoS by controlling resource provisioning. In general, each reservation domain is assigned a certain fraction of each resource (e.g., 25\% CPU, 50\% I/O). We describe its implementation in the experimental system Eclipse.

In thirt part, we study these scheduling policies as generalization of the ones present above, we allow here the aggregate quantum allocated for a domain to be particioned, and its properties. We build a simulation environment, where those policies should be design and implement for the purpose of analisys the effects of reservation domains under a system and process model and the behaviour and effectiveness in various scenarios.
\end{abstract}




\section{Sumário}

1 Introdução 9

1.1 Introdução . . . . . . . . . . . . . . . . . . . . . . 9

1.1.1 Aplicações: Terminologia, Conceitos e Propriedades . . . . . . . . . . . 9

1.1 .2 Critérios na Execução de Processos . . . . . . . . . . . . . . . . . . . 13

1.1.3 Os Sistemas Operacionais versus Aplicações . . . . . . . . . . . . . . . . 19

1.2 A Caracterização do Problema e Nossa Abordagem . . . . . . . . . . . . . . . 20

1.2.1 Limitações dos Sistema Operacionais de Propósito Geral . . . . . . . . . 20

1.2.2 Limitações dos Sistemas Operacionais Atuais . . . . . . . . . . . . . . 21

1.2 .3 Motivação . . . . . . . . . . . . . . . . . . . . . 23

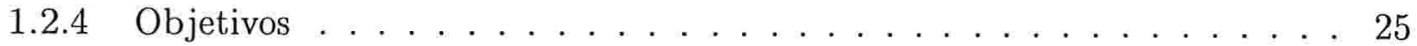

1.3 Organização dos Capítulos . . . . . . . . . . . . . . . . . 25

2 Abordagens e Conceitos $\quad 27$

2.1 Trabalhos Correlatos . . . . . . . . . . . . . . . . . . . . . 27

2.1.1 Lottery Scheduling e Stride Scheduling. . . . . . . . . . . . . . . 28

2.1.2 Weighted Fair Queuing e Earliest Eligible Virtual Deadline First . . . . 30

2.1.3 Start-Time Fair Queuing . . . . . . . . . . . . . . . . . . 33

2.1.4 Scheduler for Multimedia And Real Time . . . . . . . . . . . . 36

2.1.5 Processor Capacity Reserves. . . . . . . . . . . . . . . . . . . . . . . 39

2.1.6 Resource Kernels . . . . . . . . . . . . . . . . . . . . . . . . 43

2.1.7 Precomputed CPU scheduling . . . . . . . . . . . . . . . 45

2.1.8 Esquema de Gerenciamento de Recursos no Nemesis . . . . . . . . . . 48

2.1.9 Processor Scheduling in Virtual Computer Systems . . . . . . . . . . . 48 
2.1.10 As Garantias de QoS e o Move-To-Rear List Scheduling . . . . . . . . . 54

2.2 Conceitos Básicos no Escalonamneto de Reservas de Domínio . . . . . . . . . . 68

2.2 .1 Introdução . . . . . . . . . . . . . . . . . . . . . . . . 68

2.2 .2 Reserva de Domínios . . . . . . . . . . . . . . . . . . . . 69

2.2 .3 Garantias de QoS . . . . . . . . . . . . . . . . . . 70

2.2.4 Garantias de QoS para uma Política de Escalonamento baseada em Reserva de Domínio . . . . . . . . . . . . . . . . . . . . . . 72

3 Algoritmos de Escalonamento $\quad 75$

3.1 Move-to-Rear List Scheduling (MTR-LS) . . . . . . . . . . . . . . . 75

3.1 .1 A Política do MTR-LS . . . . . . . . . . . . . . . . . 75

3.1.2 Propriedades da Política do MTR-LS . . . . . . . . . . . . . . . . . 80

3.2 Shortest Virtual Time First Round Robin . . . . . . . . . . . . . . . . . . . . . 81

$3.2 .1 \quad$ A Política do SVF-RR . . . . . . . . . . . . . . . . 81

3.2 .2 Propriedades da Política do SVF-RR . . . . . . . . . . . . . 87

3.3 Weighted Round Robin Scheduling (WRR) . . . . . . . . . . . . . . 89

$3.3 .1 \quad$ A Política do WRR . . . . . . . . . . . . . . . . . . . . . . 89

3.3.2 Propriedades da Política do WRR . . . . . . . . . . . . . . . 93

4 Eclipse: Um Sistema Operacional com Reserva de Domínios 95

4.1 Introdução . . . . . . . . . . . . . . . . . . . . . . . . . . . 95

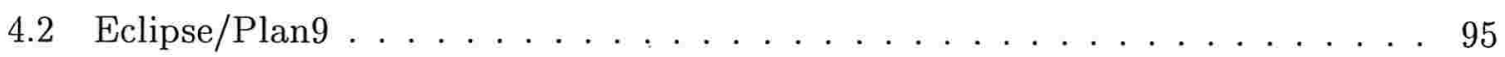

4.2 .1 Gerenciamento de Reservas de Domínios . . . . . . . . . . . . . . . . 96

$4.2 .2 \quad$ Abordagem do Escalonamento de CPU . . . . . . . . . . . . . . . . . 97

4.2 .3 Abordagem do Escalonamento de $\mathrm{I} / \mathrm{O} \quad \ldots \ldots$. . . . . . . . . . . . 97

4.2.4 Abordagem do Escalonamento de Memória . . . . . . . . . . . . . . . 99

4.2 .5 Operacionalidade . . . . . . . . . . . . . . . . . . . . . . 99

4.3 Eclipse/BSD . . . . . . . . . . . . . . . . . . . . . . . . . . . . . . . . . . 104

4.3 .1 Introdução . . . . . . . . . . . . . . . . . . . . . . . . . . . . 104

4.3 .2 Escalonadores Hierárquicos . . . . . . . . . . . . . . . . . . . . . . . 104

4.3.3 Modelo de Gerenciamento de Recursos . . . . . . . . . . . . . . . . . . . 106

4.3 .4 Escalonadores . . . . . . . . . . . . . . . . . . . . . . . . . 113 
4.3.5 Resultados Experimentais . . . . . . . . . . . . . . . . . 116

4.3 .6 Conclusões . . . . . . . . . . . . . . . . . . . . . . . . . 122

5 Procedimento Experimental 123

5.1 Introdução . . . . . . . . . . . . . . . . . . . . . . . . . . . 123

5.2 Visão Geral do rdsim . . . . . . . . . . . . . . . . . . . . . . . . . . . . . . . 124

5.3 Estratégia Geral do rdsim . . . . . . . . . . . . . . . . . . . . 125

5.4 rdsim: Especificação e Implementação do Ambiente Computacional . . . . . . . 125

5.4.1 Gerenciamento das Reservas de Domínios . . . . . . . . . . . . . . 126

5.5 rdsim: Simulação das Políticas dos Recursos . . . . . . . . . . . . . . . . . 129

5.5.1 Gerenciamento de Processos no rdsim . . . . . . . . . . . . . . . 130

5.5.2 Procedimentos Gerais na Execução das Tarefas . . . . . . . . . . . . 132

5.5.3 Escalonamento dos Recursos . . . . . . . . . . . . . . . . . . . . 135

5.6 Operacionalidade e Código Fonte . . . . . . . . . . . . . . . . . . . 144

6 Análise de Desempenho dos Algoritmos de Escalonamento 145

6.1 Introdução . . . . . . . . . . . . . . . . . . . . . . . . . . . 145

6.2 Método de Análise . . . . . . . . . . . . . . . . . . . . . . . 145

6.2 .1 Objetivo de Análise . . . . . . . . . . . . . . . . . . . 146

6.3 Ambiente e Premissas . . . . . . . . . . . . . . . . . . . . . . 146

6.3.1 A Escolha e Descrição das Variáveis . . . . . . . . . . . . . . . . . 146

6.3.2 Limitações nos Experimentos . . . . . . . . . . . . . . . . . . . . . . . 149

6.4 Experimentos e Avaliações . . . . . . . . . . . . . . . . . . . . . . . 150

6.4 .11 Domínio, $n$ Tarefas e 1 Recurso: . . . . . . . . . . . . . . . . 150

6.4 .21 Domínio, $n$ Tarefas e 2 Recursos: . . . . . . . . . . . . . . . . . . 151

$6.4 .3 m$ Domínios, $m$ Tarefas e 1 Recurso: . . . . . . . . . . . . . . . . . 152

$6.4 .4 m$ Domínios, $m$ Tarefas e 2 Recursos: . . . . . . . . . . . . . . 156

6.4.5 $m$ Domínios, $m$ Tarefas sem reserva explícita e 2 Recursos: . . . . . . 158

6.4.6 $m$ Domínios, $m$ Tarefas ( $m-1$ sem reserva explícita) e 2 Recursos: . . . 159

6.4.7 $m$ Domínios, $n$ Tarefas, onde $m>1$ e $n>m: \ldots \ldots . \ldots 162$

6.4 .8 Cenários Adicionais . . . . . . . . . . . . . . . . . . . . . . . . . . . . . 164 


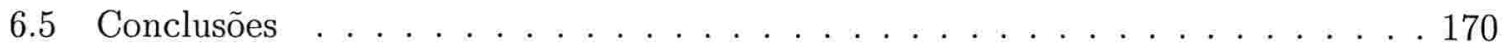

7 Conclusões e Trabalhos Futuros 172

7.1 Desafios Enfrentados e As Soluções . . . . . . . . . . . . . . . . . . . 173

7.2 Sugestões e Pesquisas Futuras . . . . . . . . . . . . . . . . . . . . 174

7.3 Conclusão Final . . . . . . . . . . . . . . . . . . . . . . . . . . 175 


\section{Lista de Figuras}

2.1 Descrição Formal do Algoritmo SFQ . . . . . . . . . . . . . . . . . . . . . 35

2.2 Procedimento Nível_ 1 para o SMART. . . . . . . . . . . . . . . . . 37

2.3 Procedimento Nível_2 para o SMART . . . . . . . . . . . . . . . . . . . . . . . . . . 38

2.4 Um Exemplo de Serviço Cumulativo. . . . . . . . . . . . . . . . . . . . . . . 59

2.5 Procedimento Inicia para o MTR-LS. . . . . . . . . . . . . . . . . 62

2.6 Procedimento Executa um Processo para o MTR-LS. . . . . . . . . . . . . . . 63

2.7 Procedimento MTR-LS . . . . . . . . . . . . . . . . . . . . . 63

2.8 Um Sistema de Reservas de Domínios. . . . . . . . . . . . . . . . . . . . . . 69

3.1 Procedimento Decision Epoch para o MTR-LS. . . . . . . . . . . . . . . . 76

3.2 Procedimento Atualiza Domínio para o MTR-LS. . . . . . . . . . . . . . 77

3.3 Procedimento Executa um Domínio para o MTR-LS. . . . . . . . . . . . . . . 78

3.4 Um exemplo do escalonamento MTR-LS. . . . . . . . . . . . . . . . . . . 78

3.5 Procedimento Inicia Tokens para o SVF-RR . . . . . . . . . . . . . . . . . . 82

3.6 Procedimento Decision Epoch para o SVF-RR. . . . . . . . . . . . . 83

3.7 Procedimento Atualiza Domínio para o SVF-RR . . . . . . . . . . . . . . 83

3.8 Procedimento Executa um Processo no SVF-RR. . . . . . . . . . . . . . . . 84

3.9 Procedimento Decision Epoch para o WRR . . . . . . . . . . . . . . . 90

3.10 Procedimento Atualiza Domínio para o WRR. . . . . . . . . . . . . . . . 90

3.11 Procedimento Executa um Processo no WRR . . . . . . . . . . . . . . . . . . . 91

4.1 Escalonamento de I/O . . . . . . . . . . . . . . . . . . . . . . . . . 98

4.2 Escalonamento de Memória Física. . . . . . . . . . . . . . . . . . . . . . . . . . 99

4.3 Comportamento do MPEG player diante da Reserva de CPU. . . . . . . . . . . . . . . 101 
4.4 Comportamento do sleeper. . . . . . . . . . . . . . . . . . . . . . . . . 102

4.5 Comportamento das aplicações $\mathrm{I} / \mathrm{O}$ sob reserva de CPU. . . . . . . . . . . . . . . . 103

4.6 Exemplo de Escalonadores Hieráquicos. . . . . . . . . . . . . . . . . . . . 105

4.7 Exemplo de Diretório /reserv. . . . . . . . . . . . . . . . . . . . . 107

4.8 Configuração para os Experimentos. . . . . . . . . . . . . . . . . . . . . . . . 117

4.9 Throughput para o site de Interesse. . . . . . . . . . . . . . . . . . . . . . . 118

4.10 Tempos de Resposta para o site de Interesse. . . . . . . . . . . . . . . . . . . . . 118

4.11 O site de Interesse diante da Largura de Banda do Disco. . . . . . . . . . . . . . . . . 119

4.12 O site de Interesse diante da Largura de Banda do Link de Saída. . . . . . . . . . . . . 120

4.13 Comportamento diante do Sobrecarregamento na Recepção da Rede. . . . . . . . . . . . . 121

4.14 Eclipse/BSD garante progresso de acordo com a reserva de CPU. . . . . . . . . . . . . . . 121

5.1 Implementação da Função Monta_Listas_por_Dominio para o MTR-LS. . . . . . . . . . . 136

5.2 Implementação da Função Simula_Mtrls para o MTR-LS. . . . . . . . . . . . . . . . 136

5.3 Implementação da Função Decision_Epoch para o MTR-LS. . . . . . . . . . . . . . 137

5.4 Implementação da Função Run_A_Domain para o MTR-LS. . . . . . . . . . . . . . . 137

5.5 Implementação da Função Update_Domain para o MTR-LS. . . . . . . . . . . . . . . . 138

5.6 Implementação da Função Execute_Domain para o MTR-LS. . . . . . . . . . . . . . . . . 139

5.7 Implementação da Função Simula_SVFRR para o SVF-RR. . . . . . . . . . . . . . . . . 140

5.8 Implementação da Função Inicia_lista_de_tokens para o SVF-RR. . . . . . . . . . . . . . 141

5.9 Implementação da Função Atualiza_Menor_Token para o SVF-RR. . . . . . . . . . . . . 141

5.10 Implementação da Função Escolhe_Tarefa_svfrr para o SVF-RR. . . . . . . . . . . . . . 142

5.11 Implementação da Função Simula_WRR para o WRR. . . . . . . . . . . . . . . . . . . 143

6.1 Tarefa de Referência para 8 Domínios e um Recurso. . . . . . . . . . . . . . . . . . 153

6.2 Tarefa de Referência para 4 Domínios e um Recurso. . . . . . . . . . . . . . . . . . . . 154

6.3 Tarefa de Referência para 2 Domínios e um Recurso. . . . . . . . . . . . . . . . . . . . . 154

6.4 Tarefa de Referência utilizando $40 \%$ do Ciclo do Recurso. . . . . . . . . . . . . . . . . 155

6.5 Tarefa de Referência utilizando $70 \%$ do Ciclo do Recurso. . . . . . . . . . . . . . . . 156

6.62 Domínios, 2 Tarefas e 2 Recursos. . . . . . . . . . . . . . . . . . . . . . 157

6.74 Domínios, 4 Tarefas e 2 Recursos. . . . . . . . . . . . . . . . . . . . . 157

6.8 8 Domínios, 8 Tarefas e 2 Recursos. . . . . . . . . . . . . . . . . . . . . 158 
6.9 Cenário a: Comportamento para Tarefas gastando $10 \%$ de $r_{1}$ e $80 \%$ de $r_{2}$. . . . . . . 160

6.10 Cenário $b$ : Comportamento para Tarefas gastando $45 \%$ de $r_{1}$ e $45 \%$ de $r_{2}$. . . . . . . . . 160

6.11 Cenário $c$ : Comportamento para Tarefas gastando $80 \%$ de $r_{1}$ e $10 \%$ de $r_{2}$. . . . . . . . . . 161

6.12 Cenário $d$ : Comportamento para Tarefas gastando $10 \%$ de $r_{1}$ e $10 \%$ de $r_{2}$. . . . . . . . . 161

6.13 Cenário e: Comportamento para Tarefas Aleatórias. . . . . . . . . . . . . . . . . . 162

6.14 Comportamento para 3 Tarefas e 2 Domínios. . . . . . . . . . . . . . . . . . . 162

6.15 Comportamento para 5 Tarefas e 4 Domínios. . . . . . . . . . . . . . . . . . . 163

6.16 Comportamento para 9 Tarefas e 8 Domínios. . . . . . . . . . . . . . . . 163

6.17 Tarefa de Referência e 8 Tarefas Concorrentes . . . . . . . . . . . . . . . . . . . . . . 164

6.18 Comportamento da Tarefa de Referência para 10\% de Reserva dos Recursos em seu Domínio. 165

6.19 Comportamento da Tarefa de Referência para 20\% de Reserva dos Recursos em seu Domínio. 166

6.20 Comportamento da Tarefa de Referência para 30\% de Reserva dos Recursos em seu Domínio. 166

6.21 Tarefa de Referência sob Diferentes Reservas de $r_{1}$ em $D_{2}$. . . . . . . . . . . . . . . . . . 167

6.22 Tarefa de Referência sob Diferentes Reservas de $r_{1}$ e $r_{2}$ em $D_{2} \ldots$. . . . . . . . . . . . . . 168

6.23 Tempos de Resposta cumpridos. . . . . . . . . . . . . . . . . . . . . . . . . . 169

6.24 Tempos de Resposta cumpridos. . . . . . . . . . . . . . . . . . . . . . . . . . 170 


\section{Lista de Tabelas}

3.1 Listas dos Tokens Iniciais utilizando SVF-RR. . . . . . . . . . . . . . . . 85

4.1 Arquivos de Controle para Reserva de Recursos. . . . . . . . . . . . . . . . . . . . 97

5.1 Exemplo de Uma Tabela Control. . . . . . . . . . . . . . . . . . . . . 126

6.1 Tipos de Tarefas Iguais. . . . . . . . . . . . . . . . . . . . . . . . . . 148

6.2 Tarefas Aleatórias. . . . . . . . . . . . . . . . . . . . . . . . . . 149

6.3 Tipos de Conjuntos de Tarefas com Carga Mista. . . . . . . . . . . . . . . . . . 149

6.4 Tempos para Tarefas Iguais utilizando um Recurso Específico. . . . . . . . . . . . . . 151

6.5 Tempos para Tarefas Aleatórias utilizando um Recurso Específico. . . . . . . . . . . . . . 151

6.6 Tempos para Tarefas Iguais utilizando Dois Recursos. . . . . . . . . . . . . . . . 151

6.7 Tempos para Tarefas Aleatórias utilizando Dois Recursos. . . . . . . . . . . . . . . 152

6.8 Reserva dos Recursos para os Domínios no Sistema. . . . . . . . . . . . . . . 155

6.9 Cenários com Ciclos de Serviço em Dois Recursos. . . . . . . . . . . . . . 156

6.10 Comportamento da Tarefa de Referência Sobrecarregando Um dos Recursos. . . . . . . . 159

6.11 Tipos de Cenários Sobrecarregando o Sistema. . . . . . . . . . . . . . . . . 159

6.12 Reserva dos Recursos para os Domínios $D_{2}$ e $D_{3} \ldots \ldots \ldots \ldots$. . . . . . . 168 


\section{Capítulo 1}

\section{Introdução}

Este capítulo apresenta uma introdução geral aos problemas de gerenciamento dos recursos em ambientes computacionais multiprogramáveis.

Inicialmente são apresentadas a terminologia, os conceitos utilizados e as propriedades fundamentais das aplicações em um sistema. A seguir, é discutida a problemática dos ambientes computacionais multiprogramáveis e são introduzidos os objetivos de nosso trabalho.

\subsection{Introdução}

Desde o surgimento dos primeiros computadores em escala comercial, há quatro décadas, houve um avanço tecnológico muito grande nas diversas áreas da computação.

Tal se deve, especialmente, à fenomenal evolução do hardware dos computadores. Inicialmente, tínhamos máquinas lentas e caras; os equipamentos e os sistema operacionais disponíveis permitiam a automatização de aplicações simples e repetitivas [Tan92]. Atualmente, o desenvolvimento de novas opções do hardware com um maior número de equipamentos cada vez mais velozes, compactos e baratos e a implementação de novas técnicas de multiprogramação em sistemas operacionais permitem o desenvolvimento de software cada vez mais mais sofisticados e complexos. Com a grande disponibilidade desse poder computacional, tornam-se cada vez mais comuns as aplicações com requisitos de tempo real.

\subsubsection{Aplicações: Terminologia, Conceitos e Propriedades}

No nosso contexto uma aplicação pode ser, desde um simples sistema transformacional que calcula valores de saída a partir de valores de entrada e depois terminam seus processamentos, até um sistema computacional que interaja permanentemente com os seus ambientes.

Aplicações com requisitos de tempo real são aquelas que apresentam comportamentos definidos segundo restrições temporais. Essas aplicações variam muito em relação à sua com- 
plexidade e às necessidades de garantia no atendimento de restrições temporais.

Entre as aplicações de tempo real mais simples estão os controladores inteligentes embutidos em eletrodomésticos. Na outra extremidade do espectro de complexidade estão os sistemas de controle em fábricas automatizadas, os sistemas militares, de defesa e os de controle de tráfego aéreo.

Algumas aplicações de tempo real apresentam restrições de tempo mais rigorosas do que outras; entre essas encontram-se os sistemas robóticos, equipamentos médico-hospitalares e sistemas de controle. Entre as que não apresentam restrições tão críticas podemos citar as teleconferências e as de multimídia em geral.

Todas essas aplicações que apresentam a característica adicional de estarem sujeitas a restrições temporais, são agrupadas no que é usualmente identificado como Sistema de Tempo Real.

\section{Conceituação}

Uma grande parte dos sistemas computacionais atuais interagem permanentemente com seus ambientes. Dentre estes, temos os que reagem enviando respostas continuamente a estímulos de entrada vindos de seus ambientes. Um sistema de tempo real é um sistema computacional que deve reagir a estímulos oriundos do seu ambiente em prazos específicos [SR90]. Sistemas de tempo real de uma forma geral se encaixam neste conceito:

- Um Sistema de Tempo Real é um sistema computacional que deve reagir a estímulos oriundos do seu ambiente em prazos específicos.

$\mathrm{O}$ atendimento destes prazos resulta em requisitos temporais sobre o comportamento do sistema. Em conseqüência, em cada reação, o sistema de tempo real deve entregar um resultado correto dentro de um prazo específico, sob pena de ocorrer uma falha temporal. Portanto, em geral, a corretude depende não apenas do resultado lógico da computação (correção lógica), mas também do tempo no qual os resultados são produzidos (correção temporal). Uma reação que ocorra além do prazo especificado pode ser sem utilidade ou até provocar conseqüências fatais.

Então, numa generalização:

- Um Sistema de Tempo Real deve ser capaz de oferecer garantias de correção temporal para o fornecimento de todos os seus serviços ${ }^{1}$ que apresentem restrições temporais.

Ou ainda, - Um Sistema de Tempo Real deve ser capaz de oferecer garantias de tempo para o fornecimento de todos os seus serviços que apresentem restrições temporais [FdSFoSdO00].

\footnotetext{
${ }^{1}$ Serviço de Tempo Real é um serviço que deve ser oferecido dentro de restrições de tempo impostas por exigências externas ao sistema.
} 


\section{Previsibilidade}

É ilusão acreditar que o problema de tempo real se resolve apenas com o aumento da velocidade computacional. Ter tempo de resposta curto, não garante os requisitos temporais. Para os sistemas de tempo real, mais do que rapidez importa a previsibilidade [SR88].

Um sistema de tempo real é dito previsível quando, independentemente de variações que ocorram no equipamento, na carga máxima gerada pelo ambiente em um intervalo de tempo entre cada reação do sistema e no limite de tempo de execução para atender os seus requisitos, o comportamento do sistema pode ser antecipado, antes de sua execução.

Portanto, para um sistema de tempo real ser previsivel precisa-se conhecer a priori todo o seu comportamento, quando se pode antecipar que todos os seus prazos serão atendidos. Ou seja, a previsibilidade está associada a uma antecipação determinista do comportamento temporal do sistema.

\section{Classificação dos Sistemas de Tempo Real}

Os sistemas de tempo real podem ser classificados a partir do ponto de vista da segurança em duas grandes categorias [SR93]: hard e soft.

Um sistema de tempo real hard é identificado como aquele em que os limites nos tempos de resposta precisam ser garantidos ou se deve garantir que um valor máximo de atraso não seja ultrapassado pela aplicação. $\mathrm{O}$ não atendimento de algum requisito temporal pode resultar em conseqüências catastróficas em termos financeiros, ambientais ou, até mesmo, de vidas humanas. A esta categoria está associada a previsibilidade determinista.

Em contrapartida, em sistemas de tempo real soft, os limites de tempo de resposta são apenas indicações de quando seria o melhor momento para concluir uma aplicação. O não atendimento de algum requisito temporal pode diminuir o desempenho do sistema porém não resulta em conseqüências catastróficas. A esta categoria de sistemas está associada a previsibilidade probabilista (quando se pode basear em estimativas ou simulações que estipulam probabilidades dos prazos a serem atendidos).

Em sistemas onde as noções de tempo e de concorrência são tratadas explicitamente, conceitos e técnicas de escalonamento formam o ponto central na previsibilidade do comportamento de sistemas de tempo real.

Na seqüência introduzimos um conjunto de conceitos que permitem a caracterização de um escalonamento. Estaremos apresentando os conceitos de forma generalizada e não apenas para sistemas de tempo real.

\section{Modelo de Processos}

Os elementos ativos que constituem uma aplicação em execução são referenciados, na literatura da àrea, por vários termos, tais como atividades, processos, tarefas ou threads. 
Estes termos podem assumir diferentes significados dependendo do contexto ou da tecnologia em questão. Adotamos o termo clássico processo.

Cada processo é uma entidade independente [Tan92], com seu próprio fluxo de controle e estado interno. Processos formam as unidades de processamento seqüencial que concorrem sobre um ou mais recursos computacionais (tais como, CPU, memória, discos e interfaces de rede) de um sistema e, muitas vezes, têm necessidade de interagir com outros.

Durante a execução de um processo, alguns eventos podem ocorrer obrigando a intervenção do sistema operacional; esta é chamada de interrupção. Pode ser o resultado da execução de instruções do próprio processo, gerada pelo sistema operacional ou por algum dispositivo de hardware. A interrupção é o mecanismo que tornou possível a implementação da concorrência nos computadores.

Um simples processo de tempo real, além da correção lógica, deve satisfazer seus prazos e restrições temporais ou seja, apresentar também uma correção temporal.

\section{Restrições Temporais}

Todos os processos de tempo real tipicamente estão sujeitos a prazos: os seus deadlines. A princípio, um processo de tempo real deve ser concluído antes de seu prazo. As conseqüências de um processo ser concluído após o seu prazo define dois tipos de processos de tempo real:

- Processos Críticos (processos "hard"): Um processo é dito crítico quando ao ser completado depois de seu deadline pode causar conseqüências catastróficas e danos irreversíveis.

- Processos Não Críticos (processos "soft"): Esses processos quando se completam após os seus deadlines, no máximo, implicam numa diminuição de desempenho da aplicação.

Outra característica temporal de processos em sistemas de tempo real está baseada na regularidade de suas ativações. Segundo suas freqüências de ativações, os modelos de processos comportam dois tipos de processos:

- Periódicos. Quando as ativações de um processo ocorrem, numa seqüência infinita, uma só ativação por intervalo de tempo regular chamado de período, esse processo é identificado como periódico. As ativações de um processo periódico formam o conjunto de diferentes instâncias do processo.

- Aperiódicos. Quando a ativação de um processo responde a eventos internos ou externos definindo uma característica aleatória nessas ativações, um processo é dito aperiódico. Como subconjunto destes, temos os processos esporádicos que apresentam como característica principal a restrição de um intervalo mínimo conhecido entre duas ativações consecutivas.

Os processos periódicos pela regularidade e portanto pela previsibilidade, usualmente são associados a processos críticos, e os esporádicos pela sua característica, também.

Os processos aperiódicos pela falta de regularidade e portanto não podendo prever as suas 
ativações, usualmente são associados a processos não críticos.

Outras restrições temporais são importantes na definição do comportamento temporal de um processo de tempo real:

- tempo necessário para execução de um processo.

- tempo relativo ao instante de início de processamento do processo em uma ativação.

- tempo relativo ao instante em que se completa a execução do processo em uma ativação.

- tempo de chegada de um processo que corresponde ao instante em que o escalonador toma conhecimento de uma ativação desse processo (para processos periódicos, o tempo de chegada coincide com o início do período da ativação).

- tempo de liberação de um processo que coincide com o instante de sua inclusão na fila de prontos para executar (dependendo do modelo de processo assumido esse tempo pode ou não coincidir com o tempo de chegada do processo).

\subsubsection{Critérios na Execução de Processos}

Nas diversas ocasiões em que dois ou mais processos estão logicamente em situação de acessar um recurso, o sistema operacional deve decidir qual deles vai utilizá-lo primeiro. A possibilidade de um recurso estar acessível a diversos processos leva todo sistema operacional a possuir critérios para determinar qual a ordem para escolha dos vários processos que concorrem pela sua utilização.

Os objetivos na execução de processos usualmente almejados são: (1) manter o recurso ocupado tanto quanto possível, (2) balancear a utilização do processador entre os diversos processos no sistema, (3) maximizar o throughput ${ }^{2}$ e (4) minimizar o turnaround ${ }^{3}$, oferecendo tempos de resposta $a^{4}$ razoáveis para os usuários interativos.

Para atender a esses objetivos, muitas vezes conflitantes, os sistemas operacionais devem levar em consideração características dos processos ou seja, se um processo é do tipo:

- batch. Um processo é do tipo batch quando precisa de pouca interação com o usuário.

- interativo. Um processo é do tipo interativo quando existe muita comunicação entre o usuário e o sistema.

- CPU-bound. Um processo é dito CPU-bound quando bloqueia pouco por outros recursos, por precisar essencialmente da CPU.

- I/O-bound. Um processo é chamado de I/O-bound quando a maior parte de suas operações são de entrada/saída.

- tempo real. Definido anteriormente.

O processo de seleção é uma das principais funções realizadas por um sistema, sendo conhecido como escalonamento [Tan92]. A parte do sistema operacional que toma esta decisão é denominada escalonador. A política que define uma precedência entre os processos no estado

\footnotetext{
${ }^{2}$ Número de processos executados num intervalo de tempo.

${ }^{3}$ Tempo do processo desde sua admissão no sistema até seu término, incluindo tempos de espera.

${ }^{4}$ Tempo decorrido do momento da submissão de um pedido ao sistema até a primeira resposta produzida (geralmente limitado pela velocidade do dispositivo de saída).
} 
pronto é chamada algoritmo de escalonamento. Um algoritmo de escalonamento expressa uma política de escalonamento. Na maioria das vezes, o tratamento de interrupções e os detalhes de ativar ou bloquear processos estão ocultos dentro do escalonador.

\section{Escalonamento não-preemptivo}

Um escalonamento é do tipo não-preemptivo quando um processo ganha o direito de utilizar o recurso, nenhum outro processo pode lhe tirar esse recurso. Alguns dos escalonamentos não-preemptivos:

\section{- Escalonamento First-In-First-Out (FIFO)}

No escalonamento FIFO o processo que chegar primeiro é o primeiro a ser selecionado para utilizar o recurso. Seu algoritmo é bastante simples de ser implementado, sendo necessária apenas uma fila, onde os processos que passam para o estado de pronto entram no seu final e são escalonados quando chegarem ao seu início.

\section{- Escalonamento Shortest Job First (SJF)}

No escalonamento SJF tem-se associado a cada processo o seu tempo de execução no recurso. Dessa forma, quando o recurso está livre, o processo em estado de pronto que precisar de menos tempo de uso no recurso é o selecionado.

\section{Escalonamento preemptivo}

A estratégia de permitir suspensão temporária de processos que poderiam continuar executando é denominada escalonamento preemptivo, ou seja, um escalonamento do tipo preemptivo é aquele que pode confiscar recursos concedidos.

Alguns dos principais escalonamentos preemptivos:

- Escalonamento Round Robin (RR)

O escalonamento RR é um dos algoritmos mais antigos, simples, justo e portanto muito utilizado. A cada processo é atribuído um tempo-limite, durante o qual ele poderá utilizar o recurso de forma contínua. A este intervalo de tempo dá-se o nome de quantum ou timeslice. Mesmo que o processo ainda precise executar, depois de esgotado seu quantum, ele cede lugar a um outro processo. Se o processo for bloqueado ou terminar antes de esgotado seu quantum, a comutação se dará no momento do bloqueio ou no término do processamento. Seu algoritmo é bastante simples de ser implementado. O escalonador mantém uma lista de processos prontos, quando o quantum de um processo se esgota, o processo é colocado no final da fila de prontos e será escalonado novamente quando chegar ao início desta fila. Esse escalonamento assume de forma implícita que todos os processos são igualmente importantes. 


\section{- Escalonamento com Prioridade}

O escalonamento com prioridade surgiu da necessidade de se considerar fatores externos na escolha para o acesso aos recursos. A cada processo é associada uma prioridade, e o processo pronto com a maior prioridade será aquele que vai executar primeiro. Toda vez que um processo for para a fila de prontos com prioridade superior ao do processo em execução, o sistema deverá interromper o processo corrente, colocá-lo no estado de pronto e selecionar o de maior prioridade para ser executado. Esse mecanismo é definido como preempção por prioridade. Para evitar que processos com alta prioridade monopolizem o recurso, o escalonador decrementa a prioridade do processo que está executando no recurso, a cada interrupção.

As prioridades podem ser atribuídas a processos de forma estática ou dinâmica.

A prioridade é estática quando não é modificada durante a existência do processo. Apesar da simplicidade de sua implementação, pode ocasionar tempos de resposta altos.

Na prioridade dinâmica, a prioridade do processo pode ser ajustada de acordo com o tipo de processamento realizado pelo processo e/ou carga do sistema. Por exemplo, um escalonador com prioridade dinâmica pode adotar uma política tal que todo processo ao sair do estado de espera recebe um acréscimo à sua prioridade.

\section{- Escalonamento por Múltiplas Filas}

Como os processos no sistema possuem características de processamento diferentes, é difícil que um único mecanismo de escalonamento seja adequado a todos os tipos de processo. Uma boa política seria classificar os processos em função do tipo de processamento realizado e aplicar a cada grupo mecanismos de escalonamentos distintos.

Partindo desse princípio, implementam-se diversas filas de processos prontos, onde cada processo é associado exclusivamente a uma delas, através de uma prévia classificação. Cada fila pode possuir um mecanismo próprio de escalonamento, em função das características do processo, e uma prioridade a ela associada. O sistema só pode escalonar processos de uma fila se todas as outras, de prioridade maior, estiverem vazias. Os processos podem mudar de classe, de forma que ao término de cada utilização do processador uma nova classificação possa ser efetuada para que um processo que comece utilizando muito o processador e depois se torne interativo não acabe sendo prejudicado. Várias políticas podem ser adotadas utilizando-se múltiplas filas [CDM97].

\section{- Escalonamento Garantido}

Uma forma diferente de tratar a questão do escalonamento é fazer promessas a uma aplicação a respeito do desempenho, e cumpri-las de alguma forma. Por exemplo, uma promessa bem realista e muito fácil de cumprir é a de que se houver $n$ aplicações ativas no sistema, cada uma vai receber em torno de $\frac{1}{n}$ da capacidade de processamento do recurso. Para tal, o sistema deve controlar o total de tempo de processamento do recurso que a aplicação utilizou desde o momento em que tornou-se ativa. O escalonador então calcula o tempo que cada aplicação deveria merecer, simplesmente dividindo o tempo decorrido desde sua ativação por $n$. Como o tempo que cada aplicação gastou até o momento é conhecido, é fácil computar a 
razão entre o tempo realmente concedido e o tempo prometido à aplicação.

\section{- Escalonamento de Sistemas de Tempo Real}

\section{Relações de Precedência e de Exclusão}

Muitas vezes em aplicações de tempo real (ou outras), os processamentos não podem executar em ordem arbitrária mas sim, em ordens previamente definidas. Implicações semânticas definem relações de precedência entre os processos da aplicação determinando uma ordem parcial entre elas. As relações de precedência podem também expressar a dependência que processos possuem de informações (ou mesmo sinais de sincronização).

O compartilhamento de recursos em exclusão mútua define outras formas de relações entre processos também significativas em escalonamento de tempo real; são as relações de exclusão. As relações de exclusão em escalonamentos dirigidos a prioridade podem levar a inversões de prioridades onde processos são bloqueados por processos menos prioritários.

As relações de precedência podem ser definidas através das necessidades de comunicação e sincronização entre os processos.

Portanto, as restrições temporais, as relações de precedência e de exclusão, usualmente impostas sobre os processos de tempo real, são determinantes na definição de um modelo de processo que é parte integrante de uma aplicação de tempo real a ser escalonada [CSR88].

De maneira geral são escalonamentos preemptivos, pois permitem que o sistema dê atenção imediata a processos mais prioritários, além de proporcionarem melhores tempos de resposta em sistemas de tempo compartilhado. Possibilitam ainda o compartilhamento do processador de uma maneira mais uniforme. A política de escalonamento deve estabelecer os critérios de preempção; no escalonamento de sistemas de tempo real não existe o conceito de quantum ou time-slice.

Tipicamente, uma solução de tempo real prescreve garantia de escalonamento, pois a capacidade do sistema não pode ser controlada previamente [MST93, MST94]. Um dos critérios em sistemas de tempo real é definir uma ordem parcial para acesso a recursos de acordo com uma política.

As políticas de escalonamento definem regras para a ordenação dos processos de tempo real [LL73]. Os escalonadores, utilizando essas políticas, produzem escalas que, se forem realizáveis, garantem o cumprimento das restrições temporais impostas aos processos de tempo real. Uma escala é dita ótima se a ordenação do conjunto de processos, de acordo com as regras pré-estabelecidas pela política de escalonamento, é a melhor possível no atendimento das restrições temporais.

Tendo como base a forma de cálculo da escala (ordenação dos processos), algumas classificações são encontradas para a grande variedade de algoritmos de escalonamento de tempo real encontrados na literatura [SR94]. Algoritmos de escalonamento são identificados como estáticos quando o cálculo da escala é feito tomando-se como base parâmetros atribuídos aos 
processos do conjunto em tempo de projeto (parâmetros fixos). Algoritmos de escalonamento dinâmicos, ao contrário, são baseados em parâmetros que mudam em tempo de execução com a evolução do sistema. Algoritmos de escalonamento são identificados como "off-line" quando a escala é produzida em tempo de projeto e como "on-line" quando a escala é produzida em tempo de execução. Podemos ter algoritmos off-line estáticos, off-line dinâmicos, on-line estáticos e on-line dinâmicos.

Inúmeros algoritmos e técnicas de escalonamento dos sistemas de tempo real são propostos e podem ser encontrados na literatura da área [LL73, GGV96, CSR88, SR94]. Alguns deles, pela sua importância aos estudiosos de Sistemas de Tempo Real e pela sua eficiência na solução de muitos sistemas de tempo real, apresentamos a seguir:

\section{- Escalonamento de Sistemas de Tempo Real para Processos Periódicos}

As atividades envolvidas na maioria das aplicações de tempo real se caracterizam basicamente pelo comportamento periódico de suas ações. As características de processos periódicos que determinam o conhecimento a priori dos tempos de chegada, conseqüentemente, da carga computacional do sistema, permitem que se obtenha garantias em tempo de projeto sobre a escalonabilidade de um conjunto de processos periódicos.

Faremos a seguir uma revisão do algoritmo clássico de prioridade fixa Rate Monotonic Algorithm e do algoritmo Earliest Deadline First que apresenta atribuição dinâmica de prioridades, propostos por Liu e Layland [LL73].

\section{- Rate Monotonic Algorithm (RMA) [LL73]}

O RMA produz escalas em tempo de execução através de escalonadores preemptivos, dirigidos a prioridades, ou seja, um processo é interrompido por outro recentemente chegado com prioridade maior. É um esquema de prioridade fixa; o que define o RMA como escalonamento on-line estático. Liu e Layland [LL73] demonstraram que o RMA é dito ótimo entre os escalonamentos de prioridade fixa na sua classe de problema, ou seja, nenhum outro algoritmo da mesma classe pode escalonar um conjunto de processos que não seja escalonável pelo RMA.

As premissas do RMA que facilitam as análises de escalonabilidade, definem o seguinte modelo de processos:

a. Os processos são periódicos e independentes, isto é, um processo não sincroniza ou se comunica com outros processos.

b. O deadline de cada processo coincide com o seu período $\left(D_{i}=P_{i}\right)$.

c. O tempo de computação $\left(C_{i}\right)$ de cada processo é conhecido e constante.

d. O tempo de chaveamento (troca de contexto) entre processos é assumido como nulo.

As condições $a$ e $b$ são muito restritivas para a utilização desse modelo na prática, contudo simplificações são importantes para que se tenha o entendimento sobre o escalonamento de processos periódicos.

A política que define a atribuição utilizando o RMA, determina uma ordenação baseada nos valores de períodos dos processos do conjunto; as prioridades decrescem em função do 
aumento dos períodos, ou seja, quanto mais freqüente o processo, maior a sua prioridade no conjunto. Como os períodos dos processos não mudam, o RMA define uma atribuição estática de prioridades (prioridade fixa).

A análise de escalonabilidade no RMA, feita em tempo de projeto, é baseada no cálculo da utilização. Para que $n$ processos tenham o atendimento de suas restrições temporais quando escalonados pelo RMA, deve ser satisfeito o teste abaixo que define uma condição suficiente:

$$
U=\sum_{i}^{n} \frac{C_{i}}{P_{i}} \leq n\left(2^{\frac{1}{n}}-1\right)
$$

Na medida em que $n$ cresce, $2^{\frac{1}{n}}-1=\ln 2 \simeq 0,69$ (a utilização do processador converge para $0,69)$. Uma utilização de aproximadamente $70 \%$ define uma baixa ocupação do processador que, certamente, implica no descarte de muitos conjuntos de processos com utilização maior e que, mesmo assim, apresentam escalas realizáveis.

Essa condição suficiente pode ser relaxada quando os processos do conjunto apresentam períodos múltiplos do período do processo mais prioritário. Nesse caso a utilização alcançada sob o RMA se aproxima do máximo teórico, coincidindo o teste a seguir com uma condição necessária e suficiente [MST93, RJMO98]:

$$
U=\sum_{i}^{n} \frac{C_{i}}{P_{i}} \leq 1
$$

\section{- Escalonamento Earliest Deadline First (EDF) [LL73]}

O EDF define um escalonamento baseado em prioridades: a escala é produzida em tempo de execução através de escalonadores preemptivos, dirigidos a prioridades. É um esquema de prioridades dinâmicas; o que define o EDF como escalonamento on-line dinâmico. O EDF é dito ótimo entre os escalonamentos de prioridade dinâmica, ou seja, nenhum outro algoritmo desta mesma classe pode escalonar um conjunto de processos que não seja escalonável pelo EDF.

As premissas que facilitam as análises de escalonabilidade e que determinam um modelo de processos do EDF são idênticas às do RMA.

A política de escalonamento do EDF associa uma atribuição dinâmica de prioridades que determina uma ordenação dos processos baseada nos seus deadlines absolutos $\left(d_{i}\right)$. O processo mais prioritário é o que tem o deadline mais próximo do tempo atual. A cada chegada de processo a fila de prontos é reordenada, considerando a nova distribuição de prioridades. A cada ativação de um processo $T_{i}$, seguindo o modelo de processos periódicos, um novo valor de deadline absoluto e determinado considerando o número de períodos que antecede a atual ativação $(k): d_{i k}=k P_{i}$.

A análise de escalonabilidade no EDF é feita em tempo de projeto baseada no cálculo da utilização do processador. Um conjunto de $n$ processos satisfazendo as premissas $a, b, c$ e $d$ 
é escalonável com o EDF se e somente se:

$$
U=\sum_{i}^{n} \frac{C_{i}}{P_{i}} \leq 1
$$

Esse teste é suficiente e necessário na classe de problema definida para o EDF pelas premissas $a, b, c$ e $d$. Se qualquer uma dessas, é relaxada, a condição acima continua a ser necessária porém não mais suficiente [MST93].

É um escalonamento apropriado para aplicações de multimídia, pois durante períodos de sobrecarga momentâneos podem ser imprevisivelmente perdidos alguns deadlines e não é possível prever totalmente se a carga atual pode ser escalonada.

\subsubsection{Os Sistemas Operacionais versus Aplicações}

Uma das funções básicas de qualquer sistema operacional é a sua capacidade de atender às exigências e às características das aplicações que o utilizam. Quando bem projetado e implementado, um sistema operacional pode ser bastante eficiente na utilização de seus recursos e no atendimento das aplicações. Cada um, a princípio, apresenta algoritmos de escalonamento adequados ao tipo das aplicações que hospeda.

Nos primeiros sistemas operacionais multiprogramáveis, onde predominava tipicamente o processamento batch, o escalonamento implementado era do tipo não-preemptivo. Em face de um processamento puramente seqüencial e com uma variação alta dos seus tempos de execução, estes sistemas podiam oferecer tempos de resposta longos.

Com novas técnicas implementadas, dentre elas a multiprogramação, e o desejo de oferecer aos usuários tempos de resposta razoáveis levaram ao desenvolvimento dos sistemas com compartilhamento de tempo (timesharing). Cada processo no sistema utiliza o processador em pequenos intervalos de tempo. O escalonamento implementado é do tipo preemptivo, geralmente é o escalonamento por múltiplas filas. Os sistemas timesharing são sistemas onde não apenas o processador é compartilhado, mas também a memória, os periféricos e dispositivos. Favorece aplicações interativas, normalmente curtas e iniciadas através de teclados de terminais de baixa velocidade. Predominam programas, geralmente pequenos e com poucos dados, onde a medida mais importante de eficiência é o tempo de resposta.

Atualmente, a utilização de computadores para controlar e monitorar processos industriais, tais como os encontrados em fábricas automatizadas, sistemas robóticos, sistemas militares de defesa e os de controle de tráfego aéreo e metroviário, tem se expandido grandemente. Estas são algumas das típicas aplicações de tempo real onde, caso haja alguma falha temporal, as conseqüências podem ser irreparáveis. São classificadas como sistemas de tempo real hard, definidas na Seção 1.1.1. Estas aplicações requerem um sistema operacional que garanta deterministicamente o atraso que seja aceito por vários processos. Os escalonadores RMA e $\mathrm{EDF}^{5}$ tratam estas aplicações convenientemente.

\footnotetext{
${ }^{5}$ Revistos nas Páginas 17 e 18 , respectivamente.
} 
Observa-se também uma grande demanda de sistemas multimídias (que manuseiam texto, som e imagens, tal como em vídeo-conferência). Aqui é essencial o gerenciamento dos recursos de forma simultânea e eficaz. Uma das características das aplicações multimídia, além de grandes consumidoras de recursos, é a de sua tolerância à perda de algumas informações de forma a adaptar-se à carga do sistema. Como por exemplo, o requisito de tempo para processamento de áudio e vídeo é herdado das características de tempo dos dados de áudio e vídeo. Para reproduzir exatamente movimentos em um vídeo, o tempo gasto para mostrar os frames ${ }^{6}$ deve ser o mesmo tempo gasto para capturá-los, gerando um ambiente altamente dinâmico. Estas são aplicações que se encaixam nos sistemas de tempo real soft definidos na Seção 1.1.1. Quando temos atividades múltiplas com diferentes restrições de tempo que precisam ser escalonadas concorrentemente, os algoritmos tradicionais de escalonamento timesharing não são suficientes. Estas aplicações requerem um sistema operacional que garanta estatisticamente um limite de atraso e maximização do throughput. As políticas baseadas em prioridade fixa (incluindo RMA) foram sempre preferidas em esquemas mistos de escalonamento. As políticas baseadas em prioridade dinâmica (como o EDF) eram consideradas por muitos autores até pouco tempo como instáveis no tratamento de carga dinâmica. Nos últimos anos, a direção dos trabalhos tem mudado e o EDF tem sido também alvo de extensões para escalonamentos mistos. Os algoritmos dinâmicos apresentam os mais altos limites de escalonabilidade o que permite uma maior utilização do processador o que, por sua vez, aumenta a capacidade de processamento da carga aperiódica. Utiliza-se técnicas de escalonamento adaptativo que tentam encontrar uma escala realizável em tempo de execução. Não existe garantia de execuções de processos atendendo suas restrições temporais.

\subsection{A Caracterização do Problema e Nossa Abordagem}

\subsubsection{Limitações dos Sistema Operacionais de Propósito Geral}

Assim como aplicações convencionais, as aplicações de tempo real são mais facilmente construídas se puderem aproveitar os serviços de um sistema operacional de propósito geral. Ao mesmo tempo, existem razões de ordem econômica para a utilização de um sistema operacional de propósito geral no projeto, ou seja, um sistema operacional mais barato e popular para o qual existe uma grande quantidade de ambientes de desenvolvimento.

O impedimento da utilização de sistemas operacionais de propósito geral está nas restrições temporais da aplicação. Para contornar o problema, estes sistemas foram adaptados para o contexto de tempo real com a existência de uma classe tempo real. O sistema operacional deve fornecer código para uma interface cujas rotinas serão chamadas sempre que uma decisão de escalonamento envolvendo processos daquela classe for necessária.

Os sistemas operacionais de propósito geral encontram dificuldades em atender as demandas específicas das aplicações de tempo real. São construídos, fundamentalmente, com o objetivo de apresentar um bom comportamento médio, ao mesmo tempo que distribuem os

\footnotetext{
${ }^{6}$ Seqüência de imagens.
} 
recursos do sistema de forma eqüitativa entre os processos e os usuários. Mecanismos como cache de disco, memória virtual, fatias de tempo do processador, melhoram o desempenho médio do sistema, mas tornam mais difícil fazer afirmações sobre o comportamento de um processo em particular frente às restrições temporais. O atendimento de tais requisitos, em geral, demanda cuidados na gerência dos recursos do sistema, que não são tomados em sistemas operacionais de propósito geral. Um exemplo é o conceito de inversão de prioridade o qual é muito importante no contexto de tempo real, mas completamente ignorado em sistemas operacionais de propósito geral.

Exemplo. Considere o algoritmo de escalonamento utilizado no sistema operacional tradicional Unix System V Release 3 (SVR3). O SVR3 emprega escalonadores baseados em prioridades variáveis. A prioridade de cada processo varia conforme o seu padrão de utilização do processador; um processo executando código do kernel não pode ser bloqueado e a prioridade é recalculada enquanto executa o código da aplicação. É uma solução engenhosa e permite um bom desempenho quando as maiores preocupações são a distribuição justa de recursos entre os processos e o tempo médio de resposta do sistema. Entretanto, a qualidade temporal é avaliada em termos de número de prazos cumpridos ou do atraso médio em relação ao prazo de cada processo, esta solução não é a mais apropriada.

Escalonadores de prioridade fixa simples utilizados em muitos sistemas de tempo real, por exemplo no Linux convencional [CDM97], não necessariamente garantem o sucesso da execução de uma coleção de processos que conflitam no tempo requerido ou quando sobrecarregam o sistema, como foi comprovado no estudo de caso, documentado em [dSVdCGN99b].

Estes sistemas foram adaptados no sentido de mostrar alguma preocupação com a resposta em tempo real. O resultado final obtido com eles é melhor do que quando um sistema operacional de propósito geral é utilizado, mas não é capaz de oferecer previsibilidade determinítica. Seu comportamento depende em grande parte da dinâmica do sistema, requerendo que as aplicações sejam modificadas em sua programação para obter garantias de tempo real [BGzS98].

\subsubsection{Limitações dos Sistemas Operacionais Atuais}

A diversidade de aplicações de tempo real gerou uma diversidade de necessidades de suportes para tempo real, em particular do tipo classe tempo real.

A classe tempo real comporta a funcionalidade típica de um sistema operacional de propósito geral, cujo kernel foi adaptado para melhorar o comportamento temporal. A qualidade temporal varia de sistema para sistema e a solução de escalonamento também. Por exemplo, o sistema operacional Solaris é um kernel que implementa a funcionalidade Unix e foi projetado para fornecer uma boa resposta temporal. Ou ainda, muitos sistemas operacionais de tempo real possuem duas interfaces, uma Posix e uma proprietária [SR93]. Isto acontece porque a interface proprietária já existia e sobre ela foi implementada uma biblioteca com interface Posix, ou porque na interface proprietária podem ser feitas otimizações que resultam em melhor desempenho. 
Embora as classes tempo real, existentes nos sistemas operacionais atuais, apresentem mecanismos para implementar escalonamentos dirigidos a prioridades, estas prioridades não refletem as restrições temporais das aplicações de tempo real soft. Na prática, a importância em termos de funcionalidades presentes nessas aplicações são determinantes nas definições dessas prioridades; o que pode ser contestado, pois os possíveis graus de importância de funções em uma aplicação nem sempre se mantêm na mesma ordem relativa durante todo o tempo de execução desta. Geralmente, um processo da classe de tempo real sendo executado somente libera o processador caso finalize sua execução, se chega na fila de prontos um processo de maior prioridade, ou solicite sua própria saída.

Essas práticas têm permitido resolver de forma aceitável, e durante muito tempo, certas classes de problemas de tempo real nas quais as exigências de garantia sobre as restrições não são tão estritas.

Analisando o comportamento de alguns ambientes de multiprogramação diante das políticas de escalonamentos adotadas, dos recursos que possuem e de suas cargas:

* O Unix SVR4 mantém os escalonadores timesharing e para tempo real, entretanto observouse que o gerenciamento dos recursos diante de alguns ambientes não é ideal para aplicações multimídia [NHNW93].

* Os esquemas de gerenciamento de recursos de sistemas timesharing, tais como Unix e WindowsNT, freqüentemente alcançam baixos tempos de resposta e alto throughput para sistemas sobrecarregados $\left[\mathrm{BBG}^{+} 99 \mathrm{~b}\right]$. Estes esquemas tornam-se inapropriados, especialmente quando numa sobrecarga incluímos aplicações que contenham requisições que devem ser processadas dentro de certos limites de desempenho (mínimo throughput).

* Através de um estudo de caso onde avaliamos o comportamento e o desempenho do sistema operacional Linux(versão 2.0.34) [CDM97, Ben96, HP96, BBD ${ }^{+}$98], desenvolvemos uma aplicação, denominada "Controle de Aproximação de Aeronaves em Aeroportos" (codificada em Tcl/Tk [Ous94, FJ97]), com características de tempo real. Desenvolvemos também duas aplicações secundárias simples que se caracterizavam pela utilização de um recurso em particular: uma com grande consumo de memória e outra com grande consumo de CPU.

A aplicação principal foi colocada nas diferentes classes de escalonamento desse sistema (a saber, timesharing, Real-Time Round Robin e Real-Time FIFO) e vários testes foram efetuados utilizando os seguintes cenários: A aplicação principal e

- sem aplicações adicionais disputando os recursos,

- disputando os recursos do sistema com várias instâncias de uma aplicação gráfica [Kim], que interagia com o Servidor de Janelas além de possuir funções das classes anteriores (menos prioritárias),

- disputando os recursos do sistema com várias instâncias das aplicações secundárias e a aplicação gráfica e

- disputando os recursos do sistema com a compilação do emacs versão 20.2.

Os resultados do comportamento da aplicação principal diante destes cenários quando colocada nas diferentes classes de escalonamento foram analisados e discutidos e estão documentados 
em [dSVdCGN99b, dSVdCGN99c, dSVdCGN99a]. Constatamos especificamente que:

- os algoritmos de escalonamento de prioridade simples não necessariamente garantem o sucesso da execução de uma coleção de processos que conflitam no tempo requerido, pois não impedem que um novo processo com prioridade maior ocupe a CPU e comprometa o sistema e - o desempenho da aplicação foi determinado pela carga do sistema. Diante de uma sobrecarga as requisições temporais da aplicação principal não são cumpridas satisfatoriamente.

Portanto, as tentativas para solucionar estes problemas, utilizando os mecanismos tradicionais baseados em prioridade, têm se revelado ineficientes.

A maioria das aplicações de tempo real possui parte de suas funções sem restrições temporais. É preciso considerar que as classes tempo real deveriam satifazer as necessidades dos processos de tempo real e fornecer funcionalidade para os convencionais. Aspectos como suporte para interface gráfica, protocolos de comunicação para a Internet fogem do escopo de um sistema operacional tempo real que execute somente processos de tempo real. Podemos afirmar que o comportamento temporal da aplicação de tempo real depende da aplicação em si, do sistema operacional que utiliza e da carga deste sistema.

Os sistemas operacionais tempo real são sistemas onde é dedicada especial atenção ao comportamento temporal, ou seja, são sistemas cujos serviços são definidos não somente em termos funcionais mas também em termos temporais. O sistema operacional tempo real deve fornecer as abstrações necessárias, processos e mecanismos para comunicação entre processos.

A área de sistemas operacionais, no que diz respeito a tempo real, é muito dinâmica. Novos sistemas ou novas versões dos sistemas existentes são apresentadas a todo momento. Uma quantidade significante de trabalhos tem sido elaborada apresentando esquemas de alocação de recursos para atender a demanda satisfazendo os requisitos nos níveis requeridos pelas aplicações. Cada trabalho pode ser classificado em várias categorias. Apresentaremos alguns critérios de escalonamento e esquemas de alocação de recursos da máquina para aplicações de tempo real e multimídia concorrentes, introduzidos e desenvolvidos por pesquisadores da área.

Em resumo, com respeito ao comportamento temporal do sistema, qualquer análise deve considerar a aplicação e o sistema operacional. Como existe um amplo espectro de aplicações de tempo real com diferentes classes de requisitos, também existirão soluções possíveis para a construção de sistema operacional tempo real, cada uma mais apropriada para cada contexto. Existe ainda hoje (início do Século XXI) uma grande distância entre a teoria de escalonamento com a prática no desenvolvimento de sistemas de tempo real.

\subsubsection{Motivação}

Com a popularização de novas categorias de aplicações, estações de trabalho e computadores pessoais estão, cada vez mais, sendo submetidos à carga mista de aplicações. Um número crescente de aplicações de importância na sociedade atual, que apresentam comportamentos definidos segundo restrições temporais e com características de grandes consumidoras de recursos das máquinas, convivem concorrentemente com aplicações convencionais, tais como 
editores de textos e planilhas, que combinam uma diversidade de comportamentos.

O propósito natural é requerer do sistema operacional que seus recursos sejam utilizados pelas aplicações com o desempenho desejado. Várias propostas [BBG ${ }^{+}$99b, BGzS98, GGV96, JRR97, MST94, BDM99, Cru98] têm surgido, procurando aperfeiçoar o gerenciamento de recursos em sistemas operacionais tradicionais, a fim de conseguir melhor desempenho para aplicações que possuem requisitos temporais. Busca-se: (1) oferecer a todos os processos a cota de processamento requerida e (2) garantir que atrasos, durante a execução, não ultrapassem limites estabelecidos. Esses dois objetivos aparecem, usualmente, na literatura [BGzS97, BGzS98] como atributos de medida da Qualidade de Serviço (QoS) das aplicações.

Em instalações utilizando sistemas stand-alone ou dedicados, onde conhecemos a priori a carga computacional e no sistema existe uma reserva de recursos suficientes para a execução das aplicações atendendo suas condições temporais, tais como os sistemas que envolvem controle de tráfego aéreo, centrais telefônicas, equipamentos médico-hospitalares, é possível controlar indiretamente a sobrecarga do sistema através de um escalonador cuidadoso e assim garantir a QoS desejada.

Mas este não é o cenário usual. Freqüentemente, o computador utilizado é tal que uma aplicação com limites restritos de tempo compartilha seus recursos com outros processos: de controle, funções de monitoramento, processos batch, outras aplicações de tempo real, etc. Neste ambiente de multiprogramação, se não conhecemos a carga computacional previamente não conseguimos prever recursos para todas as situações de carga durante toda a execução de uma aplicação e, conseqüentemente, não podemos garantir QoS. O sistema operacional necessita de suporte de tempo real para que possa apresentar comportamentos previsíveis atendendo as restrições temporais impostas pelo ambiente como um todo. Se os recursos são limitados, ao receber uma aplicação, o sistema analisa seus parâmetros (como mencionamos na Seção 1.1.2, Página 16) e verifica se é possível prover os recursos mínimos necessários para um desempenho aceitável; apenas pode garantir limite de atraso, mas requer que as aplicações sejam modificadas para obter as prerrogativas das características de tempo real [BGzS98]. O que acontece é que o desempenho de uma simples aplicação é, em parte, determinado pela carga do sistema. Entretanto, as necessidades de segurança num número cada vez maior de aplicações e a ligação dessa com a correção temporal desses sistemas colocam em xeque as metodologias e ferramentas convencionais, sob pena de perdas em termos ambiental, financeiros ou de vidas humanas.

A ausência de suporte dos sistemas operacionais e a falta de gerenciamento de recursos baseado em QoS são fatores que dificultam o tratamento de diversas aplicações resultando em baixa qualidade de serviço. Portanto, precisamos de um sistema operacional que ofereça garantias de QoS tal que possa fornecer seus recursos para todas as aplicações no sistema e que os níveis desejados de desempenho previsível sejam alcançados. Um sistema que prevendo o seu comportamento como um todo garanta, dentro de certos limites de tempo, as restrições temporais. A política de escalonamento dos recursos empregada tem um papel fundamental nas garantias de QoS.

Esta questão é uma preocupação comum dos profissionais e estudiosos das várias áreas da computação (redes, sistemas distribuídos, sistemas de tempo real, multimídia), cada qual 
procurando resolvê-la dentro de seu próprio contexto.

\subsubsection{Objetivos}

Segundo alguns pesquisadores, para efetivamente atender os requisitos de QoS para aplicações de tempo real, o sistema operacional precisa permitir capacidade de reserva de processador [MST93, MST94, RJMO98].

Todos os sistemas operacionas atuais desenvolvidos ou adaptados para tempo real mostram grande preocupação com a divisão do tempo do processador entre os processos. Entretanto, o processador é apenas um recurso do sistema. Memória, periféricos, controladores também deveriam ser escalonados visando a atender os requisitos temporais da aplicação. Por exemplo, o mecanismo de memória virtual é capaz de gerar atrasos por envolver acesso a disco. E ainda, os mecanismos tradicionais utilizados em sistemas de arquivos, tais como o de ordenar a fila do disco para diminuir o tempo médio de acesso, fazem com que o tempo para acessar um arquivo possa variar muito. O que sabemos é que muitos sistemas operacionais desenvolvidos ou adaptados para tempo real tratam os demais recursos da mesma maneira empregada por um sistema operacional de propósito geral, isto é, os processos são atendidos pela ordem de chegada.

Uma das soluções apresentadas na literatura foi a introdução de uma nova abstração de sistemas operacionais chamada reserva de dominios.

Nosso objetivo é estudar e analisar algumas formas de gerenciar os recursos do sistema, quando temos aplicações de tempo real, de forma a garantir QoS. Restringiremo-nos a esta vertente recente - reserva de dominios, conforme descrita no Capítulo 2.

Na parte inicial de nosso trabalho, apresentamos os conceitos e investigamos três políticas de escalonamento baseadas em reserva de domínios. Em seguida, estudamos seu comportamento e a sua eficácia sob diferentes cargas em um ambiente de multiprogramação.

\subsection{Organização dos Capítulos}

No Capítulo 2 enfatizamos as linhas de estudo do problema na literatura, apresentamos as notações e definições que formalizam conceitos preliminares utilizados pelos enfoques estudados. Apenas conceitos de natureza mais geral para este trabalho foram incluídos neste capítulo, de modo que definições e notações de natureza mais específica a um ou outro capítulo foram incluídas em capítulos apropriados no decorrer do texto.

Destinamos o Capítulo 3 à apresentação e à descrição sucinta dos três algoritmos de escalonamento baseados em reserva de domínios.

No Capítulo 4 descrevemos aspectos gerais do Sistema Operacional Eclipse em suas duas versões.

Os trabalhos dos pesquisadores John Bruno, Eran Gabber, Banu Özden e Abraham Silber- 
schatz fornecem uma base teórica sólida para a elaboração e implementação de um ambiente de simulação de escalonadores de processos. Aplicando a maioria das idéias apresentadas nessas propostas [BGzS97, BGzS98], desenvolvemos um simulador para algoritmos de escalonamento baseado em reserva de domínios. No Capítulo 5 apresentamos a descrição da ferramenta construída.

No Capítulo 6 exibimos a análise de desempenho dos algoritmos de escalonamento sob o ponto de vista da avaliação comportamental de diferentes conjuntos de processos.

No Capítulo 7 apresentamos as considerações gerais sobre o que foi realizado no decorrer desta dissertação e as conclusões deste trabalho, onde sugerimos alguns assuntos que poderão ser abordados em futuros projetos. 


\section{Capítulo 2}

\section{Abordagens e Conceitos}

Neste capítulo apresentamos alguns critérios de escalonamento e esquemas de gerenciamento de recursos da máquina para aplicações de tempo real concorrentes, introduzidos e desenvolvidos por pesquisadores da área. Em seguida, introduzimos as definições e os conceitos básicos que são utilizados pelos enfoques estudados.

\subsection{Trabalhos Correlatos}

Uma quantidade significante de trabalhos tem sido elaborada apresentando esquemas de alocação de recursos para atender a demanda e satisfazer as exigências específicas de cada aplicação. Cada trabalho pode ser classificado em várias categorias, dependendo do enfoque em que se baseia e na solução que apresenta.

O estudo do problema da alocação apropriada do recurso, para uma aplicação ser capaz de alcançar um nível específico de QoS, tem sido abordado sob vários contextos (incluindo, como alocar processamento de pacotes na rede, como um problema de controle de admissão fixo ou dinâmico nos canais de comunicação de tempo real). O requisito básico de um modelo de QoS é a principal garantia para aplicações e os atributos de QoS (por exemplo, limite de tempo, precisão, pontualidade) podem ser utilizados para especificação, instrumentação e validação de um sistema [RLLS97].

O que é um dos pontos importantes, em relação ao paradigma escolhido para o nosso estudo, é que os esquemas de alocação de recursos baseados em reserva de recurso são flexíveis e a reserva recebida por um processo pode ser modificada dinamicamente [SAWJ ${ }^{+}$96]. Desta forma, a razão do progresso de um processo de tempo real pode ser explicitamente controlada. Adicionalmente, algoritmos de alocação de recursos baseados nesta reserva fornecem um meio natural de degradar o sistema uniformemente em situações de sobrecarga [NL97].

A seguir, focalizamos nossa atenção em diferentes soluções aplicáveis em diferentes contextos, tratadas em suas soluções algorítmicas e presentes na literatura que apresentam esquemas de gerenciamento de recursos baseados em reserva de recurso e que fornecem algumas garantias 
de QoS.

\subsubsection{Lottery Scheduling e Stride Scheduling}

C. Waldspurger e W. Weihl propõem os escalonamentos lottery scheduling [WW94] e o stride scheduling [WW95]. Algoritmos de alocação de recursos proporcional a uma cota e de acordo com as alocações desejadas pelo usuário. A idéia central do lottery scheduling consiste em atribuir a cada processo uma fração do serviço do recurso, enquanto o stride scheduling utiliza adicionalmente uma política de enfileiramento justo que pode ser determinado de acordo com as alocações desejadas pelo usuário.

A flexibilidade destas propostas permite que as políticas de gerenciamento dos recursos possam ser definidas em vários níveis de abstração: processos, aplicações, usuários e grupos.

Apresentamos, a seguir, a descrição suscinta destes dois algoritmos:

\section{- Lottery Scheduling [WW94]}

O escalonamento lotérico é um mecanismo de alocação estatística para recursos de tempo compartilhado. Este escalonador implementa um controle de alocação de recursos proporcional a uma cota sobre o tempo do processador e de outros recursos. Os direitos aos recursos são representados por tickets de loteria.

Os tickets de loteria encapsulam direitos aos recursos que são abstratos porque quantificam os direitos aos recursos independentemente dos detalhes de máquina; são relativos porque a fração de um recurso que representam varia dinamicamente em proporção à disputa por este; e são uniformes porque os direitos para diferentes recursos podem ser homogeniamente representados como tickets.

Após o resultado de uma loteria, uma alocação é realizada e os recursos são garantidos ao processo que possui o ticket vencedor. Desta forma, aloca recursos para processos competidores proporcionalmente ao número de tickets que possuem.

O lottery scheduling é probabilisticamente justo. Como o escalonamento é aleatório, a alocação real implementada nem sempre corresponde à alocação esperada. Contudo, a disparidade entre elas decresce quando o número de alocações aumenta.

O número de loterias vencidas por um processo possui uma distribuição binomial. A probabilidade $p$ de um processo com $t$ tickets vencer uma dada loteria com um total de $T$ tickets é $p=\frac{t}{T}$. Após $n$ loterias idênticas, o número esperado de vencedores $v$ é $E[v]=n p$, com variância $\sigma_{v}^{2}=n p(1-p)$. O coeficiente de variação para a proporção observada de vencedores é $\frac{\sigma_{v}}{E[v]}=\sqrt{\frac{1-p}{n p}}$. Assim, um throughput do processo é proporcional à sua alocação de tickets, com corretude que aumenta com $\sqrt{n}$.

O número de loterias exigidas para uma primeira vitória do processo tem uma distribuição geométrica. O número esperado de loterias $n$ que um processo deve esperar antes de sua primeira vitória é $E[n]=\frac{1}{p}$, com variância $\sigma_{n}^{2}=\frac{1-p}{p^{2}}$. Assim, o tempo médio de resposta de 
um processo é inversamente proporcional à sua alocação de tickets.

Qualquer processo com um número de tickets diferente de zero eventualmente vencerá uma loteria; o problema de starvation não existe. O mecanismo de loteria também opera corretamente quando o número de processos ou tickets varia dinamicamente. A cada alocação, é dada uma chance justa de vencer proporcional à sua cota do número total de tickets.

A representação explícita de recursos como tickets de loteria favorece um gerenciamento de recursos modular. Os tickets podem ser utilizados para separar as políticas de gerenciamento de recursos em módulos independentes, porque cada ticket, probalisticamente, garante ao seu proprietário o direito de consumo de um recurso, mesmo no pior caso.

Uma maneira imediata de implementar um escalonador lotérico centralizado é selecionar aleatoriamente um ticket vencedor e buscar em uma lista de processos aquele que o possui. Isto exige uma geração de números aleatórios e utiliza $O(n)$ operações para percorrer uma lista de $n$ processos, acumulando um número de tickets até encontrar o valor do vencedor. Entretanto, para grandes valores de $n$, uma implementação mais eficiente utiliza uma estrutura de árvore com as somas de tickets parcial e com os processos nas folhas. Para localizar o processo com um ticket vencedor, caminha-se na árvore, a partir da raiz até o nó-folha, utilizando apenas $O(\log (n))$ operações.

\section{- Stride Scheduling [WW95]}

O escalonamento stride é um mecanismo de alocação determinística para recursos de tempo compartilhado. Este escalonador implementa um controle proporcional à cota sobre o tempo do processador e outros recursos utilizando adicionalmente uma política de enfileiramento justo que pode ser determinado de acordo com as alocações desejadas pelo usuário.

A idéia central do algoritmo stride é computar um intervalo de tempo, ou stride, que o processo deve esperar entre sucessivas alocações. Um processo com metade do stride do outro, executa duas vezes mais que aquele. O processo com o stride menor é o escolhido para ser executado. Os stride são representados em unidades de tempo virtuais chamadas pass.

Cada processo mantém três campos em sua estrutura: stride, ticket e pass. Cada processo especifica em ticket a sua alocação de recursos relativa aos outros processos. O stride é inversamente proporcional ao ticket, representando o intervalo de tempo entre seleções, medido em pass. O pass representa o índice de tempo virtual para a próxima seleção do processo. Executando o escalonador, o processo com o menor pass é o escolhido e o seu pass é decrementado com o seu stride. Em caso de empates, qualquer dos processos com o pass mínimo é selecionado.

Na sua primeira versão, o escalonador permite um conjunto estático de processos associados com os números fixos de tickets. Novas técnicas foram introduzidas para oferecer um ambiente mais dinâmico, tais como modificações de alocações de tickets e mudanças no número de processos competindo por um recurso. 


\subsubsection{Weighted Fair Queuing e Earliest Eligible Virtual Deadline First}

Diante da necessidade da convivência de um número variável de tipos de aplicações de tempo real em um ambiente multimídia e da preocupação de garantir limite de justiça a estas aplicações, foram desenvolvidos esquemas hierárquicos de alocação de recursos. Dentre vários outros existentes no mercado temos o Weighted Fair Queuing (WFQ) [SAWJ97] e o Earliest Eligible Virtual Deadline First (EEVDF) [SAWJ $\left.{ }^{+} 96\right]$ que descrevemos a seguir.

\section{- Weighted Fair Queuing [SAWJ97]}

Stoica et al. propõem o esquema de enfileiramento justo WFQ no qual também exploram a alocação de recursos proporcional à sua cota sendo aqui utilizada a noção de peso ao invés de tickets.

O escalonamento é feito utilizando-se de dois níveis hierárquicos para classificar os processos. No nível mais alto, os processos são divididos pelas suas classes de cotas proporcionais às suas reservas de recursos, e no nível seguinte, pelos pesos. A estratégia foi de integrar as duas características ao processo: peso e cota.

A idéia central na implementação é associar a cada processo um par $(w, s)$, onde $w$ representa o seu peso e $s$ representa a cota real do recurso que o processo deve receber.

O valor da cota $s$ é $\frac{w}{W}$ onde $W$ é a soma dos pesos de todos os processos ativos. Se o peso do processo for fixo, a sua cota será calculada por esta fórmula. Alternativamente, se o processo pedir por uma fração $s$ do recurso, utilizando-se da mesma equação, o valor do peso $w$ do processo pode ser computado por $w=\frac{\left(W^{\prime} s\right)}{(1-s)}$ onde $W^{\prime}$ corresponde à soma de todos os pesos dos outros processos.

Assim, ao se fixar o peso, obtém-se a alocação proporcional à cota e, ao se fixar a cota, obtém-se a alocação de recursos proporcional ao peso. Este escalonamento garante o limite de justiça pretendido.

\section{- Earliest Eligible Virtual Deadline First $\left[\mathrm{SAWJ}^{+} 96\right]$}

Ion Stoica et al. propõem o EEVDF um algoritmo de alocação de recursos proporcional ao share para obter melhoria de desempenho nas aplicações de tempo real em sistemas timesharing, oferecendo garantias de justiça.

Em um sistema de alocação de recursos proporcional à cota, a todo processo no sistema é garantido fazer alguma computação a uma taxa bem definida e uniforme. Formalmente, a cada processo é associada uma cota do processador. Se uma cota de um processo é $\alpha$ então, em qualquer intervalo de tempo de tamanho $t$, é garantido ao processo receber $u t$ unidades de tempo do processador, tal que $(\alpha . t)-\delta \leq u t \leq(\alpha . t)+\delta$, onde $0 \leq \delta \leq \tau$, para alguma constante $\tau$.

Este esquema de alocação de recursos proporcional à cota permite uma abordagem unificada para aplicações batch, interativas e de tempo real. Isto é alcançado atendendo uniformemente as solicitações sem considerar os tipos das aplicações na seqüência de requisições para 
o recurso. Difere dos métodos tradicionais de integração de processos de tempo real e convencionais, pois aqui estes processos não são tratados de forma distinta. Assim, em termos de modelo de processos, nenhum tratamento especial é exigido para a execução de tempo real, existindo apenas um tipo de processo.

No algoritmo proposto, a alocação de recursos é feita como muitos algoritmos de escalonamento tradicionais em sistemas timesharing, por unidades discretas ou quanta, o que facilita a sua implementação, pois os escalonamentos para aplicações de tempo real são usualmente orientados a eventos, exigindo mecanismos para interromper processos de maneira arbitrária. Para oferecer garantias em seu limite de justiça, o algoritmo desenvolvido impõe que a diferença entre o tempo de serviço que um processo deveria receber em um sistema idealizado e o tempo de serviço que ele realmente recebe em um sistema real é limitado por um quantum de tempo; considerado um limite ótimo.

Este modelo de sistema idealizado consiste de um conjunto de processos que competem por recursos de tempo compartilhado. Um processo é dito ativo enquanto está competindo pelo recurso. Caso contrário, o processo é dito passivo. Supondo que o recurso é alocado em quanta de tempo de tamanho $q$. No início de cada quantum, um processo $i$ é selecionado para utilizar o recurso. Uma vez que o processo $i$ adquira o recurso, pode utilizá-lo por todo o quantum ou liberá-lo antes deste tempo acabar.

A cada processo nesse sistema é associado um peso que determina a cota do recurso que deve ser recebida. Definindo-se $w_{i}$ como o peso associado ao processo $i, A(t)$, o conjunto de todos os processos ativos no instante $t$ e $\alpha_{i}(t)$, a cota instantânea de um processo ativo $i$ no instante $t$, onde

$$
\alpha_{i}(t)=\frac{w_{i}}{\sum_{j \in A(t)} w_{j}} .
$$

Se a cota do processo $i$ permanece constante durante um intervalo de tempo $[t, t+\Delta t]$, o processo $i$ é designado para utilizar o recurso por $\alpha_{i}(t) \Delta t$ unidades de tempo. Em um sistema de justiça perfeita, quando a cota do processo $i$ varia com o tempo no intervalo $\left[\tau_{1}, \tau_{2}\right]$, o processo $i$ deveria receber o tempo de serviço no recurso igual a $S_{i}\left(\tau_{1}, \tau_{2}\right)$ unidades de tempo, onde

$$
S_{i}\left(\tau_{1}, \tau_{2}\right)=\int_{\tau_{1}}^{\tau_{2}} \alpha_{i} \lambda d \lambda
$$

Esta equação corresponde a um sistema de fluxo ideal no qual o recurso pode ser garantido em intervalos de tempo arbitrariamente pequenos. Infelizmente, esta situação é impossível na prática, devido à troca de contexto entre processos e ao próprio algoritmo de escalonamento. Outra razão é que determinadas operações não podem ser interrompidas, isto é, uma vez iniciadas devem completar o seu quantum de tempo.

Em um sistema onde o recurso é alocado em quanta de tempo discretos não é possível para um processo sempre receber exatamente o tempo de serviço designado a ele. Supondose $\tau$ o tempo no qual o processo $i$ torna-se ativo e $s_{i}(\tau, t)$ o tempo de serviço que processo $i$ realmente recebe neste intervalo $[\tau, t]$. Definindo-se lag como tempo de serviço correspondente a diferença entre o tempo de serviço que o processo $i$ deveria receber e o tempo de serviço 
que o processo $i$ realmente recebe no intervalo $[\tau, t]$. Segue que

$$
\operatorname{lag}_{i}(t)=S_{i}(\tau, t)-s_{i}(\tau, t) .
$$

Portanto, o valor de lag é que mede a corretude da alocação. Utiliza-se este valor como principal parâmetro na caracterização do algoritmo EEVDF.

Tendo como base este modelo de um sistema de fluxo ideal, um processo deve especificar a duração de tempo de serviço quando solicitar um recurso. Atendida a solicitação, o processo pode fazer um novo pedido ou tornar-se passivo. O algoritmo foi formulado baseado neste modelo que executa processos em um domínio de tempo virtual. Abstratamente, o sistema de fluxo virtual executa cada processo por $w_{i}$ unidades de tempo real durante cada unidade de tempo virtual. Formalmente, o tempo virtual $V(t)$ é definido pela função

$$
V(t)=\int_{0}^{t} \frac{1}{\sum_{j \in A(\lambda)} w_{j}} d \lambda
$$

Observa-se que o tempo virtual aumenta a uma razão inversamente proporcional a soma dos pesos de todos os processos ativos. Quando a competição aumenta, o tempo virtual decresce lentamente e quando a competição diminui, o tempo virtual aumenta. Intuitivamente, o fluxo de tempo virtual muda para alocar todos os processos ativos em uma unidade de tempo virtual. Em outras palavras, o tamanho de uma unidade de tempo virtual é modificado tal que no sistema de fluxo correspondente, cada processo ativo $i$ recebe $w_{i}$ unidades de tempo real durante uma unidade de tempo virtual.

Das Equações 2.1 e 2.2, pode-se obter o tempo de serviço que um processo ativo $i$ deveria receber no intervalo $\left[\tau_{1}, \tau_{2}\right]$. Portanto,

$$
S_{i}\left(\tau_{1}, \tau_{2}\right)=w_{i} \int_{\tau_{1}}^{\tau_{2}} \frac{1}{\sum_{j \in A(\lambda)} w_{j}} d \lambda
$$

Das Equações 2.4 e 2.5, pode-se obter o tempo de serviço que qualquer processo ativo $i$ deveria receber no intervalo $\left[\tau_{1}, \tau_{2}\right]$, apenas multiplicando o peso do processo pelo valor da integral. Assim,

$$
S_{i}\left(\tau_{1}, \tau_{2}\right)=\left(V\left(\tau_{2}\right)-V\left(\tau_{1}\right)\right) w_{i}
$$

O EEVDF utiliza medidas realizadas no domínio do tempo virtual para fazer decisões de escalonamento. Para cada solicitação de um processo, define-de um instante elegível $\varepsilon$ e um deadline $d$ que representam os instantes inicial e final para o serviço requisitado no sistema, respectivamente.

Sejam $\tau$ o instante no qual o processo $i$ torna-se ativo e $t$ o instante em que este inicia uma nova solicitação. Então, uma solicitação torna-se elegível no instante $\varepsilon$, quando o tempo de serviço que o processo $i$ deveria receber no sistema de fluxo ideal, $S_{i}(\tau, \varepsilon)$, é igual ao tempo de serviço que o processo $i$ já recebeu no sistema real, $s_{i}(\tau, t)$. 
Se no instante $t$ o processo $i$ recebe mais tempo de serviço do que deveria receber, tem-se $\operatorname{lag}_{i}(t)<0$ (Equação 2.3). Para este caso, o instante elegível $\varepsilon$ é maior que o instante $t$ e o processo deve esperar até o instante $\varepsilon$ antes que a nova solicitação torne-se elegível. Desta maneira, um processo que vem recebendo mais tempo de serviço do que seu share,é atrasado lentamente, concedendo aos outros processos ativos a oportunidade de executar.

Se no instante $t$ o processo $i$ recebe menos tempo de serviço do que deveria receber, tem-se $\operatorname{lag}_{i}(t)>0$ (Equação 2.3). Para este caso, o instante elegível $\varepsilon$ é menor que o instante $t$, e assim, a nova solicitação torna-se elegível imediatamente.

Se no instante $t$ o processo $i$ recebe o tempo de serviço igual ao que deveria receber, tem-se $\operatorname{lag}_{i}(t)=0$ (Equação 2.3). Utilizando a Equação 2.6, obtém-se o instante elegível $V(\varepsilon)$ fazendo

$$
S_{i}(\tau, t)=(V(\varepsilon)-V(\tau)) w_{i}=s_{i}(\tau, t) \Longrightarrow V(\varepsilon)=V(\tau)+\frac{s_{i}(\tau, t)}{w_{i}}
$$

O deadline da solicitação é selecionado tal que o tempo de serviço que o processo deveria receber, entre o tempo elegível $\varepsilon$ e o deadline $d$, é igual ao tempo de serviço da nova solicitação. O tempo de serviço que um processo ativo $i$ deveria receber, ou seja, $S_{i}(\varepsilon, d)=l$, onde $l$ representa o tamanho da nova requisição. Utilizando a Equação 2.6, segue que

$$
S_{i}(\varepsilon, d)=(V(d)-V(\varepsilon)) w_{i}=l \Longrightarrow V(d)=V(\varepsilon)+\frac{l}{w_{i}}
$$

As Equações 2.7 e 2.8 fornecem o tempo elegível virtual $\varepsilon$ e o deadline virtual; não necessariamente, os $\varepsilon$ e $d$ de tempo real. Assim, o EEVDF é expresso em termos de $\varepsilon$ e deadline virtuais e aloca um novo quantum ao processo que tem a solicitação elegível com o menor tempo virtual. Este escalonamento garante o limite de justiça pretendido.

\subsubsection{Start-Time Fair Queuing}

Diante da necessidade da convivência de um número variável de classes de aplicações em um ambiente multimídia, Pawan Goyal, Xingand Guo e Harrick M. Vin [GVC96] analisaram os requisitos impostos por elas e concluíram que (1) para aplicações hard que requerem garantia determinística do atraso permitido aos vários processos, pode-se utilizar escalonadores convencionais, tais como o escalonamento RMA e o EDF que tratam convenientemente estas aplicações; (2) para uma aplicação soft que requer estatisticamente parâmetros de QoS, tais como máximo atraso e throughput (que não são fornecidos pelos escalonadores convencionais utilizados para aplicações hard) e diante da dificuldade de se prever os requisitos de computação necessários, pode-se selecionar, de algum modo, o algoritmo de escalonamento ao qual a aplicação deve ser submetida para obter o desempenho desejado; já que um algoritmo de escalonamento para tratar este tipo de aplicação ainda está para ser desenvolvido; e (3) para aplicações convencionais que não necessitem de garantias de desempenho, porém requerem alocação de CPU tal que o tempo médio de resposta seja baixo, enquanto o throughput alcançado seja alto, pode-se utilizar algoritmos timesharing com os quais estes requisitos podem ser alcançados. Como conseqüência desta análise, o adequado seria possuir um esquema de 
alocação dos recursos que pudesse oferecer diferentes escalonadores para as diferentes classes de aplicações.

Para que se permita a co-existência de diferentes algoritmos de escalonamento nas distintas classes de aplicações existentes em um ambiente multimídia, que também ofereça um mecanismo de proteção entre as várias classes, P. Goyal et al. [GGV96] sugerem um particionamento hierárquico da largura de banda da CPU, no qual um sistema operacional deveria estar apto a particionar a largura de banda da CPU entre as várias classes de aplicações e, cada uma destas, particionando sua alocação entre sub-classes ou aplicações.

No ambiente proposto, o particionamento hierárquico é especificado por uma estrutura de árvore. Cada thread no sistema pertence a exatamente um nó-folha e cada nó intermediário na árvore representa uma classe de aplicações ou uma agregação de classes de aplicações. Enquanto as threads são escalonadas de acordo com os requisitos da classe a qual pertencem, os nós intermediários são escalonados por um algoritmo que executa o particionamento hierárquico. Este algoritmo deve: (1) efetuar uma distribuição justa da capacidade do processador entre os nós competidores, (2) não exigir a priori conhecimento dos requisitos computacionais das threads, (3) fornecer garantias de throughput, e (4) ser eficiente computacionalmente.

Fundamentando-se nestas premissas, P. Goyal e seus colaboradores desenvolveram um escalonador hierárquico que atende a todas elas, o Start-time Fair Queuing Scheduling (SFQ), implementando-o no kernel do Solaris 2.4 que é uma versão do UnixSVR4 fornecido pela Sun Microsystems. Cada aplicação recebe uma cota da CPU a qual, na média, corresponde um peso ou percentagem da especificação do usuário.

O algoritmo SFQ é algoritmo de alocação de recursos que pode ser utilizado para realizar uma alocação justa. Antes de comentar o SFQ é necessário definir a noção de alocação justa. Intuitivamente, uma alocação de CPU é justa se, para todo intervalo de tempo, todas as threads executáveis recebem a mesma fração da largura de banda da CPU. Essa noção de justiça uniforme é generalizada para justiça ponderada onde as threads possuem diferentes pesos e cada thread recebe a largura de banda da CPU na proporção do seu peso.

Para formalizar esta noção, define-se $w_{i}$ como sendo o peso de uma thread $i$ e $B_{i}$, o trabalho agregado realizado no intervalo $[\tau, t]$ pela CPU para a thread $i$. Por simplicidade, determinou-se que o trabalho realizado pela CPU para uma thread é medido em número de instruções executadas pela thread. Assim, uma alocação de CPU é considerada justa se para todo intervalo $[\tau, t]$ no qual duas threads, $i$ e $j$, são executáveis, $\frac{B_{i}(\tau, t)}{w_{i}}-\frac{B_{j}(\tau, t)}{w_{j}}=0$. Esta é uma definição idealizada de justiça, pois injustiças ainda podem ocorrer porque a cada thread é concedido um quantum por vez. Conseqüentemente, o objetivo do SFQ é minimizar o grau de injustiça que possa ocorrer. Isto é, garantir que $\left|\frac{B_{i}(\tau, t)}{w_{i}}-\frac{B_{j}(\tau, t)}{w_{j}}\right|$ seja tão próximo de zero quanto possível.

Para alcançar este objetivo, o SFQ associa um valor inicial para cada thread e as escalona na ordem crescente destes valores. Para definir o valor inicial, supõem-se que o quantum destinado a cada thread tenha um tamanho variável a cada instante. Considerando $q_{i}^{n}$ o $n$ ésimo quantum da thread $i, l_{i}^{n}$ seu tamanho (medido em unidades de instruções) e $T\left(q_{i}^{n}\right)$ o tempo no qual o $n$-ésimo quantum é requisitado. Se a thread $i$ está fazendo uma transição 
do estado bloqueado para uma execução, então $T\left(q_{i}^{n}\right)$ é o instante em que esta transição é realizada ou é o instante no qual o quantum anterior finalizou.

1. Associação de um valor inicial $S_{i}$ e de um valor final $F_{i}$ para a thread $i$.

Quando o quantum $q_{i}^{n}$ é solicitado pela thread $i$, esta é marcada com um valor inicial $S_{i}$ computado como:

$$
S_{i}=\max \left\{v\left(T\left(q_{i}^{n}\right)\right), F_{i}\right\} \quad n \geq 1
$$

onde $v(t)$ é o tempo virtual no instante $t$ e $F_{i}$ é o valor final da thread $i$.

$F_{i}$ é inicialmente zero.

Quando o $n$-ésimo quantum finaliza é incrementado como:

$$
F_{i}=S_{i}+\frac{l_{i}^{n}}{w_{i}} \quad n \geq 1
$$

onde $w_{i}$ é o peso da thread $i$.

2. Associação de um tempo virtual $v(t)$.

Inicialmente o tempo virtual é zero.

Quando a CPU está ocupada, o tempo virtual no instante $t, v(t)$ é definido como o valor inicial da thread em serviço no instante $t$.

Quando a CPU está inativa, para $v(t)$ é determinado o máximo do valor atribuído a qualquer thread.

3. Seleção de uma thread para execução.

As threads têm seus serviços atendidos na ordem crescente dos seus valores iniciais. Empates são decididos arbitrariamente.

Figura 2.1: Descrição Formal do Algoritmo SFQ.

As propriedades do SFQ, descrito na Figura 2.1, são demonstradas em [GVC96] e confirmam que o SFQ atinge os objetivos requeridos por um escalonador hierárquico, ou seja:

a. Realiza alocação justa de CPU independentemente da variação da capacidade de serviço.

b. Não requer que o tamanho do quantum seja conhecido a priori.

c. Provê limites no atraso máximo ocorrido e mínimo throughput em ambiente real.

d. É computacionalmente eficiente.

O escalonador SFQ mostrou-se adequado para aplicações de vídeo e os resultados obtidos demonstraram que: (1) suporta a co-existência de escalonadores heterogêneos, (2) protege as classes de aplicações entre si, e (3) não impõe uma sobrecarga maior do que aquela apresentada por escalonadores timesharing convencionais. 
O ambiente de particionamento hierárquico proposto facilita a utilização de um gerenciador de QoS que aloca os recursos dependendo dos requisitos da aplicação. Para exemplificar este gerenciador, suponha que uma aplicação requisite serviço de tempo real hard (soft). O gerenciador de QoS pode utilizar um algoritmo determinístico (estatístico) de controle de admissão que utiliza a capacidade alocada à classe hard (soft) e determina se a requisição pode ser satisfeita. Nesta caso, atribui a aplicação a uma partição apropriada.

Um gerenciador de QoS pode trocar dinamicamente as proporções do particionamento hierárquico para refletir a importância relativa das várias aplicações. Por exemplo, para a classe de aplicações de tempo real soft pode ter sido alocada inicialmente uma pequena fração de CPU, mas quando cresce o número de requisições para serviços de tempo real soft, a alocação desta classe pode ser aumentada significativamente.

\subsubsection{Scheduler for Multimedia And Real Time}

Jason Nieh e Monica Lam [NL96, NL97] propõem o algoritmo SMART (Scheduler for Multimedia And Real Time) implementado no sistema operacional Solaris 2.5.1. Esta proposta permite aos processos especificarem suas restrições de escalonamento. Pode notificar dinâmicamente uma aplicação quando seus deadlines não podem ser alcançados, para que esta possa decidir o que fazer quando suas restrições de tempo não podem ser cumpridas. Este escalonador permite também que as aplicações se adaptem à carga do sistema. Este escalonamento é especialmente importante para aplicações multimídia que podem operar sob diferentes taxas, dependendo da condição de carga.

Os desenvolvedores utilizam um algoritmo baseado no SFQ (Seção 2.1.3, Página 33) para implementar o compartilhamento proporcional da CPU e o conceito de tempo virtual para medir a degradação para cada processo que consumiu de sua cota dos recursos. Introduzem a noção de tolerância de latência para medir a capacidade de processos convencionais de tolerar atrasos de serviço maiores e mais variados, habilitando as aplicações batch para tolerar vários atrasos de serviço. Os processos convencionais não possuem nenhum deadline artificial. São executados apenas quando estão excessivamente atrasados recebendo suas cotas proporcionais dos recursos. Isto é, um processo convencional não faz um processo de tempo real esperar seus deadlines, a menos quando o processador está sobrecarregado.

Um tempo virtual de processo é ajustado de acordo com sua tolerância de latência, para determinar seu tempo de latência virtual, o qual é utilizado como uma prioridade interna do sistema em escalonamento best-effort ${ }^{1}$ para escalonar as requisições de recurso.

Dois conceitos são introduzidos a cada aplicação: o conceito de importância, expresso pelas preferências dos usuários (o padrão é que todos os processos recebem suas cotas do recurso igualmente) e o conceito de urgência, expresso pelas restrições de tempo (separado do conceito de justiça). O SMART utiliza destes parâmetros para escolher o próximo processo a ser executado.

\footnotetext{
${ }^{1}$ Uma abordagem de escalonamento que não trata com uma carga computacional previsível, ou seja, uma carga onde os tempos de chegada dos processos não são conhecidos previamente.
} 
Quanto mais alta a importância para um processo, mais alta é a sua prioridade. Se dois processos possuem a mesma importância, irá escolher para executar o processo que, proporcionalmente, executou menos. Para processos de tempo real utiliza a urgência; o processo com o menor deadline é o mais urgente.

O escalonamento SMART é em dois níveis. No primeiro nível são identificados e selecionados todos os processos mais importantes e no segundo nível escolhe, dentre os mais importantes, um processo para executar baseado na urgência.

A importância é expressa por um par ordenado composto de: prioridade e Biased Virtual Finishing Time (BVFT) que é um valor dinâmico que o sistema utiliza para medir e conservar o grau da fatia proporcional do recurso já foi consumida pelo recurso. No primeiro nível do SMART, se dois processos possuem prioridade igual, o escolhido será o que tiver o menor BVFT.

O sistema mantém várias filas de acordo com a prioridade ordenada pelo valores do BVFT. Cada processo tem um tempo virtual que avança em uma taxa proporcional à soma do tempo de processamento efetivo dividido pela cota fornecida pelo usuário. $\mathrm{O}$ tempo virtual de cada fila avança somente se qualquer processo a ela pertencente está executando e o avanço é proporcional ao tempo real de processamento deste processo dividido pela soma total da cota de todos os processos da fila.

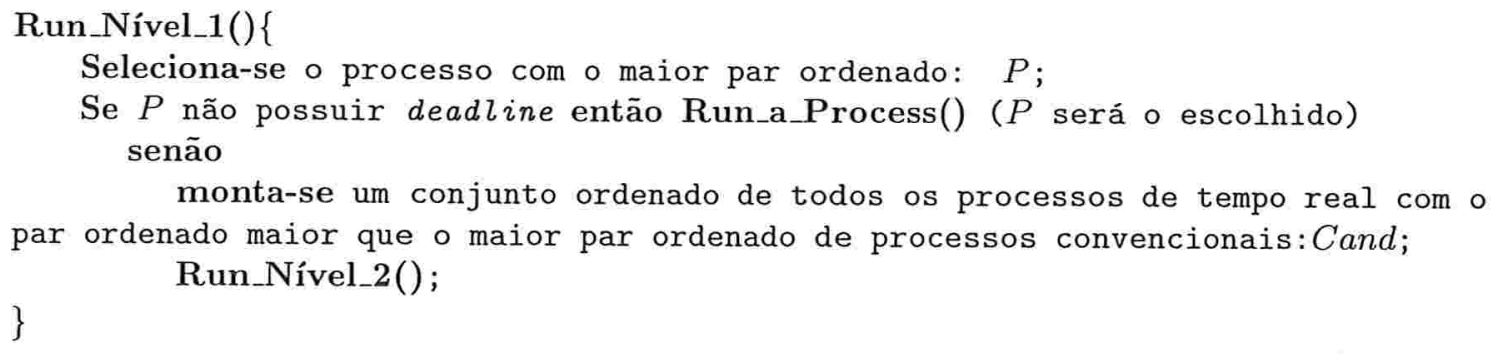

Figura 2.2: Procedimento Nível_ 1 para o SMART.

Os passos no escalonamento SMART são apresentados nas Figuras 2.2 e 2.3 .

Jason Nieh e Monica Lam analisaram e comparáram o comportamento de três tipos de aplicações: batch, interativa e de tempo real, quando colocadas sob cada um dos seguintes escalonadores [NL97]: SVR4-RT, SVR4-TS, WFQ e SMART. Vários tipos de medidas foram capturadas a cada experimento e os resultados comparados e descritos em detalhes, levandose em conta as características dos escalonadores e de suas classes.

Quando submetidas ao SVR4-RT, as aplicações de tempo real e a interativa foram colocadas na classe tempo real, deixando as aplicações batch na classe time-sharing. As observações gerais relativas a análise comportamental das aplicações neste escalonamento: SVR4-RT mantém menor controle sobre a distribuição de recursos, dedicando mais tempo da CPU para aplicações de tempo real, o que provoca e um processamento antecipado de muitos frames, resultando em uma variância enorme no tempo de exibição dos frames.

Quando submetidas ao SVR4-TS, todas as aplicações foram executadas no modo time- 


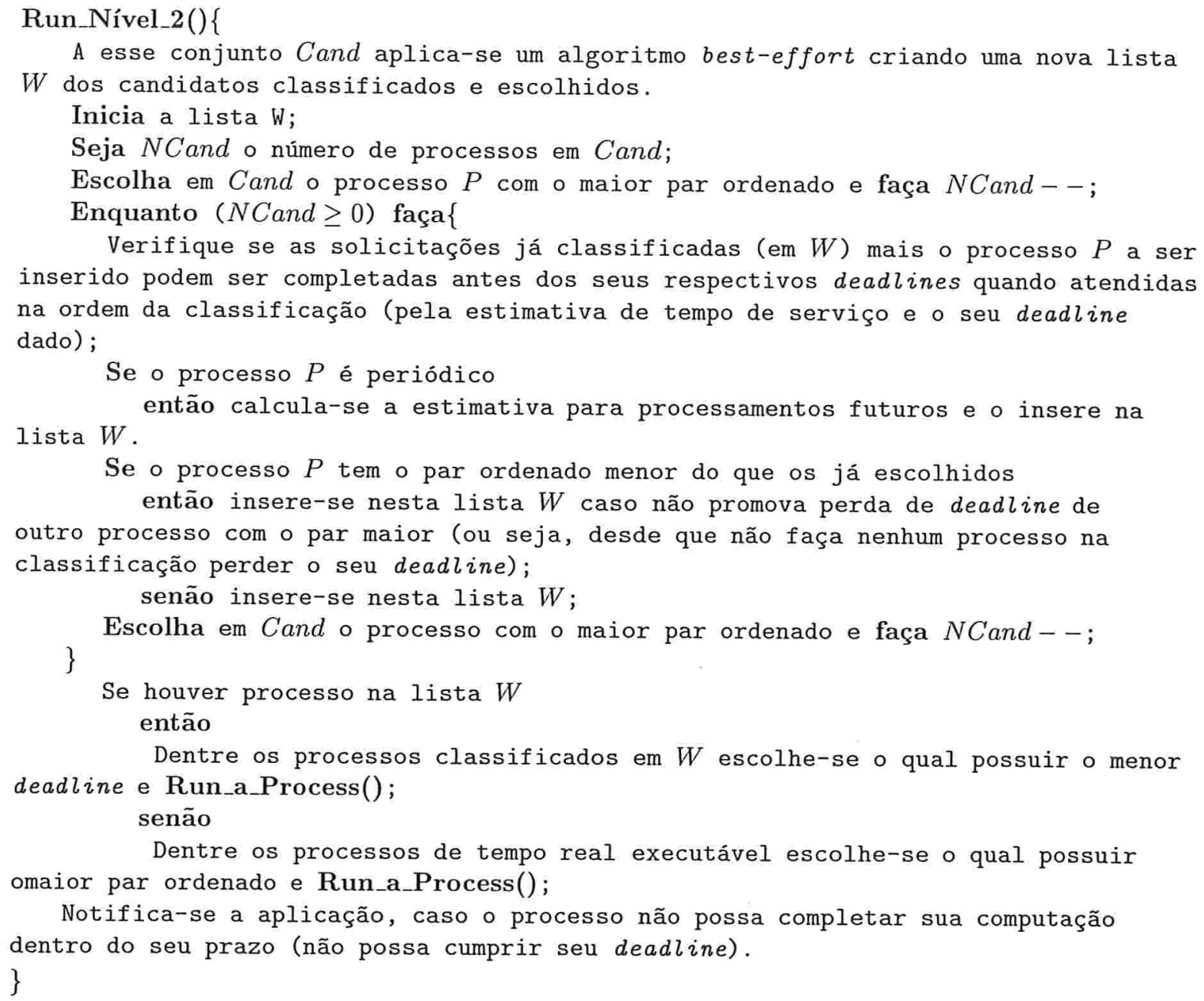

Figura 2.3: Procedimento Nível_2 para o SMART.

sharing. Aqui, a aplicação interativa obteve o pior desempenho.

Quando submetidas ao escalonador WFQ (revisto na Página 30), todas as aplicações foram executadas com o mesmo share. Utilizando-se o WFQ, observou-se que ele se dedica mais à aplicação interativa em detrimento da de tempo real (aqui a cota é proporcional e baseada no tempo em que o processo está pronto e não contabiliza o tempo de bloqueio); o atraso provocado à aplicação de tempo real faz com que o processamento se inicie mais cedo, resultando em um número maior de frames atrasados. O WFQ foi modificado para contabilizar o tempo de bloqueio dos processos, acumulando um número limitado de créditos, como acontece com o SMART. Melhorou muito para a aplicação interativa, porém a de tempo real teve o mesmo desempenho pobre, como observado anteriormente.

Quando submetidas ao escalonador SMART, todas as aplicações foram executadas com o mesma cota e mesma prioridade. Constataram que o SMART: 
- Provê desempenho previsível para aplicações de tempo real soft quando executadas concorrentemente com aplicações convencionais, e flexibilidade e controle preciso sobre o compartilhamento de tempo do processador. Coopera com as aplicações no gerenciamento dos recursos para satisfazer suas restrições de tempo dinâmicas.

- É capaz de satisfazer os requisitos de tempo real de maneira ótima e provê compartilhamento proporcional entre processos de tempo real e convencionais.

- Quando todos os requisitos de tempo não podem ser cumpridos, SMART satisfaz cada tarefa de tempo real com uma cota proporcional dos deadlines e ajusta sua taxa de execução dinamicamente.

A dissertação de mestrado de Jorge Euler Vieira [Vie99], além de uma excelente revisão da problemática relacionada com o sistema operacional Linux para tempo real, apresenta uma implementação da política SMART como um novo escalonador no sistema operacional Linux, o LINUX-SMART. Os testes de desempenho de uma mesma aplicação foram comparados aos já efetuados no Linux tradicional [dSVdCGN99b]; comprovou-se a melhoria no desempenho em todos os resultados. Em particular, um processo de tempo real não monopoliza o recurso, oferece um melhor gerenciamento por parte do usuário que pode fornecer a prioridade, o quantum, a cota e o deadline de uma aplicação e ainda, uma notificação é efetuada pelo sistema sobre a perda do deadline de uma aplicação, possibilitando um ajuste em ambiente de sobrecarga. É importante ressaltar que o LINUX-SMART tem um escalonador baseado em alocação proporcional à cota, e quando não há recursos suficientes para atender todas as solicitações de recursos, o sistema atende todos os pedidos menores do que a quantia da cota proporcional e os recursos disponíveis, após esta alocação, são distribuídos entre as tarefas que podem utilizar este excesso.

\subsubsection{Processor Capacity Reserves}

Clifford W. Mercer, Stefan Savage e Hideyuki Tokuda [MST93, MST94] também propõem um suporte para sistemas operacionais na garantia de atraso para aplicações multimídia. $\mathrm{O}$ seu objetivo é obter a previsibilidade de um sistema de tempo real conservando a flexibilidade de um sistema timesharing.

O esquema de alocação depende de um mecanismo rígido para assegurar que os processos não excedam as suas reservas. Apresentam um mecanismo de "capacidade de reserva do processador" que isola processos sensíveis ao tempo de execução das características de outros processos; do mesmo modo que um sistema de proteção de memória os isola diante de um acesso externo.

Mercer et al. [MST94] desenvolveram um escalonador que permite alocação proporcional a uma cota e controle de admissão e introduziram uma abstração do kernel, "reserva", especificamente destinada para uma arquitetura de microkernel para mensurar e controlar o uso do processador por processo. A "reserva" contém a duração do tempo de computação acumulado no período corrente e o escalonador coloca o processo no modo timesharing quando sua alocação foi consumada.

A abstração "reserva" serve o propósito de medir a corretude para uma atividade que 
requer algum serviço oferecido pelo sistema. As reservas são associadas com alocoções de processador e servem a dois propósitos: organizar os parâmetros de alocação e facilitar uma imposição das alocações medindo o uso frente à alocação. As reservas podem ser manipuladas por diferentes threads e em vários níveis em uma mesma "reserva".

O mecanismo de "capacidade de reserva do processador" é que permite ao usuário controlar a alocação dos ciclos do processador entre os processos.

Uma aplicação requisita reservas dos ciclos do processador; como uma reserva foi garantida pelo escalonador, é assegurada a sua alocação desse recurso. As aplicações têm a liberdade de acrescentar reservas a qualquer instante durante a execução (sujeita a disponibilidade do recurso adicional), e de também diminuí-las. Combina a previsibilidade das reservas com a flexibilidade de um ajuste dinâmico, podendo acomodar os diferentes requisitos de tempo das aplicações.

O escalonador utiliza destas medidas para restringir as reservas, assegurando que processos não podem monopolizar os recursos computacionais. Adicionalmente, as reservas podem ser passadas ao sistema através dos limites de proteção. Isto é especialmente importante em sistemas de microkernel pois podem tratar separadamente os serviços do sistema (a utilização real do processador para um processo inclui o uso do processador) dos serviços pedidos pelo processo.

O sistema de reservas foi desenvolvido para aceitar vários níveis de políticas de gerenciamento de recurso. Por exemplo, um gerenciador de QoS pode ser utilizado para alocação dos recursos do sistema, como um mecanismo para controlar os recursos alocados para as várias aplicações. O gerenciador de QoS transmite os parâmetros de QoS para as aplicações com suas requisições de recurso do sistema (incluindo os requisições de processador), possibilitando uma cooperação da aplicação em si. O gerenciador então é capaz de efetuar a reserva para cada processo e utilizar o desempenho analisado e, através da interação com o usuário, mudar as alocações das aplicações sob o seu controle. Esta estrutura baseada nos requisitos de QoS divide o problema de escalonamento em duas partes: (1) uma política para alocação dos recursos baseada nos requisitos da própria aplicação e (2) uma abstração e mecanismo para escalonamento e controle destes recursos. Este modelo provê essa abstração e mecanismo.

A estratégia da alocação precisa de mecanismos para possibilitar este tipo de gerenciamento de recursos. Os requisitos são:

- Prover algum meio para as aplicações especificarem suas alocações do recurso

- Avaliar as requisições do novo processo para decidir se admite ou não

- Escalonamento consistente com as políticas de controle de admissão

- Medir exatamente o tempo de computação consumida por processo, para assegurar que não ultrapassam suas alocações.

- Prover algum meio para as aplicações especificarem suas alocações do recurso

O primeiro requisito depende de um modelo de escalonamento consistente que possa acomodar diferentes espécies de alocações de processos. Por exemplo, uma aplicação de áudio precisa ser escalonada a cada $50 \mathrm{~ms}$ para montar o buffer de áudio. Muitos processos não pos- 
suem requisitos de tempo e podem executar seguidamente tanto quanto possível para fazer sua computação.

A fração do processador permite uma medida para descrever a reserva do processador para as duas espécies de processos. Esta fração é um tempo do processador requerido pelo processo durante um intervalo de tempo dividido pelo tempo real deste intervalo e a fração do processador consumida pelo processo todo o tempo define sua taxa de progresso.

Os processos periódicos (que executam repetidamente a um intervalo fixo) têm uma taxa natural descrita pelo seu período e o tempo de computação requerido durante cada período; assume-se o tempo de computação constante. Caso o tempo de computação não seja constante, uma reserva do processador é estimada para o seu pior caso; o tempo ocioso é disponibilizado para o processamento background. Os processos aperiódicos não tem a taxa natural de processamento mas recebem uma. Essa taxa determina a duração de tempo até o processo terminar; a taxa precisa ser reservada baseada no atrasos.

\section{- Avaliar as requisições do novo processo para decidir se admite ou não}

O segundo requisito, o escalonador pode avaliar as restrições de tempo do novo processo diante da capacidade disponível. É transmitida a alocação requerida e especificada por um processo individualmente em suas medidas de utilização, que é utilizada pela política de controle de admissão. Observa-se que simplesmente somando-se a utilização individual de todos os processos ativos sob uma disciplina de escalonamento por prioridade dinâmica, a avaliação seria válida, mas há desvantagens e, em contrapartida, assumindo a utilização individual de todos os processos ativos sob uma disciplina de escalonamento por prioridade fixa, esse método não possibilita a reserva de $100 \%$ do processador.

\section{- Escalonamento consistente com as políticas de controle de admissão}

$\mathrm{O}$ terceiro requisito, que a política de escalonamento escalone processos de forma consistente com a política de controle de admissão, reflete em que a proposta precisa ser consistente com todas as políticas de gerenciamento de todos os recursos no sistema. Se a política de escalonamento não garante as premissas da política do controle de admissão sobre como os processos são ordenados para execução, a operação de alocação do sistema falha.

- Medir exatamente o tempo de computação consumida por processo para assegurar que não ultrapassam as suas alocações

$\mathrm{O}$ quarto requisito demanda um desempenho rígido monitorando software o qual um sistema operacional típico não suporta. Os sistemas operacionais usualmente acumulam estatísticas para cada processo, simplesmente durante uma interrupção regular do clock, mas essa informação é imprecisa sobre intervalos pequenos. Entretanto, o comportamento de execução do programa monitorado precisa ser independente de um simples período. Um mecanismo mais apurado é preciso para medir as durações entre troca de contexto e tempo de interrupções em sobrecarga do sistema.

Sempre que o sistema necessita medir exatamente o consumo para um processo, outros 
problemas aparecem. A utilização de estatísticas num sistema operacional tradicional consiste de tempo de uso do sistema e tempo de uso do usuário para cada processo. Para sistemas operacionais monolíticos isto é suficiente, mas para o sistema de microkernel onde os serviços do sistema oferecidos estão em diferentes níveis de servidores de usuário, a utilização de estatísticas de uma atividade não pode ser obtida para um simples processo. Uma atividade pode querer utilizar os servidores separadamente para o acesso ao sistema de arquivo, rede, etc. Para manter um cenário exato de uma concepção da capacidade da atividade, o custo destes serviços precisa ser avaliado para a atividade em si e para os serviços individuais. Então, capacidade de reservas precisa manter independência entre "processos" em execução, tal que o trabalho feito por qualquer processo sobre a atividade reservada possa ser mudado por esta atividade. Isso é feito simplesmente criando uma abstração independentemente de reserva a qual pode limitar dinamicamente a execução de diferentes processos. Com a utilização de medidas exatas e com um mecanismo para gerar um escalonamento sempre que um processo inicia a utilização de sua capacidade de alocação, o escalonador pode controlar a execução dos processos e prevenir sua interferência com as outras reservas.

Um algoritmo baseado na taxa de progresso do processo provê um ambiente efetivo para a implementação da alocação do processador. Pode-se associar taxas com processos periódicos e com não periódicos. A taxa de periódicos pode ser determinada por um período que o usuário tem em mente e o tempo de computação durante este período. A taxa para os não periódicos originam dos requisitos de atraso. Em qualquer caso, só a taxa não é suficiente para cumprir os requisitos de tempo de um processo; o tempo de computação e o período são essenciais.

Têm-se três valores que descrevem os requisitos do processador para um processo e, dois deles são requeridos para especificar a percentagem do processador. Seja $\phi$ a percentagem, C o tempo de computação e T o período de tempo real sobre o tempo de computação a ser consumido. Então têm-se $\phi=\frac{C}{T}$.

Geralmente especifica-se requisitos de processador utilizando $\phi$ e T. $\phi$ é uma expressão natural de alocação do processador e o maior período das atividades em termos de $\mathrm{T}$.

O tempo de computação de uma atividade periódica é difícil para o usuário medir exatamente; nesta proposta é ter uma estimativa dada pelo usuário e então, dependendo do tempo medido pelo sistema em relação a aquele, pode ser ajustado se necessário.

Para atividades não periódicas que são limitadas por uma percentagem. O tempo de computação C não corresponde à estrutura do código então, especificando $\phi \mathrm{e} T$, define-se quanto da computação será feita no consumo de seu share do processador para cada intervalo. Este é um contraste diante das atividades periódicas que geralmente associam um bloco de código com a computação que se repete a cada período. O atraso para programas não periódicos que executam a uma dada taxa, pode ser calculado da taxa de execução e do tempo total de execução. Um processo que executa a uma taxa $\phi$ e com um total de computação (tempo de serviço) S terá D $=\frac{S}{\phi}$ de tempo para completar sua execução. Esta equação pode também ser utilizada para derivar uma taxa adequada para o tempo de computação e o maior atraso aceitável. Utilizando o maior atraso com a menor taxa de execução. Assumindo que se pode determinar estes três parâmetros, as políticas de escalonamento tradicionais por prioridade fixa e dinâmica podem ser utilizadas pois permitem as alocações e o controle de admissão. 
A utilização de escalonamento de prioridade fixa requer um método de associar prioridades aos programas que assegurem que os programas progredirão sob sua taxa. O RMA de Liu e Layland [LL73] faz exatamente isto. A sua análise é base para as alocações do processador com controle de admissão. Sejam $n$ o número de programas periódicos, o tempo de computação $C_{i} \mathrm{e}$ o período $T_{i}$ do processo $i$. Liu e Layland mostraram que todo processo cumpre seus deadlines e computações a eles associadas se a Inequação 1.1 (Seção 1.1.2) for válida ( $\sum_{i=1}^{n} \frac{C_{i}}{T_{i}} \leq n\left(2^{\frac{1}{n}}-\right.$ 1)). Para $n$ grande o limite fica pessimista; é possível que processos que não satisfaçam a inequação, cumpram seus deadlines, o que não pode ser determinado por esta análise. Precisase das taxas dos processos que têm tempo de computação reservado, o total de alocação e a soma destas taxas. Uma política simples de controle de admissão é admitir um novo processo se a soma de suas taxas e o total previsto de reserva é menor que 0,69 . O controle de admissão utiliza esta soma para determinar quanto de acréscimo a taxa de um novo processo resulta em uma soma menor que $100 \%$. Se sim, o processo e admitido senão, a alocação não pode ser garantida.

A utilização de escalonamento de prioridade dinâmica requer um método de associar prioridades aos programas que assegurem que eles progredirão sob sua taxa. O EDF (Seção 1.1.2) é efetivo para programas periódicos tais como os de média contínua. Define-se o deadline de uma computação como o fim do período, e esta política escolhe, num dado tempo, o programa com o menor valor de deadline. A estratégia de reserva é similar à estratégia do RMA $\left(\sum_{i=1}^{n} \frac{C_{i}}{T_{i}} \leq 1\right)$. Uma política simples de controle de admissão aqui utiliza esta soma para admitir um novo processo se a soma de suas taxas e o total previsto de reserva é menor que 1. Se sim, o processo é admitido senão, a alocação não pode ser garantida.

Resumindo, as alocações de recursos proporcional ao share podem ser determinadas pelo usuário ou baseadas nos requisitos dos processos. Provê cada processo com seu share da reserva e oferece garantias de atraso e limite de justiça. As aplicações são posicionadas de acordo com sua importância semântica e diferentes políticas de ajuste são utilizadas para obter ou negociar uma particular alocação de recurso.

O esquema de alocação de CPU foi implementado no Real-Time Mach (RT-Mach) para garantir e obrigar o acesso a uma alocação de recurso assim que a alocação for requerida. Um gerenciador de QoS é utilizado no RT-Mach para alocar recursos para as aplicações.

Em Providing Differentiated Quality of Service in Web Hosting Services, Almeida et al. [ADMC98] mostram que colocando prioridade aos serviços num servidor $W e b$, este pode oferecer QoS diferenciada. Em outro estudo desenvolvido na área, Banga et al. [BDM99] introduz o conceito resourse containers como o foco de gerenciamento de recursos em sistemas servidores. Esta abstração tem sido utilizada em escalonadores para CPU baseados em prioridades e combina esquemas de gerenciamento de reservas de recursos, semelhantes aos apresentados nos demais esquemas descritos nesta seção.

\subsubsection{Resource Kernels}

Rajkumar et al. [RJMO98] apresentam outra proposta para gerenciamento de recursos baseado em reserva de recursos; uma introdução de recurso centralizado para sistemas de 
tempo real e multimídia, denominada resource kernel. Resource kernel é orientado para aplicações de tempo real onde múltiplas atividades com diferentes restrições de tempo precisam ser escalonadas concorrentemente. Este esquema de gerenciamento de recursos é baseado em reservas de recurso da proposta de Mercer et al. [MST93], que descrevemos anteriormente. Um resource kernel é destinado para uso em um sistema em particular e é definido para ser um que provê acesso adequado, garantido e protegido para todos os recursos do sistema.

O resource kernel permite uma aplicação especificar apenas suas demandas deixando o kernel satisfazer essa demanda utilizando especiais esquemas de gerenciamento de recursos. Esta separação da especificação de recurso e do gerenciador permite a customização de um subsistema específico extendido, otimizando ou sempre substituindo os esquemas de gerenciamento. Como resultado, pode ser implementado com um ou mais diferentes esquemas de gerenciamento.

Os objetivos principais de um resource kernel são: aplicações precisam estar aptas para fornecer suas restrições temporais; o kernel precisa suportar alta utilização dos recursos do sistema; e uma aplicação precisa estar apta a acessar diferentes recursos do sistema simultaneamente. Uma vez que a mesma aplicação consome uma quantidade de tempo em diferentes plataformas, o resource kernel precisa permitir cada tempo de consumo de recursos ser portável pelas plataformas, e sere automaticamente calibrado.

Neste modelo de reserva de recurso os parâmetros explícitos são os mesmos da "reserva" discutida anteriormente na Seção 2.1.5, ou seja, $\{\mathrm{C}, \mathrm{T}, \mathrm{D}, \mathrm{S}$ e L $\}$. As semânticas são simples. Cada reserva aloca $\mathrm{C}$ unidades de tempo de utilização a cada $\mathrm{T}$ unidades de tempo absoluto. Estas C unidades de tempo de utilização serão garantidas e disponíveis para consumir por D unidades de tempo após o início de todo período do intervalo. As garantias começam no tempo $\mathrm{S}$ e terminam no tempo $\mathrm{S}+\mathrm{L}$. Se várias reservas são independentes e sem interações então estes parâmetros são suficientes. Entretanto, se recursos são compartilhados, podem ocorrer problemas (por exemplo, inversão de prioridade).

Uma família de protocolos de herança de prioridade podem solucionar o problema. Um parâmetro comum B é referenciado como fator de bloqueio; representa o tempo máximo que um instante de reserva precisa esperar pela reserva de prioridade menor executando. Se B não é limitado, uma reserva pode não alcançar seu deadline. O resource kernel deriva, trata e impõe o parâmetro B para cada reserva do sistema. Esta herança de prioridade é aplicada quando uma reserva bloqueia esperando por uma de prioridade menor.

Quanto ao tipo de reservas, define-se que quando uma reserva utiliza a sua alocação de $\mathrm{C}$ unidades de tempo com o intervalo $\mathrm{T}$ é dita esgotada, caso contrário, é dita não esgotada. Ao final do intervalo do tempo corrente $\mathrm{T}$, a reserva recebe uma nova cota de $\mathrm{C}$ e é dita ser reabastecida. Neste modelo o escalonamento das reservas segue um dos três comportamentos: 1) reservas hard. Uma reserva hard se esgotada, não pode ser escalonada até ser reabastecida. 2) reservas firm. Uma reserva firm se esgotada, pode ser escalonada para execução somente se não há outras não esgotadas ou threads sem reservas para executar.

3) reservas soft. Uma reserva soft se esgotada, pode ser escalonada para execução através de outras threads sem reservas e com reservas esgotadas. 
Para o processador são utilizados os esquemas de prioridade fixa. Cada reserva tem associada uma prioridade que é igual ao seu período ou deadline dependendo do esquema utilizado (RMA (Seção 1.1.2) ou deadline monotonic [LL73]). Quando uma reserva de prioridade menor bloqueia uma de prioridade maior, o formador herda a reserva. Quando a reserva de prioridade maior finalmente desbloqueia, a herança é anulada. O resource kernel trata e acumula a duração da inversão de prioridade durante uma reserva T. Se exceder o máximo B que pode ser tolerado pela reserva, uma mensagem é enviada para notificar.

O escalonamento do disco é baseado no EDF (Seção 1.1.2) e chamado just-in-time disk scheduling. O máximo slack (período) disponível para cada reserva de disco é computado sempre que uma nova requisição é admitida (ou alguma for removida). Em tempo de execução, se o slack corrente da reserva de maior prioridade é diferente de zero, outra requisição não reservada (ou de prioridade menor) pode ser escalonada se concluir na cabeça do disco. Se o slack é perdido, o slack de reserva de maior prioridade é reduzido para 1. Este processo é repetido. Se o slack de uma reserva de alta prioridade chega a zero, será servido independentemente de sua alocação. Este escalonamento utiliza os mesmos parâmetros do processador ( $\mathrm{C}$ é especificado em número de blocos). Após cada acesso completado, nova decisão é feita pelo earliest deadline scheduling.

A arquitetura do sistema de arquivo segue o esquema tradicional. Um servidor de arquivo tempo real executa sobre o resource kernel (baseado no microkernel do sistema operacional RT-Mach).

Resumindo, os desenvolvedores demonstram a funcionalidade do resource kernel e sua flexibilidade no contexto de aplicações multimídia que necessitam de ciclos de processador e/ou disco. As reservas são expressas em termos de requisições de um processador por um período de tempo. Identificam o problema da inversão de prioridade entre diferentes reservas e o problema da co-dependência do processador com recurso.

Um simples esquema de especificação de recursos pode ser utilizado para diferentes tipos de recursos. Múltiplos tipos de recursos podem ser garantidos ao mesmo tempo com níveis de desempenho aceitáveis. Reservas de diferentes tipos de recursos podem ser criadas independentemente. A implementação do esquema de gerenciamento de recurso pode ser feita por diferentes escalonadores tradicionais de tempo real e serem utilizados pelo mesmo modelo de especificação do recurso. Os gerenciadores de recursos a nível do usuário podem ser construídos no topo de um resource kernel para efetuar ou adaptar mudanças em aplicações, no sistema de recursos e no desempenho. Pode também potencialmente implementar mais complexas politicas de gerenciamento de recursos que as utilizadas neste modelo.

As abstrações do resource kernel para uso do recurso podem ser automaticamente calibradas sendo portáveis para diferentes plataformas.

\subsubsection{Precomputed CPU scheduling}

Michael B. Jones, Daniela Roşu e Marcel-Cătălin Roşu [JRR97] apresentam um algoritmo de escalonamento para aplicações de tempo real com reserva de CPU, o precomputed CPU 
scheduling. Este algoritmo de escalonamento foi implementado no sistema operacional Rialto desenvolvido pela Microsoft Research. O escalonador objetiva executar concorrentemente diversos conjuntos de aplicações na mesma máquina, satisfazendo os requisitos de tempo real para aquelas em que isto for possível, e fornecendo garantias de execução para aplicações convencionais.

Para tal, as fundamentais abstrações no Rialto são:

- atividades: para qual recursos são alocados e contra a qual a utilização de recursos é cobrado. Cada aplicação é associada a uma atividade separada.

- reserva de CPU: feita por atividades para assegurar granularidade e uma garantia mínima de execução. Feita do seguinte modo: A cada unidades $Y$ de tempo, $X$ estão reservadas para uma atividade $A$. Essa requisição significa que por todo intervalo de tempo de tamanho $Y$, threads executáveis de $A$ são escalonados por até $X$ unidades de tempo.

- restrição de tempo: solicitação dinâmica gerada por uma thread para o escalonador para que o código associado com aquela restrição seja executado no intervalo entre o instante inicial e o deadline (um tempo extra pode ser garantido, quando possível, utilizando tempo livre do escalonador).

A análise de viabilidade é feita para todas restrições de tempo submetidas, incluindo aquelas com um instante inicial posterior. Para a thread requisitante garante-se o tempo desejado e suficiente para seu serviço ou notifica-se a inviabilidade da solicitação, o que permite atitudes alternativas para a thread. Quando a thread indica que finalizou uma requisição de tempo, o escalonador retorna a ele a quantidade de tempo real de execução consumida. Com esta informação é possível computar estimativas de tempo de execução para as demais solicitações.

Os outros objetivos requeridos do escalonador precomputed CPU scheduling são:

- Baixa sobrecarga de escalonamento. O tempo para realizar decisões de escalonamentos deve ser pequeno e previsível, preferencialmente não aumentando quando cresce o número de threads.

- Compartilhamento justo do tempo disponível. O tempo de CPU não reservado ou não utilizado por uma atividade de tempo real deve ser compartilhado entre todas as atividades (tempo real ou convencional).

- Justiça para threads dentro de uma atividade. Em uma atividade, as threads executáveis e que não usam restrições de tempo devem receber quantidades sememlhantes de CPU.

- Melhor esforço para garantir reservas de CPU para atividades brevemente bloqueadas. Enquanto reservas de CPU são somente garantidas para atividades que não bloqueiam, muitas aplicações bloqueiam, inevitavelmente, por pequenos períodos devido à sincronização e ao I/O. Se possível, as atividades, brevemente bloqueadas e com risco de não obter suas reservas de $\mathrm{CPU}$, devem receber a CPU quando estiverem prontas para executar.

- Melhor esforço para satisfazer restrições de tempo negadas. Em alguns casos, se possível, 
as threads, com restrições de tempo negadas, devem ser escalonadas para aumentar a chance de satisfazê-las.

- Melhor esforço para finalizar uma restrição de tempo subestimado. Em algumas situações, se possível, as threads, com restrições que ultrapassem suas estimativas de tempo, são escalonadas para finalizarem mais cedo.

O sistema operacional Rialto apresenta-se como uma aproximação de um sistema operacional modular e sua meta é maximizar o desempenho de qualquer aplicação em particular. Nenhuma base teórica é provida para maximizar a utilidade do sistema. Esse sistema utiliza um gerenciamento centralizado no qual a aplicação negocia seus parâmetros de QoS com o recurso. Outra propriedade chave do escalonador é que atividades não violam as garantias de outras atividades (nenhuma coordenação global deve existir entre as aplicações), a restrição de tempo e a reserva de CPU podem ser utilizadas juntas, separadas ou nenhuma, que permite ao sistema a execução de diferentes tipos de aplicações sem nenhuma mudança global ou coordenação.

Aspectos gerais do escalonador precomputed CPU scheduling:

- Grafo de escalonamento pré-computado.

O fundamento básico deste escalonador é a sua habilidade de pré-computar uma classificação de maneira que todas as reservas de CPU aceitas possam ser atendidas, e as análises de restrições temporais e viabilidade também. Essa classificação para ser utilizada em tempo de execução para decidir qual a próxima atividade a ser executada em tempo limitado por uma constante, utilizando uma estrutura de árvore binária. Cada nó é associado a uma atividade específica e um intervalo de tempo periódico que é dedicado a esta atividade, ou é um nó livre, apenas para complementar o timeslice. A altura desta árvore é o período-base do grafo e corresponde ao período ativo de reserva de CPU mínimo. Repetidamente o escalonador percorre a árvore da esquerda para a direita, alternando escolhas a cada ponto de ramificação até o nó-folha. Cada nó, após um ponto de ramificação, é escalonado somente metade das vezes do qual o precede.

O escalonador pode ser atualizado de acordo com as mudanças das reservas de CPU, utilizando em sua construção critério para minimizar o número de troca de contexto entre atividades e maximizar as fatias de reservas de tempo.

- Atribuição de intervalo de tempo.

O escalonador analisa a viabilidade de cada restrição de tempo quando uma thread a solicita.

- Execução das restrições EDF (Seção 1.1.2).

Quando em um percurso na árvore de escalonamento, encontra-se uma atribuição para o momento atual, uma thread com restrição ativa é selecionada para executar. É escolhida a thread com o menor deadline dentre as com restrições ativas. 
- Política Round Robin para threads dentro de uma atividade.

Quando o escalonador seleciona uma atividade para executar e esta não possui restrições ativas, a próxima thread a ser executada será selecionada pelo escalonamento RR, executando até ser bloqueada ou pelo tempo restante no nó referente à atividade.

Quando o escalonamento encontra um nó livre sem atribuição de tempo ou dedicado a uma atividade bloqueada, deve decidir que atividade escolher. Quando restrições de tempo ou reservas de CPU não são utilizadas, as políticas resultam em timesharing, fornecendo compartilhamento justo para threads e atividades de cada atividade.

O sistema operacional Rialto, segundo os autores, demonstra eficiência e praticidade ao utilizar um grafo de escalonamento pré-computado para reservas de CPU garantidas por períodos definidos pela aplicação e restrições de tempo garantidas pela análise de viabilidade.

Diversos esquemas de gerenciamento de recursos utilizam-se de mecanismos de alocação via reserva de recursos ou via share proporcional. Entretanto não oferecem meios para garantir antecipadamente que específicas aplicações respeitarão seus prazos quando exigem mais tempo de CPU do que seus respectivos shares podem assegurar ou quando são adiadas por algum tempo. Este trabalho provê reserva de recurso semelhante aos esquemas implementados no sistema operacional experimental Eclipse, descritos no Capítulo 3.

\subsubsection{Esquema de Gerenciamento de Recursos no Nemesis}

Um outro sistema operacional existente no mercado, o Nemesis $\left[\mathrm{LMB}^{+} 96\right]$, apresenta o esquema de gerenciamento de recursos similar ao resource kernel. Ambos adotam um modelo semelhante de especificação e alocação de recurso baseado no $\{\mathrm{C}, \mathrm{T}\}$, modelo originariamente proposto por Liu e Layland [LL73]. O Nemesis implicitamente associa um deadline de T que depois de cada $\mathrm{C}$ unidades de tempo precisa estar disponível.

O seu kernel contém apenas o escalonamento e os outros serviços do Nemesis são implementados como bibliotecas que são ligadas às aplicações e executadas no espaço de endereçamento destas aplicações. Este sistema provê um bom desempenho na alocação de CPU e I/O de disco, para seus domínios. Defende a minimização de serviços para capacitar a utilização correta do recurso pelas aplicações.

Entretanto, comparando os sistemas Nemesis e Eclipse [BGzS98], há uma diferença radical em suas estruturas, sendo necessário aqui reescrever a maioria das aplicações e dispositivos de I/O para possibilitar a sua utilização e funcionamento.

\subsubsection{Processor Scheduling in Virtual Computer Systems}

Silberschatz et al. [GzS93] apresentam um estudo com os mesmos propósitos dos trabalhos já apresentados nas soluções do problema de gerenciamento de recursos, onde é introduzido o paradigma de computadores virtuais (VC) que é uma coleção de recursos próprios, o qual incorpora as propriedades de previsibilidade e escolha no projeto de sistemas operacionais. 
A previsibilidade refere-se à habilidade do sistema de oferecer a cada aplicação um ambiente computacional cujo desempenho seja independente da presença de aplicações concorrentes.

A escolha refere-se à habilidade de uma aplicação em selecionar um sistema de computação que alcance suas especificações e suas necessidades.

A motivação fundamental do VC está em que (1) os usuários querem desempenho previsível para suas tarefas, contudo, não são cuidadosos quanto ao hardware do computador, sua localização ou quantos outros usuários compartilham o sistema e (2) os usuários podem necessitar de políticas de escalonamento distintas para diferentes tarefas. Aplicando o paradigma VC a um sistema, incentiva os proprietários a compartilhar seus recursos, visto que os proprietários estão garantidos de receber um nível de serviço que é sempre melhor ou igual ao nível de serviço recebido quando seus recursos não são compartilhados. Aplicando o paradigma VC a um sistema no qual não há concepção de propriedade, provê cada usuário com um ambiente de computação previsível de sua escolha.

Um sistema baseado no paradigma VC é referenciado como um sistema VC. Em um sistema VC, cada usuário possui um ou mais computadores imaginários - computadores virtuais. O computador virtual é apenas uma descrição de um computador. A descrição de um sistema VC inclui o tipo de CPU (por exemplo, velocidade) e um algoritmo de escalonamento local (first come first served, round robin, earliest deadline first). Qualquer computador real pode ser utilizado num sistema VC; depende do modelo do sistema. O sistema considerado pelos autores consiste simplesmente de um conjunto de processadores $P=\left\{P_{1}, P_{2}, \cdots, P_{m}\right\}$ onde $m$ é o número de processadores.

Seja $V=\left\{V_{1}, V_{2}, \cdots, V_{n}\right\}$ o conjunto de $n$ computadores virtuais. Cada um pode diferir em termos de suas especificações; a associação feita pelo usuário depende do ambiente computacional.

Supondo a tarefa $T_{i}$ submetida a um computador virtual sendo executada em um computador que é equivalente ao computador virtual. Esta execução é referenciada como execução em computador virtual.

A imaginária execução de $T_{i}$ pode ser caracterizada por dois atributos: tempo de chegada $a_{i}$ e tempo de término $\overline{c_{i}}$. O tempo de chegada $a_{i}$ é o tempo no qual $T_{i}$ é submetida ao sistema. O tempo de término $\overline{c_{i}}$ é o tempo no qual $T_{i}$ completou sua execução no sistema. Obviamente, tempo de término $\overline{c_{i}}$ depende do algoritmo de escalonamento do computador virtual, do tamanho da tarefa $T_{i}$, e da carga do sistema VC. Denota-se $c_{i}$ o tempo atual de término da tarefa $T_{i}$. O modelo de tarefas periódicas é definido como uma seqüência de tarefas independentes com os tempos de chegada e de término separados.

Para garantir a previsibilidade, além das medidas de desempenho relativas a tempos médios de resposta ${ }^{2}$ e de throughut ${ }^{3}$, pode ser expressa em termos de deadlines. Cada tarefa $T_{i}$ tem

\footnotetext{
${ }^{2} \mathrm{O}$ tempo médio de resposta no tempo $t$ é a soma dos tempos de resposta $\left(c_{i}-a_{i}\right)$ de todas as tarefas completadas antes ou até o tempo $t$ pelo número de tarefas completadas.

${ }^{3} \mathrm{O}$ throughput em um dado intervalo é o número de tarefas completadas neste intervalo. Divide-se o tempo $t$ em intervalos detempo de tamanho $\bar{t}$ e define-se a médio de throughput no tempo $t$ como a média sobre $\left\lfloor\frac{t}{t}\right\rfloor$ intervalos de tempo.
} 
associada um deadline $d_{i}$, que é o tempo no qual a tarefa deve terminar.

Um sistema VC é um conjunto de $k$ tarefas $T=\left\{T_{1}, T_{2}, \cdots, T_{k}\right\}$ que devem ser escalonadas nos processadores em $P$ sob os requisitos $a_{i}$ e $d_{i}$ de cada tarefa.

Em um sistema baseado neste paradigma VC, a cada usuário é garantida uma qualidade e tipo de serviço e o sistema procura oferecer a cada usuário o nível mínimo do serviço prometido. É natural um usuário desejar receber o serviço prometido independentemente do úmero de usuários acessando o sistema, do local onde a execução está se realizando e de onde o usuário acessa o sistema. Um sistema VC visa oferecer um nível de serviço ao usuário que é proporcional ao que ele teria obtido no seu computador virtual. Os usuários podem requerer um tipo e nível diferente de serviço e sua escolha correspondente a um tipo diferente de computador virtual; cada usuário pode ter mais de um computador virtual.

Cada nível de serviço define um tipo diferente de sistema VC: strict, average e bounded. O conjunto de escalonadores para um sistema VC bounded contém o conjunto de escalonadores para um sistema VC average que por sua vez, contém o conjunto de escalonadores para um sistema VC strict.

Em um sistema VC strict é imposto que o tempo atual de término da tarefa deve ser menor que o tempo de término no computador virtual. Esta restrição pode ser expressa em termos do deadline para cada tarefa $T_{i}$ como $d_{i}=\overline{c_{i}}$. Neste sistema se todas as tarefas são escalonadas e cumprem suas restrições, estes escalonamentos são chamados de strictly realizáveis. O tempo médio de resposta para cada usuário será sempre menor ou igual ao tempo médio de resposta que ele teria obtido no seu computador virtual. O throughput médio será sempre maior ou igual ao throughput médio do virtual. Obviamente, o deadline de uma tarefa depende do tamanho da tarefa, da velocidade da CPU, do algoritmo de escalonamento e da carga do sistema VC.

Em um sistema VC average cada usuário é provido com um nível de serviço que é, na média, menor que ou tão bom quanto num computador virtual enquanto mantém limitado o atraso para cada tarefa. Especificamente, um sistema VC average assume um intervalo de tempo $\overline{t_{i}}$ e requer que: (1) o throughput médio das tarefas submetidas a um computador virtual seja maior ou igual ao throughput médio das tarefas no computador virtual para todo intervalo de tamanho $\bar{t},(2)$ cada tarefa pode ser atrasada até $\bar{t}$. Estas restrições podem ser expressas por $d_{i}=\left\lceil\frac{\overline{c_{i}}}{\bar{t}}\right\rceil . \bar{t}$ para cada tarefa $T_{i}$. Neste sistema todas as tarefas são escalonadas e cumprem suas restrições e seus escalonamentos são chamados average realizáveis. Se um algoritmo de escalonamento é strictly realizável é também average realizável.

Em um sistema VC bounded, um usuário tolera atrasos por um limite conhecido. Este atraso pode ser imposto pelo sistema sendo expresso por um limite de atraso que a tarefa pode aceitar. Neste sistema VC, os deadlines são expressos como $d_{i}=\overline{c_{i}}+b_{i}$ onde $b_{i}$ é uma constante ou uma função limitada por uma constante. Neste sistema todas as tarefas são escalonadas e cumprem suas restrições sob escalonamentos limitadamente praticável. Se um algoritmo de escalonamento é average realizável é também bounded realizável.

Seja $b_{\max }$ o $b_{i}$ máximo para as tarefas submetidas ao computador virtual. A qualquer tempo, o tempo médio de resposta para essas tarefas será menor ou igual à soma de $b_{\max }$ 
e o tempo médio de resposta que poderia obter num computador virtual. Supondo que sobre $k-\left\lceil\frac{b_{\max }}{\bar{t}}\right\rceil$ intervalos de tempo o throughput médio no computador virtual é $a$, então o throughput médio sobre $k$ intervalos de tempo para tarefas submetidas a um computador virtual será maior ou igual a $a-\left\lceil\frac{b_{\max }}{\bar{t}}\right\rceil \cdot \frac{1}{k}$ para $a \geq\left\lceil\frac{b_{\max }}{\bar{t}}\right\rceil \cdot \frac{1}{k}$ e $k \geq\left\lceil\frac{b_{\max }}{\bar{t}}\right\rceil$ e, caso contrário, será zero.

São apresentadas várias políticas de escalonamento do processador em sistemas de computadores virtuais. Assume-se algumas simplificações: as tarefas são independentes mutuamente e bloqueáveis; o custo do bloqueio é irrisório. O sistema é analisado sob o ponto de vista da CPU e assume-se que sempre possui quantidade suficiente de outros recursos. Os processadores são considerados idênticos e o algoritmo local de escalonamento de todos os computadores virtuais é o First Come First Served.

Primeiramente foram examinados escalonadores on-line (definidos na Seção 1.1.2) realizáveis para sistema VC com apenas um processador.

A velocidade de cada computador virtual $V_{i}$ é definida em termos de taxa do clock do computador virtual, clock $_{i}$ que é o número de vezes do $c l o c k$ imaginário de computador virtual em ticks por segundo.

Um sistema VC com um processador pode ser implementado de várias maneiras dependendo da seleção das taxas do clock para os computadores virtuais. Neste trabalho foi considerada a seleção das taxas do clock para cada computador virtual $V_{i}$ como sendo clock $_{i}=\frac{s_{i}}{p}$.clock, onde o inteiro $p$ é um parâmetro do sistema referente a um período comum, e o inteiro $s_{i}$ é selecionadp pelo usuário qeu escolhe a taxa do clock para o computador virtual $V_{i}$. A velocidade relativa do computador virtual é $\frac{p}{s_{i}}$. Isso implica em que se a execução da tarefa utiliza de $l_{j}$ unidades de tempo do processador, executará por $l_{j} \cdot \frac{p}{s_{i}}$ unidades de tempo no simulador.

O seguinte algoritmo gera escalonadores bounded realizáveis com um limite igual a $b_{i}=$ $p-s_{i}$ para cada computador virtual $V_{i}$. Isto é, qualquer tarefa no computador virtual $V_{i}$ pode ser atrasada por até $p-s_{i}$ unidades de tempo na execução no simulador.

Os computadores virtuais são ordenados em um ciclo. Uma fila é mantida para cada computador virtual. O algoritmo percorre as filas nesta ordem cíclica. A cada iteração, se houver qualquer tarefa na fila do computador virtual $V_{i}$, o processador é alocado por até $s_{i}$ unidades de tempo para o computador virtual. Caso contrário, o algoritmo passa a verificação para a fila do próximo computador virtual. A alocação do processador para o computador virtual $V_{i}$ termina ao final das $s_{i}$ unidades de tempo ou quando a última tarefa na sua fila termina. Este algoritmo é referenciado como round robin with variable timeslice (RRVT), onde $s_{i}$ é o tamanho do timeslice para o computador virtual $V_{i}$.

Silberschatz et al. mostraram que ao se considerar um sistema VC com um processador onde o escalonamento dos computadores virtuais é o FCFS, o algoritmo RRVT com um período comum de tamanho $p$ e timeslice de tamanho $s_{i}$ para cada computador virtual $V_{i}$ é limitado em $b_{i}=p-s_{i}$ para cada computador virtual $V_{i}$ se

$$
\sum_{i=1}^{n} \text { clock }_{i} \leq \text { clock. }
$$


Há sempre um escalonador strictly realizável para um sistema VC com um processador. Contudo, algoritmos de escalonamento strictly realizável necessitam ter pontos de decisão para todo tick do clock e portanto não são suficientes. É possível também derivar algoritmos de escalonamento average realizável os quais requerem inclusão da chegada de uma tarefa nos pontos de decisão.

Foram examinados também escalonadores on-line realizáveis para sistema VC com multiprocessadores.

Um sistema VC com multiprocessadores pode ser implementado de diversas maneiras que incluem a associação de um conjunto de computadores virtuais que satisfaz a Fórmula 2.9 para cada processador com o algoritmo RRTV. Outro algoritmo é apresentado, chamado reservation, que incrementa o número de computadores virtuais que podem ser admitidos simultaneamente. Esse algoritmo é baseado na premissa que os processadores são idênticos. Para cada computador virtual $V_{i}$, o algoritmo reservation aloca $s_{i}$ unidades de tempo a cada $p$ unidades de tempo.

O algoritmo reservation consiste de um conjunto de requisições de reservas periódicas. Cada requisição de reserva é atribuída a um processador e corresponde a um computador virtual. Quando da chegada de uma requisição de reserva, o processador correspondente é alocado ao computador virtual pelo tamanho da requisição de reserva.

Uma ou duas requisições de reservas periódicas são definidas para cada computador virtual. Três parâmetros caracterizam cada requisição de reserva: período, tamanho e fase inicial. $\mathrm{O}$ período de cada requisição de reserva é igual a período comum $p$. Assim, uma requisição de reserva é uma seqüência de instâncias de reserva cada qual dista da anterior de um $p$ unidades de tempo. Para uma requisição de reserva correspondente a um computador virtual $V_{i}$ para o qual apenas uma requisição de reserva é definida, o tamanho da requisição de reserva é igual a $s_{i}$. Por outro lado, a soma dos tamanhos $s_{i}^{\prime}$ e $s_{i}^{\prime \prime}$ de duas requisições de reserva que correspondem a um computador virtual $V_{i}$ é igual a $s_{i}$. A fase inicial de uma requisição de reserva é sua fase relativa a algum tempo de origem fixado. O cálculo dos valores de $s_{i}^{\prime}$ e $s_{i}^{\prime \prime}$ e de fases iniciais é apresentado a seguir.

Uma seqüência de computadores virtuais são designadas para cada processador. Um computador virtual $V_{i}$ é designado a um processador para o qual a soma dos tamanhos das requisições de reserva correspondentes aos computadores virtuais atribuídos para este processador é menor que $p$ e maior que zero. Se não houver tal processador, o computador virtual é designado para um processador vazio. A fase inicial da requisição de reserva correspondente recebe o valor da soma dos tamanhos das requisições de reserva correspondentes aos computadores virtuais no mesmo processador antes do $V_{i}$. Se adição de $s_{i}$ faz o valor da soma ser maior que $p$, então o computador virtual $V_{i}$ é designado para este processador e para um outro vazio. A requisição de reserva correspondente ao primeiro processador tem um tanmanho de $s_{i}^{\prime}$ tal que a soma dos tamanhos de todas as requisições de reserva para este processador é igual a $p$. A segunda requisição de reserva tem o tamanho $s_{i}^{\prime \prime}$ onde $s_{i}^{\prime \prime}=s_{i}-s_{i}^{\prime}$ e a fase inicial de zero. Como cada computador virtual permite $s_{i} \leq p$, duas requisições de reserva correspondes a um computador virtual nunca se sobrepõem. 
Mostraram neste trabalho que considerando um sistema de VC com multiprocessador onde o escalonamento local dos computadores virtuais é o FCFS, o algoritmo reservation com um período comum de tamanho $p$ é bounded realizável com um limite $b_{i}=p-s_{i}$ para cada computador virtual $V_{i}$, se satisfaz às seguintes condições:

$$
\text { clock }_{i} \leq \text { clock e } \sum_{i=1}^{n} \text { clock }_{i} \leq \text { m.clock. }
$$

Os autores assumiram nos sistemas VC o FCFS como algoritmo local de escalonamento de todos os computadores virtuais. Em contrapartida, salientam a importância de possibilitar a co-existência de computadores virtuais com diferentes algoritmos de escalonamento local. Isso é essencial especialmente em ambientes computacionais onde aplicações requerem acesso a diferentes tipos de políticas e onde aplicações de média contínua, que requerem uma taxa garantida de processamento, são executadas concorrentemente a aplicações convencionais.

Cada aplicação é tipicamente modelada por uma tarefa periódica com um período $p_{i}$ e tempo de computação $l_{i}$. Em um sistema VC, um computador virtual $V_{i}$ pode ser designado para esta tarefa onde o timeslice $s_{i}$ é selecionado tal que a inequação $s_{i} \geq \frac{l_{i} \cdot p}{p_{i}}$ seja satisfeita. Se $p>p_{i}$, então $p$ precisa ser trocado pelo sistema VC.

Os algoritmos RRVT e reservation alocam $s_{i}$ unidades de tempo para cada computador virtual $V_{i}$ em todas $p$ unidades de tempo. A ordem na qual as tarefas submetidas ao computador virtual $V_{i}$ são executadas pode ser alterada pois os computadores virtuais podem admitir outros algoritmos de escalonamento local diferente do FCFS, ou seja, esta ordem depende do algoritmo de escalonamento adotado para tarefas do $V_{i}$. O objetivo é completar cada tarefa submetida a um computador virtual no máximo com um certo limite posterior ao que ela seria completada no computador virtual imaginário. Todavia, devido a anomalias causadas pelo atraso de uma tarefa para um dado limite, pode não ser suficiente utilizar o mesmo algoritmo como o algoritmo de escalonamento local para ordenar a execução de tarefas submetidas a um computador virtual.

Por exemplo, considerando um computador virtual com um algoritmo de escalonamento local EDF (Seção 1.1.2) no sistema VC que gera escalonadores bounded realizáveis com um limite $b_{i}$ para cada computador virtual. Supondo que a tarefa $T_{1}$ submetida a esse computador virtual é atrasada $b_{i}$ unidades de tempo e antes de $T_{1}$ terminar uma outra tarefa $T_{2}$ chega e tem o deadline menor ao de $T_{1}$. Apesar de que a execução imaginária no computador virtual da tarefa $T_{1}$ pode ter sido completada antes da execução imaginária de $T_{2}$, se as tarefas na fila do computador virtual são executadas sob o critério EDF, a execução da tarefa $T_{1}$ no sistema pode ser atrasada além do limite superior à execução no computador virtual.

Silberschatz et al. [GzS94] complementaram este estudo com os resultados básicos para escalonamentos em sistema VC através de escalonadores on-line para sistema VC de um processador e multiprocessador centralizados e distribuídos.

Aplicando o paradigma VC a um sistema dedicado permite-se diversos computadores virtuais com diferentes especificações. Os usuários podem selecionar políticas de escalonamento distintas para tarefas diferentes e/ou alocar os recursos disponíveis para tarefas concorrentes. Aplicando o paradigma VC a um sistema time-sharing permite-se o compartilhamento pre- 
visível de recursos pelos usuários. Aplicando o paradigma VC a um sistema distribuído, que corresponde a uma coleção de resursos próprios, permite-se o compartilhamento dos ciclos ociosos sem degradar o desempenho das demais tarefas, o que difere de sistema distribuídos onde este compartilhamento utiliza critérios de desempenho baseados na média de throughput, tempos de resposta e ciclos ociosos de processador.

A partir dos resultados do trabalho constataram que aplicando o paradigma de computadores virtuais ao sistema pode-se receber um nível de serviço melhor ou igual a quando seus recursos não são compartilhados e permite-se que os usuários utilizem o ambiente de sua escolha, podendo almejar políticas de escalonamentos distintas para diferentes tarefas.

Com respeito à implementação de um sistema VC apresentam numerosos problemas e desafios futuros, tais como o desenvolvimento de métricas secundárias de desempenho adequadas que reflitam o uso justo dos ciclos ociosos, o desenvolvimento de algoritmos de escalonamento para várias métricas secundárias de desempenho sujeitas às restrições do VC, escalonamento sob restrições de precedência, escalonamento de tarefas IO-bound, escalonamento com informação parcial em sistemas descentralizados e escalonamento quando os computadores virtuais têm diferentes algoritmos de escalonamento local e o sistema consiste de recursos heterogêneos.

\subsubsection{As Garantias de QoS e o Move-To-Rear List Scheduling}

No âmbito da solicitação e da aquisição de recursos por parte de uma aplicação, é uma questão primordial a qualidade de serviço (QoS). A QoS é utilizada como uma ferramenta de gerenciamento dos recursos do sistema utilizada para referenciar o tipo de serviço sendo fornecido e para medir a quantidade (ou número de vezes) deste serviço que é disponibilizada para uma aplicação.

Quando o objetivo é executar diversas aplicações de tempo real na mesma máquina, o sistema operacional precisa oferecer garantias de QoS tal que os recursos do sistema possam ser provisionados pelas aplicações para conquistar níveis desejados de desempenho previsível [BGzS97].

Para oferecer garantias de QoS, além dos parâmetros tradicionais que incluem atraso, justiça e throughput, Silberschatz et al. [BGzS97] introduzem um novo critério de QoS chamado serviço cumulativo ${ }^{4}$. O critério serviço cumulativo permite o relacionamento do total de serviço obtido por um processo sob uma política de escalonamento com o serviço ideal que o processo teria acumulado executando em cada recurso e tivesse reservado uma porção do serviço de cada um destes.

Informalmente, garantir serviço cumulativo significa que os atrasos dos escalonamentos obtidos por um processo nos vários recursos, não é acumulado sobre o tempo de vida do processo. Em outras palavras, um processo que está competindo por recursos executará a uma taxa prevísivel que é determinada pela porção dos serviços dos recursos e que está reservada para este processo, sem considerar a interferência dos outros processos na competição pelo

\footnotetext{
${ }^{4}$ Cumulativo significa feito por acumulação; que consiste em acumular.

Obs.: Acumulativo significa que tem a faculdade de acumular; que se acumula.
} 
recursos.

Uma garantia de serviço cumulativo é vital para aplicações, tais como, serviços de vídeo, que requerem diversos recursos e demanda previsível agregada a throughput sobre todos estes recursos.

Afirma-se que uma política de escalonamento oferece garantia de serviço cumulativo se o desempenho do sistema real difere do sistema ideal por, no máximo, uma porção constante.

A política de escalonamento empregada tem um papel fundamental nas garantias de QoS. Silberschatz et al. [BGzS97] apresentam um algoritmo de escalonamento chamado Move-ToRear List Scheduling (MTR-LS), o qual oferece estas garantias. Este é um dos algoritmos de escalonamento dentre os que estaremos concentrando nosso estudo e investigando sua política no restante desta dissertação.

As principais contribuições desta proposta são: (1) a introdução do critério de serviço cumulativo como um importante parâmetro de QoS para escalonamentos em sistemas operacionais e (2) a política MTR-LS que provê uma garantia de serviço cumulativo e garante outras tais como justiça (cota proporcional) e limites de atraso.

Antes de apresentarmos a política do MTR-LS iremos expor o modelo de sistema utilizado, as definições e as premissas associadas para que uma política de escalonamento ofereça as garantias de QoS citadas.

No modelo proposto, um sistema é basicamente um fornecedor de serviços. No contexto de um sistema operacional há múltiplos servidores, tais como CPU, memória RAM, discos e interfaces de rede, que são compartilhados pelos processos que por eles competem. Cada servidor (recurso) é capaz de oferecer em "trabalho" sob uma certa taxa.

Exemplo. Uma CPU executa 100 milhões de instruções por segundo (100MIPS), um disco pode transferir um bloco de dados (512 bytes) em $12 \mathrm{~ms}$ e uma interface de rede pode liberar bits em seu nó a 10 milhões de bits por segundo (10Mbps).

Os processos no contexto de um sistem operacional, que em rede corresponde aos "fluxos", são modelados como uma seqüência de fases onde cada fase consiste do nome de um servidor e a correspondente quantidade de "trabalho".

Exemplo. (CPU, 100milhōes de instruçōes) é uma fase que especifica a CPU como o servidor e o "trabalho" consiste da execução de 100 milhões de instruções. A quantidade de tempo gasto pela fase depende da velocidade da CPU. Uma CPU que execute 100 milhões de instruções por segundo gastará 1 segundo para completar esta fase.

Ao se completar uma fase, o processo seguirá para a sua próxima fase a qual consiste de uma nova requisição de servidor e "trabalho", que no sistema atual, não é conhecida antecipadamente. Com o modelo de processos como uma seqüência de fases, qualquer atraso ocorrido enquanto se completa uma fase será propagado para todas as fases subseqüentes. Contrariamente, se um processo ganha um tempo de vantagem por receber serviço extra, essa vantagem é também passada para as fases subseqüentes. O tempo de chegada de uma fase é independente das fases anteriores. Por exemplo, se uma fase de um processo gerou 
interrupções, é possível uma nova fase chegar antes da fase anterior completar o seu serviço.

No contexto de um sistema operacional assume-se que cada servidor possui um intervalo de preempção o qual especifica os limites temporais onde as preempções podem ocorrer. Isto significa que a "granularidade" de compartilhamento é determinada pelas propriedades do servidor e do escalonamento.

Outra característica desse modelo é que é negociado com o sistema os limites de bloqueio. Por exemplo, uma operação de I/O de disco ocorre em múltiplos do tamanho de um bloco básico e uma vez que uma transferência se inicia, o próximo evento escalonado pode ocorrer antes da transferência se completar. Porém, a granularidade para o escalonamento da CPU é feita de maneira arbitrária.

Para especificar QoS associa-se a cada processo e a cada servidor uma reserva chamada de fração de serviço. Essa fração fornece a cota do servidor requerida pelo processo.

Para obtermos a garantia de tempo (o tempo em que um recurso é compartilhado pelas aplicações é que precisa ser gerenciado globalmente) devemos incluir ao modelo a capacidade de controle de admissão e os recursos suficientes disponíveis para tratar a demanda dos processos [BGzS97].

Em um modelo de sistema baseado em garantia de serviço, a aplicação solicita ao sistema recursos e este, baseado na disponibilidade dos mesmos, decide se pode aceitar aquela solicitação sem afetar as restrições anteriores. Para tal, o modelo adota controle de admissão que consiste em assegurar que frações de serviço de um novo processo com as frações de serviço dos processos já no sistema não excedam um determinado limite pré-determinado. Controle de admissão é necessário se deseja-se oferecer garantias de atraso e de serviço cumulativo que são independentes do número de processos no sistema.

Exemplo. Suponha um processo com 0,25 de reserva de CPU. No caso de uma CPU que execute 100 milhões de instruções por segundo, significa que o processo necessita de, no mínimo, 25MIPS de CPU para alcançar seus objetivos de desempenho. Foi escolhido o uso de frações de serviço pois refletem, em termos absolutos, a requisição de serviço de um processo e simplifica o controle de admissão.

O objetivo de desempenho mais correto especificado pelas reservas é a garantia de serviço cumulativo que significa uma garantia regular que o sistema real conserva relativa à execução ideal baseada nas reservas do servidor.

Exemplo. Suponha um processo que reserva $20 \%$ de CPU e $50 \%$ de disco. Considere que a CPU efetua 100MIPS e o disco transfere um bloco de $4 \mathrm{~Kb}$ em $12 \mathrm{~ms}$. De acordo com a reserva, este processo pode "ver" até 20MIPS para CPU e para uma operação de I/O de disco capaz de transferir um simples bloco em $24 \mathrm{~ms}$. Suponha que o processo alterne suas fases entre CPU e disco com cada fase de CPU requerendo a execução de 4 milhões de instruções e cada fase de disco consistindo em transferir 6 blocos de dados. Conseqüentemente, o processo pode receber não mais que $200 \mathrm{~ms}$ para cada fase na CPU e $144 \mathrm{~ms}$ para cada fase no disco independentemente do número de fases do processo e dos processos concorrentes. Outro parâmetro de QoS para processos pode ser definido, o atraso. O atraso de uma fase em um servidor é o tempo 
acumulativo gasto pela fase, tanto esperando pelo servidor, como nele executando. É fácil ver que garantindo limites de atraso (isto é, limitando o tempo para completar a fase) não é suficiente para oferecer garantias de serviço cumulativo porque o atraso da fase, pode acumular sobre as outras fases deixando uma discrepância entre o serviço real e o ideal. Por exemplo, os atrasos da fase em um servidor pode reduzir a taxa de serviço de outros servidores em um sistema fechado.

Outro parâmetro de QoS para processos pode ser definido, a justiça. A noção de justiça é definida como medida da habilidade do sistema em assegurar que processos simultaneamente requerendo o mesmo servidor "compartilham" esse servidor na proporção de suas reservas. A justiça no contexto de sistemas operacionais, algumas vezes sendo referenciada como compartilhamento proporcional, pode gerar problemas pois o custo desta justiça (troca de contexto) cresce na medida em que a granularidade do compartilhamento do servidor decresce. Nao é evidente que compartilhamento de granulação fina é sempre desejável em um sistema operacional de propósito geral, particularmente para processos batch onde o compartilhamento de granulação grossa é aceitável e substancialmente reduz trocas de contexto.

Os algoritmos de escalonamento, apresentados anteriormente neste capítulo, tais como o stride scheduling (Seção 2.1.1) que atende e oferece a cada processo com um share do servidor na proporção de seu correspondente peso (número de tickets), o start-time fair scheduling (Seção 2.1.3) que é baseado em algoritmos de rede, o EEVDF (Seção 2.1.2) que provê cada processo com um share de um servidor na proporção de seu correspondente peso e a política de escalonamento de CPU (Seção 2.1.5) que provê cada processo com seu share reservado, não oferecem a medida de serviço cumulativo e portanto, as propriedades que eles possuem não são suficientes para prover essa garantia.

O modelo de sistema e de processos e as definições formais dos termos utilizados nesta proposta são introduzidos a seguir.

No modelo adotado, um sistema consiste de uma coleção de servidores $\mathrm{S}$ (recursos, tais como CPU, discos e rede). Cada servidor $s \in S$ é representado nesse modelo por uma taxa de serviço $B_{s}$ e um intervalo de preempção, o qual especifica os limites temporais onde a preempção pode ocorrer, $\Delta t_{s} \geq 0$. Se $w$ é a taxa de serviço a ser efetuada pelo servidor $s$, então o tempo para completar $w$ no servidor $s$ é $w / B_{s}$.

Quando um processo está executando num servidor com intervalo de preempção $\Delta t_{s}$, o tempo de execução precisa ser uma integral múltipla de $\Delta t_{s}$ e o processo pode apenas ser preemptado em integrais múltiplas de $\Delta t_{s}$. $\mathrm{O}$ caso de $\Delta t_{s}=0$ corresponde ao servidor para o qual os tempos de execução são tempos arbitrários de execução e as preempções não são restritas.

Uma fase é um par servidor-duração $(s, t)$, onde $s \in \mathrm{S}$ e $t$ é a quantidade de tempo solicitada pelo processo na utilização do servidor $s$ para completar a fase executando sozinho neste servidor. Um processo é visto como uma sequência de fases (finita ou infinita), $P=$ $\left(s_{1}, t_{1}\right),\left(s_{2}, t_{2}\right), \cdots$. As fases de um processo não são conhecidas a priori. A identificação da próxima fase somente será conhecida após a execução da fase anterior.

Inicialmente, a única informação que temos de um processo é a identificação do primeiro 
servidor, isto é, $P=\left(s_{1},.\right)$. Executando um processo $P$ no servidor $s_{1}$, eventualmente, conhecemos $t_{1}$, que é a duração da primeira fase, e $s_{2}$, o servidor requerido na segunda fase, isto é, $P=\left(s_{1}, t_{1}\right)\left(s_{2},.\right)$. Executando $P$ no servidor $s_{2}$, eventualmente, descobrimos $t_{2}$ e o servidor requerido para a terceira fase, e assim sucessivamente.

Seja $0<a_{1}<a_{2}<\cdots$ a seqüência de tempos que os processos $P_{1}, P_{2} \ldots$ entram no sistema. O tempo de saída de um processo depende do próprio processo e da política de escalonamento. Assumimos que cada processo tem um tempo de saída. Um processo $P_{i}$ é ativo no tempo $t$ se $a_{i} \leq t$ e o seu tempo de saída é maior que $t$. Seja $A(t)$ o conjunto de índices de processos ativos no tempo $t$.

Cada processo $P_{j}$, depois de admitido no sistema, especifica uma fração de serviço, $\alpha_{j}$, para cada servidor $s$, onde $0 \leq \alpha_{j}^{s} \leq 1$. Para todo $s \in \mathrm{S}, \sum_{j \in A(t)} \alpha_{j}^{s} \leq 1$. A soma das frações de serviço de todos os processos ativos, em relação a $s$, não excede a 1 .

Desejando o desempenho do sistema sobre todos os servidores é suficiente estudar o desempenho de apenas um servidor. Sob o ponto de vista do servidor $s$, um processo é denotado por uma seqüência de fases que alternam entre $s$ e um outro servidor qualquer. O seu tempo em $s$ depende da duração da fase e da política de escalonamento utilizada pelos vários servidores.

O modelo permite que os processos entrem e saiam do sistema dinamicamente; um processo chega ao servidor $s$ se começa pela solicitação de $s$ ou requer $s$ após completar uma fase em outro servidor. Um processo deixa o servidor $s$ caso eventualmente saia do sistema ou quando completar uma fase em $s$.

Uma vez que considera-se o desempenho de um servidor $s$, pode-se suprimir a referência $s$. Da mesma forma, $B$ denota a taxa de serviço do servidor, $\Delta t$ o intervalo de preempção do servidor e $\alpha_{j}$ denota a fração de serviço do processo $P_{j}$.

Quando um processo está executando num servidor é designado um tempo máximo de execução, um quantum. $\mathrm{O}$ algoritmo de escalonamento não requer uma utilização de um tamanho fixo de quantum. As decisões são tomadas em tempos chamados decision epochs que correspondem à expiração do quantum corrente, à finalização da fase do processo ou ao fim do intervalo de preempção seguida da chegada de um processo ao recurso. No último caso, se a chegada de um processo ocorre no tempo $\tau$, enquanto o servidor está no intervalo de preempção $[t, t+\Delta t]$, então o escalonador precisa esperar até $t+\Delta t$, ou seja, a decision epoch ocorre em $t+\Delta t$. A cada decision epoch, o processo corrente pode ser bloqueado e o escalonador pode alocar outro processo para o servidor.

As políticas de escalonamento realizáveis requerem a execução de um processo por vez no servidor. Isto significa que se há mais de um processo esperando para executar no servidor, um ou ambos processos atrasarão (enfileirados). Ainda não foi mostrada a dependência das seguintes quantidades na política de escalonamento; é importante tê-las em mente.

Seja $[\tau, t]$ um intervalo de tempo real arbitrário. Define-se $w_{j}(\tau, t)$ como o tempo de espera real cumulativo (bloqueado por outros processos executando no servidor) e $s_{j}(\tau, t)$ como o tempo de serviço real (executando no servidor) obtidos pelo processo $P_{j}$ no intervalo $[\tau, t]$. Para $t \geq a_{j}$ define-se $w_{j}(t)=w_{j}\left(a_{j}, t\right)$ e $s_{j}(t)=s_{j}\left(a_{j}, t\right)$. 
Considerando $r_{j}(\tau, t)=w_{j}(\tau, t)+s_{j}(\tau, t)$ e para $t \geq a_{j}$, define-se $r_{j}(t)=w_{j}\left(a_{j}, t\right)+s_{j}\left(a_{j}, t\right)$. Por definição, $r_{j}(t)$ é o tempo total dispendido pelo processo $P_{j}$ no servidor no intervalo $[\tau, t]$.

Exemplificando o comportamento de um processo no sistema baseado neste modelo:

Seja o comportamento de um processo no sistema, relativo a um servidor $s$, expresso pela seguinte seqüência de fases: $(z, 4),(w, 5),(s, 3),(w, 2),(s, 3),(z, 6),(w, 2),(s, 2) \ldots$ onde $z$ indica que o processo está em outro servidor, $w$ esperando pelo serviço e $s$ executando no servidor.

Na Figura 2.4 temos ilustradas as quantidades definidas nesta seção. Os intervalos de tempo no eixo $x$ estão representando o comportamento do processo no sistema e no eixo $y$ observamos o tempo de serviço ou espera.

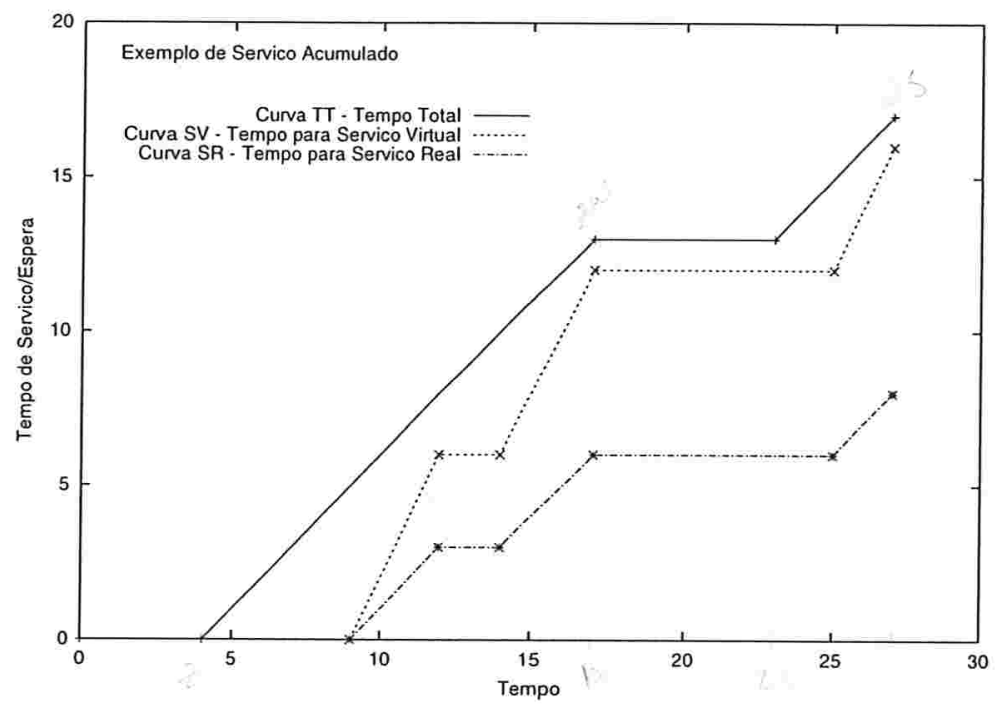

Figura 2.4: Um Exemplo de Serviço Cumulativo.

A curva TT denota o acúmulo de tempo de espera e de serviço do processo no recurso. A inclinação dessa curva segue 1 ou 0 , dependendo do processo estar no recurso ou não, respectivamente. Pela figura observamos que o processo chega ao recurso no tempo 4 e o deixa no tempo 17 indo para outro recurso.

A curva SR representa o serviço obtido pelo processo. A curva tem a inclinação para 1 ou 0 dependendo do processo estar utilizando ou esperando o recurso, respectivamente. Desde que o processo deixa o recurso em 17, isto significa que o serviço requerido pela fase é 6 . Podemos representar as seguintes quantidades: $r(4,17)=5+3+2+3+6=13 ; w(4,17)=5+2=7$; $s(4,17)=3+3=6 ; r(12,23)=2+3=5 ; w(12,23)=2 ; s(12,13)=3$.

Para a avaliação do desempenho do algoritmo de escalonamento foi introduzido um modelo de processador compartilhado no qual o servidor pode executar qualquer número de processos simultaneamente desde que a soma de suas frações de serviço não exceda o valor um. Neste modelo, processos não bloqueiam outros podendo ser executados simultaneamente no servidor, 
respeitando sua taxa. O tempo de serviço neste modelo é referenciado como tempo de serviço virtual.

Um processo com fração de serviço $\alpha$ que recebe $t$ unidades de tempo de serviço real ganha $\frac{t}{\alpha}$ unidades de tempo de serviço virtual para obter a mesma quantia de serviço num processador compartilhado executando a uma taxa $\alpha$.

Exemplo. Considere um processo com fração de serviço 0,25 que recebe 1 unidade de tempo de serviço real. Significa que o processo ganha $\frac{1}{0,25}=4$ unidades de tempo de serviço virtual num processador compartilhado executando a uma taxa de 0,25 .

Similarmente, uma fase utilizando $v$ unidades de tempo de serviço virtual para se completar em um modelo de processador compartilhado requer $\alpha_{i} \cdot v$ unidades de tempo real de serviço no servidor.

Exemplo. Supondo uma fase do processo recebendo 4 unidades de tempo de serviço virtual num processador compartilhado executando a uma taxa de 0,25 . Requer $0,25 \times 4=1$ unidade de tempo de serviço real no recurso.

Considerando $v_{j}(\tau, t)$ o tempo de serviço virtual cumulativo obtido pelo processo $P_{j}$ no intervalo $[\tau, t]$. Para $t \geq a_{j}$ define-se $v_{j}(t)=v_{j}\left(a_{j}, t\right)$. Observa-se que $\alpha_{j} v_{j}(\tau, t)=s_{j}(\tau, t)$ e $\alpha_{j} v_{j}(t)=s_{j}(t)$ para $t \geq a_{j}$.

Na Figura 2.4 a curva SV denota o tempo de serviço virtual conseguido pelo processo com uma fração de serviço igual a $\frac{1}{2}$. A inclinação dessa curva segue 2 ou 1 dependendo do processo ser servido ou não, respectivamente. A fase de duração 6 (do tempo 4 ao 17) requer 12 unidades de tempo de serviço virtual para se completar.

As definições e as condições que permitem a garantia de QoS para uma política de escalonamento, utilizando as notações e o modelo proposto são apresentadas a seguir.

Definição 2.1.1. Dizemos que uma política de escalonamento provê garantia de serviço cumulativo se existe uma constante $K$ tal que para todo processo $P_{j}$ e $\tau \leq t$, temos:

$$
v_{j}(\tau, t) \geq r_{j}(\tau, t)-K \text {. }
$$

Da Figura 2.4, temos: $v(4,9)=0 ; r(4,9)=5$ e $v(9,14)=3 \times 2=6 ; r(9,14)=3+2=5$ e $v(4,23)=3 \times 2+3 \times 2=12 ; r(4,23)=13$. Considerando a porção do processo ilustrada na Figura 2.4, concluímos que $v(\tau, t) \geq r(\tau, t)-5$, para todo $\tau \leq t$ e $\tau, t \in[0,27]$.

Outra interpretação para a garantia de serviço cumulativo é que o total de tempo real utilizando o servidor (incluindo esperando e executando) não é mais que uma quantidade constante de tempo a mais que o tempo de serviço virtual requerido para uma equivalente quantidade de tempo se serviço real.

Embora a definição de garantia de serviço cumulativo ser em termos de um simples servidor, isso implica em uma garantia de serviço cumulativo "global" (utilizando o tempo de serviço virtual cumulativo e o tempo real cumulativo sobre todos os servidores) no caso de multi-servidor onde há um número constante de servidores. 
Exemplo. Considere um processo $P=\left(s_{1}, t_{1}\right),\left(s_{2}, t_{2}\right),\left(s_{1}, t_{3}\right),\left(s_{2}, t_{4}\right), \cdots$ que requeira os servidores $s_{1}$ e $s_{2}$, e reserve $\alpha$ de $s_{1}$ e $\beta$ de $s_{2}$. Seja $K_{1}$ e $K_{2}$ os limites de serviço cumulativo nos servidores $s_{1}$ e $s_{2}$, respectivamente. Num sistema que garante serviço cumulativo, o total de tempo real para os recursos promoverem

$$
\sum_{i=1}^{\frac{n}{2}} t_{2 i-1}+\sum_{i=1}^{\frac{n}{2}} t_{2 i}
$$

unidades de tempo de serviço é limitado por

$$
\frac{1}{\alpha} \cdot \sum_{i=1}^{\frac{n}{2}} t_{2 i-1}+\frac{1}{\beta} \cdot \sum_{i=1}^{\frac{n}{2}} t_{2 i}+K_{1}+K_{2} .
$$

Notamos aqui um contraste diante de outras políticas de escalonamento [MST93, WW95, GGV96, SAWJ ${ }^{+96]}$ que provêm atraso limitado por fase do processo. Neste caso, a discrepância entre o serviço cumulativo obtido e o tempo para adquirir o serviço pode crescer com $n$ (o número de fases).

Definição 2.1.2. Dizemos que uma política de escalonamento provê limite de atraso se, para qualquer processo $P_{j}$, o tempo de espera real pelo tempo de serviço completar uma fase de duração d é de uma constante maior que $\frac{d}{\alpha_{j}}$.

Uma política de escalonamento "justa" assegura que vários processos requerendo o mesmo recurso compartilha o servidor na proporção de suas reservas, independentemente de sua prévia utilização do recurso. Isto é, uma política de escalonamento justa não penaliza um processo que utilizou um servidor inativo além de suas reservas quando outros processos tornam-se ativos neste servidor.

Definição 2.1.3. Dizemos que uma política de escalonamento é justa se existe uma constante $D$ tal que, para qualquer intervalo de tempo $[\tau, t]$, durante o qual um par de processos $P_{i}$ e $P_{j}$ requerem o servidor continuamente, temos:

$$
\left|\frac{s_{i}(\tau, t)}{\alpha_{i}}-\frac{s_{j}(\tau, t)}{\alpha_{j}}\right| \leq D
$$

O processador compartilhado provê justiça perfeita. Entretanto, não pode ser implementado na prática ( o custo pode ser alto, como comentado anteriormente nesta seção, e nem sempre justificado no contexto de sistemas operacionais). Entretanto, justiça é importante quando os serviços são sobrecarregados e é necessário a todos os processos um progresso uniforme e proporcional.

- Move-To-Rear List Scheduling 
O algoritmo de escalonamento MTR-LS provê garantia de serviço cumulativo, justiça e limite de atraso.

O ponto central da política do MTR-LS é uma lista ordenada $L$ dos processos que estão ativos o tempo todo. Um processo na lista $L$ é executável se não está utilizando outro servidor. A política MTR-LS serve os processos na ordem em que eles aparecem em $L$.

A política MTR-LS faz uso de uma constante $\Gamma$ chamada quantum de tempo virtual. A cada processo $P_{j}$ na lista $L$ está associado um valor left $t_{j}$. O valor inicial de $l e f t_{j}$ é $\alpha_{j} \Gamma$. Quando os processos são servidos, executam por um quantum que é limitado pelo valor em left $t_{j}$. Ao final do período de serviço, left $t_{j}$ é decrementado pela quantidade de tempo de serviço que o processo obteve e se o resultado for zero, $P_{j}$ é movido para o final da lista $L$ e o valor de left $t_{j}$ é reiniciado com $\alpha_{j} \Gamma$. O valor de $\alpha_{j} \Gamma$ é o quantum real. Um processo que avança por $\alpha_{j} \Gamma$ de tempo real avança por $\Gamma$ tempo virtual de serviço.

O serviço obtido por um processo pode ser menor que o quantum alocado devido ao término da fase ou à chegada de um processo. Formalmente, a fase termina, o processo vai para outro servidor e o primeiro processo executável em $L$ é o próximo a ser servido. No outro caso, se o processo que chegou está a frente do corrente processo na lista $L$, então o processo que está executando é bloqueado (desde que o intervalo de preempção permita) e o primeiro processo executável em $L$ é o próximo a ser servido.

Sempre que um novo processo $P_{j}$ entra no sistema é adicionado no final de $L$ (independentemente de requisitar o servidor ou não) e a left $t_{j}$ é associado $\alpha_{i} \Gamma$. Qualquer que seja o processo que sai do sistema, é removido da lista $L$.

A iniciação da lista $L$ está apresentada na Figura 2.5. A política MTR-LS considera um instante inicial de referência igual a zero.

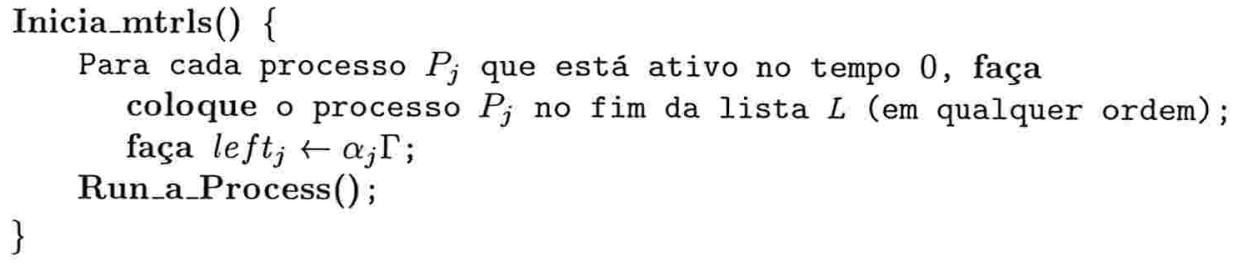

Figura 2.5: Procedimento Inicia para o MTR-LS.

Para o servidor é associado um estado. Quando todos os processos em $L$ estão em outros servidores, o estado do servidor é idle. Caso contrário, o servidor está executando um processo e seu estado é busy. As decision epochs correspondem ao término do quantum corrente, à finalização da fase do processo corrente ou ao final do intervalo de preempção seguido da chegada de um processo no servidor. No último caso, se a chegada de um processo ocorre no tempo $\tau$, enquanto o servidor está no meio do intervalo de preempção $[t, t+\Delta t]$, então o escalonador deve esperar até o instante $t+\Delta t$, ou seja, a decision epoch ocorre em $t+\Delta t$.

O comando wait causa ao escalonador um "sleep" até a próxima decision epoch. Sempre que um processo inicia sua execução, um "timer" chamado elapsed é iniciado de zero. Elapsed pode ser utilizado para determinar o serviço obtido pelo processo corrente. 
O procedimento Run_a_Process, mostrado na Figura 2.6, é chamado para selecionar o próximo processo para executar no servidor. O Run_a_Process investiga o primeiro processo na lista $L$. Se a lista $L$ está vazia, o estado do servidor é designado idle e o escalonador espera a próxima decision epoch. Caso contrário, o primeiro processo executável na lista em $L$ é selecionado e executa por um quantum que é, no máximo, left $t_{j}$ unidades de tempo. O estado do servidor é designado busy e o escalonador espera pela próxima decision epoch. A variável elapsed registra o tempo de serviço obtido pelo processo corrente para ser utilizado na próxima decision epoch.

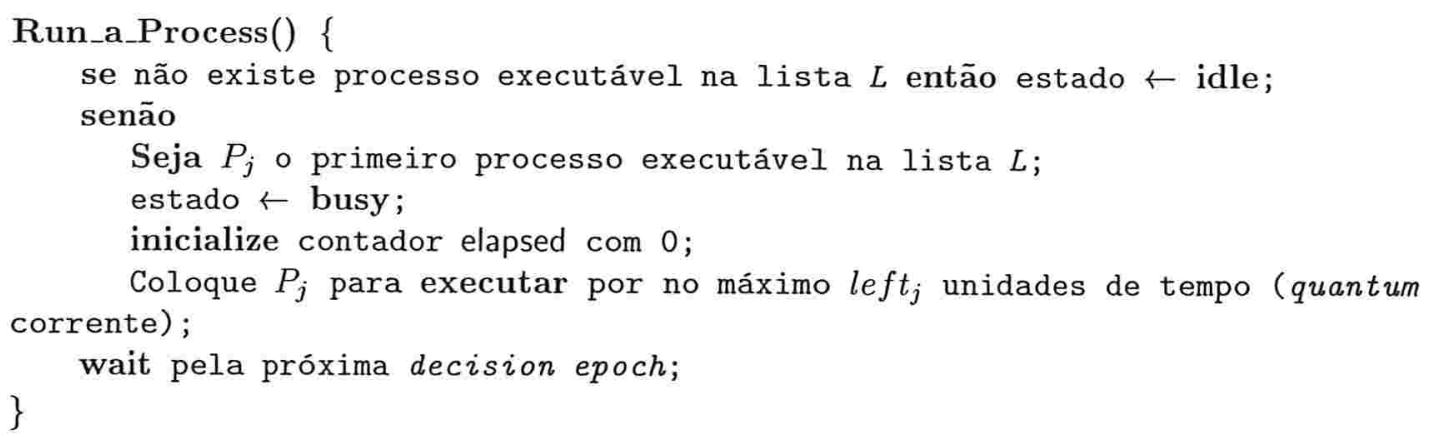

Figura 2.6: Procedimento Executa um Processo para o MTR-LS.

A política de escalonamento MTR-LS, exibida na Figura 2.7, é chamada a cada decision epoch. O procedimento MtrLs() determina se algum processo estava utilizando o servidor no intervalo anterior a esta decision epoch, verificando o estado do servidor. Se o estado do servidor é busy, do valor de $l e f t_{j}$ é decrementado o tempo decorrido desde a anterior decision epoch; se o valor resultante em left $t_{j}$ é nulo, o processo correspondente é movido para o final da lista $L$ e é restituído o valor de left $t_{j}$ para $\alpha_{j} \Gamma$.

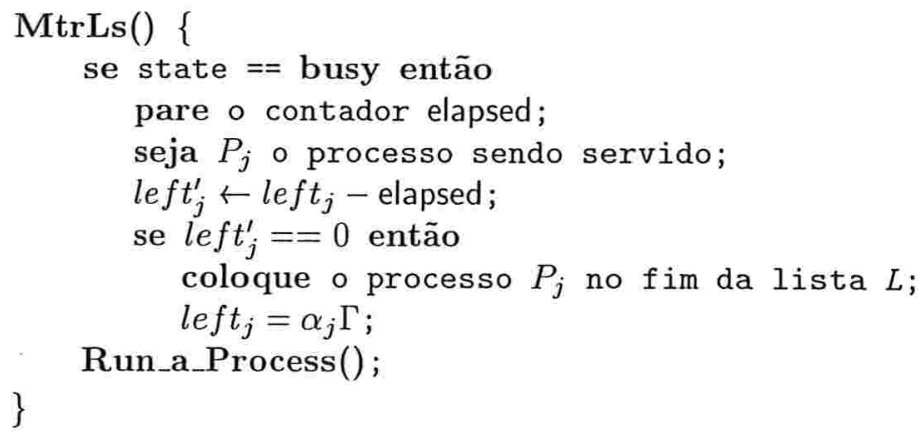

Figura 2.7: Procedimento MTR-LS.

Na política MTR-LS há duas maneiras para um processo ser bloqueado: (1) Por processos executáveis na frente dele na lista $L$ ou (2) por servidores com um intervalo de preempção positivo $(\Delta t>0)$; um processo executável pode ser bloqueado por processos atrás dele na lista $L$. Isso acontece quando um processo chega no servidor enquanto outro processo está executando e não terminou um intervalo de preempção. Se o processo $P_{i}$ torna-se ativo e está na frente do processo executando $P_{j}$ na lista $L$, então $P_{i}$ será bloqueado pelo menos até o 
final do intervalo de preempção corrente. Essa espécie de bloqueio é chamada $\Delta$-blocking. É importante observar que se um processo é $\Delta$-blocked então, devido a sua posição na lista $L$, ele obterá serviço antes do processo que causou o $\Delta$-blocking retornar ao serviço.

Uma implementação mais eficiente para o MTR-LS pode utilizar um heap para guardar os processos executáveis em $L$ [CLR90]. Quando um processo é movido para o final da lista $L$, ele recebe o maior valor de um contador timestamp. Os processos que chegam e os executáveis que são movidos para o final da lista, são inseridos no heap em tempo $O(\ln (n))$, onde $n$ é o número de processos executáveis em $L$. O processo executável em $L$ com menor valor no contador timestamp (que corresponde ao primeiro processo executável na lista $L$ ) pode ser encontrado em tempo constante. Em $O(\ln (n))$ operações faz-se a reconstrução do heap quando o primeiro processo é removido do heap e não estará por algum tempo executável neste servidor (vai para outro servidor).

Lema 2.1.1. A complexidade do MTR-LS é $O(\ln (n))$ onde $n$ é o número de processos ativos.

As propriedades da política do MTR-LS quanto às garantias de QoS que oferece são apresentadas a seguir.

A política MTR-LS oferece garantia de justiça cuja "granularidade" depende de $\Gamma$, o quantum virtual. Diferente de outros parâmetros de QoS, a garantia de justiça não depende, nem do tamanho do intervalo de preempção, nem da soma da frações do serviço ser menor ou igual a um.

Lema 2.1.2. A política do MTR-LS é justa com um limite de $2 \Gamma$. Isto é, para qualquer intervalo de tempo real $[\tau, t]$ durante o qual $P_{i}$ e $P_{j}$ estão ambos executáveis continuamente,

$$
\left|s_{i}(\tau, t) / \alpha_{i}-s_{j}(\tau, t) / \alpha_{j}\right| \leq 2 \Gamma \text {. }
$$

Prova. A situação do pior caso ocorre quando um dos processos, por exemplo $P_{i}$, está na frente de $P_{j}$ na lista $L$ e left $t_{j}$ é extremamente pequeno $(\Delta t)$. É possível o processo $P_{i}$ utilizar o servidor por $\Gamma$ unidades de tempo virtual e $P_{j}$ executar por $l e f t_{j} / \alpha_{j}$ unidades de tempo virtual e ser colocado no fim da lista $L$. Se $P_{i}$ for executar por outras $\Gamma$ unidades de tempo virtual, o tempo resultante de $P_{i}$ estará na frente do tempo resultante de $P_{j}$ por um valor que é limitado por $2 \Gamma$.

Pode-se observar pela prova que a política do MTR-LS admite compartilhamento proporcional por processos com frações de serviço não negativas, arbitrárias. Porém, as garantias de serviço cumulativo e de limite de atraso são dependentes da fração de serviço e do tamanho do intervalo de preempção.

Analisa-se, primeiramente, o caso no qual a política do MTR-LS é submetida a um servidor com o intervalo de preempção nulo $(\Delta t=0)$. Assume-se $j \in A(t)$ e left $t_{j}(t)$ denotando o valor da variável left $t_{j}$ no tempo $t$.

Lema 2.1.3. Assumindo $\tau \geq a_{j}$ e $j \in A(\tau)$. Então para todo $t \geq \tau$ temos

$$
v_{j}(\tau, t) \geq r_{j}(\tau, t)-\left(1-\alpha_{j}\right)\left(2 \Gamma-\frac{\text { left }}{\alpha_{j}(\tau)}\right)
$$


Prova. A idéia da prova é construir um cenário, $\Sigma$, onde $P_{j}$ obtém serviço somente depois de bloqueado o máximo possível por outros processos. Pela construção deste cenário, qualquer outra execução na qual $P_{j}$ obtém o mesma quantidade de serviço, a quantidade de bloqueio por outros processos não será maior que $\Sigma$. Mostrando que neste caso extremo o lema vale, então vale para todas as outras execuções.

A execução do $\Sigma$ assegura que $P_{j}$ é bloqueado o máximo possível. Tendo isso em mente, assume-se que no tempo $\tau$ todos os processos $P_{i} \operatorname{com} i \in A(\tau)$ e $i \neq j$ estão na frente de $P_{j}$ na lista $L$. Também assume-se que todos esses processos executam sua maior cota, $\alpha_{i} \Gamma$, enquanto impedem $P_{j}$ executar. Assim, $r_{j}$, o tempo real gasto por $P_{j}$ esperando para executar, é limitado por $\left(1-\alpha_{j}\right) \Gamma$. Segue-se que ${ }^{5}$ :

$$
r_{j}(\tau, .) \leq\left(1-\alpha_{j}\right) \Gamma+v_{j}(\tau, .)
$$

Neste ponto $P_{j}$ não pode ser mais bloqueado até obter o seu tempo de serviço real $l e f t_{j}(\tau)$. No ponto onde $P_{j}$ obtém $l e f t_{j}(\tau)$ de tempo de serviço tem-se:

$$
r_{j}(\tau, .) \leq\left(1-\alpha_{j}\right)\left(\Gamma-\operatorname{left} t_{j}(\tau) / \alpha_{j}\right)+v_{j}(\tau, .)
$$

Agora $P_{j}$ está no final da lista $L$ e o pior caso é todos os outros processos ocuparem o servidor pelo seu tempo máximo enquanto impedem $P_{j}$ de executar. No ponto em que $P_{j}$ alcança o começo da lista e nenhum outro processo pode bloqueá-lo tem-se:

$$
r_{j}(\tau, .) \leq\left(1-\alpha_{j}\right)\left(2 \Gamma-\operatorname{left} t_{j}(\tau) / \alpha_{j}\right)+v_{j}(\tau, .)
$$

Repetindo-se esta situação, para todo tempo $v_{j}$ avançar por $\Gamma$, os outros processos podem apenas bloquear $P_{j}$ por no máximo $\left(1-\alpha_{j}\right) \Gamma$. Como o tempo real de execução de $P_{j}$ é $\alpha_{j} \Gamma$, o seu tempo virtual avança igual aos tempos do pior caso de bloqueio e de serviço. Assim, a Inequação 2.11 é o pior caso para a execução de $\Sigma$ e portanto o lema vale para este cenário.

Em conclusão, para qualquer outra execução, a quantidade de bloqueio provocada por outros processos para a mesma quantidade de tempo de execução de $P_{j}$ não é maior que a obtida pelo cenário $\Sigma$.

Corolário 2.1.4. A política do MTR-LS provê garantia de servico cumulativo com um limite de T.

Obtém-se o limite do pior caso considerando $l e f t_{j}(\tau)=0$ e $\alpha_{j}=0$. Aplicando o Lema 2.1.3 segue que, para todo $j$ e $\tau \leq t$,

$$
v_{j}(\tau, t) \leq r_{j}(\tau, t)-2 \Gamma
$$

Para $\tau=a_{j}$, ou seja, o momento no qual $P_{j}$ entrou no sistema, obtemos $v_{j}(t) \geq r_{j}(t)-\Gamma$, já que $\operatorname{left}_{j}\left(a_{j}\right)=\alpha_{j} \Gamma$.

\footnotetext{
${ }^{5}$ A notação $r_{j}(\tau,$.$) significa que o segundo argumento tem algum valor apropriado. Esta notação é utilizada$ para evitar a criação novos símbolos para estes valores.
} 
Corolário 2.1.5. A política do MTR-LS provê atraso limitado.

Prova. Considera-se uma fase do processo $P_{j}$ que requer $w$ de trabalho. A duração da fase é $\frac{w}{B}$ e o tempo virtual distribuído é igual a $\frac{w}{\alpha_{j} B}$. Seja $\tau$ o tempo de início da fase e $t$ o tempo que a fase termina sob esta política. Substituíndo estes valores na Equação 2.10, segue que

que equivale a

$$
w / \alpha_{j} B \geq r_{j}(\tau, t)-\left(1-\alpha_{j}\right) /\left(2 \Gamma-\operatorname{left} t_{j}(\tau) / \alpha_{j}\right)
$$

$$
r_{j}(\tau, t) \leq w / \alpha_{j} B+\left(1-\alpha_{j}\right)\left(2 \Gamma-l e f t_{j}(\tau) / \alpha_{j}\right)
$$

Esta equação estabelece que o tempo de espera mais o tempo de serviço para completar a fase alcança quando muito uma quantidade constante de tempo maior que $\frac{1}{\alpha_{j}}$ vezes a duração da fase.

Analisa-se agora, o caso no qual a política do MTR-LS é submetida a um servidor com o intervalo de preempção positivo (isto é, $\Delta t>0$ ). Assume-se $j \in A(t)$ e left $t_{j}(t)$ denotando o valor da variável $l e f t_{j}$ no tempo $t$. Quando o intervalo de preempção é positivo, tem-se o caso no qual o processo $P_{j}$ chega ao servidor enquanto este está executando $P_{i}$ e não terminou o intervalo preemptivo corrente. Neste caso a próxima decision epoch ocorre no final do intervalo de preempção.

Considerando-se, por exemplo, um sistema onde existam dois processos $P_{1}$ e $P_{2}$. O processo $P_{2}$ executa continuamente no servidor e $P_{1}$ alterna o serviço entre este servidor e outro. Assumindo-se que $P_{1}$ executa exatamente um intervalo de preempção neste servidor e depois vai para outro por um tempo. Devido a uma incrível falta de sorte, sempre que o processo $P_{1}$ chega ao servidor, este está executando o processo $P_{2}$ e está exatamente no início do intervalo de preempção corrente. Por esta razão, o processo $P_{1}$ deve esperar $\left(P_{1}\right.$ é $\Delta$-blocking $) \Delta t$ unidades de tempo real antes de executar no servidor. Essa seqüência de $\Delta$-blocking pode persistir por $\alpha_{1} \Gamma$ unidades de tempo antes de $P_{1}$ ser colocado no final da lista $L$. Continuando a falta de sorte, além destes $\Delta$-blocking, sempre que $P_{1}$ é colocado no fim da lista $L$, o processo $P_{2}$ bloqueia $P_{1}$ por $\alpha_{2} \Gamma$ unidades de tempo. Assim, o tempo real gasto no servidor para $P_{1}$ conseguir as $\Gamma$ unidades de tempo virtual é limitado em $2 \alpha_{1} \Gamma+\alpha_{2} \Gamma$. Em conseqüência disso, $\alpha_{1} \leq 1-\left(\alpha_{1}+\alpha_{2}\right)$ é suficiente para se ter uma garantia de servico cumulativo para o processo $P_{1}$ no servidor. Sem perda de generalidade, pode-se permutar as regras de $P_{1}$ e $P_{2}$, obtendo-se $\alpha_{2} \leq 1-\left(\alpha_{1}+\alpha_{2}\right)$ que é suficiente para se ter uma garantia de servico cumulativo para o processo $P_{2}$ no servidor.

Como este exemplo mostra, para se oferecer uma garantia de servico cumulativo necessitase de restrições adicionais sobre as frações de serviço associadas aos servidores que possuem intervalos de preempção positivos. O resultado seguinte apresenta uma condição suficiente sobre as frações de serviço associadas ao servidor para que a política do MTR-LS ofereça uma garantia de servico cumulativo.

Lema 2.1.6. Seja $\Delta t>0$.

Assume-se que para todo $t$ e $\forall j \in A(t)$ temos $\alpha_{j} \leq 1-\sum_{i \in A(t)} \alpha_{i}$. Então para todo $t \geq \tau$ tem-se:

$$
v_{j}(\tau, t) \geq r_{j}(\tau, t)-\left(1-\alpha_{j}\right) 2 \Gamma-\left(2 \alpha_{j}-1\right) l e f t_{j}(\tau) / \alpha_{j}
$$


Prova. A prova deste lema é similar a do Lema 2.1.3. Constrói-se um cenário onde o processo $P_{j}$ obtém o recurso somente após ser bloqueado o máximo possível pelos outros processos. Além do bloqueio utilizado na prova do Lema 2.1.3, esta construção utiliza $\Delta$ blocking para incrementar a quantidade de bloqueio obtida pelo processo $P_{j}$. Pela construção do cenário $\Sigma$, qualquer outra execução na qual $P_{j}$ obtém o mesma quantidade de serviço, a quantidade de bloqueio por outros processos não será maior que $\Sigma$. Mostrando que neste caso extremo o lema vale, então vale para todas as outras execuções.

A execução do $\Sigma$ assegura que $P_{j}$ é bloqueado o máximo possível. Assume-se que no tempo $\tau$ todos processos $P_{i}$ com $i \in A(\tau)$ e $i \neq j$ estão na frente de $P_{j}$ na lista $L$ e também que todos estes processos executam o seu máximo, $\alpha_{i} \Gamma$, enquanto impedem $P_{j}$ de executar. Assim $r_{j}$, o tempo real gasto pelo processo $P_{j}$ esperando para executar, é limitado por $\left(1-\alpha_{j}\right) \Gamma$. Neste ponto tem-se:

$$
r_{j}(\tau, .) \leq\left(1-\alpha_{j}\right) \Gamma+v_{j}(\tau, .)
$$

Na prova do Lema 2.1.3, o processo $P_{j}$ não pode ser bloqueado até obter $l e f t_{j}(\tau)$ unidades de tempo real de serviço. Todavia, como por hipótese o intervalo de preempção do servidor é positivo, o processo $P_{j}$ pode sofrer $\Delta$-blocking enquanto consegue left $_{j}(\tau)$ de tempo de serviço. Como $P_{j}$ foi bloqueado até este ponto, deve executar um mínimo de $\Delta t$ antes de ir para outro servidor. Quando $P_{j}$ chega de outro servidor assume-se que outro processo está executando e que $P_{j}$ é $\Delta$-blocking por até $\Delta t$ unidades de tempo. Então $P_{j}$ executa por $\Delta t$ unidades de tempo real e novamente vai para outro servidor. Essa situação se repete até $P_{j}$ adquirir $l e f t_{j}(\tau)$ unidades de tempo de processamento. Neste ponto tem-se:

$$
r_{j}(\tau, .) \leq\left(1-\alpha_{j}\right) \Gamma+\left(2 \alpha_{j}-1\right) l e f t_{j}(\tau) / \alpha_{j}+v_{j}(\tau, .)
$$

Uma vez que todos os outros processos estão na frente de $P_{j}$ na lista $L$, podem bloquear $P_{j}$ por até $\left(1-\alpha_{j}\right) \Gamma$ unidades de tempo. Neste ponto, $P_{j}$ está uma vez mais no início da lista e tem-se:

$$
r_{j}(\tau, .) \leq\left(1-\alpha_{j}\right) 2 \Gamma+\left(2 \alpha_{j}-1\right) l e f t_{j}(\tau) / \alpha_{j}+v_{j}(\tau, .)
$$

Deste ponto em diante, $P_{j}$ é $\Delta$-blocked todo tempo para receber $\Gamma$ unidades de tempo virtual e então bloqueado por todos processos até alcançar o início da lista. Toda iteração resulta num ganho de $\Gamma$ de tempo virtual para o processo $P_{j}$ que adquire

$$
\alpha_{j} \Gamma-\Delta t+\Gamma \sum_{i \in A(.)} \alpha_{i}
$$

de tempo real ( $\Delta$-blocking, bloqueio comum e tempo de serviço). Por hipótese, a quantidade acima é menor que $\Gamma$ e o lema vale.

Corolário 2.1.7. Seja $\Delta t>0$. Assume-se que para todo $t$ e $\forall j \in A(t), \alpha_{j} \leq 1-\sum_{i \in A(t)} \alpha_{i}$. A política do MTR-LS provê uma garantia de serviço cumulativo com um limite de $2 \Gamma$.

Utilizando a Equação 2.12 e para $l e f t_{j}=0$ e $\alpha_{j}=0$ tem-se:

$$
v_{j}(\tau, t) \geq r(\tau, t)-2 \Gamma
$$


para todo $j$ e $\tau \leq t$. Para o caso $\tau=a_{j}$, tem-se $v_{j}(t) \geq r_{j}(t)-\Gamma$.

Corolário 2.1.8. Seja $\Delta t>0$. Assume-se que para todo $t$ e todo $j \in A(t), \alpha_{j} \leq 1-$ $\sum_{i \in A(t)} \alpha_{i}$. A política do MTR-LS provê atraso limitado.

A principal contribuição deste trabalho desenvolvido por Silberschatz et al. [BGzS97] está na introdução do critério de serviço cumulativo como importante parâmetro de QoS para escalonadores de um sistema operacional que ofereça desempenho previsível para aplicações que requerem múltiplos recursos. Uma versão do algoritmo de escalonamento Move-To-Rear List Scheduling e que oferece tais garantias, está detalhada no Capítulo 3.

\subsection{Conceitos Básicos no Escalonamneto de Reservas de Domínio}

No restante deste capítulo apresentamos os principais aspectos da abordagem alternativa no desenvolvimento de ambientes computacionais multiprogramáveis introduzida por Silberschatz et al. [BGzS98]; particularmente, os conceitos, hipóteses e definições que fundamentam o objeto de nosso estudo.

\subsubsection{Introdução}

A necessidade de possuir múltiplas aplicações de tempo real numa mesma plataforma requer que o sistema operacional ofereça garantias de $\mathrm{QoS}^{6}$, tal que possa fornecer seus recursos para todas as aplicações no sistema e que os níveis desejados de desempenho previsível ${ }^{7}$ sejam alcançados. Para tal, Silberschatz et al. [BGzS98] propõem um sistema operacional experimental chamado Eclipse que descreveremos posteriormente no Capítulo 4.

Nesta proposta introduzem uma nova abstração em sistemas operacionais chamada reserva de dominio que permite um controle explícito sobre o aprovisionamento dos recursos do sistema pelas aplicações para obter níveis desejados de desempenho previsível. Em geral, a cada reserva de domínio é designada uma certa fração de reserva de cada recurso (por exemplo, $25 \% \mathrm{CPU}, 50 \% \mathrm{I} / \mathrm{O})$. A estratégia em se utilizar reserva de domínios é a possibilidade de isolar o desempenho uma da outra. Em particular, processos de tempo real podem conviver com processo batch num mesmo sistema.

Nessa seção apresentamos o conceito de reserva de dominios, os parâmetros de QoS de interesse e as definições de garantias de QoS para uma política de escalonamento baseada em reservas de domínios.

\footnotetext{
${ }^{6}$ Vide Seção 1.2.3.

${ }^{7} \mathrm{Um}$ sistema que prevendo o seu comportamento como um todo garanta, dentro de certos limites de tempo, as restrições temporais.
} 


\subsubsection{Reserva de Domínios}

Para incorporar QoS e combinar os requisitos dos sistemas de tempo real, timesharing e stand-alone, foi introduzida a noção de reserva de domínio. Uma reserva de domínio é uma coleção de processos e as frações de reservas dos recursos correspondentes.

Um sistema de computação pode executar várias reservas de domínios e dispor de vários tipos de recursos tais como CPU, disco, rede, memória física, que são reservados e escalonados independentemente.

Os processos que pertencem a uma reserva de domínio específica podem receber no mínimo as frações das reservas dos recursos do domínio associado.

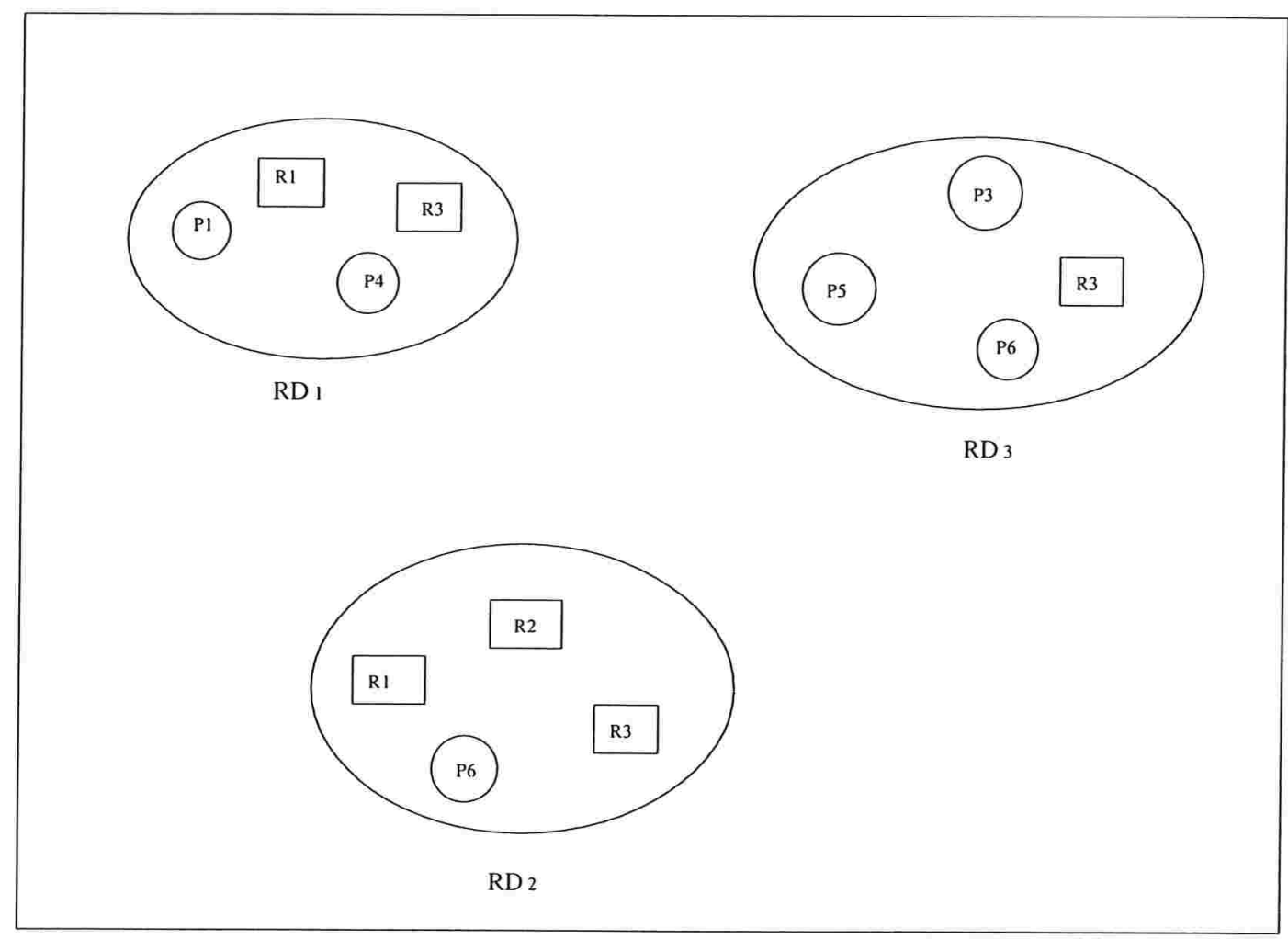

Figura 2.8: Um Sistema de Reservas de Domínios.

A Figura 2.8 ilustra um sistema que executa três reservas de domínios $R D_{1}, R D_{2}$ e $R D_{3}$. Cada domínio contém uma reserva explícita dos recursos $R_{1}, R_{2}$ e $R_{3}$. Um número qualquer de processos pode pertencer a uma dada reserva de domínio; um ou mais processos podem executar dentro de uma reserva de domínio.

Uma reserva de domínio especifica seus requisitos de QoS possuindo uma fração de reserva para cada recurso do sistema. O controle de admissão assegura que a soma das frações de reserva de todos os domínios não excedem certos limites prescritos. 
Os benefícios [BGzS98] das reserva de domínios, alguns que são impossíveis de serem alcançados com escalonadores baseados em prioridade ou com outros tipos de abordagens de escalonamento para sistemas de tempo real, são apresentados a seguir:

- Provê garantias de QoS mesmo quando o sistema está sobrecarregado. Uma reserva de domínio é similar a uma pequena máquina dedicada. As aplicações não precisam ser reescritas para utilizar os serviços de tempo real para obter a QoS previsível em ambiente compartilhado.

- Concede divisão de recursos de acordo com uma política. Por exemplo, duas reservas de domínios e cada uma reservando metade da CPU, apesar de uma possuir mais processos que a outra e todos os processos serem $C P U$-bound.

- Permite diferentes formas de controle do ambiente da computação. Por exemplo, o servidor de janelas pode ser capaz de mudar as reservas do recurso de domínios associado com a janela em foco (importante) e de fechar janelas (menos importantes). Outra possibilidade é um supervisor de recurso, que adapta reservas de recurso dinamicamente de acordo com as "reclamações" dos processos. O supervisor aumentará a reserva do recurso de um processo de tempo real que não cumpre seus prazos. Em contrapartida, um processo que alcança todos os seus prazos sem "reclamar" receberá uma reserva menor.

Uma variedade de aplicações pode ser beneficiada pelas reservas de domínios. Por exemplo, aplicações de tempo real soft podem se utilizar dos seus limites de tempos de resposta, aplicações de rede podem ser beneficiadas no aprovisionamento de recursos e aplicações OLAP (on-line analytical processing) podem se utilizar da proteção entre as reserva de domínios para completar suas tarefas em tempo, independentemente do ambiente corrente. Pode beneficiar computadores pessoais, que executam várias aplicações concorrentemente, quando as aplicações são desenvolvidas presumindo que vão ser executadas em uma máquina dedicada.

\subsubsection{Garantias de QoS}

Nesta seção retornamos aos parâmetros de QoS em sistemas operacionais já citados: serviço cumulativo, limite de atraso e justiça.

Iniciamos com um exemplo que mostra a necessidade da garantia de serviço cumulativo em um sistema. As definições de justiça e limite de atraso serão fornecidas no final desta seção.

Exemplo. Um sistema executa um processo IO-bound juntamente com $n$ processos $C P U$ bound. O processo IO-bound efetua requisições de entrada e saída, seqüencialmente, utilizando $1 \mathrm{~ms}$ de CPU entre elas. Cada uma destas requisições de I/O requer $23 \mathrm{~ms}$. Não há disputa no dispositivo de I/O. Primeiramente utilizando o escalonador Weighted Round Robin, similar ao descrito no Capítulo 3. Supondo que reservamos 0.5 de CPU para o processo IO-bound. Esperamos que cada iteração seja de $2+23=25 \mathrm{~ms}$, onde $2 \mathrm{~ms}$ é o tempo esperado da fase de 
CPU para cada iteração (1ms sem interferências de outros processos é equivalente a $2 \mathrm{~ms}$ quando o processo reserva 0.5 de CPU). Assim, a taxa de execução esperada ${ }^{8}$ para o processo IO-bound é de 1000/25 = 40 iterações por segundo. Entretanto, empregando o escalonador Round Robin tradicional, tem-se: quando o processo IO-bound chega a CPU, é colocado no final da fila de prontos e assim, deve esperar pelo menos $n$ time slices antes de executar. O tempo real de execução de cada iteração é $1+n \delta+23$, onde $\delta$ é o tamanho do time slice. Por exemplo, para $n=10$ e $\delta=10 \mathrm{~ms}$, a taxa de execução do processo IO-bound é de $1000 /(1+100+23) \approx 8$ iterações por segundo, que corresponde a um quinto da taxa provida pelo outro escalonador ${ }^{9}$ !

O escalonador Round Robin oferece justiça e o atraso é limitado, uma vez que todos os processos são escalonados com $n+1$ fatias de tempo. Entretanto, a taxa de execução do processo IO-bound pode ser muito baixa, uma vez que não provê garantia de serviço cumulativo, ou seja, os atrasos dos escalonamentos obtidos por um processo nos vários recursos, é acumulado sobre o tempo de vida do processo.

Apresentamos a seguir as definições necessárias para o resto da seção.

\section{Modelo de Sistema}

No modelo adotado neste trabalho [BGzS98], um sistema consiste de uma coleção de recursos (serviços).

Cada recurso é representado nesse modelo por uma "taxa de serviço" e um "intervalo de preempção" $\Delta t$. $\Delta t$ é o tempo mínimo que o recurso deve executar antes de permitir uma preempção. Quando um recurso possui o intervalo de preempção nulo $(\Delta t=0)$, um processo pode ser bloqueado a qualquer tempo.

\section{Modelo de Processo}

Os processos podem ser traduzidos em fluxos e modelados como um conjunto de fases ordenadas, onde uma fase é um par recurso-duração, $(r, t)$, onde $r$ é um dos recursos do sistema e $t$ é a quantidade de tempo que o processo requisita na utilização do recurso $r$ para completar a fase executando sozinho no recurso. As fases de um processo não são conhecidas a priori. A identificação da próxima fase somente será conhecida após a execução da fase anterior.

Exemplo. Considere uma fase de um processo contendo a seguinte especificação $(r, 1 \mathrm{~ms})$. Corresponde a uma fase que especifica $r$ como o recurso e $1 \mathrm{~ms}$ é o tempo requerido para esta fase do processo e para completá-la executando sozinho no recurso.

Sempre estamos interessados no desempenho de nosso sistema sobre todos os recursos, da definição de garantia de serviço cumulativo exposta na Seção 2.1.10, Página 54, é suficiente estudarmos o desempenho de um simples recurso. Do ponto de vista do recurso $r$, um processo

\footnotetext{
${ }^{8} \mathrm{~A}$ taxa de execução esperada pelo processo é a taxa previsível.

${ }^{9} \mathrm{~A}$ taxa previsível é 40 iterações por segundo.
} 
é denotado por um conjunto ordenado de fases que alternam entre o recurso $r$ e outro. O "outro" representa as fases do processo em recursos que não o $r$.

A motivação está na possibilidade de isolar cada reserva de domínio das outras, o que permite garantir um limite de atraso no desempenho de uma reserva de domínio, o qual é independente do de outras reservas de domínios.

A seguir, vamos apresentar algumas notações utilizadas nas definições das garantias de QoS para uma política de escalonamento baseada em reserva de domínio.

Um domínio $D_{i}$ está ativo no sistema se possui pelo menos um processo sendo executado. Seja $\alpha_{i}$ a fração de um recurso alocada para uma reserva de domínio $D_{i}$. Idealmente, cada reserva de domínio $D_{i}$ recebe no mínimo $\alpha_{i}$ de fração do recurso sempre que tenha um processo requerendo o recurso (dizemos que o domínio $D_{i}$ está pronto ou executável no recurso). A referência para o tempo mínimo de serviço recebido em um modelo de serviço idealizado é chamada de tempo de serviço virtual. É denotado o tempo de serviço virtual recebido por uma reserva de domínio $D_{i}$ em qualquer intervalo de tempo $[\tau, t]$ por $v_{i}(\tau, t)$. Similarmente, é denotado o tempo de serviço real (efetivamente utilizando o recurso) recebido pela reserva de domínio $D_{i}$ em qualquer intervalo de tempo $[\tau, t]$ por $s_{i}(\tau, t)$. Observa-se que

$$
s_{i}(\tau, t)=\alpha_{i} v_{i}(\tau, t) \text {. }
$$

As políticas de escalonamento realizáveis requerem que executemos, no máximo, um processo de cada vez no recurso. Isso significa que se há mais de um processo esperando para executar no recurso, então um ou mais processos obterão atraso (enfileirados). É definido $w_{i}(\tau, t)$ como tempo real acumulado de espera (bloqueado por outros processos dos domínios executando no recurso), obtido pelo domínio $D_{i}$, no intervalo $[\tau, t]$. Por definição, $w_{i}(\tau, t)+s_{i}(\tau, t)$ é o total de tempo real gasto pelo domínio $D_{i}$ no intervalo $[\tau, t]$ tanto executando como esperando.

No modelo idealizado, recebendo $v_{i}(\tau, t)$ de tempo de serviço virtual, o domínio $D_{i}$ terá no máximo $v_{i}(\tau, t)$ de tempo real. Com políticas de escalonamento realizáveis e na ordem de prover um desempenho tão bom quanto em um modelo idealizado, o total de tempo real gasto pelo domínio $D_{i}$ no recurso, no intervalo $[\tau, t]$, e recebendo $v_{i}(\tau, t)$ de tempo de servico virtual, deve ser menor ou igual a $v_{i}(\tau, t)$.

\subsubsection{Garantias de QoS para uma Política de Escalonamento baseada em Reserva de Domínio}

Definição 2.2.1. Dizemos que uma política de escalonamento provê garantia de serviço cumulativo se existe uma constante $K$ tal que, para todo domínio $D_{j}$ e $\tau \leq t$, temos:

$$
v_{j}(\tau, t) \geq w_{j}(\tau, t)+s_{j}(\tau, t)-K \text {. }
$$


O tempo real total (incluindo tempo de espera e tempo de serviço) é uma constante a mais que o tempo de serviço virtual requerido por uma equivalente cota de serviço real. Apesar da definição de garantia de serviço cumulativo ser em termos de um único recurso, pode ser estendida em uma garantia de serviço global para o caso de multi-recursos onde existe um número constante e finito de recursos.

A garantia de serviço cumulativo é vital para aplicações que requerem múltiplos recursos, sendo que a chegada de uma fase no recurso depende da saída de fases anteriores. A garantia de serviço cumulativo é necessária para assegurar demandas agregadas a throughput sobre todos estes recursos $\left[\mathrm{BGz}^{+} 97\right]$ pelas aplicações.

O atraso para uma fase referente a um recurso em particular é o tempo gasto por ela esperando pelo recurso ou executando no correspondente recurso.

Definimos aqui a garantia de atraso para o caso em que a qualquer tempo há apenas um processo em uma reserva de domínio. Para o caso mais geral, onde existem múltiplos processos concorrentes pertencentes a um só domínio, o atraso referente a uma fase depende de como o domínio escalona suas fases. (Este caso, por exigir um tratamento mais elaborado e complexo, não foi investigado pelos desenvolvedores.)

Definição 2.2.2. Dizemos que uma política de escalonamento provê atraso limitado se para uma fase em qualquer domínio $D_{j}$, o tempo de espera real pelo serviço para completar a fase de duração d é de uma constante maior que $\frac{d}{\alpha_{j}}$; para o caso em que, num dado tempo, há apenas um processo na reserva de domínio $D_{j}$.

O parâmetro justiça $a^{10}$ mede a habilidade do sistema em assegurar que domínios que simultaneamente desejem o mesmo recurso o "compartilhem" na proporção de suas reservas, independentemente de suas prévias utilizações do recurso. Isto significa que uma política de escalonamento justa não penaliza um domínio que utilizou um recurso sem interferência de outro domínio além de sua reserva quando outros domínios começam estar ativos no recurso.

A definição de justiça é baseada em um outro modelo idealizado chamado processador compartilhado [BGzS97, $\mathrm{SAWJ}{ }^{+} 96$ ], onde cada domínio recebe um serviço proporcional a sua fração de serviço em um recurso. Como um processador compartilhado ideal não pode ser implementado na prática, justiça é definida da seguinte forma:

Definição 2.2.3. Dizemos que uma política de escalonamento é justa se existe uma constante $F$ tal que, para qualquer intervalo de tempo $[\tau, t]$, em que um par de domínios $D_{i}$ e $D_{j}$ requer continuamente o mesmo recurso, temos:

$$
\left|s_{i}(\tau, t) / \alpha_{i}-s_{j}(\tau, t) / \alpha_{j}\right| \leq F .
$$

As reservas de domínios especificam seus requisitos de QoS reservando uma fração de serviço $\alpha_{i}$ de cada recurso. O controle de admissão assegura que a soma das frações de

\footnotetext{
${ }^{10}$ Vide observações na Página 57.
} 
serviço de todos os domínios não ultrapassam certos limites prescritos. As garantias de serviço cumulativo e de atraso limitado dependem do controle de admissão e do tamanho do intervalo de preempção. Estaremos considerando que o sistema admita os domínios mediante o controle de admissão determinando que $\sum_{i} \alpha_{i} \leq 1$. 


\section{Capítulo 3}

\section{Algoritmos de Escalonamento}

Neste capítulo apresentamos os algoritmos que investigamos em nossas experimentações: Move-to-Rear List Scheduling (MTR-LS), Shortest Virtual Time First Round Robin (SVF-RR) e Weighted Round Robin Scheduling (WRR). Detalhamos a política, a complexidade e as propriedades de cada um deles.

Os modelos de sistema e processos, bem como as definições dos parâmetros e garantias de QoS e o conceito de reserva de domínio que utilizamos neste capítulo, são os introduzidos no Capítulo 2.

\subsection{Move-to-Rear List Scheduling (MTR-LS)}

O MTR-LS, conforme descrevemos detalhadamente na Seção 2.1.10, surgiu como um novo algoritmo de alocação de recursos que além de garantir os parâmetros tradicionais de $\mathrm{QoS}^{1}$, ainda garante o novo critério de QoS, o serviço cumulativo (Seção 2.2.3).

A política de escalonamento que apresentamos na Subseção 3.1.1, é a versão do MTR-LS para escalonamento de domínios [BGzS98]; é uma generalização desta política para alocação de recursos, onde a principal diferença é que o quantum alocado para um domínio pode ser particionado. Descrevemos o algoritmo, as estruturas de dados, os mecanismos utilizados e sua complexidade. Na Subseção 3.1.2 apresentamos as propriedades do MTR-LS.

\subsubsection{A Política do MTR-LS}

O ponto central dessa política é uma lista ordenada $L$ de domínios ativos ${ }^{2}$. É mantida uma lista $L$ para cada recurso do sistema. Estes domínios em $L$ são representados por pares $(i, l e f t)$, onde $i$ é o identificador de um domínio $D_{i}$ e left é o tamanho do quantum, que é a quantidade máxima de tempo de serviço que o domínio $D_{i}$ pode receber sem ser interrompido. Pode

\footnotetext{
${ }^{1}$ Como definidos na Seção 2.1.10: justiça, limite de atraso e throughput.

${ }^{2}$ Um domínio ativo está definido na Página 72.
} 
haver múltiplas ocorrências do domínio $D_{i}$ na lista $L$, isto é, pares aparecendo em diferentes posições na lista $L$ os quais possuem a mesma coordenada $i$. Estes pares (i,left) são chamados de tokens. Cada domínio ativo tem no mínimo um token em $L$. O sistema define o ciclo do serviço para um recurso como sendo uma constante $T$ (quantum do tempo virtual) limitada pela soma de todos quanta (coordenada left dos tokens) representados na lista $L$. A soma dos quanta em $L$ que pertencem ao domínio $D_{i}$ é igual a $\alpha_{i} T$ ( $\alpha_{i}$ está definida na Página 72). $\mathrm{O}$ algoritmo não requer a utilização de um tamanho fixo de quantum, porém $\alpha_{i} T$ precisa ser inteiro (unidades discretas).

A descrição da política do MTR-LS depende de poucos mecanismos que apresentamos a seguir.

Sempre que um novo domínio ativo $D_{j}$ entra no sistema, é inserido no final da lista $L$ e left $f_{j}$ recebe $\alpha_{j} T$ (sujeito ao controle de admissão, ou seja, $\sum_{i} \alpha_{i}$ precisa ser menor que um). Quando todos os processos pertencentes ao domínio $D_{j}$ saem do sistema, $D_{j}$ torna-se nãoativo e é removido de $L$ e sua porção de reserva é distribuída entre todos os domínios em $L$. Por exemplo, a reserva efetiva de cada domínio ativo $k$ será $\alpha_{k}+\frac{\alpha_{j}}{n}$, onde $n$ é o número de domínios ativos.

Uma variável estado é associada com cada recurso submetido ao MTR-LS. O estado do recurso é dito desocupado sempre que todos os processos dos domínios em $L$ estão executando ou requerendo outros recursos. Caso contrário, o estado do recurso é dito ocupado.

As decisões são tomadas em tempos chamados decision epochs. A idéia central do algoritmo MTR-LS é computar uma representação de intervalo de tempo ou elapsed, que o domínio corrente executou no recurso entre sucessivas decision epochs. Sempre que um domínio inicia sua ocupação no recurso, o contador elapsed recebe o valor 0 . O elapsed registrará o tempo que foi utilizado pelo domínio para a próxima decision epoch. O MTR-LS aciona o procedimento ilustrado na Figura 3.1 a cada decision epoch.

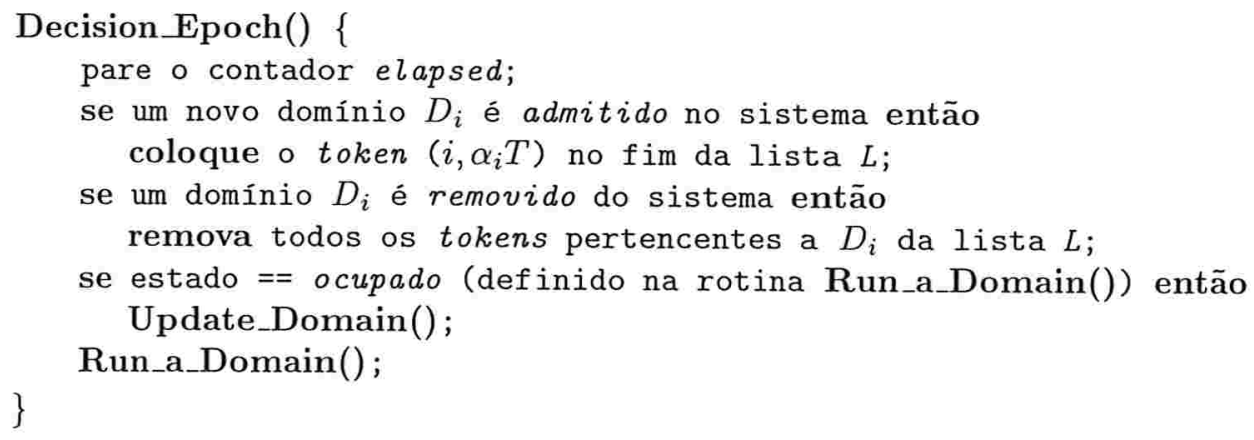

Figura 3.1: Procedimento Decision Epoch para o MTR-LS.

A rotina DecisionEpoch() será chamada na chegada de um novo domínio, na remoção de um domínio, na expiração do quantum corrente, na conclusão da fase do processo corrente (ou seja, o bloqueio do próprio processo) ou no final do intervalo de preempção corrente. Em outras palavras, o processo utilizando o recurso pode ser interrompido apenas no final do intervalo de preempção corrente $(\Delta t)$ ou no final do quantum corrente. A cada decision 
epoch, o respectivo procedimento recebe o contador elapsed contendo o tempo decorrido desde a última decision epoch. A Decision_Epoch() avalia o valor da variável estado do recurso; se este valor se traduz como ocupado, significa que um domínio estava utilizando o recurso no momento desta interrupção e, portanto, os seus tokens em $L$ devem ser atualizados, o que será efetuado no procedimento Update_Domain(). E, em seguida, seleciona o próximo domínio pronto $^{3}$ a ocupar o recurso.

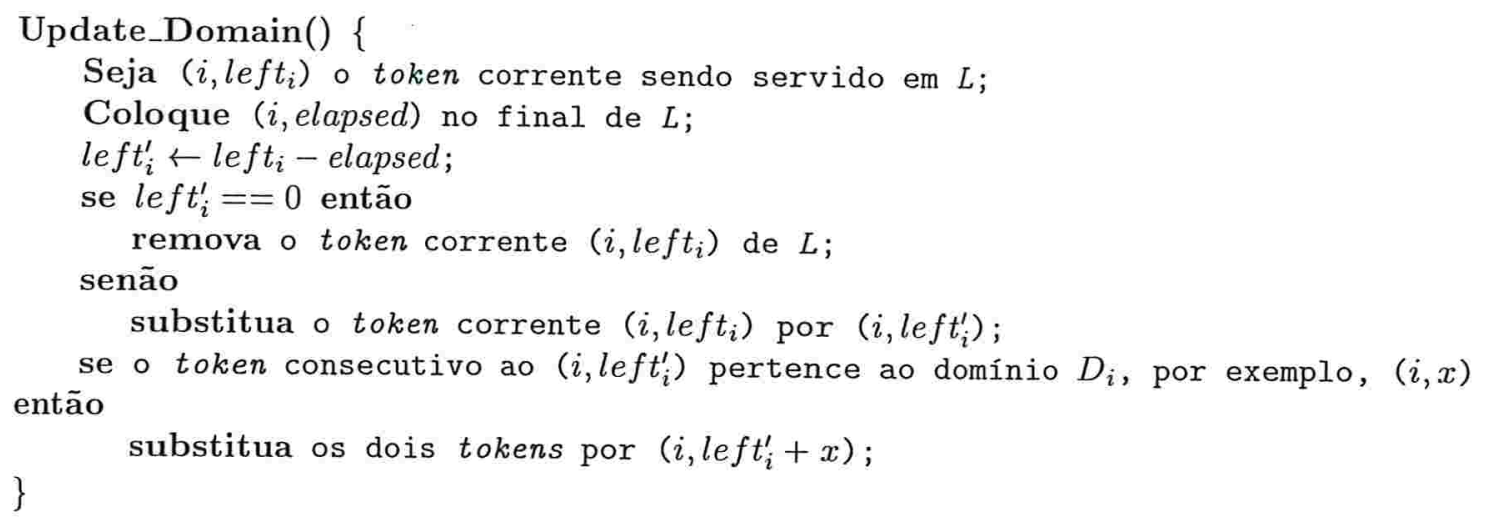

Figura 3.2: Procedimento Atualiza Domínio para o MTR-LS.

A rotina Update_Domain (), apresentada na Figura 3.2, será chamada a cada decision epoch para atualizar o token do domínio corrente.

Ela tanto pode dividir o token corrente em dois (deixando um token no lugar atual e colocando o outro no fim da lista $L$ ) como pode mover o token inteiro para o fim da lista. Em qualquer caso, a soma dos quanta dos dois tokens é igual ao quantum do token original. Para que a lista $L$ não possua tokens consecutivos de um mesmo domínio, sempre que um domínio sofre uma atualização, o procedimento examina os tokens adjacentes dessa última alteração e, caso houver dois de um mesmo domínio, são substituídos por um contendo a soma dos seus quanta.

A Figura 3.3 mostra a rotina Run_a_Domain(). É esse procedimento que define o estado do recurso. Sempre que todos os domínios em $L$ não estão prontos, o estado do recurso é designado desocupado e o escalonador espera pela próxima decision epoch. Caso contrário, seleciona o primeiro domínio pronto em $L$ para executar no recurso. O estado do recurso é assinalado ocupado.

O serviço obtido por um processo pode ser menor que o quantum alocado devido ao término de uma fase ou à chegada de um processo. No primeiro caso, a fase termina, o processo vai utilizar outro recurso qualquer e o primeiro domínio pronto em $L$ é o próximo a ser servido. No último caso, quando tem-se a chegada de um processo, se este pertence a um domínio que precede na lista $L$ o domínio do processo corrente então o processo corrente é interrompido (desde que o intervalo de preempção $(\Delta t)^{4}$ permita.) e um processo do primeiro domínio

\footnotetext{
${ }^{3}$ Definido na Página 72.

${ }^{4} \Delta t$ é o tempo mínimo que o recurso deve executar antes de permitir uma preempção.
} 


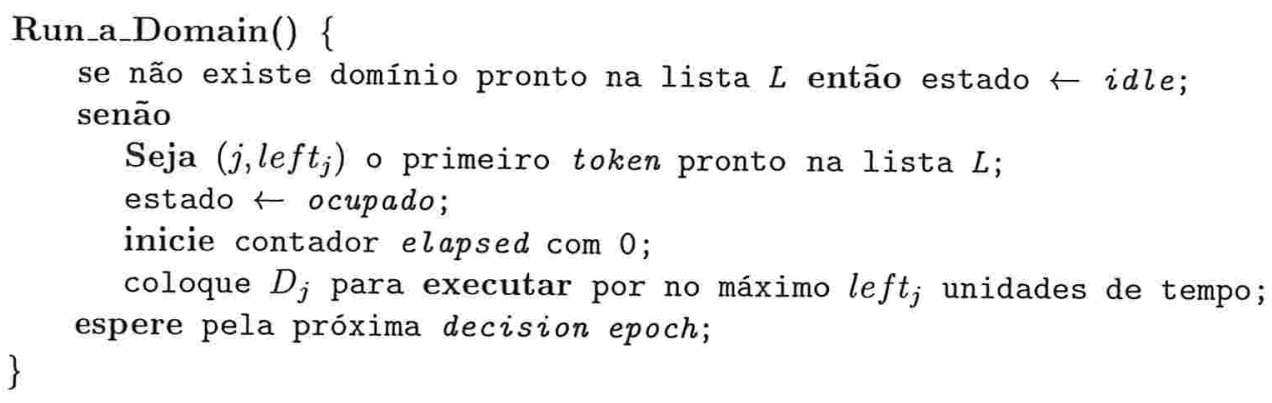

Figura 3.3: Procedimento Executa um Domínio para o MTR-LS.

pronto em $L$ será o próximo a ocupar o recurso.

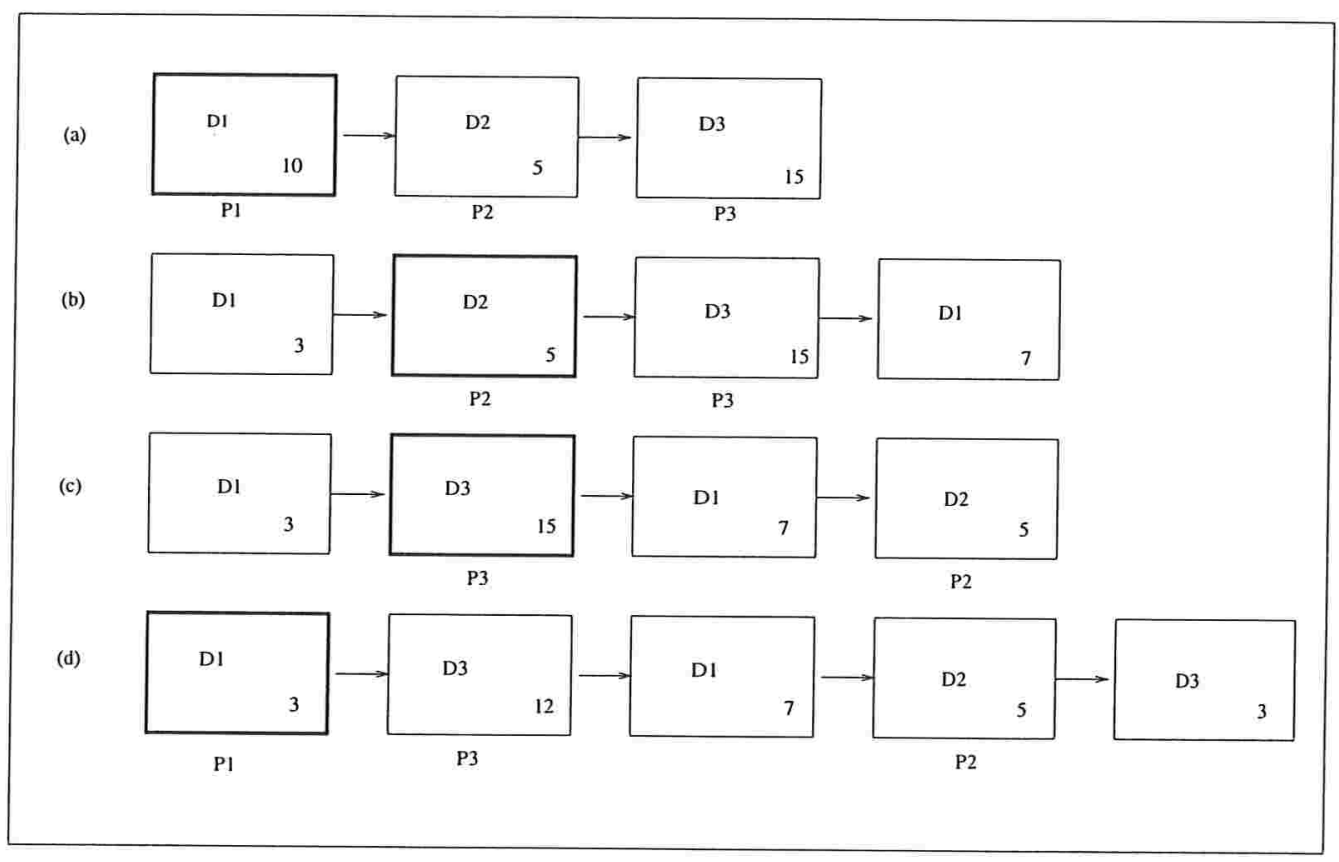

Figura 3.4: Um exemplo do escalonamento MTR-LS.

Exemplo. A Figura 3.4 ilustra a operação do escalonador MTR-LS. Há três tokens em $L$ correspondentes às reserva de domínios $D_{1}, D_{2}$ e $D_{3}$. Os processos $P_{1}, P_{2}$ e $P_{3}$ estão associados aos domínios $D_{1}, D_{2}$ e $D_{3}$, respectivamente. O quantum de $D_{1}$ é 10 , de $D_{2}$ é 5 e de $D_{3}$ é 15 . Inicialmente (Figura 3.4a) todos os domínios estão prontos ou seja, pelo menos um processo no domínio requer o início de uma fase no recurso. Como o primeiro domínio pronto em $L$ é $D_{1}$, o processo $P_{1}$ é executado. Suponhamos que o processo $P_{1}$ decida utilizar outro recurso após receber 7 unidades de tempo de serviço. A lista $L$ é atualizada tal que o quantum de $D_{1}$ é particionado em dois: o tempo já utilizado é colocado em um novo token de $D_{1}$ no final da lista $L$ e o quantum do token corrente será substituído pelo restante de sua cota como mostra a Figura 3.4b. Agora, o primeiro domínio pronto em $L$ é $D_{2}$. Conseqüentemente, $P_{2}$ é 
executado. $\mathrm{O}$ quantum de $D_{2}$ é esgotado em 5 unidades de tempo. Como esgotou sua cota de tempo, o token de $D_{2}$ é removido de sua posição em $L$ e inserido no fim da lista (Figura 3.4c). O próximo domínio pronto é $D_{3}$. Portanto, $P_{3}$ é selecionado para execução. Suponhamos agora que após 3 unidades de tempo, $D_{1}$ fica pronto ( $P_{1}$ requisita o recurso). Como um token de $D_{1}$ precede o token de $D_{3}$ na lista $L, P_{3}$ é bloqueado. O quantum de $D_{3}$ é particionado, como mostra a Figura 3.4 d, ficando o token corrente com 12 unidades de tempo e o tempo que já utilizou neste ciclo de serviço é inserido em um novo token no final da lista $L$ e, a seguir, $P_{1}$ é escalonado.

\section{Complexidade do MTR-LS}

Durante a operação do MTR-LS, um domínio pode ter múltiplos tokens em L. Cada token corresponde a um quantum de um dado tamanho e a soma de todos os quanta para um dado domínio é igual a $\alpha_{i} T$.

A lista $L$ possui as seguintes operações:

1) encontrar o primeiro domínio pronto em $L$;

2) quebrar um token e colocar parte dele no final de $L$; o token original é removido ou atualizado na mesma posição em $L$;

3) colocar os tokens de um novo domínio no final de $L$;

4) remover todos os tokens de um domínio;

5) combinar tokens em $L$, caso existam dois tokens consecutivos em $L$ pertencentes ao mesmo domínio.

Todas as operações exceto a primeira podem ser executadas em tempo constante. O pior caso de tempo de execução do MTR-LS ocorre quando todos domínios possuem $\alpha_{i} T$ tokens de um quantum de tempo cada um. Portanto, a primeira operação pode ser feita em tempo $O(T)$, onde $T$ é o ciclo de serviço do recurso, definido pelo sistema.

Numa outra implementação mais eficiente do MTR-LS, este pior caso de tempo de execução pode ser melhorado, colocando-se os domínios ativos num heap [CLR90] ao invés de numa lista, marcando os tokens por um incremento de timestamp e classificando os domínios pelo menor timestamp que eles têm no momento. Os domínios que possuem pelo menos um processo que requisite o recurso são inseridos no final da lista $L$. No entanto, utilizando a estrutura de heap são inseridos em tempo $\mathrm{O}(\ln (n))$, onde $n$ é o número de domínios prontos. O domínio com o menor timestamp, que corresponde ao primeiro domínio executável (pronto) na lista $L$, pode ser encontrado em tempo constante. É necessário $O(\ln (n))$ para reconstruir o heap quando o primeiro domínio é removido. 


\subsubsection{Propriedades da Política do MTR-LS}

A política do MTR-LS provê garantias de justiça, serviço cumulativo e limite de atraso.

Propriedade 3.1.1. A política do MTR-LS para reserva de domínios é justa com um limite de T. Para qualquer intervalo de tempo real $[\tau, t]$ durante o qual $D_{i}$ e $D_{j}$ estão ambos prontos,

$$
\left|\frac{s_{i}(\tau, t)}{\alpha_{i}}-\frac{s_{j}(\tau, t)}{\alpha_{j}}\right| \leq T
$$

Justificativa. A pior situação ocorre quando um dos domínios $D_{i}$ está na frente de $D_{j}$ na lista $L$ e left $t_{j}$ é extremamente pequeno. É possível o domínio $D_{i}$ executar por $\alpha_{i} T$ unidades de tempo virtual e, em seguida, $D_{j}$ executar por $l e f t_{j} / \alpha_{j}$ unidades de tempo virtual e ser colocado no fim da lista $L$. Se $D_{i}$ for executar por outras $\alpha_{i} T$ unidades de tempo virtual, o tempo resultante de $D_{i}$ estará na frente do tempo resultante de $D_{j}$ por um valor que é limitado por $T$.

Como o intervalo de preempção $(\Delta t)$ é uma característica do recurso, as demais propriedades da política do MTR-LS são providas mediante esta característica do recurso.

Propriedade 3.1.2. Se $\sum_{i} \alpha_{i} \leq 1$ e $\Delta t=0$ então a política do MTR-LS para reserva de domínios provê garantia de servico cumulativo com um limite de $T$.

Justificativa. Por hipótese, $\Delta t=0$. Isso significa que um processo em execução é bloqueado imediatamente por um processo que requisita o recurso e pertence a um domínio pronto na frente do domínio corrente na lista $L$.

A pior situação ocorre quando $D_{j}$ obtém serviço somente depois de bloqueado o máximo possível pelos outros domínios. Seguindo a mesma idéia utilizada na prova do Lema 2.1.3 (Seção 2.1.10), se $\Sigma_{i} \alpha_{i} \leq 1$, os outros domínios podem apenas bloquear $D_{j}$ por, no máximo, $\left(1-\alpha_{j}\right) T$. Como o tempo real de execução é $\alpha_{j} T$, o tempo virtual é igual ao tempo do pior caso de bloqueio e serviço. Assim, $v_{j}(\tau, t) \geq w_{j}(\tau, t)+s_{j}(\tau, t)-T$.

Propriedade 3.1.3. Se $\sum_{i} \alpha_{i} \leq 1$ e $\Delta t=0$ então a política do MTR-LS para reserva de domínios provê atraso limitado.

Justificativa. O atraso limitado provido pelo MTR-LS vem diretamente da garantia de serviço cumulativo (Seção 2.2.3).

Porém, quando o intervalo de preempção do recurso é positivo temos que a decision epoch ocorre no final do intervalo de preempção corrente. Consideremos o caso em que o domínio $D_{j}$ fica pronto no recurso enquanto este está sendo utilizado por $D_{i}$ e não terminou o intervalo de preempção corrente.

O MTR-LS para reserva de domínios requer que $\alpha_{j} \leq 1-\Sigma_{i} \alpha_{i}$ para todos os domínios $D_{j}$ $(i \neq j)$ na lista $L$ para prover a garantia de serviço cumulativo com o limite de $T$. A razão é que um processo pronto pode ser atrasado pelo processo em execução até o fim do intervalo de preempção. 
Propriedade 3.1.4. Seja $\Delta t>0$. Assuma que para todo $t$ e $\forall$ domínio $D_{j}$ temos $\alpha_{j} \leq$ $1-\Sigma_{i} \alpha_{i}$. Então a política do MTR-LS para reserva de domínios provê garantia de serviço cumulativo com um limite de $T$.

Propriedade 3.1.5. Seja $\Delta t>0$. Assuma que para todo $t$ e todo dominio $D_{j}$ temos $\alpha_{j} \leq$ $1-\Sigma_{i \in A(t)} \alpha_{i}$. A política do MTR-LS para reserva de domínios provê atraso limitado.

O atraso limitado provido pelo MTR-LS segue diretamente da garantia de serviço cumulativo (Seção 2.2.3).

\subsection{Shortest Virtual Time First Round Robin}

O escalonamento Shortest Virtual Time First Round Robin (SVF-RR) é um esquema de alocação de recursos similar ao MTR-LS; a diferença está na aplicação de uma política que utiliza a classificação dos tokens de um domínio, marcando-os com um incremento de timestamp [BGzS98].

O SVF-RR foi implementado com o intuito de adaptar os modelos de sistema e processos definidos para o escalonador MTR-LS aos ambientes tradicionais de multiprogramação, utilizando em sua implementação estruturas mais simples.

\subsubsection{A Política do SVF-RR}

O sistema mantém uma lista $L$ de todos os domínios ativos. Estes domínios em $L$ são representados por triplas $\left(i\right.$, left $_{i}$, rec_time $\left._{i}\right)$, onde $i$ é o identificador de um domínio $D_{i}$ left $t_{i}$ é o tamanho do quantum reservado ao domínio $D_{i}$ e rec_time $e_{i}$ é o tamanho do quantum corrente, que é a quantidade máxima de tempo de serviço que o domínio corrente $D_{i}$ pode receber sem ser interrompido. Há apenas uma ocorrência de $D_{i}$ em $L$. O sistema define o ciclo do serviço para um recurso como sendo uma constante $T$ limitada pela soma de todos quanta ( coordenada left dos domínios) representados na lista $L$. O quantum em $L$ que pertence ao domínio $D_{i}$, left $t_{i}$, é igual a $\alpha_{i} T$ e rec_time $e_{i}$ a cada início de ciclo recebe left $t_{i}$. O algoritmo não requer a utilização de um tamanho fixo de quantum. Cada domínio $D_{i}$ em $L$ mantém em sua estrutura uma lista cíclica, $L C_{i}$, cuja dimensão é o número de unidades de tempo que designe a sua fração de serviço do recurso, contendo em seus elementos, os tokens do domínio. Cada token com a representação de um tempo de serviço virtual corrente (o timestamp corrente). Para a manipulação da lista cíclica, cada domínio dispõe de duas variáveis que representam os índices de iní cio e fim da lista cíclica. O índice início mantém em seu conteúdo o token mais recentemente criado na lista cíclica e o índice fim, o token que contém o menor timestamp desta lista. Para melhor eficiência, o domínio conserva uma variável lo_tok representando o seu menor tempo virtual corrente.

A descrição da política do SFV-RR depende dos mecanismos que detalhamos em seguida.

Sempre que um novo domínio $D_{j}$ é admitido no sistema, é inserido no final da lista $L$ e left e $_{j}$ rec_time $e_{j}$ recebem $\alpha_{j} T$ (sujeito ao controle de admissão, ou seja, $\sum_{i} \alpha_{i}$ precisa ser 
menor que um). Quando todos os processos pertencentes ao domínio $D_{j}$ saem do sistema, $D_{j}$ é removido de $L$ e sua porção de reserva é distribuída entre todos os domínios em $L$. Por exemplo, a reserva efetiva de cada domínio ativo $k$ será $\alpha_{k}+\frac{\text { left }}{n}$, onde $n$ é o número de domínios ativos.

A idéia central do algoritmo SVF-RR é computar uma representação de unidades discretas de tempo de serviço virtual ou timestamp, que marcam cada token das listas cíclicas de cada domínio em $L$. Inicialmente, timestamp recebe zero e é limitado ao valor $65.535^{5}$.

Sempre que um domínio $D_{j}$ é admitido no sistema, é removido do sistema ou quando o contador timestamp contém o valor zero, acionamos a rotina Inic_Tok_List (), mostrada na Figura 3.5, onde a lista cíclica dos tokens de todos os domínios em $L$ é montada. Primeiramente, para cada domínio inicia-se o menor token (lo_tok) e o primeiro token da lista cíclica fazendo-os receber o timestamp incrementado de um e os índices início e fim recebem o valor um.

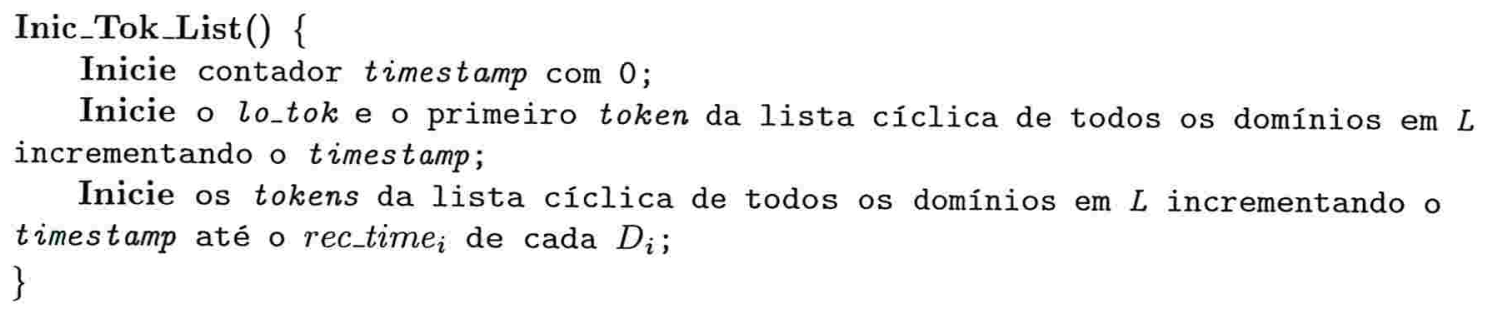

Figura 3.5: Procedimento Inicia Tokens para o SVF-RR.

Após a criação do primeiro token da lista cíclica de todos os domínios, montamos os tokens intermediários de cada uma. Cada domínio possuirá tantos tokens (início) quanto for o valor em unidades discretas do seu rec_time. Assim, cada domínio cujo valor de seu índice início ainda não represente a sua reserva do recurso, recebe mais um token na lista cíclica com o valor de timestamp incrementado de um. Esse procedimento se repete até que o índice de início de cada lista represente toda a reserva do recurso do domínio, left, para todos os domínios.

Uma variável estado é associada com cada recurso submetido ao SVF-RR. O estado do recurso é dito desocupado sempre que todos os processos dos domínios em $L$ estão executando ou requisitando outros recursos. Caso contrário, o estado do recurso é dito ocupado. As decisões são tomadas em tempos chamados decision epochs.

O ponto principal de controle do SFV-RR é computar uma representação de intervalo de tempo ou elapsed, que o domínio corrente executou no recurso entre sucessivas decision epochs. Sempre que um domínio inicia sua ocupação no recurso, o contador elapsed recebe o valor 0 . O elapsed registrará o tempo que foi utilizado pelo domínio corrente até a próxima decision epoch.

O SVF-RR aciona o procedimento, mostrado na Figura 3.6, a cada decision epoch. A

\footnotetext{
${ }^{5} \mathrm{O}$ tipo de dado, referente ao timestamp, unsigned int [Sch90] (Páginas 20-21) definido no padrão ANSI $\mathrm{C}$ possui a faixa mínima: 0 a 65.535 . Ao incrementarmos o timestamp de 1 , ocorre overflow e o conteúdo da variável será zero.
} 
rotina Decision_Epoch() será chamada na chegada de um novo domínio, na remoção de um domínio, na expiração do quantum corrente, na conclusão da fase ${ }^{6}$ do processo corrente (ou seja, o bloqueio do próprio processo) ou no final do intervalo de preempção corrente. Em outras palavras, o processo utilizando o recurso pode ser interrompido apenas no final do intervalo de preempção corrente $(\Delta t)$ ou no final do quantum corrente.

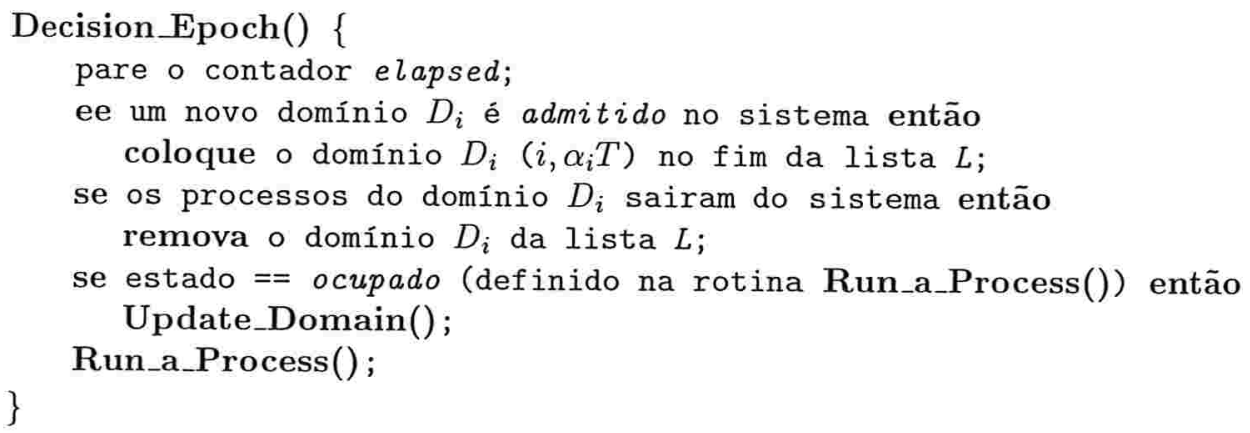

Figura 3.6: Procedimento Decision Epoch para o SVF-RR.

Este procedimento recebe o contador elapsed registrando o tempo decorrido desde a última decision epoch. Decision_Epoch() avalia o valor da variável estado do recurso; se este se traduz em ocupado significa que um processo estava utilizando o recurso no momento desta interrupção e portanto, o campo rec_time do seu domínio, o valor do menor tempo virtual do seu domínio e sua lista cíclica devem ser atualizados. Em seguida, seleciona-se o próximo processo pronto a ocupar o recurso.

A rotina Update_Domain(), apresentada na Figura 3.7, será chamada a cada decision epoch para atualizar as variáveis do domínio corrente.

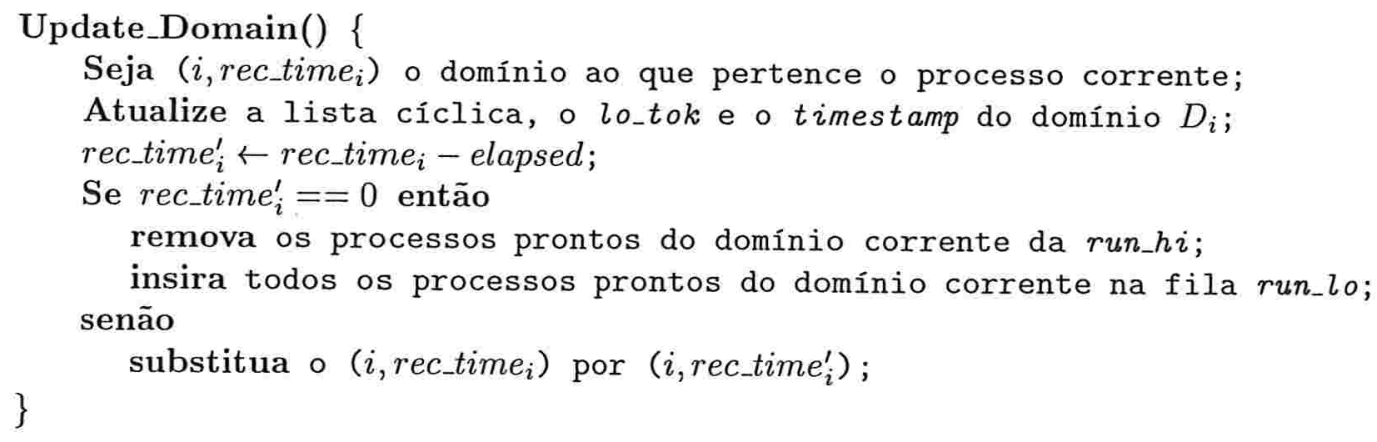

Figura 3.7: Procedimento Atualiza Domínio para o SVF-RR.

Este algoritmo utiliza duas filas de processos prontos para ocupar o recurso: run_hi e run_lo. A fila run_hi recebe os processos prontos que pertencem aos domínios que ainda têm suas fatias de tempo do ciclo de serviço disponíveis, isto é, o campo rec_time $e_{i}>0$. A fila run_lo recebe os processos prontos de domínios que já têm esgotada sua fatia de tempo de serviço no recurso, isto é, o campo rec_time $e_{i} \leq 0$.

\footnotetext{
${ }^{6} \mathrm{O}$ modelo de processo é o mesmo definido na Seção 2.2.3, Página 71.
} 
O campo rec_time $i$ da reserva de domínio $D_{i}$ corrente recebe o seu tempo restante de serviço no recurso $\left(\right.$ rec_time $_{i}-$ elapsed). Caso o resultado da operação seja nulo ou negativo, os processos prontos de $D_{i}$ são colocados na fila run_lo, caso contrário, o processo é colocado no final da fila apropriada (da run_hi ou vai para outro recurso).

Os tokens do domínio ao qual o processo corrente pertence também são atualizados: criase mais um elemento na lista, incrementando o índice início com o valor incrementado do timestamp corrente e atribuindo ao lo_tok o conteúdo da lista cujo índice é fim como o menor token, atualiza o índice fim, fazendo-o conter o próximo menor token da lista e novamente é chamado o escalonador.

A Figura 3.8 mostra a rotina Run_a_Process (). É esse procedimento que define o valor da variável estado do recurso. Sempre que todos os domínios em $L$ não estão prontos, o estado do recurso é designado desocupado e o escalonador espera pela próxima decision epoch. Caso contrário, Run_a_Process () seleciona o primeiro processo pronto em run_hi para executar no recurso. O estado do recurso é assinalado ocupado.

Quando a fila run_hi está vazia, isto é, todos os domínios esgotaram suas reservas no recurso, inicia-se um novo ciclo: renovam-se os campos rec_time de todos os domínios em $L$ com o valor correspondente à sua fração original de serviço no recurso $\left(\alpha_{i} T\right)$, ou seja, recebem o valor em left. Nesse momento todos os processos prontos que encontram-se na fila run_lo são transferidos para a fila run_hi.

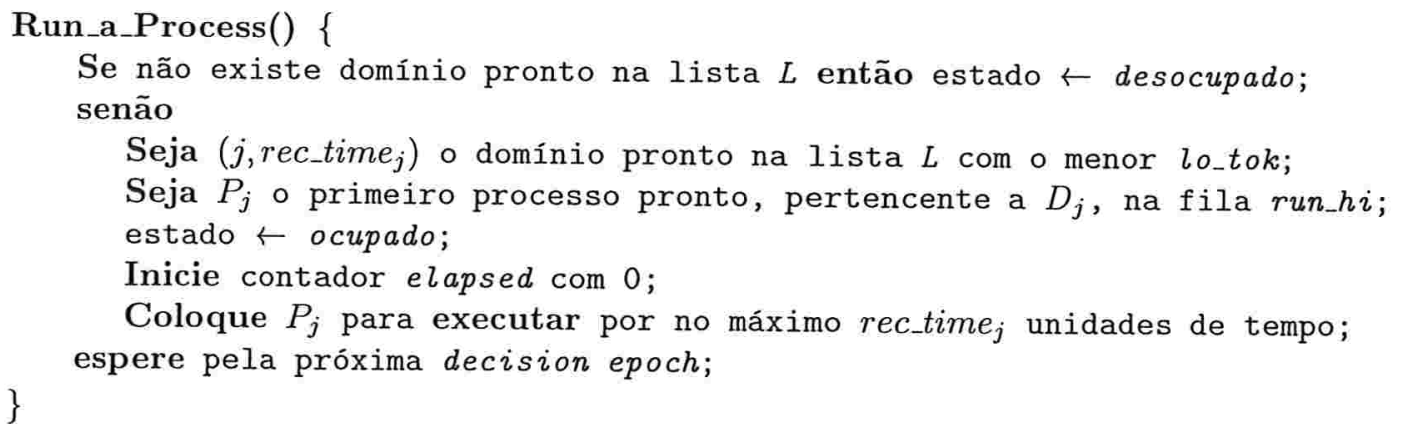

Figura 3.8: Procedimento Executa um Processo no SVF-RR.

O escalonador percorre a fila run_hi e o processo escolhido pelo SVF-RR é aquele que pertence ao domínio que possui o menor tempo virtual corrente, ou seja, o escalonador seleciona o processo pelo valor da variável lo_tok que está guardando o token com o menor timestamp corrente do domínio. Observa-se que cada reserva de domínio consome seus tokens na ordem de seus timestamp's.

O tempo de serviço obtido por um processo pode ser menor que o quantum alocado devido ao término da fase corrente ou quando terminar o ciclo de serviço corrente. No primeiro caso, a fase termina, o processo vai utilizar outro recurso qualquer, o escalonador atualiza as variáveis e o primeiro processo na fila run_hi com o menor tempo virtual é o próximo a ser servido. No último caso, quando terminar o ciclo de serviço corrente, os processos prontos que esgotaram suas reservas são inseridos na fila run_lo. 
Exemplo. Ilustramos com um exemplo a operação do escalonador SVF-RR. Considere um recurso com o ciclo de serviço $T=30$ unidades de tempo. Há três tokens em $L$ correspondentes às reservas de domínios $D_{1}, D_{2}$ e $D_{3}$. Os processos $P_{11}, P_{21}$ e $P_{31}$ estão associados aos domínios $D_{1}, D_{2}$ e $D_{3}$, respectivamente. A reserva do recurso, left, para $D_{1}$ é 10 , para $D_{2}$ é 5 e para $D_{3}$ é 15 . Suponha que os três domínios estão prontos no sistema. Primeiramente montamos as listas cíclicas de tokens dos três domínios. Seguindo o método descrito no Algoritmo 3.5 para inicializarmos as listas, temos os conteúdos das listas cíclicas dos três domínios, como mostradas na Tabela 3.1.

\begin{tabular}{|c|c|c|c|}
\hline início & $D_{1}$ & $D_{2}$ & $D_{3}$ \\
\hline 0 & $\mathbf{0}$ & 1 & 2 \\
1 & 3 & 4 & 5 \\
2 & 6 & 7 & 8 \\
3 & 9 & 10 & 11 \\
4 & 12 & 13 & 14 \\
5 & 15 & & 16 \\
6 & 17 & & 18 \\
7 & 19 & & 20 \\
8 & 21 & & 22 \\
9 & 23 & & 24 \\
10 & & & 25 \\
$\vdots$ & & & $\vdots$ \\
14 & & & 29 \\
\hline rec time & 10 & 5 & 15 \\
\hline
\end{tabular}

Tabela 3.1: Listas dos Tokens Iniciais utilizando SVF-RR.

Após a montagem da lista cíclica de cada domínio, teremos os seguintes menores tempos virtuais: de $D_{1}$ é 0 , de $D_{2}$ é 1 e de $D_{3}$ é 2 . Inicialmente, todos os processos estão na fila run_hi, ou seja, os processos requerem o início de uma fase no recurso.

fila run_hi: $P_{11} P_{21} P_{31}$

fila run_lo: vazia

Como o menor tempo virtual, $\min \{0,1,2\}$, pertence ao domínio $D_{1}$, o processo $P_{11}$ é executado. $\mathrm{O}$ processo decide utilizar outro recurso após receber 7 unidades de tempo de serviço. O domínio $D_{1}$ na lista $L$ é atualizado na sua reserva do recurso tal que: o quantum corrente de $D_{1}, r e c \_t i m e_{1}$ valerá 3 , seu menor tempo virtual, lo_tok será 3 , o início, 10 e o timestamp, 30 .

fila run_hi: $P_{21} P_{31}$

fila run_lo: vazia

Agora, o menor tempo virtual, $\min \{1,2\}$ pertence ao domínio $D_{2}$ e $P_{21}$ é executado. O quantum de $D_{2}$ é esgotado em 5 unidades de tempo. O domínio $D_{2}$ na lista $L$ é atualizado 
na sua reserva do recurso tal que: o quantum de $D_{2}$ rec_time 2 valerá zero, seu menor tempo virtual será 4 , o início, 5 e o timestamp, 31. Como esgotou a cota do domínio $D_{2}$ o processo $P_{21}$ é colocado na fila run_lo.

fila run_hi: $P_{31}$

fila run_lo: $P_{21}$

Agora, o menor tempo virtual, $\min \{2\}$, pertence ao domínio $D_{3}$ e $P_{31}$ é selecionado para ser executado. Após 3 unidades de tempo, $D_{1}$ fica pronto ( $P_{11}$ chega no recurso), é inserido na fila run_hi. O domínio $D_{3}$ na lista $L$ é atualizado na sua reserva do recurso tal que: o quantum de $D_{3}$ valerá 12 , seu menor tempo virtual será 5 , o início valerá 15 e o timestamp conterá 32 .

fila run_hi: $P_{31} P_{11}$

fila run_lo: $P_{21}$

Agora, o menor tempo virtual, $\min \{5,3\}$ pertence ao domínio $D_{1}$ e $P_{11}$ é executado. O quantum de $D_{1}$ é esgotado em 3 unidades de tempo. O domínio $D_{1}$ na lista $L$ é atualizado na sua reserva do recurso tal que: o quantum de $D_{1}$ rec_time $_{1}$ valerá zero, seu menor tempo virtual será 6 , o início, 11 e o timestamp, 33 . Como esgotou a cota do domínio $D_{1}$ o processo $P_{11}$ é colocado na fila run_lo.

fila run_hi: $P_{31}$

fila run_lo: $P_{21} P_{11}$

Agora, o menor tempo virtual, $\min \{\mathbf{5}\}$ pertence ao domínio $D_{3}$ e $P_{31}$ é selecionado para

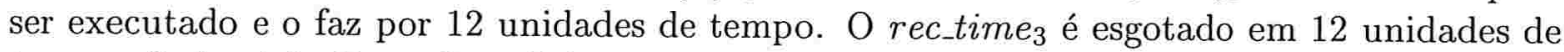
tempo. O domínio $D_{3}$ na lista $L$ é atualizado na sua reserva do recurso tal que: o quantum de $D_{3}$ valerá zero, seu menor tempo virtual será 8 , o início estará com 16 e o timestamp conterá 34. Como esgotou a cota do domínio $D_{3}$ o processo $P_{31}$ é colocado na fila run_lo.

fila run_hi: vazia

fila run_lo: $P_{21} P_{11} P_{31}$

Como a fila run_hi está vazia, inicia-se um novo ciclo de serviço: renovam-se os campos rec_time de todo domínio em $L$ com o valor correspondente à sua fração original (left) de serviço no recurso. Nesse momento todos os processos prontos que encontram-se na fila run_lo são transferidos para a fila run_hi.

fila run_hi: $P_{21} P_{11} P_{31}$

fila run_lo: vazia

O menor tempo virtual, $\min \{4,6,8\}$ e o procedimento se repete até todos os processos sairem do sistema...

Como consideramos os mesmos dados para os pequenos exemplos da operação do MTRLS e do SVF-RR, podemos observar que o desempenho provido pelo MTR-LS é melhor que 
o provido pelo SVF-RR, embora todos os processos tenham sido atendidos em sua fração requerida por ambos escalonadores.

\section{Complexidade do SVF-RR}

Na operação do SVF-RR temos a lista $L$ e as duas filas run_hi e run_lo para serem manipuladas.

Na lista de domínios $L$ efetuamos as seguintes operações:

1) iniciar o primeiro token da lista cíclica;

2) completar a construção dos tokens intermediários iniciais;

3) renovar todas as reservas do recurso em $L$ (rec_time).

Todas operações efetuadas em $L$ podem ser executadas em $O(n)$ onde $n$ é o número de domínios ativos no sistema.

As filas run_hi e run_lo possuem as seguintes operações:

1) encontrar o processo com o menor tempo virtual em run_hi;

2) colocar os processos no final de uma fila;

3) remover todos os processos que esgotaram as suas reservas de run_hi e inserir no final da fila $r u n_{-} l o ; ;$

4) transferir todos os processos da fila run_lo para run_hi.

Todas operações, exceto a segunda que é feita em tempo constante, efetuadas nas filas run_hi e run_lo, podem ser executadas em tempo $O(m)$, onde $m$ é o número de processos prontos.

Podemos constatar que $m$ pode ser maior de $n$ quando temos mais do que um processo pertencente um mesmo domínio. Portanto, a complexidade para cada decisão do escalonador é $O(m)$, onde $m$ é o número de processos prontos. O pior caso ocorre quando o processo com o menor tempo virtual (lo_tok) é o último da lista e precisamos percorrê-la toda ou ainda quando houver a transferência de todos os processos prontos da fila run_lo para run_hi. A manutenção dos tokens e a atualização do rec_time, a cada interrupção do clock, é constante pois o acesso ao domínio é direto.

\subsubsection{Propriedades da Política do SVF-RR}

A política do SVF-RR provê, como a do MTR-LS, garantias de justiça, limite de atraso e serviço cumulativo (definidas na Seção 2.2.4). As provas para estas propriedades são similares às apresentadas na Seção 2.1.10, a partir da Página 64 .

Propriedade 3.2.1. A política SVF-RR é justa com um limite de T. Isto é, para qualquer intervalo de tempo $[\tau, t]$, durante o qual os processos $P_{i} \in D_{i}$ e $P_{j} \in D_{j}$ estão na fila run_hi temos:

$$
\left|\frac{s_{i}(\tau, t)}{\alpha_{i}}-\frac{s_{j}(\tau, t)}{\alpha_{j}}\right| \leq T
$$


Justificativa. A pior situação, seguindo a mesma idéia utilizada ao MTR-LS, ocorre quando um dos domínios, por exemplo $D_{i}$, possui $l o_{-} t o k_{i}$ menor que o $l o_{-} t o k_{j}$ e o valor do rec_time $j$ do domínio $D_{j}$ é extremamente pequeno $(\Delta t)$. É possível que o processo $P_{i} \in D_{i}$ execute por $T$ unidades de tempo virtual e, em seguida, $P_{j} \in D_{j}$ executar por rec_time $e_{j} / \alpha_{j}$ unidades de tempo virtual. O tempo virtual resultante de $P_{i}$ estará na frente do tempo resultante de $P_{j}$ por um valor que é limitado por $T$.

As garantias de serviço cumulativo e de atraso são dependentes da fração do serviço e do comprimento do intervalo de preempção.

Propriedade 3.2.2. Se $\sum_{i} \alpha_{i} \leq 1$ e $\Delta t=0$ então a política do SVF-RR para reserva de domínios provê garantia de servico cumulativo com um limite de $T$.

Justificativa. Por hipótese, o intervalo de preempção é igual a zero significa que um processo em execução pode ser bloqueado imediatamente pelo processo pronto que possui o campo lo_tok em seu domínio menor que o valor de lo_tok no domínio do processo corrente. A pior situação ocorre quando $P_{j}$ obtém serviço somente depois de bloqueado o máximo possível pelos outros processos. Seguindo a mesma idéia utilizada na prova do Lema 2.1.3, se $\Sigma_{i} \alpha_{i} \leq 1$, os outros processos podem apenas bloquear $P_{j}$ por, no máximo, $\left(1-\alpha_{j}\right) T$. Como o tempo real de execução é $\alpha_{j} T$, o tempo virtual é igual ao tempo do pior caso de bloqueio e serviço. Assim, $v_{j}(\tau, t) \geq w_{j}(\tau, t)+s_{j}(\tau, t)-T$.

Propriedade 3.2.3. Se $\sum_{i} \alpha_{i} \leq 1$ e $\Delta t=0$ então a política do SVF-RR para reserva de domínios provê atraso limitado.

Justificativa. O atraso limitado provido pelo SVF-RR vem diretamente da garantia de serviço cumulativo (Seção 2.2.3).

Porém, quando o intervalo de preempção do recurso é positivo temos que a decision epoch ocorre no final do intervalo de preempção corrente. Consideremos o caso em que o domínio $D_{j}$ fica pronto no recurso enquanto este está sendo utilizado por $D_{i}$ e não terminou o intervalo de preempção corrente.

Para obtermos garantia de serviço cumulativo, necessitamos de restrições adicionais associadas aos recursos tendo intervalos de preempção positivos. O SVF-RR requer que $\alpha_{j} \leq 1-\Sigma_{i} \alpha_{i}$ para todos os domínios $D_{j}$ para prover a garantia de serviço cumulativo com o limite de $T$. A razão é que um processo pronto pode ser atrasado pelo processo em execução até o fim do intervalo de preempção.

Propriedade 3.2.4. Seja $\Delta t>0$. Assuma que para todo $t$ e todo dominio $D_{j}$ temos $\alpha_{j} \leq$ $1-\Sigma_{i} \alpha_{i}$. Então a política do SVF-RR para reserva de domínios provê garantia de serviço cumulativo com um limite de $T$.

Propriedade 3.2.5. Seja $\Delta t>0$. Assuma que para todo $t$ e todo domínio $D_{j}$ temos $\alpha_{j} \leq$ $1-\Sigma_{i \in A(t)} \alpha_{i}$. A política do SVF-RR para reserva de domínios provê atraso limitado.

O atraso limitado provido pelo SVF-RR segue diretamente da garantia de serviço cumulativo (Seção 2.2.3). 


\subsection{Weighted Round Robin Scheduling (wRR)}

O WRR [BGzS98] é um algoritmo de escalonamento que fornece um mecanismo de alocação proporcional ao share sobre o ciclo de serviço do recurso. O WRR considera frações de utilização de um recurso como fator de ponderação para atendimento dos processos. Descrevemos aqui o seu escalonamento quando temos reserva de domínios.

A fração de utilização do recurso por um processo pertencente a um domínio é proporcional à reserva desse recurso requerida pelo domínio.

O WRR sem uma reserva explícita do recurso é idêntico ao round-robin scheduling tradicional.

\subsubsection{A Política do WRR}

A Política do WRR é similar a do SVF-RR.

O sistema mantém uma lista $L$ de todos os domínios ativos. Estes domínios em $L$ são representados por triplas $\left(i\right.$, left $_{i}$, rec_time $\left._{i}\right)$, onde $i$ é o identificador de um domínio $D_{i}$ left $t_{i}$ é o tamanho do quantum reservado ao domínio $D_{i}$ e rec_time $e_{i}$ é o tamanho do quantum corrente, que é a quantidade máxima de tempo de serviço que o domínio corrente $D_{i}$ pode receber sem ser interrompido. Há apenas uma ocorrência de $D_{i}$ em $L$. O sistema define o ciclo do serviço para um recurso como sendo uma constante $T$ limitada pela soma de todos quanta (coordenada left dos domínios) representados na lista $L$. O quantum em $L$ que pertence ao domínio $D_{i}$, left $t_{i}$, é igual a $\alpha_{i} T$ e rec_time $e_{i}$ a cada início de ciclo recebe left $t_{i}$. O algoritmo não requer a utilização de um tamanho fixo de quantum.

A descrição da política do WRR depende dos mecanismos que apresentamos a seguir.

Sempre que um novo domínio $D_{j}$ entra no sistema, é inserido no final da lista $L$ e left $t_{i}$ e rec_time $e_{i}$ recebem $\alpha_{j} T$ (sujeito ao controle de admissão, ou seja, $\sum_{i} \alpha_{i}$ precisa ser menor que um). Quando todos os processos pertencentes ao domínio $D_{j}$ saem do sistema, $D_{j}$ é removido de $L$ e sua porção de reserva é distribuída entre todos os domínios em $L$. Por exemplo, a reserva efetiva de cada domínio ativo $k$ será $\alpha_{k}+\frac{\text { left }}{n}$, onde $n$ é o número de domínios ativos.

Uma variável estado é associada com cada recurso submetido ao WRR. O estado do recurso é dito desocupado sempre que todos os processos dos domínios em $L$ estão utilizando ou requerendo outros recursos. Caso contrário, o estado do recurso é dito ocupado. As decisões são tomadas em tempos chamados decision epochs.

O ponto principal de controle do WRR é computar uma representação de intervalo de tempo ou elapsed, que o domínio corrente executou no recurso entre sucessivas decision epochs. Sempre que um domínio inicia sua ocupação no recurso, o contador elapsed recebe o valor 0. O elapsed registrará o tempo que foi utilizado pelo domínio corrente até a próxima decision epoch.

O WRR aciona o procedimento, mostrado na Figura 3.9, a cada decision epoch. A rotina Decision_Epoch() será chamada na chegada de um novo domínio, na remoção de um domínio, 
na expiração do quantum corrente, na conclusão da fase ${ }^{7}$ do processo corrente (ou seja, o bloqueio do próprio processo) ou no final do intervalo de preempção corrente. Em outras palavras, o processo utilizando o recurso pode ser interrompido apenas no final do intervalo de preempção corrente $(\Delta t)$ ou no final do quantum corrente.

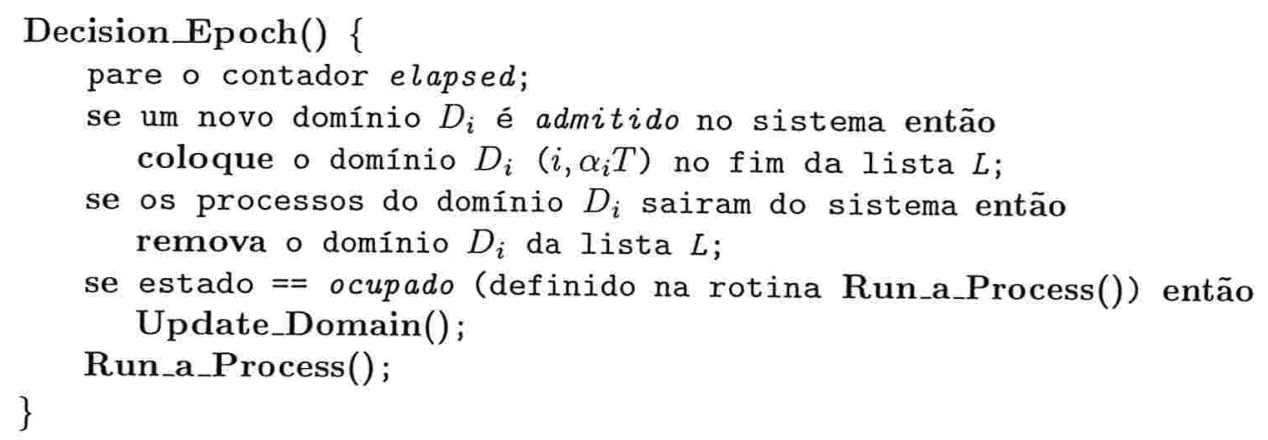

Figura 3.9: Procedimento Decision Epoch para o WRR.

A cada decision epoch, este procedimento recebe o contador elapsed registrando o tempo decorrido desde a última decision epoch. Decision_Epoch() avalia o valor da variável estado do recurso; se este se traduz em ocupado significa que um processo estava utilizando o recurso no momento desta interrupção e portanto, o campo rec_time do seu domínio deve ser atualizado. Em seguida, seleciona-se o próximo processo pronto a ocupar o recurso.

A rotina Update Domain(), apresentada na Figura 3.10, será chamada a cada decision epoch para atualizar o valor do rec_time do domínio corrente.

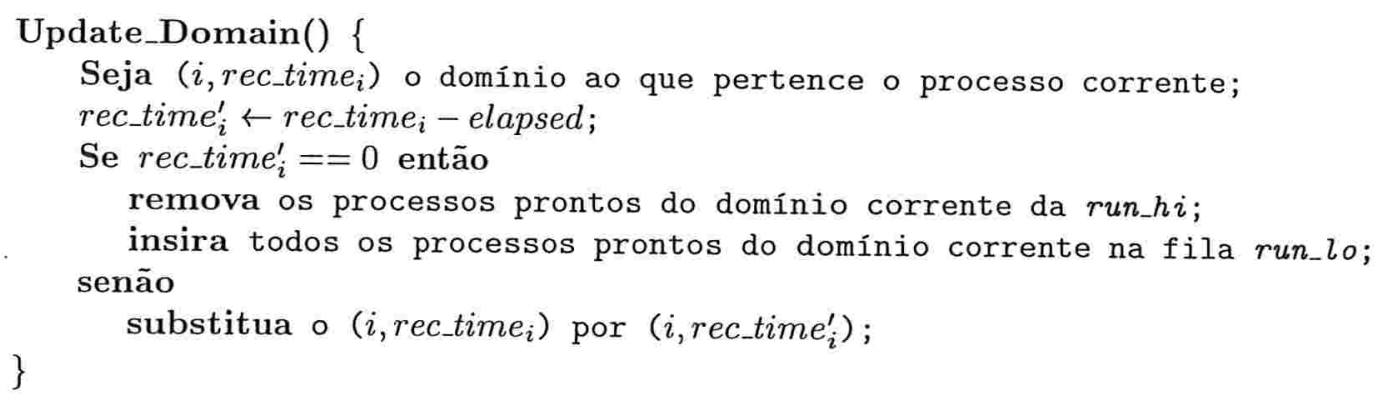

Figura 3.10: Procedimento Atualiza Domínio para o WRR.

Este algoritmo utiliza duas filas de processos prontos para ocupar o recurso: run_hi e run_lo. A fila run_hi recebe os processos prontos que pertencem aos domínios que ainda têm suas fatias de tempo do ciclo de serviço disponíveis, isto é, o campo rec_time $_{i}>0$. A fila run_lo recebe os processos prontos de domínios que já têm esgotada sua fatia de tempo de serviço no recurso, isto é, o campo rec_time $e_{i} \leq 0$.

O campo rec_time $i$ da reserva de domínio $D_{i}$ corrente recebe o seu tempo restante de serviço no recurso $\left(\right.$ rec_time $_{i}-$ elapsed $)$. Caso o resultado da operação seja nulo ou negativo,

\footnotetext{
${ }^{7} \mathrm{O}$ modelo de processo é o mesmo definido na Seção 2.2.3, na Página 71.
} 
os processos prontos de $D_{i}$ são colocados na fila run_lo, caso contrário, o processo é colocado no final da fila apropriada (da run_hi ou vai para outro recurso).

A Figura 3.11 mostra a rotina Run_a_Process(). É esse procedimento que define o valor da variável estado do recurso. Sempre que todos os domínios em $L$ não estão prontos, o estado do recurso é designado desocupado e o escalonador espera pela próxima decision epoch. Caso contrário, Run_a_Process() seleciona o primeiro processo pronto em run_hi para executar no recurso. O estado do recurso é assinalado ocupado.

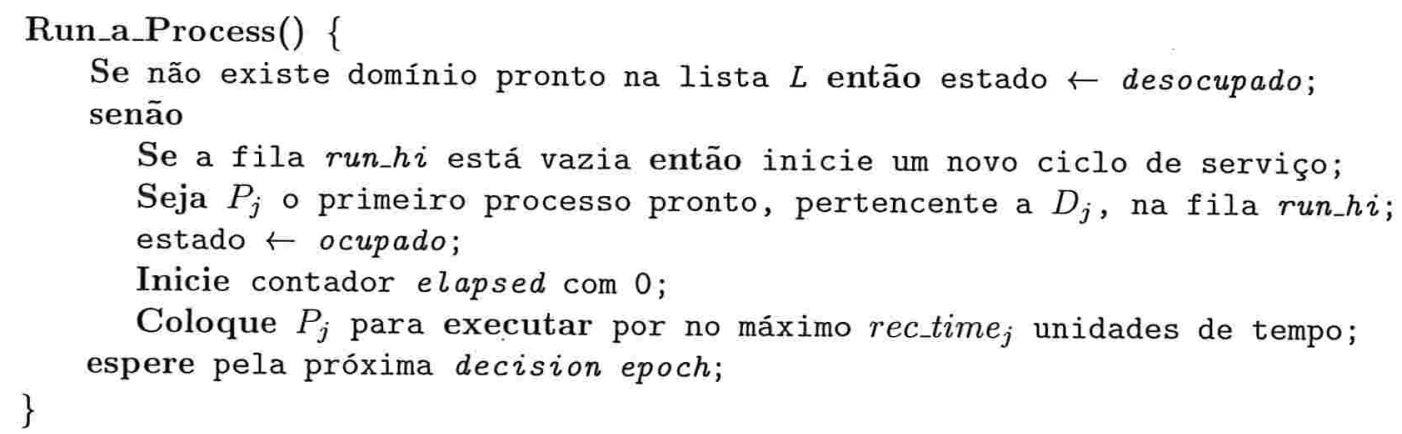

Figura 3.11: Procedimento Executa um Processo no WRR.

Quando a fila run_hi está vazia ou todos os domínios esgotaram suas reservas no recurso, inicia-se um novo ciclo: renovam-se os campos rec_time de todos os domínios em $L$ com o valor correspondente à sua fração original de serviço no recurso $\left(\alpha_{i} T\right)$, ou seja, recebem o valor guardado em left. Nesse momento todos os processos prontos que encontram-se na fila run_lo são transferidos para a fila run_hi.

Os processos são atendidos pela ordem de chegada na fila run_hi.

O tempo de serviço obtido por um processo pode ser menor que o quantum alocado devido ao término da fase corrente ou quando terminar o ciclo de serviço corrente. No primeiro caso, a fase termina, o processo vai utilizar outro recurso qualquer, o escalonador atualiza o rec_time da reserva de domínio do processo corrente e o primeiro processo na fila run_hi é o próximo a ser servido. No último caso, quando terminar o ciclo de serviço corrente, os processos prontos que esgotaram suas reservas são inseridos na fila run_lo.

Quando a fila run_hi está vazia inicia-se um novo ciclo de serviço, renovam-se os campos rec_time de todos os domínios em $L$ com o valor correspondente à sua fração de serviço no recurso. Nesse momento todos os processos prontos que encontram-se na fila run_lo são transferidos para a fila run_hi.

Podemos observar que o escalonador WRR segue os mesmos passos gerais do SVF-RR, apenas utiliza o esquema FIFO no atendimento dos processos na fila run_hi.

Exemplo. A seguir, ilustramos com um exemplo a operação do escalonador WRR. Considere um recurso com o ciclo de serviço de 30 unidades de tempo. Há três tokens em $L$ correspondentes às reserva de domínios $D_{1}, D_{2}$ e $D_{3}$. Os processos $P_{11}, P_{21}$ e $P_{31}$ estão associados aos domínios $D_{1}, D_{2}$ e $D_{3}$, respectivamente. As reservas do recurso para $D_{1}$ é 10 , 
para $D_{2}$ é 5 e para $D_{3}$ é 15 . Inicialmente, todos os processos estão na fila run_hi, ou seja, os processos requerem o início de uma fase no recurso.

fila run_hi: $P_{11} P_{21} P_{31}$

fila run_lo: vazia

O escalonador seleciona o primeiro processo pronto na fila run_hi. Assim, o processo $P_{11}$ é executado. $O$ processo decide utilizar outro recurso após receber 7 unidades de tempo de serviço. O domínio $D_{1}$ na lista $L$ é atualizado na sua reserva do recurso tal que o quantum de $D_{1}$ valerá 3 .

fila run_hi: $P_{21} P_{31}$

fila run_lo: vazia

Agora, o primeiro processo pronto na fila run_hi e $P_{21}$ é executado. O quantum de $D_{2}$ é esgotado em 5 unidades de tempo. O domínio $D_{2}$ na lista $L$ é atualizado na sua reserva do recurso tal que o quantum de $D_{2}$ valerá 0 . Como esgotou a cota do domínio $D_{2}$ o processo $P_{21}$ é colocado na fila run_lo.

fila run_hi: $P_{31}$

fila run_lo: $P_{21}$

Agora, o primeiro processo pronto na fila run_hi e $P_{31}$ é executado. Após 3 unidades de tempo, $P_{11}$ chega no recurso, é inserido na fila run_hi, pois o domínio $D_{1}$ não tem sua cota esgotada. O quantum de $D_{3}$ é esgotado em 15 unidades de tempo. O domínio $D_{3}$ na lista $L$ é atualizado na sua reserva do recurso tal que o quantum de $D_{3}$ valerá 0 . Como esgotou a cota do domínio $D_{3}$ o processo $P_{31}$ é colocado na fila run_lo.

fila run_hi: $P_{11}$

fila run_lo: $P_{21} P_{31}$

Agora, o primeiro processo pronto na fila run_hi e $P_{11}$ é executado. O quantum de $D_{1}$ é esgotado em 3 unidades de tempo. O domínio $D_{1}$ na lista $L$ é atualizado na sua reserva do recurso tal que o quantum de $D_{1}$ valerá 0 . Como esgotou a cota do domínio $D_{1}$ o processo $P_{11}$ é colocado na fila run_lo.

fila run_hi: vazia

fila run_lo: $P_{21} P_{31} P_{11}$

Como a fila run_hi está vazia, um novo ciclo se inicia: renovam-se os campos rec_time de todos os domínios em $L$ com o valor correspondente à sua fração de serviço no recurso. Nesse momento todos os processos prontos que encontram-se na fila run_lo são transferidos para a fila run_hi.

fila run_hi: $P_{21} P_{31} P_{11}$

fila run_lo: vazia 
E todo procedimento se repete...

Como consideramos os mesmos dados para os pequenos exemplos que ilustram a operação do MTR-LS, do SVF-RR e do WRR podemos observar que o desempenho provido pelo MTR-LS é melhor que o provido pelo SVF-RR e pelo WRR. O resultado foi semelhante ao utilizarmos o SVF-RR e o WRR. Todos os processos foram atendidos na fração de serviço de seu domínio pelos três escalonadores.

\section{Complexidade do WRR}

Na operação do WRR temos a lista $L$ e as duas filas de processos prontos, run_hi e run_lo, para serem manipuladas.

Na lista de domínios $L$ efetuamos as seguintes operações:

1) atualizar o rec_time de um domínio em $L$;

2) renovar todas as reservas do recurso em $L$ (rec_time).

Podemos atualizar o rec_time de um domínio em tempo constante. Para renovarmos as frações de serviço de todos os domínios em $L$ são necessárias $O(n)$ operações, onde $n$ é o número de domínios ativos no sistema.

As filas run_hi e run_lo possuem as seguintes operações:

1) remover o primeiro processo da fila;

2) colocar os processos no final de uma fila;

3) remover todos os processos que esgotaram as suas reservas;

4) transferir todos os processos da fila run_lo para run_hi.

As operações (3) e (4) efetuadas nas filas run_hi e run_lo, podem ser executadas em tempo $O(m)$, onde onde $m$ é o número de processos prontos.

Portanto, a complexidade para cada decisão do escalonador é $O(m)$, onde $m$ é o número de processos prontos. O pior caso ocorre quando houver a transferência dos processos prontos da fila run_lo para run_hi e eles são todos os processos ativos no sistema. A seleção do processo e a atualização do rec_time, a cada interrupção do clock, podem ser executadas em tempo constante, pois o acesso ao primeiro processo da fila e ao seu domínio em $L$ é direto.

\subsubsection{Propriedades da Política do WRR}

A política do WRR provê, como a do SVF-RR, garantias de justiça, limite de atraso e serviço cumulativo (definidas na Seção 2.2.4). As provas para estas propriedades são similares às apresentadas na Seção 2.1.10, a partir da Página 64 .

Propriedade 3.3.1. A política WRR é justa com um limite de T. Isto é, para qualquer intervalo de tempo $[\tau, t]$, durante o qual os processos $P_{i} \in D_{i}$ e $P_{j} \in D_{j}$ estấo na fila run_hi temos:

$$
\left|\frac{s_{i}(\tau, t)}{\alpha_{i}}-\frac{s_{j}(\tau, t)}{\alpha_{j}}\right| \leq T
$$


Justificativa. A pior situação, seguindo a mesma idéia utilizada ao SVF-RR, ocorre quando o processo em um dos domínios, por exemplo $D_{i}$, é o primeiro na fila run_hi e o valor do rec_time $j$ do domínio $D_{j}$ é extremamente pequeno $(\Delta t)$. É possível que o processo $P_{i} \in D_{i}$ execute por $T$ unidades de tempo virtual e, em seguida, $P_{j} \in D_{j}$ executar por $r e c \_t i m e_{j} / \alpha_{j}$ unidades de tempo virtual. O tempo virtual resultante de $P_{i}$ estará na frente do tempo resultante de $P_{j}$ por um valor que é limitado por $T$.

As garantias de serviço cumulativo e de atraso são dependentes da fração do serviço e do comprimento do intervalo de preempção.

Propriedade 3.3.2. Se $\sum_{i} \alpha_{i} \leq 1$ e $\Delta t=0$ então a política do WRR provê garantia de servico cumulativo com um limite de $T$.

Justificativa. A pior situação ocorre quando $P_{j}$ obtém serviço somente depois de bloqueado o máximo possível pelos outros processos. Seguindo a mesma idéia utilizada na prova do Lema 2.1.3, se $\Sigma_{i} \alpha_{i} \leq 1$, os outros processos podem apenas bloquear $P_{j}$ por, no máximo, $\left(1-\alpha_{j}\right) T$. Como o tempo real de execução é $\alpha_{j} T$, o tempo virtual é igual ao tempo do pior caso de bloqueio e serviço. Assim, $v_{j}(\tau, t) \geq w_{j}(\tau, t)+s_{j}(\tau, t)-T$.

Propriedade 3.3.3. Se $\sum_{i} \alpha_{i} \leq 1$ e $\Delta t=0$ então a política do WRR para reserva de domínios provê atraso limitado.

Justificativa. O atraso limitado provido pelo WRR vem diretamente da garantia de serviço cumulativo (Seção 2.2.3).

Porém, quando o intervalo de preempção do recurso é positivo temos que a decision epoch ocorre no final do intervalo de preempção corrente. Consideremos o caso em que o processo $P_{j} \in D_{j}$ fica pronto no recurso enquanto este está sendo utilizado por $P_{i} \in D_{i}$ e não terminou o intervalo de preempção corrente.

Para obtermos garantia de serviço cumulativo, necessitamos de restrições adicionais associadas aos recursos tendo intervalos de preempção positivos. O WRR requer que $\alpha_{j} \leq 1-\Sigma_{i} \alpha_{i}$ para todos os domínios $D_{j}$ para prover a garantia de serviço cumulativo com o limite de $T$. A razão é que um processo pronto pode ser atrasado pelo processo em execução até o fim do intervalo de preempção.

Propriedade 3.3.4. Seja $\Delta t>0$. Assuma que para todo $t$ e $\forall$ domínio $D_{j}$ temos $\alpha_{j} \leq 1-$ $\Sigma_{i} \alpha_{i}$. Então a política do WRR para reserva de domínios provê garantia de serviço cumulativo com um limite de $T$.

Propriedade 3.3.5. Seja $\Delta t>0$. Assuma que para todo $t$ e todo dominio $D_{j}$ temos $\alpha_{j} \leq$ $1-\Sigma_{i \in A(t)} \alpha_{i}$. A política do WRR para reserva de domínios provê atraso limitado.

O atraso limitado provido pelo WRR segue diretamente da garantia de serviço cumulativo (Seção 2.2.3). 


\section{Capítulo 4}

\section{Eclipse: Um Sistema Operacional com Reserva de Domínios}

Neste capítulo apresentamos sucintamente as duas versões do sistema operacional Eclipse, desenvolvidas e projetadas por Silberschatz et al. [BGzS98, $\mathrm{BBM}^{+} 99, \mathrm{BGz}^{+}, \mathrm{BBG}^{+} 99 \mathrm{a}$, $\left.\mathrm{BBG}^{+} 99 \mathrm{~b}\right]$ publicadas até o momento. Dedicamos este espaço do trabalho nesta apresentação porque, além de pioneiro na implementação e aplicação dos algoritmos utilizando a abstração reserva de domínio no escalonamento dos processos, nos oferece elementos para o discernimento e à compreensão deste conceito.

\subsection{Introdução}

A primeira versão do sistema operacional Eclipse [BGzS98] é derivada do Plan9 construído pelo Computing Sciences Research Center do Bell Laboratories [ $\left.\mathrm{PPF}^{+} 95\right]$, o mesmo grupo que desenvolveu o Unix e as linguagens $\mathrm{C}$ e $\mathrm{C}++$.

Recentemente $\left[\mathrm{BBM}^{+}\right.$99, $\mathrm{BBG}^{+}$99b] (Outubro de 1999) foi apresentada uma nova versão deste sistema, o Eclipse/BSD $\left[\mathrm{BGz}^{+}\right]$derivado do sistema operacional FreeBSD versão 4.4 [BSD, LMKQ96] originário do sistema operacional BSD Unix e disponível para computadores pessoais.

Na Seção 4.2 abordamos o sistema operacional Eclipse nos principais enfoques utilizados na implementação de sua primeira versão, que denominamos Eclipse/Plan9, e na Seção 4.3 apresentamos alguns aspectos importantes do Eclipse/BSD.

\subsection{Eclipse/Plan9}

O Eclipse/Plan9 implementa reserva de domínio no topo do sistema operacional Plan9, sem qualquer alteração nos servidores ou nas aplicações. É um sistema compatível ao Plan9, ou seja, retém a interface externa deste sistema (system calls, protocolos, estrutura do name 
space, etc.). O Eclipse/Plan9 implementa escalonadores de domínios para múltiplos recursos: CPU, I/O e memória física, que descreveremos nas seções 4.2.2, 4.2 .3 e 4.2.4, respectivamente. Os recursos são gerenciados independentemente. As reservas de recurso e as reservas de domínios podem ser definidas através do $s h e l l^{1}$; nenhuma programação em nível do sistema é necessária.

Uma vez que a soma das reservas explícitas de um recurso, $\sum_{i} \alpha_{i}$, deve ser menor que $u^{2}{ }^{2}$, o Eclipse/Plan9 distribui a porção não reservada dos recursos igualmente por todas as reservas de domínios ativas ${ }^{3}$. A reserva efetiva de um recurso do domínio $D_{i}$ é

$$
\alpha_{i}+\left(1-\sum_{j=1}^{n} \alpha_{j}\right) / n
$$

onde $n$ é o número de reservas de domínios.

\subsubsection{Gerenciamento de Reservas de Domínios}

O Eclipse/Plan9 mantém uma lista de todas as reservas de domínios ativas (RDs). Cada processo pertence a uma única reserva de domínio. Um novo processo herda a reserva de seu processo-pai, exceto se o processo é criado pela system call rfork, a qual coloca o processo na reserva de domínio mais recente. Um processo pode se remover de sua reserva de domínio corrente e iniciar uma nova reserva de domínio através de uma chamada apropriada da rfork. De fato, cada processo pode pertencer a uma reserva de domínio diferente. Uma nova reserva de domínio é criada sem qualquer reserva explícita. Entretanto, ao novo domínio é designada uma reserva efetiva, que inclui seu share proporcional da porção não reservada dos recursos, como descrito acima (Equação 4.1).

O sistema Eclipse/Plan9 mantém arquivos especiais de controle para reserva de recursos. A Tabela 4.1 descreve alguns dos arquivos de controle. Cada linha da tabela apresenta o nome de um arquivo de controle, o tipo de acesso permitido a este arquivo (podendo ser consultado e/ou alterado) e sua descrição.

Uma reserva de recurso é atribuída a uma reserva de domínio através de um comando shell ao arquivo de controle apropriado ou definida em tempo de compilação do kernel alterado. Por exemplo, o comando shell echo $50>/ \mathrm{dev} / \mathrm{rdcpu}$ requisita uma reserva de $50 \%$ de CPU para a reserva de domínio que executa esse comando.

O Eclipse/Plan9 recusa reservas de recurso quando o total de reserva exceder o limite correspondente. O sistema remove uma reserva de domínio e libera seus recursos assim que o último processo pertencente a esta reserva de domínio termine.

\footnotetext{
${ }^{1}$ Interpretador de comandos.

${ }^{2}$ Controle de admissão.

${ }^{3} \mathrm{~A}$ definição de uma reserva de domínio ativa está na Página 72.
} 


\begin{tabular}{|l|c|l|}
\hline \multicolumn{1}{|c|}{ nome } & acesso & \multicolumn{1}{|c|}{ descrição } \\
\hline rdcpu & $\mathrm{r} / \mathrm{w}$ & reserva de CPU da RD corrente \\
rdcpusum & $\mathrm{r}$ & total de reserva de CPU corrente \\
rdcpulim & $\mathrm{r}$ & máximo permitido para reserva de CPU \\
rdio & $\mathrm{r} / \mathrm{w}$ & reserva de I/O da RD corrente \\
rdiosum & $\mathrm{r}$ & total de reserva de I/O corrente \\
rdiolim & $\mathrm{r}$ & máximo permitido para reserva de I/O \\
rdmem & $\mathrm{r} / \mathrm{w}$ & reserva de memória física em KB \\
rdmemsum & $\mathrm{r}$ & total de reserva de memória física \\
rdmemlim & $\mathrm{r}$ & memória física disponível \\
rdsched & $\mathrm{r} / \mathrm{w}$ & algoritmo corrente de escalonamento da CPU \\
\hline
\end{tabular}

Tabela 4.1: Arquivos de Controle para Reserva de Recursos.

\subsubsection{Abordagem do Escalonamento de CPU}

O Eclipse/Plan9 implementa os algoritmos MTR-LS e WRR (descritos nas Seções 3.1 e 3.3, respectivamente). Um escalonador é atribuído à CPU através de um comando shell ao arquivo de controle rdsched. Por exemplo, o comando echo w $>/$ dev/rdsched seleciona WRR e o comando echo $\mathrm{m}>/$ dev/rdsched seleciona MTR-LS.

O Eclipse/Plan9 não mantém propriamente uma lista global de tokens como a descrita na Seção 3.1 para o MTR-LS. Efetua a criação de timestamp para cada token e classifica as reservas de domínios pelo menor timestamp dos tokens existentes na lista $L C$ de cada domínio. Desse modo, a lista $L C$ é montada com uma coleção de buffers cíclicos, uma para cada reserva de domínio, contendo os tokens do domínio. Cada reserva de domínio consome seus tokens na ordem de seus timestamps. Nesta implementação, percorre-se a fila de processos prontos e seleciona-se o processo pronto que está associado com a reserva de domínio que contém o token com menor timestamp, ou seja, o processo com o menor tempo virtual de serviço é escolhido para ser executado até esgotar a sua reserva.

A implementação do Eclipse/Plan9 utiliza o intervalo de interrupção do clock de $200 \mathrm{~Hz}$. O ciclo de serviço da CPU $(T)$ é $500 \mathrm{~ms}$.

\subsubsection{Abordagem do Escalonamento de I/O}

O Eclipse/Plan9 assume que os dispositivos de entrada e saída tratam uma série de requisições independentemente (uma requisição de cada vez), ainda que os servidores possam enfileirar diversas requisições internamente. A implementação do escalonamento de I/O é descrita na estrutura name space do Eclipse/Plan9. O name space é formado por uma hierarquia independente de arquivos que são providos por servidores de arquivos e dispositivos do kernel. Os servidores de arquivos são processos no nível de usuário, que respondem por requisições 9P sobre pipes bidirecionais. Os dispositivos do kernel são chamados diretamente pelo kernel, o que dispensa o overhead do protocolo 9P. Apenas uma parte do name space correpondente 
a mount points ou binds pode estar sujeita ao escalonamento de I/O. Todas as outras partes do name space não são afetadas pelo escalonamento de I/O. Isso é essencial, uma vez que todos os recursos no Eclipse/BSD são parte do name space. Por exemplo, seria inapropriado escalonar requisições de tela e mouse.

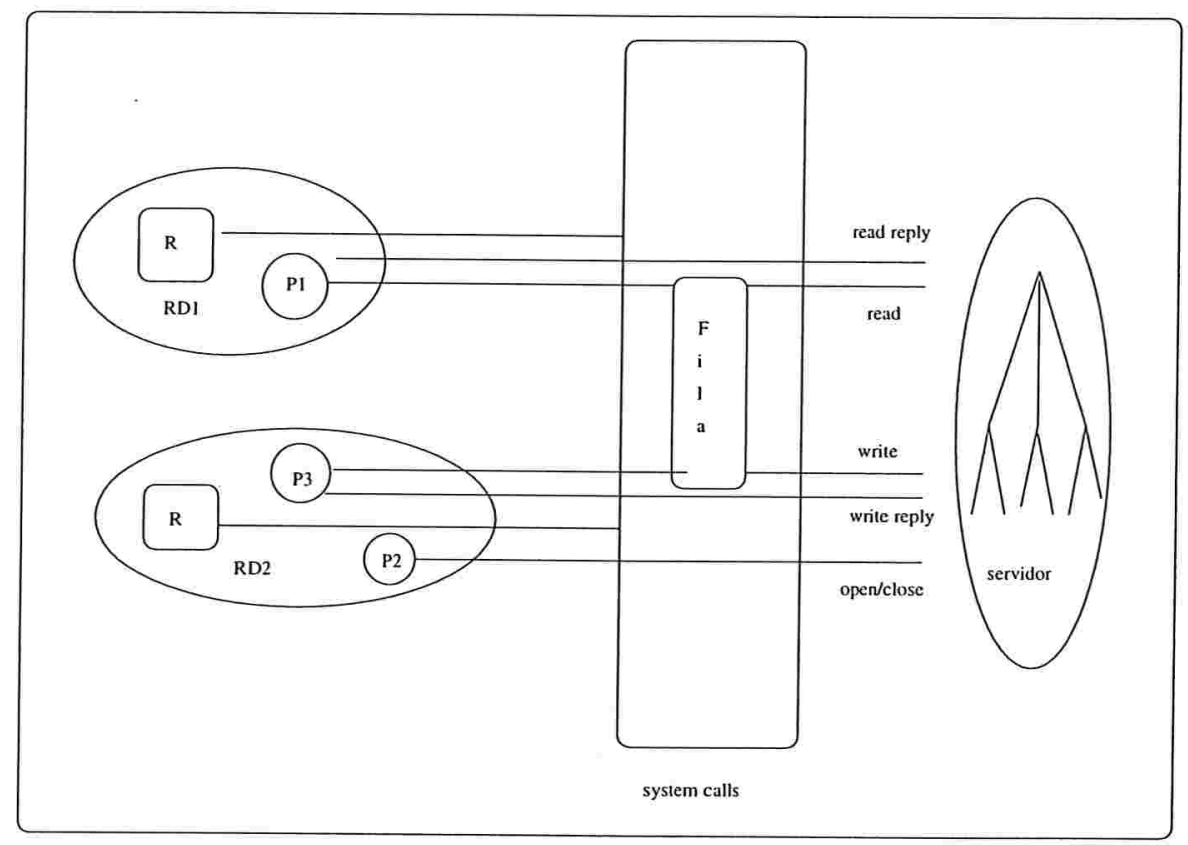

Figura 4.1: Escalonamento de I/O.

O sistema operacional Eclipse/Plan9 implementa escalonamento de I/O interceptando as chamadas de sistema read e write, como ilustrado na Figura 4.1. Os retângulos dentro de cada reserva de domí nio representam as reservas de recurso, e os círculos representam os processos. Uma vez que todas as requisições de I/O passam pela mesma interface de chamadas de sistema, o escalonamento de I/O pode ser aplicado para todos clientes e todos servidores, para servidores de arquivos e dispositivos do kernel com a mesma facilidade e sem mudança no código.

O escalonamento de I/O é implementado de modo similar ao WRR (Seção 3.3) utilizado para escalonamento da CPU mantendo duas filas de I/O: io_hi e io_lo. O escalonador dispõe de um campo io_time_left para cada reserva de domínio, que é atualizado utilizando o tempo decorrido entre requisições. Uma vez que o servidor pode reordenar as requisições, o cálculo do tempo decorrido é feito ao final da requisição anterior (que pode terminar depois da requisição corrente ser liberada pelo servidor). As reservas são reiniciadas no começo de todo ciclo de serviço de I/O e todas as requisições em io_lo são movidas para a fila io_hi.

Esta implementação do Eclipse/Plan9 trata de apenas uma fila global de requisições. Em futuras versões os desenvolvedores pretendem manter uma fila para cada servidor. Para um ciclo de serviço de I/O foi utilizado $\frac{1}{2}$ segundo. O algoritmo de escalonamento acima é 
ignorado no fluxo de execução caso o servidor esteja desocupado ou não houver disputa (todas requisições ativas pertençam a uma mesma reserva de domínio).

\subsubsection{Abordagem do Escalonamento de Memória}

O Eclipse/Plan9 implementa reserva de memória física pela estratégia page-out seletivo. $\mathrm{O}$ processo paginador examina toda memória e seleciona páginas que não foram acessadas desde a sua última investigação e que pertencem às reservas de domínio que excederam suas reservas de memória física. Esta estratégia assegura que o tamanho do working set ${ }^{4}$ não fica

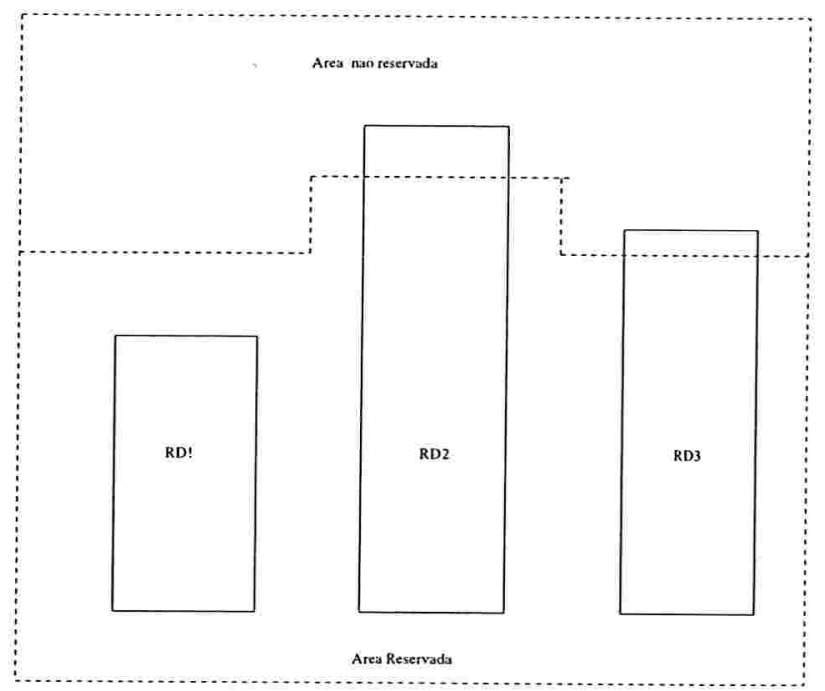

Figura 4.2: Escalonamento de Memória Física.

abaixo da reserva, e todas as páginas que estejam acima da reserva estão sujeitas à seleção do algoritmo LRU global. Na Figura 4.2, a área reservada representa o working set reservado para os domínios $R D_{1}, R D_{2}$ e $R D_{3}$ e a área não reservada representa o working set sujeito à subtituição de páginas pelo LRU.

\subsubsection{Operacionalidade}

Segundo os desenvolvedores, o Eclipse/Plan9 mostrou-se estável e, em particular, foi possível demonstrar e controlar condições extremas, tais como overloading ${ }^{5}$, memory thrashing ${ }^{6}$ e starvation ${ }^{7}$. Foram submetidas aplicações multimídia, tais como aplicações MPEG $^{8}$ players, con-

\footnotetext{
${ }^{4}$ Conjunto de páginas referenciadas durante um certo intervalo de tempo.

${ }^{5} \mathrm{Um}$ sistema sobrecarregado de aplicações.

${ }^{6}$ Elevada taxa de paginação.

${ }^{7}$ Dificuldade em conseguir acesso ao recurso compartilhado. Situação em que um processo permaneça indefinidamente esperando pela utilização do processador ou de qualquer outro recurso. [TW97].

${ }^{8}$ Aplicações que seguem o padrão MPEG (Motion Pictures Experts Group). MPEG é um grupo de pessoas que se reúnem de acordo com a ISO (Organização Internacional de Padrões) para gerar padrōes para o vídeo
} 
correntemente com outras atividades de demanda. Observou-se também que as aplicações respeitaram seus deadlines quando executaram em reservas de domínios com reservas dos recursos apropriadas.

Utilizou-se dois métodos para a determinação de reservas apropriadas: o método manual de "tentativa e erro" e um monitor de recurso automático, um processo em nível de usuário, que coleta tempos diversos das aplicações e ajusta as reservas apropriadamente. O monitor automaticamente aumenta a reserva quando a aplicação tem atrasos, e a reduz quando a aplicação não obtém atrasos.

O Eclipse/Plan9 possui dois MPEG-1 ${ }^{9}$ players: um que lê de um arquivo, e um cliente Fellini [zRS96], que recebe uma stream de informação do servidor de mídia contínua Fellini.

O resto desta seção descreve diversos experimentos efetuados pelos desenvolvedores e que ilustram a eficiência do escalonador MTR-LS. Nestes experimentos utilizaram amplamente reservas de domínio para distinguir as diferentes classes de aplicações que executam numa mesma máquina.

\section{Experimentos}

Os experimentos compararam três algoritmos de escalonamento: (1) o escalonador original do Plan9, que é um escalonador baseado em prioridades, que ajusta a prioridade dos processos de acordo com seu consumo de CPU, (2) o MTR-LS e (3) o WRR.

$\mathrm{O}$ primeiro experimento executa um MPEG player diante do sistema sobrecarregado. O MPEG-1 player executando 10 threads de leitura, que lê um filme do disco local e o envia para o decodificador MPEG. O MPEG player requer os recursos CPU e I/O. Criou-se a sobrecarga da CPU através da execução de múltiplas cópias do programa onoff. Cada cópia deste programa consome $11 \mathrm{~ms}$ de CPU e dorme por $5 \mathrm{~ms}$. O programa onoff apresenta um desafio para a maioria dos escalonadores de CPU, uma vez que ele consome CPU com um ciclo obrigatório acerca de $60 \%$, e dorme freqüentemente.

\section{(a) Provendo QoS em Sistema Sobrecarregado por Reserva de Recurso}

A Figura 4.3 apresenta o efeito da reserva de recurso de uma aplicação MPEG-1 player diante da CPU sobrecarregada. No experimento para sobrecarregar a CPU do sistema foram colocados para executar, concorrentemente, o MPEG player e 8 instâncias do programa onoff. No experimento para sobrecarregar o I/O foram adicionados 10 processos I/O-bound que acessavam posições aleatórias do disco onde se encontrava o filme MPEG. Em todos os casos, ao sistema de arquivos foi designada a reserva de domínio $D_{1}$ com $20 \%$ de reserva de CPU. O MPEG player foi colocado em $D_{2}$, os processos de I/O em $D_{3}$ e cada instância do onoff

e áudio digital.

${ }^{9}$ MPEG-1 corresponde à codificação de imagem em movimento e respectivos canais de áudio para armazenamento em suportes digitais com débito binário de cerca de $1.5 \mathrm{Mbits} / \mathrm{s}$. Cerca de $1.2 \mathrm{Mbits} / \mathrm{s}$ reservados para vídeo, os restantes $0.3 \mathrm{Mbits} / \mathrm{s}$ para áudio. 
executava em sua própria reserva de domínio, sem um valor explícito para suas reservas. Em todos os casos, variava-se a fração de serviço do recurso correspondente da reserva de domínio $D_{2}$.

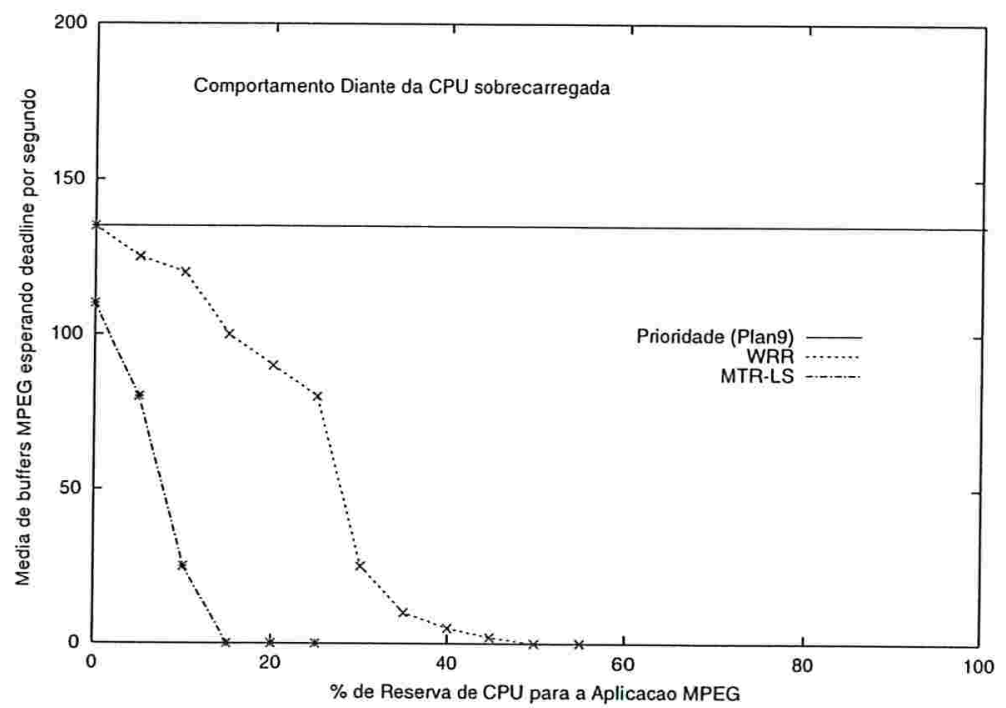

Figura 4.3: Comportamento do MPEG player diante da Reserva de CPU.

A Figura 4.3 mostra o número médio de buffers esperando deadlines no cartão MPEG. Os buffers esperando deadlines são fornecidos a uma taxa de $200 \mathrm{~Hz}$. Um valor zero indica que não há deadlines esperando, e é sempre alcançado quando o MPEG player está executando em um sistema desocupado. $\mathrm{O}$ valor 200 indica que todos os deadlines são esperados. O experimento demonstra que reservas de domínios provê taxa de execução garantida num sistema sobrecarregado. Os escalonadores MTR-LS e WRR proveram uma boa QoS sob sobrecarga de CPU. Entretanto, o MTR-LS requisitou uma reserva de $15 \%$ para cumprir os deadlines esperados, enquanto o WRR requisitou uma reserva de 55\%. A razão da superioridade do MTR-LS é que ele dá preferência a processos como o MPEG player ao onoff, pois este consome mais de $60 \%$ de CPU numa máquina ociosa e no caso, foi lhe reservado cerca de $9 \%$ de CPU. O escalonador do Plan9 baseado em prioridade falha neste experimento, uma vez que ele não escolhe uma aplicação em especial; embora detectando a utilização de CPU dos processos, o escalonamento do Plan9 não reconhece o onoff como um programa que utiliza CPU em excesso, pois este dorme freqüentemente.

\section{(b) Comparando o MTR-LS com o Escalonamento baseado em Prioridade e o WRR}

A Figura 4.4 compara os atrasos dos escalonamentos do MTR-LS com o escalonador do Plan9 e o WRR. Apenas um processo sleeper foi colocado para executar concorrentemente com um número variado de programas onoff sob algoritmos de escalonamento diferentes. $\mathrm{O}$ programa sleeper consome $11 \mathrm{~ms}$ de CPU e dorme $100 \mathrm{~ms}$, repetidamente; mede a diferença 
entre seu tempo wakeup atual e o anterior e informa o atraso médio. O sleeper foi colocado para executar na reserva de domínio $D_{2}$, e cada instância do onoff numa reserva de domínio separada sem qualquer reserva explícita de CPU. A Figura 4.4 ilustra a vantagem do MTR-LS

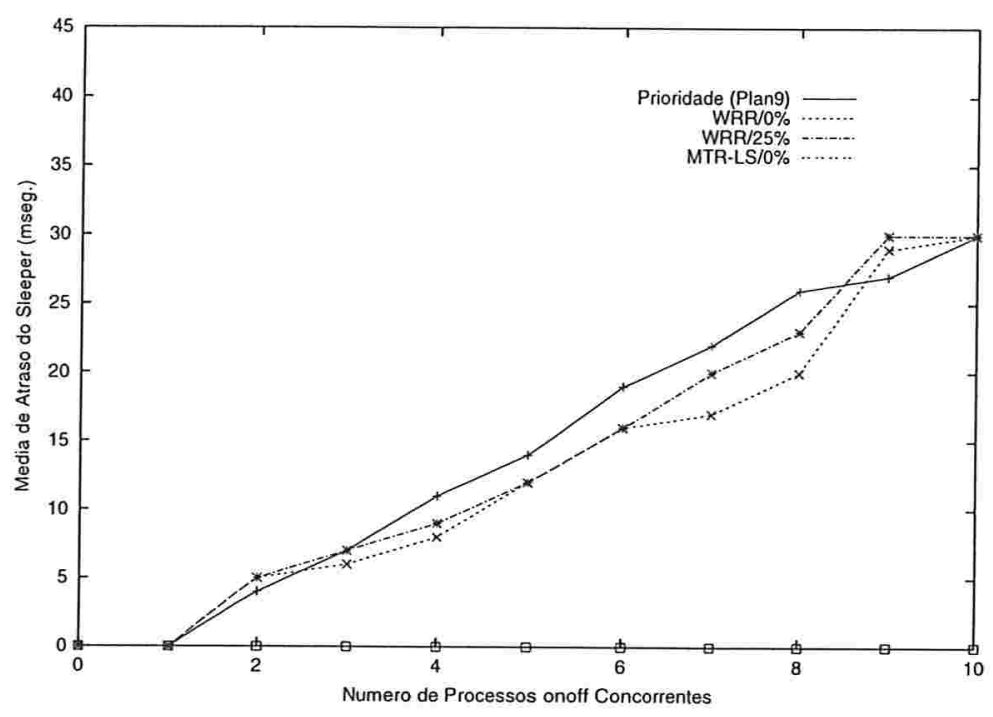

Figura 4.4: Comportamento do sleeper.

sobre os outros escalonadores. Pode-se observar que ele sempre escalonou o sleeper antes do onoff, uma vez que o sleeper consome pouca CPU, e então seus tokens tendem a migrar para o início da lista L. Em outras palavras, MTR-LS prefere processos "pouco gulosos", ou seja, que utilizam o recurso em porções pequenas. Este experimento mostra que o MTR-LS provê um limite de atraso para processos que não excedem a sua reserva. Naturalmente, se o sleeper tivesse uma prioridade explícita (nice) no escalonador baseado em prioridades, não obteria atrasos. Entretanto, alterar a prioridade do processo pode não ser possível em muitas situações, podendo provocar efeitos colaterais indesejáveis.

\section{(c) Escalonamento da CPU de Processos I/O-bound}

A Figura 4.5 apresenta a taxa de I/O de apenas um thread de um processo I/O-bound quando executando concorrentemente com um número variado de programas onoff sob os diferentes algoritmos de escalonamento. O programa I/O-bound executou na reserva de domínio $D_{2}$, e cada instância do programa onoff pertencendo a um domínio sem reserva de CPU explícita.

O resultado mais interessante desse experimento é que a taxa de I/O diminuiu à medida em que aumentava a carga da CPU com o escalonador do Plan9 e com o WRR. A explicação para o fato é a seguinte: apesar do processo de I/O ter um acesso ilimitado ao disco, precisa esperar pelo seu retorno para a CPU para depois emitir a próxima requisição de I/O. O processo de I/O não é atendido imediatamente pela CPU no WRR, uma vez que é sempre colocado no final da fila de prontos e após $n$ processos onoff. Isto é porque o throughput do I/O decresce à 


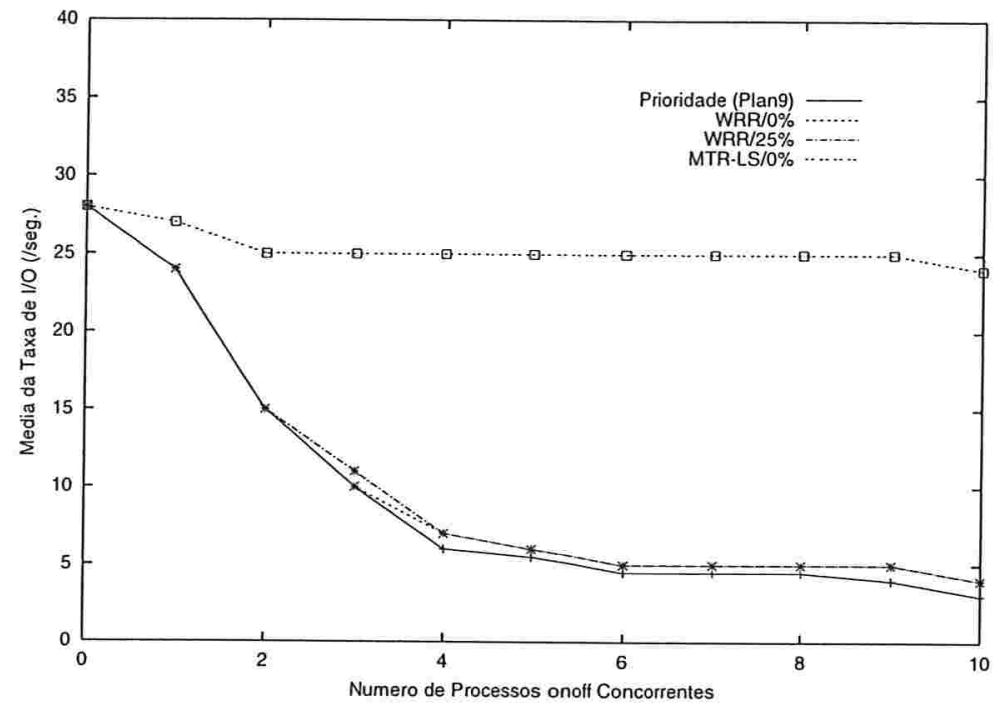

Figura 4.5: Comportamento das aplicaçōes I/O sob reserva de CPU.

medida em que a disputa pela CPU cresce. O escalonamento baseado em prioridade do Plan9 falha escolhendo o processo de I/O antes dos onoff, pois estes dormem freqüentemente.

O escalonador MTR-LS separa o processo de I/O da CPU sobrecarregada. A razão é que o processo de I/O utiliza menos CPU que os processos onoff. Em outras palavras, o MTR-LS provê uma garantia de serviço cumulativo para o processo I/O-bound que não foi atrasado pela CPU.

Em resumo, o sistema operacional experimental Eclipse/Plan9 que implementa reservas de domínios e o escalonamento MTR-LS, pode escalonar três tipos de recursos: CPU, I/O de disco e memória física (working set). Segundo os autores, o Eclipse/Plan9 é um sistema independente, fácil de transportar para outras arquiteturas. Os resultados experimentais indicam que o Eclipse/Plan9 provê limites de atraso e de serviço cumulativo em situações de sobrecarga. O MTR-LS prefere processos "menos gulosos", que significa que ele automaticamente provê melhor desempenho em muitas situações, como mostrado nos experimentos [BGzS98]. O escalonador MTR-LS mostrou-se superior aos demais escalonadores em muitos casos. 


\subsection{Eclipse/BSD}

Nesta seção estaremos focalizando a versão do sistema operacional Eclipse $\left[\mathrm{BGz}^{+}\right]$, derivada do FreeBSD.

\subsubsection{Introdução}

Levando-se em conta a atenção especial recebida atualmente pelos aspectos teóricos dos escalonadores baseados na alocação de recursos proporcional ao share e constatando-se que a adoção destas políticas no setor produtivo não acontece no mesmo ritmo, Silberschatz et al. $\left[\mathrm{BBG}^{+} 99 \mathrm{~b}\right]$ apresentam formas de se utilizar estes escalonadores em suportes de tempo real mais populares. Constataram que um sistema sobrecarregado, possuindo em sua carga aplicações de tempo real, deve cumprir controle de admissão e garantir QoS; um sistema necessita de mecanismos para processar as aplicações com os limites de QoS especificados e com justiça.

Diante das necessidades mencionadas, Silberschatz et al. [BBG $\left.{ }^{+} 99 \mathrm{~b}, \mathrm{BBM}^{+} 99\right]$ implementaram no sistema operacional FreeBSD: (1) escalonadores hierárquicos ${ }^{10}$ baseados na alocação de recursos proporcional ao share, (2) o sistema de arquivo /reserv provendo uma API para manipular "reservas" e (3) um mecanismo de etiquetas para a associação das reservas com as operações escalonáveis, adotando um esquema de acesso e de controle de admissão que conduz a uma nova noção de reserva de domínio. O sistema modificado foi chamado de Eclipse/BSD. O sistema operacional Eclipse/BSD ${ }^{11}\left[\mathrm{BBM}^{+} 99\right]$ é baseado no FreeBSD 2.2.8 derivativo do 4.4 BSD Unix.

A Subseção 4.3.2 discute os esquemas hierárquicos utilizados no Eclipse/BSD. A Subseção 4.3.3 apresenta o modelo de gerenciamento de recursos e sua adaptação no FreeBSD. Na Subseção 4.3.4 são apresentados os escalonadores utilizados no Eclipse/BSD. Os experimentos na Subseção 4.3.5 ilustram como o Eclipse/BSD oferece o isolamento entre sites Web hospedados no mesmo sistema.

\subsubsection{Escalonadores Hierárquicos}

O Eclipse/BSD utiliza escalonadores hierárquicos [GVC96] e cota proporcional de recursos em nível de controladores de dispositivos para gerenciamento de disco, rede e CPU. Estes escalonadores foram implementados de forma que são dinamicamente reconfiguráveis, obedecendo ao controle de acesso e ao de admissão, no sentido hierárquico e/ou em seus pesos, sem interromper o escalonamento. Estas configurações estão sujeitas ao controle de acesso e admissão.

Os escalonadores hierárquicos de cota proporcional de recursos incorporam uma noção geral de reserva de recurso estruturada. No escalonamento hieráquico, cada nó representa

\footnotetext{
${ }^{10}$ Este tipo de escalonamento está exemplificado na Seção 2.1.3, Página 33.

${ }^{11}$ Seu código está disponível no endereço: www.bell-labs.com/what/eclipse.
} 
uma reserva cujo valor de seu share é igual a divisão de seu peso pela soma dos pesos de todos os nós do nível. Dependendo de como está montada a hierarquia, quando o nó não está utilizando o recurso, o cálculo da reserva efetiva dos outros nós terá um resultado diferente.

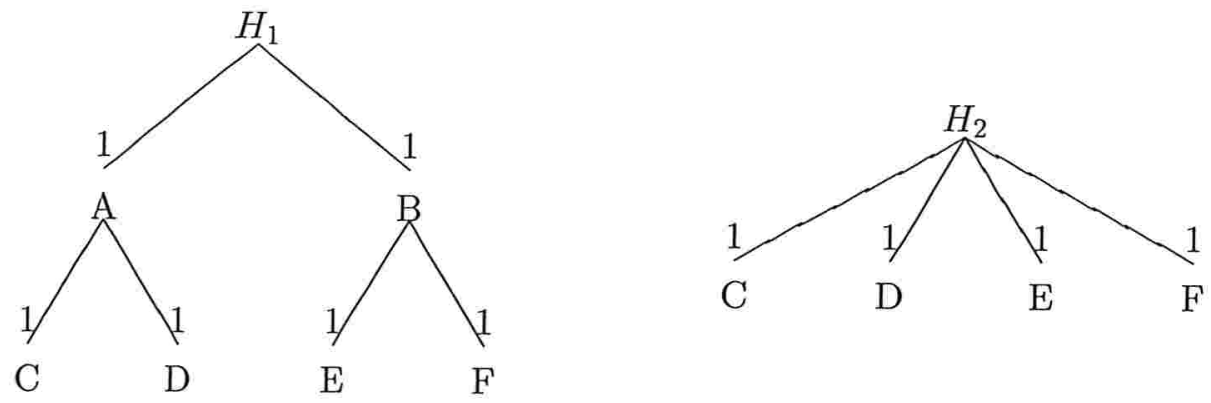

Figura 4.6: Exemplo de Escalonadores Hieráquicos.

Por exemplo, a Figura 4.6 ilustra dois escalonadores hierárquicos $H_{1}$ e $H_{2}$ para disco. Cada um dos nós $\mathrm{A}$ e $\mathrm{B}$ em $H_{1}$ representam $50 \%$ da reserva do recurso. No próximo nível, cada nó C, D, E e F representa $25 \%$ da reserva ou do ponto de vista de $\mathrm{C}$ e D, cada um tem $50 \%$ de A. No escalonador $\mathrm{H}_{2}$, cada nó C, D, E e $\mathrm{F}$ tem $25 \%$ de todo o recurso. A diferença entre os dois escalonadores está em como eles dinamicamente distribuem a porção não utilizada do recurso. Por exemplo, se o nó C não utiliza o recurso então em $H_{1}$, os nós $\mathrm{D}, \mathrm{E}$ e $\mathrm{F}$ obtêm $50 \%, 25 \%$ e $25 \%$ do recurso, respectivamente, e em $H_{2}$, cada um terá $\frac{1}{3}$ do total do recurso.

$\mathrm{O}$ escalonador classifica as requisições ${ }^{12}$ para acessar o recurso. Estruturalmente, um escalonador é uma árvore onde distingüem-se duas espécies de nós: scheduler e (requisição) queue.

- nó-escalonador (scheduler node) - implementa um algoritmo de escalonamento de recurso que atende aos nós imediatamente descendentes e

- nó-fila (queue node) - ponto onde a requisição atual é enfileirada. As filas são atendidas pelo escalonador hieráquico do recurso.

Por exemplo, na Figura 4.6, o nó-folha $\mathrm{C}$ em $H_{1}$ é uma queue na qual as requisições do recurso podem ser enfileiradas. Um nó-escalonador pode ter filas e nós_escalonador imediatamente descendentes. Na implementação do Eclipse/BSD cada um contém os arquivos denominados: share, newsched e newqueue. A raiz de um escalonador precisa ser um nóescalonador.

Um nó-fila não tem descendentes; utiliza FIFO. Cada um possui os arquivos: share e backlog. No exemplo exibido na Figura 4.6, o nó $\mathrm{C}$ em $H_{1}$ é um nó-fila, onde as requisições podem ser enfileiradas.

Todas as requisições que chegam num escalonador de um recurso são etiquetadas com uma referência para uma fila; são inseridas nas filas correspondentes às suas etiquetas.

\footnotetext{
${ }^{12} \mathrm{~A}$ ordenação é baseada em seu algoritmo de escalonamento.
} 
Um nó-escalonador com apenas uma fila descendente representa um escalonador que utiliza a política FIFO. Um nó-escalonador que possua todos os seus descendentes imediatos como filas são designados com prioridades dinâmicas e implementam escalonadores de prioridade. Similarmente, um nó-escalonador, cujas filas descendentes possuem peso, implementam escalonador baseado em cota proporcional. Escalonadores hieráquicos permitem a incorporação de nós-escalonador adicionais na hierarquia.

A implementação dos escalonadores permite a inserção ou remoção de nó-escalonador e de filas e a alteração do peso na utilização do recurso sem parar o escalonamento do recurso.

\subsubsection{Modelo de Gerenciamento de Recursos}

O sistema de arquivo /reserv é o centro de todo gerenciamento dos recursos no Eclipse/BSD.

Nesta seção descrevemos o modelo hierárquico de gerenciamento de recursos e a API /reserv do Eclipse/BSD e sua implementação no FreeBSD.

\section{Reservas de Recurso}

As aplicações no Eclipse/BSD obtêm QoS requerendo inicialmente uma reserva de recurso para cada recurso físico requerido. Os recursos físicos incluem CPU, memória, discos, e interfaces de rede, cada recurso possuindo uma política de escalonamento própria. Uma reserva de recurso especifica uma fração do recurso para uso exclusivo de um ou mais processos. As aplicações podem subdividir reservas de recurso hierarquicamente. O controle de admissão garante que as reservas não excedem a capacidade do recurso. Os escalonadores compartilham as reservas com justiça para aplicações utilizando o recurso concorrentemente.

Para compartilhamento de recurso proporcionalmente hierárquico, o sistema de arquivo mantém uma API baseada no sistema de arquivo do Unix onde pode-se acessar, utilizar e reconfigurar o esquema de escalonamento (inserir, remover, alterar). Cada recurso no sistema está representado por um diretório dentro do /reserv, como mostra a Figura 4.7, e cada reserva na hierarquia dentro do diretório correspondente e assim sucessivamente.

As aplicações especificam as reservas de recurso como diretórios num novo sistema de arquivo montado sob o /reserv. Cada recurso é escalonado independentemente. Por exemplo, /reserv/cpu (CPU), /reserv/mem (memória física), /reserv/fxp0 (interface de rede 0), /reserv/sd0 (disco 0), como ilustrado na Figura 4.7.

O diretório hierárquico do sistema de arquivo /reserv corresponde a dois tipos de diretórios: diretórios-escalonadores e diretórios-filas. Cada diretório-escalonador contém os arquivos: share, newsched e newqueue. Cada diretório-fila contém dois arquivos: share e backlog. Os arquivos newsched e newqueue são utilizados para criar novo diretórioescalonador e diretório-fila, respectivamente. Para alterar os parâmetros do escalonador, escreve-se no arquivo share e, para alterar a capacidade do buffer, escreve-se no arquivo backlog. Todos estes arquivos no /reserv são representados por nós reserv\{\}. A estrutura reserv \{\} mantém entre outras informações o inode \{\} do sistema de arquivo tradicional do 


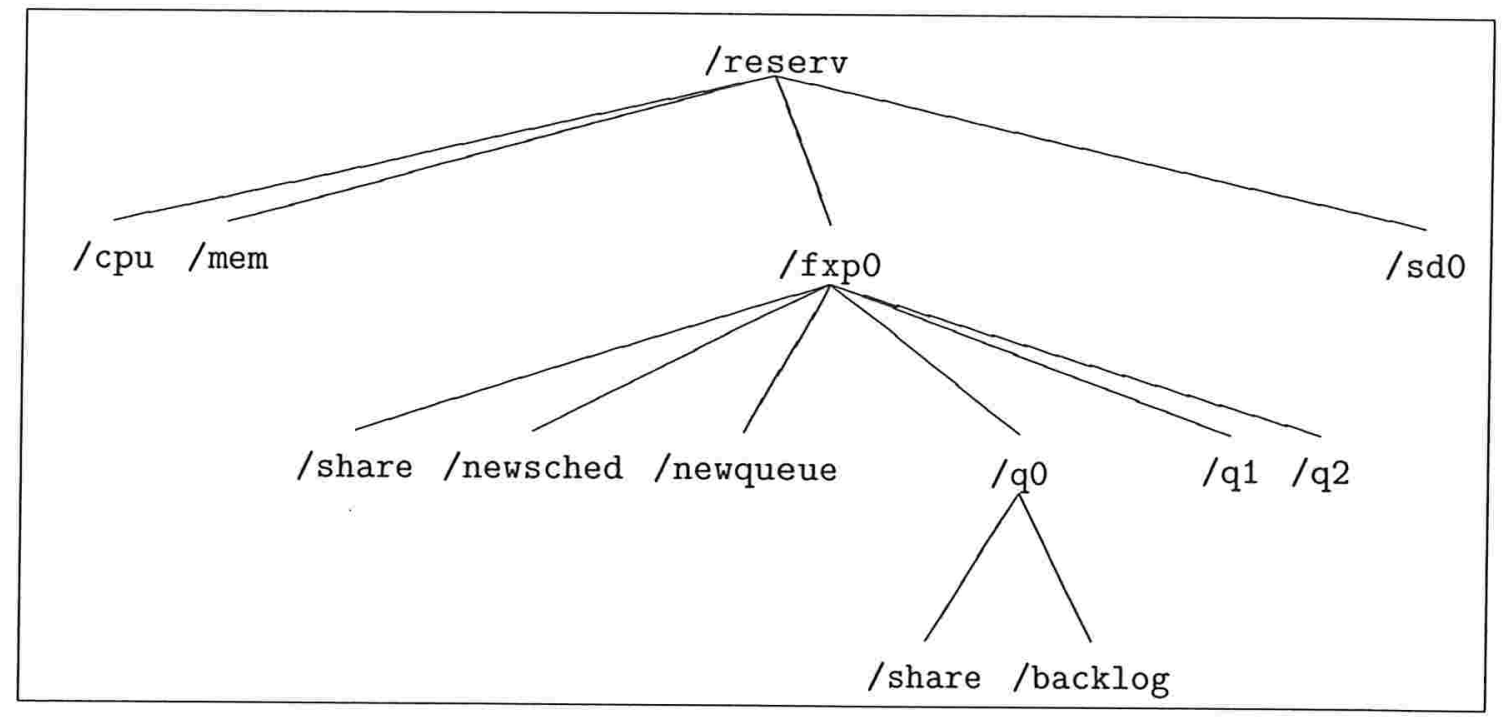

Figura 4.7: Exemplo de Diretório /reserv.

sistema Unix.

Para detalharmos o modelo na utilização destes arquivos no sistema, apresentamos a organização de uma reserva em particular, segundo os desenvolvedores:

Uma reserva de recurso $r$ é chamada de uma reserva interna se pode ter descendente ou uma fila. Se uma reserva de recurso $\mathrm{p}$ é ascendente de $\mathrm{r}$ então $\mathrm{p}$ é sempre um /reserv ou outra reserva para o mesmo recurso. Cada reserva de recurso $r$ contém um arquivo share. $\mathrm{O}$ arquivo $r$ /share especifica dois valores: $\phi_{r}$ - o peso com o qual $r$ estabelece a porção do recurso disponível de $\mathrm{p}$, isto é, com o qual $\mathrm{r}$ compartilha $\mathrm{p}$ e $m_{\mathrm{r}}$ - um valor absoluto correspondente ao mínimo garantido, ou seja, ao mínimo valor dos recursos que $r$ obtém de p. $m_{\mathrm{r}}$ é especificado nas unidades apropriadas ao recurso $\mathrm{r}$ (por exemplo, bytes para memória física, kbps para interfaces de rede). Se p é /reserv então $m_{\mathrm{r}}=V$, onde $V$ é a capacidade total do recurso e $\phi_{\mathrm{r}}=100 \%$. A quantidade de recursos aquinhoada para uma reserva $r, v_{\mathrm{r}}$, depende dinamicamente de quais reservas estão sendo utilizadas no momento. Toda requisição chegando a um escalonador precisa especificar uma fila para processamento desta requisição; a requisição usa a fila especificada. Os escalonadores enfileiram e servem na ordem FIFO as requisições numa mesma fila. Uma reserva de recurso $r$ é dita ocupada enquanto há pelo menos uma requisição que utiliza $r$ ou um descendente de $r$.

Se uma reserva de recurso $r$ é interna, então também contém os arquivos newsched e newqueue. Através da chamada de sistema open() para qualquer destes arquivos, uma aplicação cria uma reserva interna ou fila que é descendente de $r$, respectivamente. A chamada de sistema open() retorna um descritor de arquivo para o novo arquivo criado share, iniciado com $m_{\mathrm{r}}=0$ e $\phi_{\mathrm{r}}=0$. As reservas internas assim criadas são consecutivamente numeradas $r 0, r 1, \cdots$, as filas são numeradas $q 0, q 1, \cdots$.

Se uma reserva de recurso $\mathrm{r}$ é um diretório-fila, então também contém o arquivo backlog. 
Escrevendo no arquivo backlog limpa-se o número de requisições servidas e a quantidade de serviço provida, e coloca-se o número máximo de requisições e a quantidade de serviço que pode concorrentemente estar esperando na fila. Lendo do arquivo backlog retorna-se o número de requisições servidas e a quantidade de serviço provido (numa unidade correspondente a do recurso).

O Eclipse/BSD controla as reservas para que não excedam a capacidade do recurso. Seja $S_{\mathrm{p}}$ o conjunto dos descendentes de p e $M_{S_{\mathrm{p}}}=\sum_{i \in S_{\mathrm{p}}} m_{i}$. Então, ao se escrever no arquivo share de $r \in S_{\mathrm{p}}$, sujeita-se à seguinte regra de controle de admissão: ocorre a falha se p é /reserv (isto é, o total de recurso possui um valor fixo), $m_{\mathrm{p}}<M_{S_{\mathrm{p}}}$ (isto é, um mínimo dos recursos do ascendente de $p$ precisa ser menor ou igual à soma de seus descendentes mínimos após a escrita ser atendida), ou $\phi_{\mathrm{r}}<0$ (isto é, os pesos não podem ser negativos).

O Eclipse/BSD compartilha os recursos com justiça, de acordo com os pesos das reservas ocupadas. Se a reserva de recurso r está desocupada, então $v_{\mathrm{r}}=0$. Por outro lado, se $\mathrm{p}$ é ascendente de $\mathrm{r}, B_{\mathrm{p}}$ o conjunto dos descendentes ocupados de $\mathrm{p}$, e $\Phi_{B_{\mathrm{p}}}=\sum_{i \in B_{\mathrm{p}}} \phi_{i}$. Se p é /reserv, então $v_{\mathrm{r}}=V$, onde $V$ é a capacidade total do recurso, senão $v_{\mathrm{r}}=\frac{\phi_{\mathrm{r}}}{\Phi_{B_{p}}} v_{p}$.

Em resumo, uma reserva corresponde a um nó num escalonador do recurso e representa uma cota deste recurso a ser utilizada pelo algoritmo de escalonamento. Através da API /reserv temos a organização e a estrutura da reserva onde podemos criar um novo diretórioescalonador ou diretório-fila (utilizando os arquivos newsched e newqueue), trocar parâmetros do escalonador (alterando o arquivo share) e modificar a capacidade do buffer (alterando os arquivos backlog).

\section{Reservas de Domínios}

O controle de acesso e de admissão aplicados ao sistema de arquivo /reserv oferece uma oportunidade para definir uma noção de reserva de domínio. De forma abstrata, o controle de acesso e de admissão são utilizados para restringir o acesso, a utilização, e/ou reconfiguração do sistema de arquivo /reserv. Uma vez que o sistema de arquivo /reserv é o centro de todo gerenciamento no Eclipse/BSD, o conjunto instantâneo de todos os direitos adiquiridos por um processo para utilizar, acessar, e/ou reconfigurar o sistema de arquivo /reserv é chamado de reserva de dominio do processo. Neste esquema, as credenciais do processo incluem o PID bem como UID e GID. O controle de acesso e de admissão oferece restrições e direitos no uso dos diretórios-fila para: etiquetagem, a criação de novas reservas, mudança de pesos de escalonamento e/ou capacidade das filas, colocação de em flags para coleta de lixo, etc. Esta noção de uma reserva de domínio ${ }^{13}$ é particularmente útil no modelo cliente-servidor onde um controle apurado sobre o uso dos recursos é necessário. Em suma, a reserva de domínio de um processo determina sua habilidade para manipular e utilizar o sistema de arquivo /reserv.

No Eclipse/BSD, uma reserva de domínio do processo $P$ é uma lista de reservas-raiz internas de $P$, uma para cada recurso. A fila $q 0$ da reserva-raiz $\mathrm{r}$ do processo $P$ é chamada fila default para o respectivo recurso. Um processo $P$ pode listar qualquer diretório sob o /reserv e abre

\footnotetext{
${ }^{13}$ Podemos observar que o conceito de reserva de domínio aqui é algo diferente do utilizado na Eclipse/Plan9.
} 
e lê qualquer arquivo share ou backlog, porém escreve nos arquivos share ou backlog ou abre os arquivos newsched ou newqueue (isto é, cria descendentes) apenas em reservas que são iguais ou descendentes de uma das reservas-raiz de $P$.

A reserva de domínio do processo pid é representada por um novo arquivo read-only, $\mathrm{proc} / \mathrm{pid} / \mathrm{rdom}$, adicionado ao sistema de arquivo proc do FreeBSD (onde rdom entende-se por reserva de domínio). Por exemplo, o arquivo /proc/103/rdom poderia conter:

\section{/reserv/cpu/r2, /reserv/mem/r1, /reserv/fxp0/r0 e /reserv/sdo/r3}

significando que o processo 103 tem a reserva-raiz de CPU r2, de memória $r 1$, de rede r0 e de disco r3. Se o processo 104 tem a mesma reserva de domínio do processo 103, /proc/104/rdom tem o mesmo conteúdo. A reserva de domínio do processo corrente chamase /proc/curproc/rdom.

A reserva de domínio de processos criados por um processo pid é dada por um novo arquivo /proc/pid/crdom (onde crdom significa "reserva de domínio descendente"). Quando um descendente é criado, seus arquivos rdom e crdom são iniciados com o conteúdo do arquivo crdom do ascendente. $\mathrm{O}$ arquivo /proc/pid/crdom é gravável por qualquer processo pid com o mesmo usuário efetivo id como deste processo pid ou por um super-usuário. Escrevendo nos arquivos crdom, para cada reserva-raiz $\mathrm{r}$ em /proc/pid/rdom, /proc/pid/crdom deve conter uma reserva interna $r$ ' que é igual ou descendente de $r$.

A destruição das reservas de domínios não referenciadas é feita pelo coletor de lixo. (O Eclipse/BSD $\left[\mathrm{BBM}^{+} 99\right]$ possui o coletor de lixo.)

\section{Etiquetagem e lista default}

No Eclipse/BSD, toda requisição que chega a um escalonador de recurso precisa ser etiquetada com um ponteiro para um nó-fila utilizada para esta requisição. A etiqueta é utilizada para rapidamente localizar a fila a qual a requisição pertence.

As reservas de recurso sempre não podem estar simplesmente associadas com objetos compartilhados porque requisições de clientes distintos podem especificar o mesmo objeto, mesmo estando em filas diferentes. Por exemplo, dois processos pertencentes à reserva de domínio diferente e que necessitam utilizar filas diferentes do disco para acessarem um arquivo compartilhado, ou uma fila diferente de link de saída de rede para enviar pacotes sobre um socket compartilhado.Torna-se difícil compor reservas utilizadas no mesmo objeto corretamente se reservas são associadas com o objeto, desde então um cliente poderia ser beneficiado por reservas de outros clientes.

Conseqüentemente, as filas no Eclipse/BSD estão associadas com referências a objetos compartilhados, tanto mais que entre eles próprios. Isso é efetuado através da modificação das seguintes estruturas de dados do FreeBSD:

- O escalonador de CPU gerencia ativações em vez de processos. Uma ativação aponta para um processo e para a fila de CPU na qual o processo executa. 
- A estrutura da região da memória aponta para o objeto da região da memória e fila da memória.

- A estrutura do descritor de arquivo aponta para o arquivo (e desse modo para o vnode ou socket) e para a fila do dispositivo utilizado para I/O para este descritor.

Um importante aspecto desta proposta é a associação de uma reserva (diretório-fila) com uma operação sobre um objeto. As operações sobre objetos incluem: ler/escrever um arquivo, enviar uma mensagem para um socket e executar um thread (um processo no FreeBSD) As reservas correspondentes são largura de banda de disco, largura de banda de interface de transmissão de rede e ciclos de CPU, respectivamente.

No caso de um arquivo $f$, etiqueta-se um descritor de arquivo para $f$ com uma reserva. A reserva precisa ter um diretório-fila para o dispositivo onde $\mathrm{f}$ reside. Para um socket conectado $\mathrm{s}$, etiqueta-se um descritor de arquivo para s com uma reserva. A reserva precisa ter uma diretório-fila para a interface de rede utilizada pelos pacotes de s. Recorre-se ao mecanismo de etiquetagem mais tarde, quando se deseja desconectar a interface e o endereço de destino não é conhecido. No caso de processos escalonados, etiqueta-se cada processo com uma reserva de CPU e provê um mecanismo para trocar a etiqueta dinamicamente.

As etiquetas são utilizadas para determinar a fila apropriada para requisições de I/O baseadas nos descritores de arquivo etiquetados. Por exemplo, se fd é um descritor de arquivo etiquetado com a diretório-fila q, então todo I/O baseado no fd será enfileirado no nó-fila correspondente ao diretório-fila q. A etiqueta de um descritor de arquivo pode ser explicitamente designado ou lido por uma nova chamada de sistema fcntl com novos comandos: F_SET_QUEUE, para explicitamente designar uma etiqueta de descritor de arquivo, e F_GET_QUEUE, para obter o nome do diretório-fila correspondente à etiqueta correntemente associada com o descritor de arquivo. As etiquetas de descritor de arquivo são utilizadas nas chamadas de sistema read(), write(), sendto() e sendmsg() para determinar a etiqueta da fila da requisição que chega ao escalonador do recurso Se for um I/O de disco, então as estruturas buf \{\} representando I/O resultando de operações de leitura/escrita baseada no fd será incluída uma referência à fila apropriada. Similarmente, um processo etiquetado será escalonado da fila de cpu correspondente.

Um diretório-fila representa um nó-fila num escalonador e as requisições nela contidas obterão a QoS especificada para esse nó-fila. O mecanismo de etiquetagem possibilita associar diretório-fila com descritor de arquivo e com os processos e suporta QoS para operações destes objetos. A atribuição de reservas para objetos é flexível. As reservas podem ser compartilhadas por um ou mais objetos (a mesma etiqueta pode estar associada a descritores de arquivos distintos representando diferentes arquivos) e um arquivo pode estar associado com mais de uma reserva (diferentes etiquetas para um mesmo descritor de arquivo).

Os ponteiros para as filas dos recursos são sempre iniciados apontando para a fila default do processo para o respectivo recurso. Os ponteiros para filas podem ser subseqëntemente modificados apenas por descendentes da reserva-raiz do processo para o respectivo recurso, o que ocorre quando inicializa ativação na CPU, aloca memória ou fd é inicializado. Assim, a lista default de um processo é uma lista de etiquetas vnode \{\} , uma para cada nó inicial dos diretórios-fila criados para cada recurso. A lista default de um processo é utilizada para 
atribuir etiquetas automaticamente quando uma etiqueta não é designada de outra maneira. A lista default de um processo PID é representado como um novo arquivo /proc/PID/default que contém as etiquetas. Lendo o arquivo default retorna-se os nomes dos diretórios-fila correspondentes às etiquetas, por exemplo /reserv/cpu/q2, /reserv/wd0/r1/q0.

Quando um processo utiliza as chamadas de sistema open(), accept() ou connect(), o kernel automaticamente etiquetará o descritor de arquivo com a etiqueta para o recurso correntemente listado na lista default do processo.

Em tempo de boot, após a chamada da função start(priv, root) e o sistema de arquivo /reserv ser montado, a lista default do processo init contém as etiquetas para cada diretóriofila criada para cada recurso.

A destruição das etiquetas não referenciadas é feita pelo coletor de lixo.

\section{A Interface de um Escalonador de Recurso}

Aqui descrevemos a interface que um escalonador de recurso precisa prover ao kernel a fim de "participar" do sistema de arquivo /reserv. O sistema de arquivo /reserv se comunica com um escalonador de recurso exclusivamente através dessa interface. Os escalonadores precisam "registrar" em tempo de boot um conjunto de rotinas de interface para o kernel. O registro consiste na utilização da reservfs_register() para passar ponteiros para as rotinas de interface e um valor de pointer opaque (void *) para o kernel. O sistema mantém uma Device Translation Table (DTT) que contém a informação do registro de cada escalonador de recurso. $\mathrm{O}$ valor do opaque pointer (priv) é passado como um argumento sempre que o kernel utiliza uma das funções de interface. As funções de interface providas pelos escalonadores para o kernel, utilizando reservfs_register(), incluem:

init(priv): O kernel chama esta função sempre que inicia o processo de boot e após qualquer nó-escalonador ou nó-fila seja criado. O escalonador de recurso tem a chance de alocar e inicializar qualquer estrutura de dados que necessite antes de qualquer chamada create(). $\mathrm{O}$ parâmetro priv é obtido pelo kernel durante o registro.

create(priv, parent, type): Uma chamada para esta função retorna um ponteiro opaque pointer para um novo nó-escalonador ou nó-fila (determinado pelo type: SCHED ou QUEUE, respectivamente). O parâmetro parent é um opaque pointer para um nó-escalonador criado anteriormente que será o ancestral imediato do nó-escalonador ou nó-fila recentemente criado. Se parent é null, então o nó-escalonador recentemente criado é considerado o nó-escalonador raiz do escalonador de recurso.

start(priv, root): Esta função é chamada pelo kernel após todos os nós iniciais serem criados (pelo menos o nó-escalonador root e uma fila) e é utilizada para iniciar o escalonamento das requisições etiquetadas para este recurso.

delete(priv, node): Esta função é chamada para remover node, onde node é um ponteiro opaque 
pointer para um nó-escalonador ou para um nó-fila. A deleção imediata pode requerer um fluxo de requisições pendentes. Se o escalonador de recurso não puder efetuar a remoção imediatamente (por exemplo, o escalonador de rede precisa continuar enviando pacotes previamente enfileirados), o escalonador de recurso pode indicar o sucesso da remoção sempre que a remoção recente seja colocada após todas as requisições pendentes serem servidas. Caso contrário, a função pode retornar uma indicação de que não foi possível no momento e, neste caso, o kernel chamará delete novamente mais tarde.

get/set(priv, node, values, type): Estas funções permitem ao kernel a alteração dos parâmetros do escalonador. A API interpreta values diferentemente dependendo do escalonador do recurso, do argumento type, e da referência do node (nó-escalonador ou nó-fila). O resultado de um conjunto de operações permite a sua rejeição (controle de admissão).

As funções de interface create(), delete() e set() não devem interferir com a operação do escalonador; podem ser chamadas quando o escalonador do recurso estiver executando.

Para o sistema inicializar o /reserv: A inicialização do /reserv ocorre sempre que os escalonadores dos recursos são registrados e após todo sistema de arquivo ser montado. $\mathrm{O}$ kernel chama a função init (priv) para todo escalonador de recurso registrado no DTT ${ }^{14}$, dando a oportunidade a cada escalonador de alocar e iniciar qualquer estrutura de dados interna. Em seguida, o kernel cria um nó reserv\{\} para o diretório-raiz do sistema de arquivo /reserv. Cria mais dois nós reserv\{\} para cada escalonador de recurso: um para o diretório-raiz do escalonador e outro para um diretório-fila no diretório-raiz do escalonador. Em seguida, o kernel cria nós reserv\{\} para os arquivos share em cada diretório, o arquivo backlog no diretório-fila, e os arquivos newqueue e newsched no diretório-escalonador. Para cada escalonador de recurso, o kernel chama create(priv, root, SCHED) para criar o nó-raiz do escalonador, root, e chama create(priv, root, QUEUE) para criar um nó-fila. A seguir, cria os diretórios subseqüentes, e assim sucessivamente para cada escalonador de recurso. Finalmente, o registra utilizando a função start(priv, root). Neste ponto o kernel está apto a utilizar os nós-fila de todos os escalonadores.

O acesso à API do /reserv é feito através da interface do sistema de arquivo vnode/vfs do FreeBSD. Oa dados dependentes do sistema de arquivo /reserv corresponde aos nós reserv\{\} e os sistemas de arquivo dependente vnodeops e vfsops foram implementados para suportar a API do /reserv. As operações do sistema de arquivo não podem ser feitas até que o sistema de arquivo /reserv seja montado. Após a inicialização do sistema, um vnode \{\} é criado para a raiz do sistema de arquivo/reserv e montado sobre o /reserv. Deste ponto em diante, a API do /reserv está disponível.

\section{Controle de Acesso}

Um processo pode efetuar diversas operações no arquivo /reserv. Os processos são definidos com credenciais que determinam quais são as operações permitidas; as do padrão Unix não são suficientes para construir o mecanismo de controle do /reserv. Por exemplo no

\footnotetext{
${ }^{14}$ Device Translation Table
} 
Unix, os subprocessos são todos criados com as mesmas credenciais.

De forma abstrata, a política de controle de acesso é representada por uma matriz, ACC, de elementos (processos credenciados) e objetos do /reserv (diretório-escalonador, fila compartilhada, etc.). Uma entrada denotada $\operatorname{ACC}[S, O]$ é uma lista de operações permitidas ao elemento $S$ no objeto $O$. Há uma lista de processos associada com uma entrada da matriz ACC[] designando a estes processos as suas permissões $S$ aos objetos $O$. O acesso permitido a um processo com a credencial $S$ está representado pela coluna $S$ de acesso desta matriz. As operações especificadas em $\operatorname{ACC}[S$, ,.] são exatamente aquelas que são disponíveis para $S$ (sujeitas às restrições adicionais de controle de admissão). Conceitualmente, identifica-se a reserva de domínio de um processo com seus correspondentes na coluna da matriz.

\section{Controle de Admissão}

Sejam dir um diretório-escalonador e $d_{1}, d_{2}, \cdots, d_{n}$ seus subdiretórios. Seja $s_{j}$ o arquivo share de $d_{j}$, contendo: $w_{j}$ para o peso e $m_{j}$ para a quantidade mínima de recurso permitida.

O peso reservado para dir determina como o ciclo de serviço do recurso é dividido entre os seus diretórios descendentes. Especificamente, a fração do recurso reservada para $d_{j}$ é $w_{j} / \sum_{j=1}^{n} w_{j}$.

Supondo que $m$ é a quantidade mínima de reserva garantida para dir (especificado no arquivo share), a condição $m_{j} \leq w_{j} m / \sum_{j=1}^{n} w_{j}$ é analisada para o controle de admissão para todos os diretórios que podem ser afetados quando se altera um arquivo share. Cada alteração é admissível se e somente se esta condição não for violada em qualquer reserva no /reserv.

\subsubsection{Escalonadores}

A API do /reserv provê uma interface para escalonadores do tipo proporcional ao share. O Eclipse/BSD incorpora um escalonador proporcional ao share para cada recurso.

O escalonamento da CPU utiliza a política MTR-LS [BGzS97]. Emprega o algoritmo Yet another Fair Queueing (YFQ) [BBG $\left.{ }^{+} 99 \mathrm{a}\right]$ para escalonar disco, o Worst-case Fair Queueing $\left(\mathrm{WF}^{2} \mathrm{Q}\right)$ [BZ96b] para o link de saída e o Signaled Receiver Processing (SRP) [BGS] para processos de entrada em rede.

\section{Abordagem do Escalonamento de CPU}

O escalonador da CPU do Eclipse/BSD utiliza o algoritmo MTR-LS (Seção 2.1.10), um exemplo de escalonador proporcional ao share. Quando o processo é bloqueado (esperando por I/O), o MTR-LS coloca a porção não utilizada da sua cota de processamento na mesma posição da lista de escalonamento, diferentemente do algoritmo WRR (Seção 3.3), que remove o processo da fila de prontos e, quando o processo torna-se executável novamente, é colocado 
no final da lista. Conseqüentemente, o MTR-LS pode atrasar muito menos os processos I/Obound do que o WRR. O MTR-LS pode também prover throughput maior do que o WRR, cujos atrasos no escalonamento pode impedir que processos I/O-bound utilizem totalmente suas reservas de CPU.

O MTR-LS foi especificamente designado para o escalonamento de CPU onde o tempo necessário para processar uma requisição não pode ser previsível. Os autores consideram o MTR-LS o único algoritmo até o momento que provê a garantia ótima de serviço cumulativo quando as durações dos serviços requisitados são desconhecidas a priori.

Entretanto, a política MTR-LS assume que as requisições podem ser bloqueadas a qualquer instante ou a intervalos de tempo fixos, o que acontece no escalonamento de CPU e não é usual em disco ou rede, onde uma requisição não pode ser bloqueada após iniciada e pode ter tempo variado para se completar. Por conseguinte, o Eclipse/BSD utiliza outros algoritmos para o escalonamento de I/O.

\section{Abordagem do Escalonamento de I/O}

Os escalonadores de I/O do Eclipse/BSD usam aproximações do modelo de GPS (Generalized Processor Sharing) [PG93]. O GPS assume um sistema de fluxo ideal onde cada fluxo de solicitações no sistema recebe serviço na proporção direta do share do fluxo inversamente proporcional à soma dos shares de todos os fluxos (onde um fluxo solicitado é análogo ao de uma fila busy). O modelo ideal de GPS não pode ser implementado de forma precisa para I/O porque tipicamente (1) um servidor de I/O pode servir apenas uma requisição de cada vez e (2) uma requisição de I/O não pode ser bloqueada depois que o serviço se inicia. As aproximações de GPS estimam o tempo necessário para servir cada requisição e intercalam requisições de diferentes filas, onde cada fila recebe um serviço proporcional a seu share (embora que não instantaneamente). Entretanto, o tempo necessário estimado pode ser difícil de ser computado com precisão pois a taxa de serviço do GPS para cada fluxo depende de quais fluxos são acumulados a cada instante [BZ96a].

\section{Escalonamento de disco}

O escalonador de disco do Eclipse/BSD utiliza uma nova aproximação do GPS, o algoritmo $\mathrm{YFQ}\left[\mathrm{BBG}^{+} 99 \mathrm{a}\right]$.Trata-se de um algoritmo de escalonamento de disco para tempo real, cuja proposta é oferecer garantias de QoS sem perder totalmente o vínculo com os algoritmos convencionais. Tais qualidades de serviço buscam impedir que a utilização deste algoritmo para aplicações convencionais possa impedir otimizações globais do disco.

O YFQ trabalha com reservas de recursos de I/O procurando garantir alto rendimento no acesso aos arquivos. Diferente de outros algoritmos que têm sido propostos e que oferecem QoS [CSKT91, BZ96a, GVC96], este procura levar em consideração a interação entre recursos.

Quando uma requisição de I/O chega ao escalonador, especifica a reserva de recurso desejada. O escalonador enfileira então cada requisição $r_{i}$ que utiliza a reserva $i$, na fila $q_{i}$ 
correspondente.

Um estado é associado com cada reserva submetida ao YFQ. Uma reserva $i$ é dita busy caso possua pelo menos uma requisição de I/O solicitando seu serviço ou esperando na fila $q_{i}$ (possui pelo menos uma fila busy). Caso contrário, a reserva é dita idle. Um recurso por sua vez é considerado busy se estiver vinculado a no mínimo uma reserva busy. Caso contrário, também é dado por idle.

Para o controle das reservas, o YFQ associa uma etiqueta-de-início, $S_{i}$, e uma etiqueta-defim, $F_{i}$, a cada fila $q_{i}$. Estas duas etiquetas, $S_{i}$ e $F_{i}$, são inicialmente zero.

$\mathrm{O}$ YFQ define uma função de trabalho virtual dada por $v(t)$, tal que:

(1) $v(0)=0$;

(2) enquanto um recurso está busy, $v(t)$ é o mínimo valor das etiquetas-de-início das filas busy no tempo $t$; e

(3) quando o recurso passa ao estado $i d l e, v(t)$ recebe o máximo valor de todas as etiquetasde-fim do recurso.

Ao chegar uma nova requisição $r_{i}$ que utiliza uma fila busy $q_{i}$ :

(1) se a fila $q_{i}$ estiver vazia, o YFQ faz $S_{i}=\max \left(v(t), F_{i}\right)$ seguido por $F_{i}=S_{i}+\frac{l_{i}}{w_{i}}$ onde $l_{i}$ é o comprimento dos dados da requisição $r_{i}$ e $w_{i}$ é o peso da fila $q_{i}$; e

(2) esta nova requisição $r_{i}$ é inserida no final da fila $q_{i}$.

O YFQ seleciona a requisição $r_{i}$ do topo da fila busy $q_{i}$ com menor etiqueta-de-fim, $F_{i}$. A requisição $r_{i}$ permanece no topo da fila enquanto o serviço solicitado estiver em execução. Quando este serviço se completar, o YFQ retira a requisição da fila e, se a fila não estiver vazia, faz $S_{i}=F_{i}$ e depois altera o valor de $F_{i}$ pela equação $F_{i}=S_{i}+\frac{l_{i}^{\prime}}{w_{i}^{\prime}}$, onde $l_{i}^{\prime}$ e $w_{i}^{\prime}$ são os dados de comprimento e peso, respectivamente, da requisição $r_{i}^{\prime}$ agora no topo da fila $q_{i}$.

Selecionando uma requisição por vez, o YFQ aproxima-se do GPS, provendo garantias de serviço cumulativo, de atraso e de justiça. Para se evitar custos em latência, pode-se configurar uma opção que seleciona as requisições batch numa fila ordenada. O dispositivo pode reordenar as requisições minimizando a latência.

\section{Abordagem do Escalonamento de link de Saída}

O escalonador de link de saída de rede do Eclipse/BSD utiliza o algoritmo hierárquico WF $^{2} \mathrm{Q}$ (Worst-case Fair Weighted Fair Queuing) [BZ96b]. Este algoritmo é similar a uma aproximação anterior do GPS, o WFQ (Página 30). Entretanto, diferentemente do WFQ, o $W^{2} \mathrm{Q}$ não escalona um pacote até ser elegivel, ou seja, até que sua transmissão comece sob GPS. Esta implementação mantém uma simulação GPS enquanto permite

(i) a inserção e remoção de nós para os escalonadores hieráquicos,

(ii) a mudança de peso do escalonador, e

(iii) um ajuste automático no trabalho virtual e escalas de tempo durante períodos longos de ocupação do recurso,

fazendo com que o $\mathrm{WF}^{2} \mathrm{Q}$ tenha ótimo limite justo de pior caso, obtendo uma boa escolha 
para um escalonador hierárquico.

Observa-se que os algoritmos YFQ e $W^{2} \mathrm{Q}$ não devem ser utilizados para escalonar CPU pois assumem que o tempo necessário para processar uma requisição pode ser estimado e que uma requisição nunca é bloqueada.

\section{Abordagem do Escalonamento de Entrada em Rede}

O Eclipse/BSD implementa o SRP (Signaled Receiver Processing) [BGS] para o processamento de entrada da rede. Diferentemente de uma simples fila de entrada IP do FreeBSD e do protocolo de entrada processando em nível de interrupção da aplicação, o SRP utiliza uma UIQ (Unprocessed Input Queue) por socket e processa protocolos de entrada no contexto das respectivas aplicações. Se a fila do socket está cheia, suspende novo pacote para este socket imediatamente, o que não ocorre no FreeBSD que de modo devastador processa pacotes que deveriam estar suspensos. Como o SRP processa protocolos de entrada no contexto das respectivas aplicações, SRP pode evitar receive livelock, uma condição de sobrecarga de entrada de rede que evita que qualquer pacote seja processado por uma aplicação.

Quando enfileira um pacote na UIQ de um socket, o SRP sinaliza (SIGUIQ) para a aplicação que se apropriou deste socket. A ação padrão deste sinal é processar o protocolo de entrada. Contudo, as aplicações podem sincronizar cada processamento capturando o sinal SIGUIQ e retardando o processamento do protocolo até uma chamada de entrada posterior.

\subsubsection{Resultados Experimentais}

Nos trabalhos $\left[\mathrm{BBM}^{+} 99, \mathrm{BBG}^{+} 99 \mathrm{~b}\right]$, Silberschatz et al. apresentam experimentos que indicam que aplicações podem utilizar a API do /reserv do Eclipse/BSD e os escalonadores de $\mathrm{CPU}$, disco e rede tal que obtenham garantias mínimas de desempenho, indiferentemente de outra carga no sistema.

Os experimentos foram executados sobre a configuração mostrada na Figura 4.8, onde clientes HTTP nos nós $A, B, C$ e $D$ fazem requisições para o servidor HTTP no nó $S$. Os nós de $A$ a $D$ executam FreeBSD. O sistema operacional varia apenas no nó $S$, sendo ou FreeBSD ou Eclipse/BSD. Todos os nós estão conectados por um switch. O nó $S$ executa um servidor HTTP Apache 1.3.3 e hospeda múltiplos sites Web. Os nós $A$ a $D$ executam aplicações dos clientes que fazem requisições ao servidor.

A seguir, destacamos algumas abordagens consideradas nos experimentos e comentamos sucintamente os resultados obtidos.

\section{(a) Contemplando a Utilização da CPU}

Neste experimento, um número crescente de clientes fazem requisições CGI a um de dois dos sites Web em $S$, continuamente. O processamento de cada uma destas requisições CGI consiste da computação de quinhentos números aleatórios retornando $1 \mathrm{~KB}$ como resposta. 


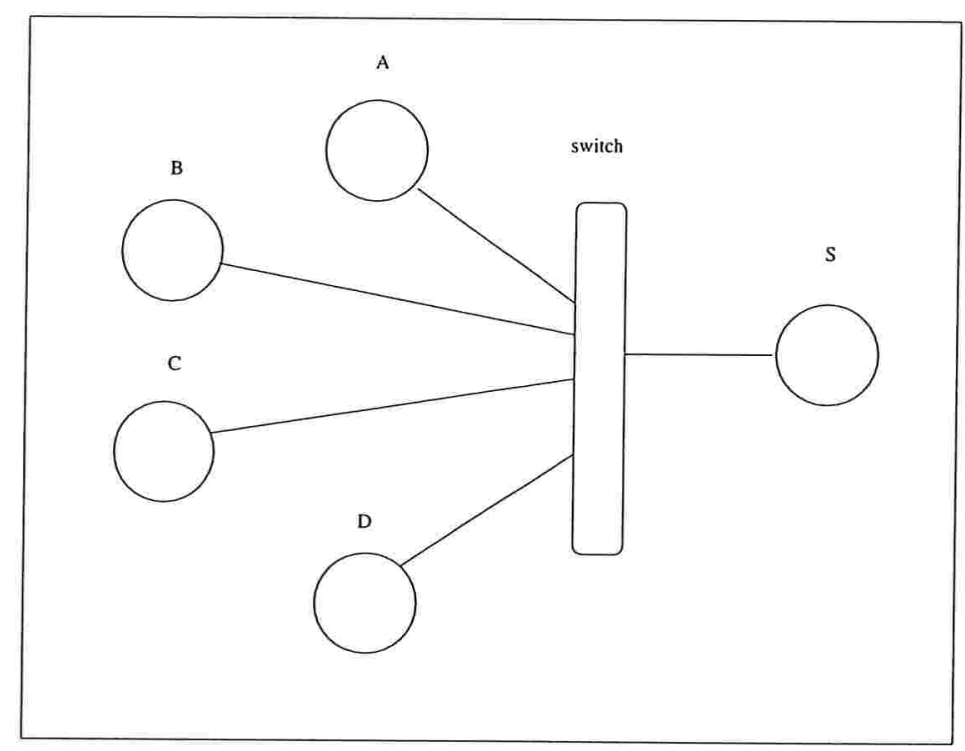

Figura 4.8: Configuração para os Experimentos.

Portanto, o recurso a ser analisado é a CPU. Foram medidas as médias de throughput e tempo de resposta (sobre três minutos) para os seguintes cenários:

(a) o nó $S$ submetido ao Eclipse/BSD e o site de interesse reserva $50 \%$ de CPU e o site de competição reserva $49 \%$;

(b) o nó $S$ submetido ao Eclipse/BSD e o site de interesse reserva $99 \%$ de CPU;

(c) o nó $S$ submetido ao Eclipse/BSD e ambos os sites executam na mesma reserva de CPU e a reserva é de $99 \%$ de CPU e

(d) o nó $S$ submetido ao FreeBSD.

A Figura 4.9 mostra o throughput do site de interesse quando o site de interesse possui 10 clientes e o site de competição tem um número de clientes variado, e a Figura 4.10 mostra os tempos de resposta correspondentes.

Quando o site de interesse reserva $50 \%$ de CPU (cenário a), o desempenho é ótimo sem carga adicional, mas, como era esperado, o throughput cai pela metade e o tempo de resposta dobra quando há pelo menos um cliente do site de competição. Porém, o throughput e o tempo de resposta do site de interesse permanece constante quando mais clientes do site de competição são adicionados, enquanto que no FreeBSD o throughput decresce e o tempo de resposta cresce sem limite.

Quando o site de interesse reserva 99\% de CPU (cenário b), seu desempenho não é afetado com o aumento do número de clientes do site de competição. 
Observa-se em ambas as figuras que o desempenho é o mesmo para os cenários $c$ e $d$, ou seja, quando os sites executam na mesma reserva no Eclipse/BSD, e quando executam no FreeBSD.

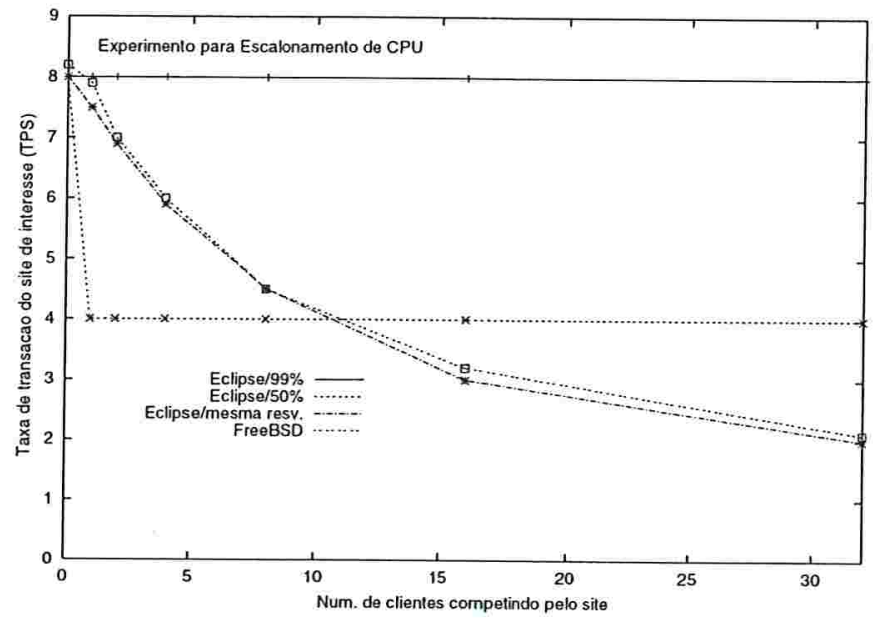

Figura 4.9: Throughput para o site de Interesse.

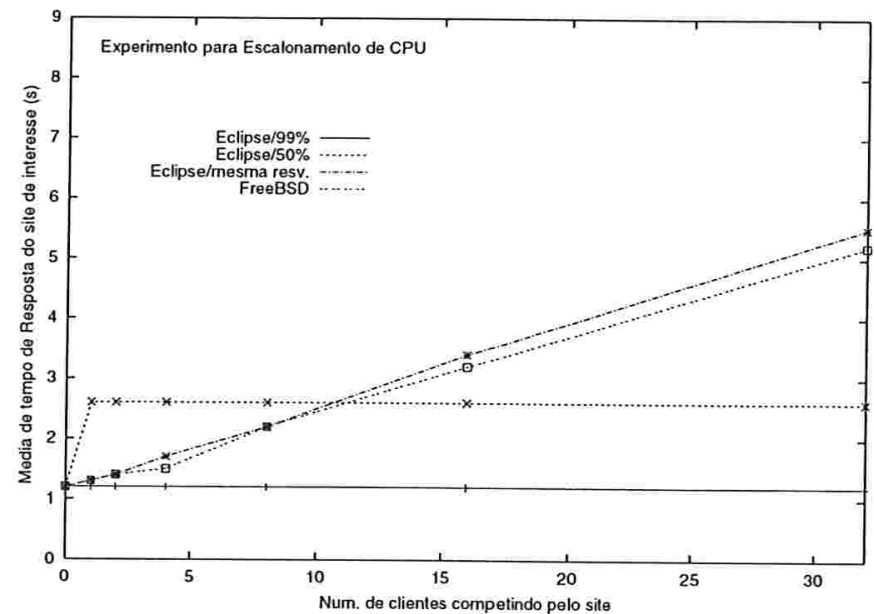

Figura 4.10: Tempos de Resposta para o site de Interesse.

Foi constatado que ambos os sistemas operacionais, o FreeBSDe o Eclipse/BSD, são igualmente bons se há excesso do recurso (da capacidade de CPU), mas o Eclipse/BSD pode também garantir uma certa alocação mínima de CPU (e, conseqüentemente, mínimo throughput e máximo tempo de resposta). 


\section{(b) Contemplando a Utilização de Disco}

Neste experimento, um crescente número de clientes continuamente fazem requisições CGI a um de dois dos sites Web em $S$. Entretanto, estas requisições são de I/O intenso, consistindo da leitura de $100 \mathrm{MB}$ e o retorno de um arquivo de 10KB. Como a quantidade de dados na requisição e resposta são pequenos, e cada requisição envolve considerável I/O de disco e pouco processamento, pode-se analisar o escalonamento do disco. Foi reservado $50 \%$ da largura de banda do disco de $S$ para o site de interesse e mediu-se o throughput médio para três minutos. A classificação da fila do YFQ foi configurada com um tamanho de 4 requisições. Durante as medições, o site de interesse mantinha 10 clientes e o site de competição, um número variado de clientes. A Figura 4.11 mostra que na ausência de clientes do site de competição, o Eclipse/BSD oferece ao site de interesse essencialmente todo o recurso de disco, mesmo o site tendo apenas $50 \%$ de reserva. Quando o número de clientes do site de competição aumenta, o throughput do site de interesse decresce. Porém, no Eclipse/BSD, o throughput baseia-se na quantidade reservada, enquanto que no FreeBSD o throughput decresce sem limite.

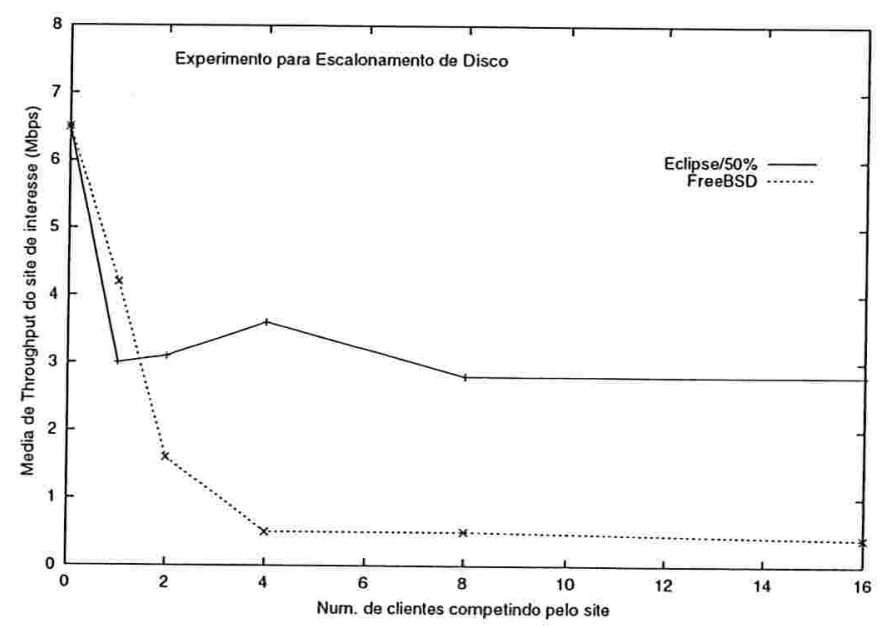

Figura 4.11: O site de Interesse diante da Largura de Banda do Disco.

O experimento indica que Eclipse/BSD e FreeBSD são igualmente bons quando há largura de banda de disco em excesso, mas quando ela é escassa, o Eclipse/BSD é capaz de garantir uma alocação mínima de largura de banda de disco.

\section{(c) Contemplando a Utilização de Link de Saída}

Neste experimento, um crescente número de clientes continuamente requisitam o mesmo documento de 1.5MB de um de dois dos sites Web em $S$. Dado que as requisições são muito menores que as respostas ${ }^{15}$, um pequeno processamento é requerido por requisição, e o documento requisitado é armazenado facilmente no buffer cache de $S$, o recurso a ser analisado é o

\footnotetext{
${ }^{15}$ No experimento, todos os nós são conectados por um switch Lucent P550 Cajun Ethernet a 100Mbps.
} 
link de saída de rede em $S$. Reservou-se $50 \%$ da largura de banda do link de saída de $S$ para o site de interesse e mediu-se a média de throughput sobre três minutos. Durante as medições, o site de interesse manteve 10 clientes e o site de competição possuia um número variado de clientes. Observa-se que os resultados apresentados na Figura 4.12 são muito similares aos obtidos na análise do escalonamento do disco (Figura 4.11).

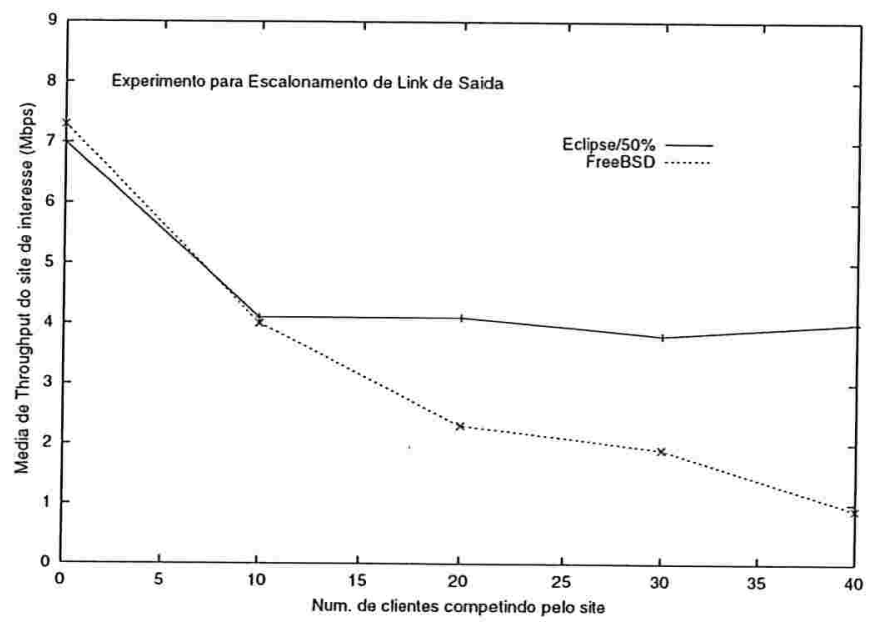

Figura 4.12: O site de Interesse diante da Largura de Banda do Link de Saída.

O experimento indica que Eclipse/BSD e FreeBSD são igualmente bons quando há largura de banda de link de saída em excesso, mas quando ela é escassa, o Eclipse/BSD é capaz de garantir uma alocação mínima de largura de banda de link de saída.

\section{(d) Contemplando a Utilização de Link de Entrada}

Foram efetuados dois experimentos analisando-se a recepção sobrecarregada de rede. A rede operou a 100Mbps e as medidas foram médias de 5 execuções.

No primeiro experimento, uma aplicação do cliente envia pacotes UDP de 10bytes a uma taxa fixa para uma aplicação do servidor executando no nó $S$. Tanto no Eclipse/BSD como no FreeBSD, a aplicação do servidor recebeu essencialmente todos os pacotes quando a taxa de transmissão foi em torno de 5600 pacotes por segundo (pac/s). Sobre esta taxa de transmissão, conforme pode-se observar na Figura 4.13, a taxa de recepção no Eclipse/BSD alcança um patamar em torno de 5700pac/s, enquanto que no FreeBSD, a taxa de recepção cai precipitadamente. Esse experimento indica que a aplicação no Eclipse/BSD pode obter um progresso maior sempre que houver sobrecarga na recepção da rede, enquanto que a aplicação no FreeBSD pode entrar em livelock em cada situação. O Eclipse/BSD previne a atuação de livelock devido ao SRP [BGS]. Todavia, o SRP não pode sozinho garantir que aplicações importantes obterão o progresso maior. O Eclipse/BSD pode oferecer esta garantia combinando SRP e reservas de CPU.

No segundo experimento, quatro aplicações de diferentes clientes enviam pacotes UDP de 


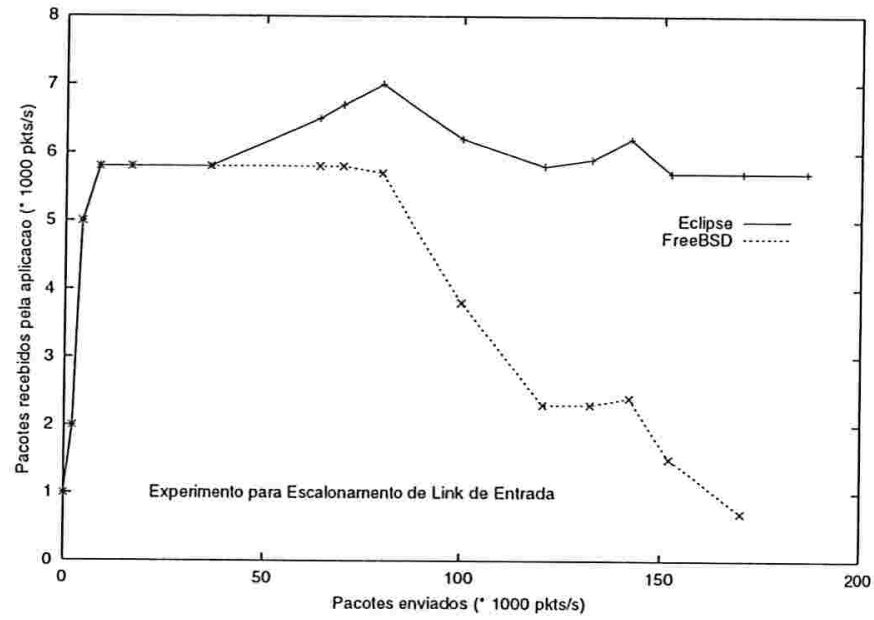

Figura 4.13: Comportamento diante do Sobrecarregamento na Recepção da Rede.

10bytes a uma mesma taxa fixa para uma aplicação diferente do servidor executando no nó $S$. Mediu-se taxas de recepção em dois cenários: (1) Todas as quatro aplicações do servidor reservaram 25\% de CPU cada; e (2) Uma aplicação do servidor reservando $97 \%$ da CPU e as aplicações restantes do servidor com $1 \%$ de reserva cada.

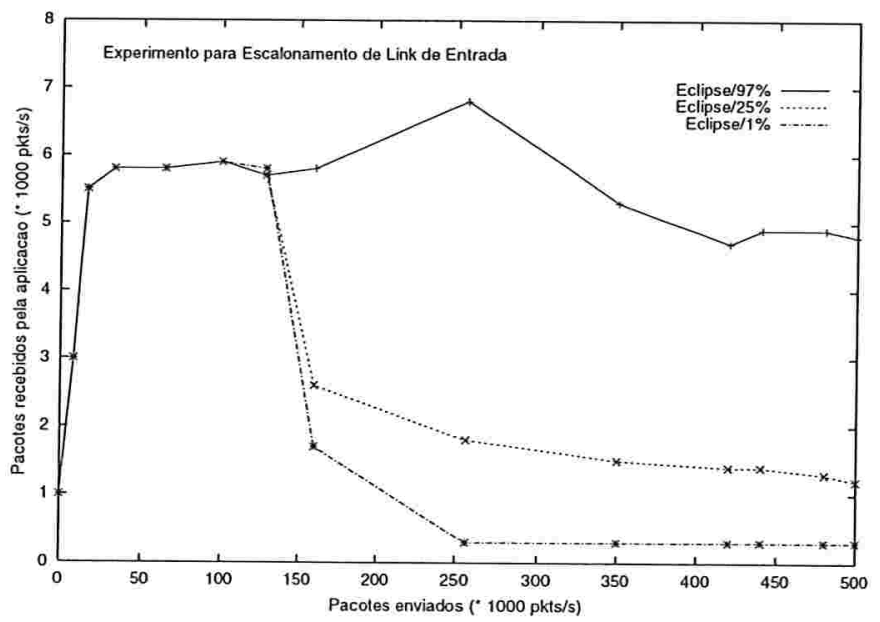

Figura 4.14: Eclipse/BSD garante progresso de acordo com a reserva de CPU.

Enquanto a taxa de recepção estava abaixo de $5600 \mathrm{pac} / \mathrm{s}$, essencialmente todos os pacotes foram recebidos. As taxas de recepção aumentaram suavemente para 5900 para uma taxa de transmissão de $28.5 \mathrm{Kpac} / \mathrm{s}$. Sob esta taxa, os resultados diferem para os dois cenários, como pode-se observar na Figura 4.14. No primeiro cenário, a taxa de recepção cai para 1200pac/s. No segundo cenário, a taxa de recepção da aplicação com $97 \%$ de reserva de CPU cai para $4800 \mathrm{pac} / \mathrm{s}$, enquanto a taxa de recepção das aplicações com $1 \%$ de reserva de CPU cai para 
$160 \mathrm{pac} / \mathrm{s}$.

\subsubsection{Conclusões}

O Eclipse/BSD aceita as mesmas systems calls, protocolos, drivers de dispositivos e aplicações do FreeBSD. Todos os comandos e aplicativos do FreeBSD executam no Eclipse/BSD. A base desta proposta está na utilização de escalonadores hierárquicos utilizando cota proporcional dos recursos. O sistema de arquivo /reserv provê uma API para manipular as reservas, podendo substituir os diferentes algoritmos implementados. Adoção de esquemas de acesso e controle de admissão associados a reservas de domínios e sua implementação no sistema de arquivo /reserv. Um mecanismo de senhas $\left[\mathrm{BBG}^{+} 99 \mathrm{a}\right]$ é utilizado para para associar reservas com operações escalonáveis.

Uma reserva corresponde a um nó num escalonador do recurso e representa uma cota deste recurso a ser utilizada pelo algoritmo de escalonamento. Através da API do /reserv tem-se a organização e a estrutura da reserva onde pode-se criar um novo diretório-escalonador ou diretório-fila (utilizando os arquivos newsched e newqueue), trocar parâmetros do escalonador (alterando o arquivo share) e modificar a capacidade do buffer (alterando os arquivos backlog).

Salienta-se que outros sistemas, tais como os citados no Capítulo 2 , especialmente os que dão ênfase aos escalonadores de tempo real, não estendem o sistema de arquivo para gerenciar recursos. Além disso, pode-se incorporar novos escalonadores ao Eclipse/BSD, registrando-os no sistema de arquivo /reserv.

Demonstrou-se experimentalmente que o Eclipse/BSD permite resguardar o desempenho de aplicações selecionadas, de sobrecarregamentos de CPU, disco, ou redes causados por outras aplicações. Esta capacidade de isolamento entre aplicações é importante para aplicações de tempo real soft, multimídia, Web e cliente-servidor distribuído. 


\section{Capítulo 5}

\section{Procedimento Experimental}

Neste capítulo descrevemos a implementação de um ambiente de simulação de políticas de escalonamento que incorporam em seu gerenciamento reservas de domínios, o rdsim.

\subsection{Introdução}

Para avaliarmos o impacto da abstração reserva de domínio para sistemas operacionais através de simulações, a nossa intenção inicial incluia a utilização de uma ferramenta já pronta, o projeto gRMA [Tre99].

O gRMA v0.01a é um arcabouço para simulação de aplicações de tempo real, um produto com fonte aberto, em sua versão alpha, originalmente criado por Sam Tregar em meados de 1999. O gRMA v0.01a é "software free" no sentido que pode ser copiado, utilizado de qualquer forma e redistribuído sem nenhuma restrição. Desenvolvido e modificado nos termos do "GNU General Public License" [Fou] redistribuído, implementado em Perl/Tk [per99]. O gRMA é um projeto para aplicações que efetuam Rate Monotonic Analysis (RMA) [LL73, SG91] de sistemas de tempo real. O gRMA v0.01a consiste de uma GUI ${ }^{1}$ onde pode-se especificar um sistema composto de ambiente computacional e de aplicações de tempo real, possuindo uma interface que apresenta os resultados da análise desse sistema simulado.

Após analisarmos as características, os requisitos e modelo de funcionamento desta ferramenta, com a finalidade de adaptá-la para simularmos ambientes onde convivem tanto aplicações convencionais como de tempo real e reservas de domínios, verificamos suas restrições. As limitações mais relevantes estão na sua aceitação específica de aplicações de tempo real expressas para esquemas de prioridades fixas, nas premissas do $\mathrm{RMA}^{2}$, nas políticas para utilização dos recursos restritas e dirigidas a prioridades, e no recebimento on-line dos dados de entrada.

Como os nossos propósitos incluem escalonar reserva de domínios e analisar políticas par-

\footnotetext{
${ }^{1}$ Graphical User Interface.

${ }^{2}$ Apresentadas na Seção 1.1.2, Página 17.
} 
ticulares dos recursos para ambientes onde convivem tanto aplicações convencionais como de tempo real, e diante da dificuldade de incorporá-los eficientemente no gRMA v0.01a, optamos por desenvolver nosso próprio simulador, o rdsim.

Neste capítulo descrevemos o rdsim, que é uma ferramenta de auxílio à análise do comportamento dos algoritmos de escalonamento que selecionam reserva de domínio para a alocação dos recursos e do impacto das reservas de domínio no desempenho de tarefas em ambiente de multiprogramação.

\section{Organização deste Capítulo}

A Seção 5.2 descreve a visão geral do rdsim. Apresentamos na Seção 5.3 uma síntese da estratégia adotada pelo rdsim. Destinamos a Seção 5.4 à apresentação do ambiente computacional, suas estruturas e limitações. Descrevemos como adaptamos o modelo de sistema (descrito no Capítulo 2, Seção 2.2) à nossa implementação. Destacamos os procedimentos adotados nas diversas situações aceitáveis a fim de atender adequadamente aos objetivos da construção dessa ferramenta. A implementação para simularmos a ocupação dos recursos está descrita na Seção 5.5. Visando o leitor não familiarizado com concorrência de processos, apresentamos na Seção 5.5.1 alguns aspectos do mecanismo de gerenciamento e sincronização de processos. Na Seção 5.5.2 descrevemos os procedimentos envolvidos no consumo de cada fase das tarefas durante uma execução do rdsim. Na Seção 5.5 .3 expomos algumas das funções referentes aos algoritmos de escalonamento implementados no rdsim.

\subsection{Visão Geral do rdsim}

Os trabalhos de Silberschatz et al. [BGzS97, BGzS98], apresentados nos capítulos anteriores, fornecem os fundamentos teóricos para a implementação do rdsim.

O rdsim implementa a construção de um ambiente computacional segundo o modelo apresentado na Seção 2.2 e a partir de dados especificados em arquivos. Um ambiente computacional é formado por um conjunto de estruturas e mecanismos que definem recursos, reservas de domínios conceituadas na Seção 2.2.2 e processos que denominaremos tarefas.

O rdsim implementa os três algoritmos de escalonamento apresentados no Capítulo 3 . O rdsim escalona múltiplos recursos independentemente.

De acordo com a política implementada e associada a cada recurso, o rdsim simula a alocação pelas tarefas, gerencia e controla o mecanismo de acesso aos recursos presentes no ambiente computacional. Fornece como resultados os dados estatísticos tais como os referentes à utilização dos recursos, aos tempos dispendidos pelos domínios esperando ou utilizando um recurso, e ao tempo de computação das tarefas. 


\subsection{Estratégia Geral do rdsim}

A arquitetura do rdsim é bastante simples e modular. O rdsim consiste basicamente de dois módulos. No primeiro deles, implementa mecanismos de consistência das informações contidas nos dados de entrada a partir dos quais o rdsim compõe o ambiente de simulação e cria os conjuntos de filas de eventos ${ }^{3}$ nos recursos.

O rdsim recusará um ambiente onde houver uma política de escalonamento não definida, ou que utilize recurso inexistente no ambiente, ou que não cumpra o controle de admissão ${ }^{4}$.

Uma vez aceito o ambiente computacional, no segundo módulo, um ativador de simulação manipula as filas de eventos. O ativador da simulação do rdsim repete as operações de inserção e remoção de tarefas nas filas de eventos (simulando a alocação dos recursos existentes no ambiente e seguindo a política associada a cada recurso), utilizando-se dos mecanismos de sincronização, e computa os resultados estatísticos parciais do ambiente até que: (1) todas as ocorrências (fases) de todas as tarefas tiverem sido alocadas ou (2) todas as ocorrências de uma tarefa específica tiverem sido alocadas ou (3) se possa concluir que um tempo prédeterminado de simulação ocorreu. A condição de parada está expressa na especificação do ambiente a ser simulado.

\section{4 rdsim: Especificação e Implementação do Ambiente Com- putacional}

Seguindo o modelo de sistema operacional (Seção 2.2), definimos um ambiente computacional como uma coleção de recursos, onde cada um destes está submetido a um algoritmo de escalonamento específico. Estes recursos têm seu ciclo de serviço distribuído entre as diversas reservas de domínios. Uma tarefa sempre pertence a alguma reserva de domínio. As tarefas estão definidas como uma seqüência ordenada de fases, onde cada fase é o par recurso-duração, $(r, t)$, onde $r$ é um dos recursos do ambiente e $t$ é a quantidade de tempo requerida para utilizar o recurso $s$.

Cada recurso admitido no ambiente é modelado por um identificador do recurso, um nome, seu respectivo ciclo de serviço e intervalo de preempção, e a sua política de escalonamento.

Cada reserva de domínio admitida no ambiente é modelada por um identificador de domínio, um nome e por um número finito de pares formados por um identificador de recurso e sua fração de reserva do ciclo de serviço.

Cada tarefa admitida no ambiente é modelada por um identificador da tarefa, um nome, um identificador de reserva de domínio estática ${ }^{5}$ e por uma seqüência ordenada de ciclos que

\footnotetext{
${ }^{3}$ Denominamos fila de eventos toda fila mantida pelo rdsim para o gerenciamento dos estados das tarefas (por exemplo, fila de tarefas prontas, fila de tarefas bloqueadas, etc.).

${ }^{4}$ Lembremos que o controle de admissão consiste em assegurar para cada recurso do sistema, que a fração de serviço de um novo domínio juntamente com as frações de serviço dos domínios já no sistema, não excedam certos limites prescritos.

${ }^{5}$ Quando a tarefa for admitida sem reservas explícitas, a percentagem (fração) dos ciclos de serviço dos
} 
definem a tarefa, que satisfaz as seguintes regras de formação: (1) um ciclo contendo uma seqüência com uma ou mais fases define uma tarefa, (2) se $x$ define uma tarefa, então um ciclo ou mais ciclos de $x$ definem tarefa, e (3) se $x$ e $y$ definem tarefas, então um ou mais ciclos de $x y$ definem uma tarefa. Uma fase de tarefa é modelada por triplas contendo um identificador da fase, um identificador de recurso e a quantidade requerida de tempo para completar a fase no recurso. Podemos afirmar que, por definição, uma tarefa pode ter inúmeros ciclos e fases, porém sempre terminam.

A estrutura responsável pela manutenção de todas as informações necessárias aos recursos do ambiente denominamos Control. O rdsim mantém a tabela Control com uma entrada por recurso. Esta entrada contém informações sobre a descrição do recurso, o seu ciclo de serviço $(T)$, intervalo de preempção, da existência do recurso (um sinal que indica a presença do recurso no ambiente), a política de escalonamento do recurso, a quantidade das reservas de cada recurso já alocadas (zero, inicialmente), a quantidade das reservas disponíveis no momento corrente (iniciado com o valor total do ciclo de serviço), um apontador para o domínio corrente utilizando o recurso, o ciclo de serviço corrente (a cada início de ciclo de serviço recebe o valor zero), o número de ocupações do recurso, a percentagem (taxa) de utilização do recurso (calculada durante uma execução) e o estado do recurso (idle, disponível para alocação neste instante, ou busy, sendo alocado por alguma tarefa). Control está exemplificada em alguns de seus elementos na Tabela 5.1.

\begin{tabular}{|c|c|c|l|c|c|}
\hline rec_id & rec_name[] & rec_ciclo & $\cdots$ & rec_sum & rec_policy \\
\hline 1 & CPU-1 & 30 & $\cdots$ & 0 & SVFRR \\
2 & CPU-2 & 100 & $\cdots$ & 0 & MTRLS \\
3 & I/O-disco & 64 & $\cdots$ & 0 & WRR \\
4 & rede/in & 100 & $\cdots$ & 0 & WRR \\
$\vdots$ & $\vdots$ & $\vdots$ & $\ldots$ & $\vdots$ & $\vdots$ \\
\hline
\end{tabular}

Tabela 5.1: Exemplo de Uma Tabela Control.

O rdsim pode aceitar um número finito de recursos ${ }^{6}$, tais como a CPU, I/O (console, teclado, impressora, $\mathrm{CD}$, disco, rede), memória, e seus respectivos ciclos de serviço.

Cada recurso está sujeito a uma política de escalonamento; são rejeitados ambientes nos quais algum recurso utilize política não suportada.

\subsubsection{Gerenciamento das Reservas de Domínios}

Uma reserva de domínio está associada a uma coleção de tarefas e suas correspondentes reservas de recursos. O rdsim pode executar várias reservas de domínios e provê vários tipos de recursos (presentes na tabela Control) que são reservados e escalonados independentemente.

recursos a ser oferecida ao novo domínio é adquirida da especificação desta tarefa.

${ }^{6} \mathrm{O}$ número de recursos é limitado pelo tamanho de Control, o qual na versão corrente possui o valor 10. 
O rdsim mantém uma lista ligada Rd de todas as reservas de domínios no ambiente. Cada reserva de domínio contém informações sobre a descrição do domínio, a quantidade de tarefas ativas que pertencem ao domínio, o estado do domínio (indicando se as suas tarefas já consumiram todas as suas fases), os estados de existência dos recursos (quais recursos possui).

Cada reserva de domínio em Rd mantém tabelas com uma entrada por recurso. Cada entrada contém informações a serem manipuladas pela política de escalonamento designada ao recurso correspondente, incluindo a fração do ciclo de serviço reservada (left), a fração corrente do ciclo de serviço (mantida para a implementação do WRR), um ponteiro para o início da sua lista Task de tarefas, sua contabilidade no uso do recurso (tempo de espera e tempo de ocupação), um ponteiro para o primeiro token do domínio na lista Token (lista de tokens exclusiva para a implementação do MTR-LS), um contador do número corrente de tarefas que pertencem ao domínio, e as informações utilizadas na implementação do SVF-RR: o menor token do domínio, a lista cíclica de tokens do domínio, o índice de início na lista cíclica de tokens e o índice de fim na lista cíclica de tokens.

Para cada recurso submetido ao MTR-LS, o rdsim mantém uma lista Token das reservas de domínios ativas que possuem reserva do recurso, ou seja, uma lista com todos os tokens das reservas de domínios que possuem pelo menos uma tarefa que pode utilizar o recurso. Estes domínios são representados por tokens, que mantêm em suas estruturas pares de informações, onde cada par é composto da um ponteiro para a reserva de domínio na lista Rd e o tamanho do quantum designado a este domínio para este token, que é a quantidade de tempo de serviço no recurso que o domínio pode receber sem ser interrompido. Um domínio $D$ possui $T \alpha$ de unidades de tempo em toda a lista Token, onde $T$ é o ciclo de serviço do recurso. O rdsim remove todos os tokens do domínio da lista Token e libera seus recursos assim que todas as ocorrências (fases) das tarefas desta reserva de domínio tiverem sido alocadas.

\section{Reserva dos Recursos}

Ao admitir uma nova reserva de domínio, o rdsim atualiza e confere os valores de ocupação dos recursos no Control corrente.

O rdsim mantém no Control o valor da porção não reservada corrente e a porção já alocada dos recursos no ambiente. Sejam $d_{r}$ a porção disponível corrente do ciclo do recurso $r, r e s_{r}$ a porção já reservada do total do ciclo do recurso $r$ (já alocada) e $\alpha_{r}$ a fração do ciclo de serviço do recurso $r$ a ser reservada para o domínio $D$. A cada $D_{i}$ admitido no ambiente, atualiza-se $d_{r}$ no Control fazendo

$$
d_{r}=d_{r}-\alpha_{r}^{i}
$$

e, similarmente, acumula-se $\alpha_{r}^{i}$ à porção do ciclo de serviço do recurso $r$ já reservada, fazendo

$$
r e s_{r}=r e s_{r}+\alpha_{r}^{i}
$$

O controle de admissão assegura que a soma da porção da reserva de um recurso (reservas explícitas) seja menor que um. 


\section{Reserva Efetiva das Reservas de Domínios}

Todo domínio $D_{i}$ no rdsim possui uma fração $\alpha_{i}$ de tempo de serviço de cada recurso que possui. Como o somatório de todas as frações de reserva dos recursos dos domínios ativos pode não completar todo o ciclo de serviço do recurso, o rdsim distribui a porção não reservada entre todos estes domínios (cota_extra); calcula-se a reserva efetiva para todas as reservas de domínios ativas.

A fração de tempo de serviço efetiva a ser dada para cada reserva de domínio ativa no ambiente, que tenha em suas especificações o recurso $r$ em questão, será calculada a partir da porção disponível $d_{r}$. Como a soma das reservas explícitas de um recurso $\sum_{i} \alpha_{i}$ deve ser menor que um, enquanto o Eclipse/Plan9 distribui a porção não reservada dos recursos ${ }^{7}$ igualmente, o rdsim distribui proporcionalmente, para todos os domínios ativos ${ }^{8}$. A cota_extra do domínio ativo $D_{i}$ é calculada da seguinte forma:

$$
\text { cota_extra }=\frac{\alpha_{i}^{r}}{\sum_{j=1}^{n} \alpha_{j}^{r}} \cdot d_{r}
$$

onde $n$ é o número de domínios ativos no ambiente.

Para cada reserva de domínio ativa no ambiente e para cada recurso existente em suas especificações, se existe uma porção disponível não-nula, calcula-se a cota_extra que o domínio irá receber, tomando a proporção relativa a esta reserva de domínio, da parte a ser distribuída. Como o rdsim trata apenas de cotas inteiras, utiliza a aproximação balanceada da cota extra $x$, adicionando ao cálculo o valor real .5. Assim, a cota extra será $x+1$, caso seu valor decimal for maior ou igual a 0.5 , e será $x$, caso seu valor decimal seja menor que 0.5 .

A reserva efetiva do domínio ativo $D_{i}$ é calculada da seguinte forma:

$$
\alpha_{i}^{r}=\alpha_{i}^{r}+\text { cota_extra. }
$$

\section{Tarefas}

O modelo de tarefa está baseado no definido na Seção 2.2.3. No rdsim uma tarefa é considerada como uma seqüência ordenada de fases, onde cada fase (recurso-duração) representa uma ocorrência da tarefa a ser alocada.

Cada fase de um ciclo é mantida em uma estrutura de lista Fases e é representada pela identificação da fase, a identificação do recurso que irá ocupar nesta fase e a correspondente fração de tempo no recurso.

O rdsim mantém uma lista ligada Task de todas as tarefas no ambiente. Cada tarefa pertence a uma única reserva de domínio. Uma tarefa mantém em sua estrutura informações sobre a descrição da tarefa, um ponteiro para a sua correspondente reserva de domínio, o estado da tarefa (executando, pronta, bloqueada), sua contabilidade no uso dos recursos (tempo de

\footnotetext{
${ }^{7} \mathrm{~A}$ porção não reservada dos recursos no Eclipse/Plan9 está formalizada na Seção 4.2.1.

${ }^{8} \mathrm{~A}$ definição de um domínio ativo está na Página 72.
} 
espera e tempo de ocupação), tempo total no ambiente e demais informações necessárias para o gerenciamento, para a manipulação e execução das fases que a modelam.

\section{Tratamento de Tarefas Sem Reservas Explícitas}

Cada tarefa pertence a uma única reserva de domínio. Ao ser admitida no ambiente, a nova tarefa pode pertencer a uma reserva de domínio de forma estática, isto é, sua reserva de domínio está pré-definida na lista Rd. Pode ainda estar associada a uma reserva de domínio de forma dinâmica, ou seja, sem reservas explícitas, e é quando é criada uma reserva de domínio exclusiva para ela.

Quando o ambiente recebe uma tarefa sem reservas explícitas, uma reserva efetiva de cada recurso no ambiente é atribuída ao seu domínio. A fração $\alpha_{j}$ dos ciclos de serviço dos recursos a ser oferecida ao novo domínio é adquirida da especificação desta tarefa. Caso esta fração não esteja especificada, o rdsim assume um valor padrão estático share ${ }^{9}$ correspondendo à percentagem da porção não reservada dos ciclos de serviço dos recursos a ser recebida pela tarefa.

Assim, a fração do ciclo de serviço de cada recurso $r$ para este novo domínio $D_{j}$ será calculada da seguinte forma:

$$
\alpha_{j}^{r}=\text { share. } d_{r}
$$

onde $d_{r}$ é a porção não reservada do ciclo de serviço do recurso $r$. Aqui também, utiliza-se da aproximação balanceada descrita na Seção 5.4.1.

\section{5 rdsim: Simulação das Políticas dos Recursos}

Após a montagem do ambiente computacional e confirmando-se a sua viabilidade, o ativador de simulação gera instâncias do programa rdsim para a operação de ocupação dos recursos definidos no ambiente computacional.

Cada instância estará simulando a alocação de um recurso diante de apenas uma política de escalonamento, seguindo os seguintes passos: Uma tarefa é selecionada para ocupar o recurso de acordo com a política de escalonamento designada ao recurso (é retirada da fila de prontas), ocupa o recurso (pelo tempo gerenciado pelo intervalo de preempção do recurso e pelo quantum corrente), acumula os tempos de ocupação (global, do recurso, do domínio corrente e da tarefa corrente) e os tempos de espera (global, das tarefas na fila de prontas e dos correspondentes domínios (diferentes do domínio corrente)), e é encaminhada para outro recurso (é inserida na fila de prontos do recurso de sua próxima fase). As instâncias precisam se comunicar com outras instâncias. Por exemplo, na inserção de tarefas nas filas de eventos ou o número de tarefas ativas no ambiente (seções críticas).

Para o leitor não familiarizado com aspectos de concorrência, na seção seguinte, discutimos algumas abordagens no tratamento de múltiplas atividades realizadas em paralelo, do

\footnotetext{
${ }^{9}$ No rdsim, share recebeu o valor 30 .
} 
mecanismo de comunicação e sincronização de processos, e justificamos a escolha de nossa abordagem.

\subsubsection{Gerenciamento de Processos no rdsim}

$\mathrm{Na}$ tentativa de diminuirmos o tempo gasto na criação e na eliminação de processos, bem como economizarmos recursos do sistema como um todo, utilizamos threads (LinuxThreads [Ler]) no rdsim. Em um ambiente com múltiplas threads, não é necessário haver vários processos para se implementar aplicações concorrentes. No ambiente multithreads, cada processo pode responder a várias solicitações concorrentemente.

Uma thread compartilha o processador da mesma maneira que um processo. Por exemplo, enquanto uma thread espera por uma operação de entrada/saída, outra pode ser executada. Cada uma possui seu próprio conjunto de registradores (contexto de hardware), porém compartilha o mesmo espaço de endereçamento com as demais threads do processo. Quando uma thread está sendo executada, o contexto de hardware está armazenado nos registradores do processador. No momento em que uma delas perde a utilização do processador, o sistema salva suas informações. Threads passam pelos mesmos estados de um processo, como apresentamos no início do Capítulo 1.

A grande diferença entre subprocessos e threads é em relação ao espaço de endereçamento. Enquanto subprocessos possuem espaços independentes e protegidos, as threads compartilham o mesmo espaço de endereçamento do processo, sem nenhuma proteção, permitindo assim que uma thread possa alterar dados de outra thread. Apesar dessa possibilidade, as threads são desenvolvidas para trabalhar de forma cooperativa, voltadas para desempenhar uma tarefa em comum.

\section{Mecanismos de Sincronização}

As threads precisam se comunicar com outras threads. Por exemplo, na inserção de tarefas nas filas de eventos ou o número de tarefas ativas no ambiente.

Essa comunicação se dá através do uso de variáveis compartilhadas. Para que a comunicação ocorra, é necessário que os envolvidos estejam prontos em seus postos: uma thread pronta para dar a comunicação, outra(s) para receber. Os mecanismos que garantem a comunicação entre threads concorrentes e o acesso a variáveis compartilhadas são chamados mecanismos de sincronização.

No rdsim, a concorrência não pode ser evitada porque é uma parte inerente ao sistema. Os vários recursos presentes no ambiente computacional, nos quais as tarefas consomem suas fases, precisam ser executados simultaneamente. Tornou-se, portanto, fundamental a utilização de mecanismos de sincronização que garantissem a integridade e confiabilidade do rdsim.

$\mathrm{Na}$ abordagem dos problemas e soluções decorrentes da comunicação entre threads (ou processos em programas concorrentes em geral), utilizamos diversos procedimentos que necessitam de estruturas que permitam a especificação de concorrência em programas. Existem 
várias notações utilizadas para especificar as partes de um programa que devem ser executadas concorrentemente. As técnicas mais recentes tentam expressar a concorrência nos programas de uma forma mais estruturada e clara de se identificar.

Por exemplo, no momento em que uma thread almeja acessar o número de tarefas ativas no ambiente ou quando uma tarefa chega a um novo recurso e deve ser inserida na fila de prontas, deve existir sincronismo. Devemos portanto, proibir que mais de uma thread lide com a variável compartilhada ao mesmo tempo, ou seja, tenham acesso a esta variável de forma sincronizada, garantindo assim, a exclusão mútua.

Quando há necessidade de sincronização, alguns problemas podem ocorrer durante o processamento: (1) O resultado do processamento pode ser diferente dependendo de qual thread é executada primeiro (condições de corrida). (2) Quando uma thread nunca consegue executar a sua região crítica e, conseqüentemente, acessar o recurso compartilhado (starvation). Estes problemas ocorrem quando duas ou mais threads esperam por um recurso alocado. No momento em que o recurso é liberado, o sistema deve determinar qual thread, entre as que estão esperando, ganhará o acesso ao recurso. Uma solução trivial é a criação de filas de pedidos de alocação para o recurso, onde as threads esperam para poder utilizar um recurso. Porém, somente isto não resolve o problema, pois estas entrarão aleatoriamente na fila e poderão criar uma situação de deadlock ${ }^{10}$.

Como um dos mecanismos de sincronização de processos concorrentes, está o conceito de semáforos, proposto em 1965 por Dijkstra [Dij65]. Conceitualmente, um semáforo é uma estrutura de dados que é compartilhada por vários processos. São freqüentemente utilizados para operações de sincronização quando múltiplos processos acessam um recurso comum e não-compartilhável.

Um semáforo é um tipo de variável que denota não somente como uma determinada informação é armazenada, mas também como esta informação pode ser manipulada; ou seja, que operações estão disponíveis para uso da variável. Um tipo específico de variável, útil apenas para lidar com sincronização. Um aspecto importante dos semáforos é que sua forma de obter sincronização não se baseia em espera ocupada ${ }^{11}$ e sim, em permitir que o processo seja posto de lado, parando de consumir recursos, até que chegue o momento dele sincronizar.

O rdsim implementa a criação de múltiplas threads, uma para cada recurso, e o sincronismo entre elas é feito através de semáforos. As variáveis mais importantes que são compartilhadas na execução do rdsim são: o número de tarefas ativas no ambiente, o número de tarefas em estado de bloqueio, o número de tarefas pertencentes a cada domínio, a quantidade de unidades de tempo acumuladas durante as execuções das threads.

São alteradas por uma thread de cada vez, através de um semáforo tipo mutexes $^{12}$; um para cada variável compartilhada.

\footnotetext{
${ }^{10}$ Situação onde processos ficam bloqueados para sempre.

${ }^{11}$ Um solução de exclusão mútua com espera ocupada faz com que o processo utilize o processador, a cada momento, para verificar se pode entrar na região crítica, gastando ciclos de CPU e voltando para a fila de prontos.

${ }^{12}$ mutual exclusion semaphores - Semáforos binários que são usados por duas ou mais threads para garantir que somente uma delas possa entrar em sua região crítica.
} 


\subsubsection{Procedimentos Gerais na Execução das Tarefas}

\section{Inicialização das Filas de Tarefas por Recurso}

Para a montagem das filas de prontos (de tarefas) por recurso, coloca-se cada tarefa admitida no ambiente na fila de prontos do recurso que compete à sua primeira fase.

A primeira ocorrência (fase) de cada tarefa no ambiente é obtida iniciando-se o contador corrente de sua seqüência de ciclos e o ponteiro para o início da seqüência de fases deste ciclo. Acessa-se a sua primeira fase: o recurso a ser ocupado e o tempo de duração da fase.

\section{Ativador da Simulação}

São geradas instâncias do programa (threads) para simular a execução de uma política própria para cada recurso.

Enquanto houver alguma ocorrência (fase) de tarefa a ser alocada, serão executadas operações de inserção e remoção de tarefas das filas apropriadas a cada recurso de acordo com a política de escalonamento associada a cada recurso, descritas na Seção 5.5.3), bem como serão computados os tempos gastos e os totais parciais acumulados.

Para cada recurso definido no ambiente, o rdsim mantém um arquivo para armazenar os resultados relevantes que são obtidos durante a simulação.

\section{Tratador de uma Fila de Tarefa Vazia}

Para qualquer política de escalonamento, encontrando a fila de prontos (de tarefas) vazia:

(1) O rdsim verifica se existe alguma tarefa bloqueada que já cumpriu seu tempo de bloqueio (analisando o relógio global) e, em caso afirmativo, acerta o relógio e procede o tratamento de desbloqueio da tarefa. Caso contrário,

(2) O rdsim verifica se o sistema possui apenas tarefas bloqueadas (analisando o número de tarefas bloqueadas em relação ao número de tarefas no ambiente) e, em caso afirmativo, efetua o mesmo procedimento de desbloqueio de tarefas. Aqui, cada recurso é consultado para desbloquear as suas tarefas na ordem crescente do tempo de desbloqueio.

\section{Tratamento na Ocupação do Recurso}

A partir da fase corrente da tarefa escolhida na fila de prontas a ocupar o recurso:

(1) O tempo na alocação do recurso depende do valor corrente da reserva do recurso da sua reserva de domínio, do intervalo de preempção do recurso e de acordo com a política. 
(2) Incrementa-se o relógio global, o tempo total da tarefa e do domínio corrente na utilização do recurso. Decrementa-se o tempo alocado do valor corrente da reserva do recurso de seu domínio.

(3) Percorre-se a lista de tarefas que esperam pelo acesso ao recurso e adiciona-se o tempo gasto pela tarefa aos tempos de espera de cada uma.

(4) Para cada tarefa executada no recurso, acumula-se aos demais domínios ativos no recurso, o seu tempo de espera pelo recurso.

(5) Toda vez que se executa uma fase no recurso, coloca-se a tarefa na lista apropriada: no mesmo recurso, caso sua fase corrente não terminou, ou na lista de tarefas do recurso designado em sua próxima fase, caso sua fase corrente tenha sido completada. Para cada tarefa, ao se obter a sua próxima fase, verifica-se qual é o recurso subseqüente e a coloca na fila do recurso indicado, retirando-a da fila do recurso corrente e mudando o seu estado (pronto para outro recurso).

\section{Obtenção da Próxima Ocorrência de uma Tarefa}

Para a obtenção da próxima fase de uma tarefa, o rdsim mantém informações na estrutura Task da tarefa, tais como seu número de ciclos externos, o número de ciclos externos corrente, o número total do ciclo interno sendo simulado, um contador do número de vezes que já executamos o ciclo interno e um ponteiro para a fase atual.

O tratador deste acesso considera que a tarefa possui um ponteiro para a sua fase atual corrente:

(a) Verifica se acabaram os ciclos externos da tarefa. Se sim, acabou a tarefa. Retorna um indicador de fim de tarefa.

(b) Verifica se acabou o ciclo interno da tarefa. Se sim, inicia novo ciclo externo. Retorna a tarefa com o ponteiro para a primeira fase do ciclo externo.

(c) Verifica se já passaram todas as fases do ciclo corrente. Se sim, reinicia o mesmo ciclo. Retorna a tarefa com o ponteiro para a primeira fase do ciclo corrente, atualizando o número de vezes que este ciclo foi executado.

(d) Se nada dos itens anteriores aconteceu, retorna a próxima fase no ciclo corrente.

\section{Tratamento da Fase de Bloqueio para uma Tarefa}

No rdsim toda fase de uma tarefa sem identificação do recurso é tratada como uma fase de bloqueio, ou seja, uma fase em que a tarefa está simulando o estado de bloqueio. O rdsim não aceita nenhuma tarefa que inicia sua execução por uma fase no estado bloqueado. 
O rdsim mantém uma estrutura de lista ordenada de ocorrências de bloqueios Fila_sleep para cada recurso existente no ambiente e um contador do número corrente de tarefas bloqueadas. Estas ocorrências na lista Fila_sleep são representadas por elementos que contêm em suas estruturas um ponteiro para a tarefa bloqueada em Task e o valor do relógio global em que deve ser desbloqueada.

Durante a execução de uma tarefa, ao se constatar que a sua próxima fase é de bloqueio, o rdsim deve inserir a ocorrência na Fila_sleep do recurso que será alocado em sua fase subseqüente, pela ordem crescente do valor do contador do tempo (relógio global) em que deverá ser desbloqueada.A tarefa que possui a sua próxima fase após a de bloqueio, no recurso $r$, será inserida a sua ocorrência na Fila_sleep de $r$.

Exemplo. Considere o instante da execução em que o valor do relógio global indica 75 unidades de tempo. Suponha que uma tarefa $t$ possua a seguinte seqüência de fases intermediárias: $\cdots,\left(r_{1}, 5\right),(0,10),\left(r_{2}, 6\right), \cdots$, ou seja, utiliza 5 unidades de tempo no recurso $r_{1}$, uma fase de bloqueio de 10 unidades de tempo e 6 unidades de tempo no recurso $r_{2}$. A tarefa $t$ ocupa o recurso $r_{1}$ por 5 unidades de tempo, atualiza-se o relógio global $(75+5=80$ unidades de tempo) e a ocorrência na sua próxima fase que é o estado de bloqueio. Para o tratamento de bloqueio, inicialmente, obtém-se o recurso de sua fase seguinte, $r_{2}$. A ocorrência de $t$ será inserida na Fila_sleep de $r_{2}$. Calcula-se o valor do contador de tempo no momento em que a tarefa $t$, supostamente, deverá ser desbloqueada, ou seja, o valor do contador do relógio global corrente somado com o tempo de bloqueio.Assim, a ocorrência deverá ser removida da fila de bloqueadas de $r_{2}$ quando o relógio global estiver com o valor igual a 90 unidades de tempo. É criada uma nova célula para a Fila_sleep do recurso $r_{2}$, onde indica-se o valor 90 para o desbloqueio e a insere em ordem crescente deste valor na Fila_sleep, isto é, se houver alguma outra tarefa nesta fila que tiver este valor menor, esta deverá estar na sua frente na Fila_sleep.

Toda vez que se altera o relógio global, são consultadas as Fila_sleep's de todos os recursos existentes no ambiente, verificando se há alguma que pode ser desbloqueada no momento. Como as filas Fila_sleep estão ordenadas, a pesquisa é efetuada na primeira célula destas listas. Enquanto o tempo estipulado em valor não foi ultrapassado, a tarefa permanece neste mesmo estado. Caso contrário, é removida da Fila_sleep e inserida na fila de prontos do recurso correspondente, sempre atualizando o número corrente de tarefas bloqueadas no sistema.

\section{Tratamento de Fim de Tarefa}

Quando o rdsim efetua o tratamento da próxima fase da tarefa e recebe a indicação de fim de tarefa, efetua alguns procedimentos especiais: calcula a taxa de ocupação efetiva de cada recurso pela tarefa (executando no recurso), calcula a taxa de utilização de cada recurso obtida pela tarefa (esperando e executando no recurso), decrementa o contador de tarefas ativas no sistema e o contador de tarefas existentes em seu domínio, verifica se acabaram as tarefas deste domínio e, em caso afirmativo, efetua o tratamento de fim de domínio. 


\section{Tratamento de Fim de Domínio}

A cada fim das tarefas de um domínio, calcula-se, para cada recurso, a percentagem de sua alocação pelo domínio, redistribui a fração correspondente a ele entre os ativos no sistema. Não elimina a sua célula da lista dos domínios Rd, porém não será mais investigado nos procedimentos subseqüentes da simulação.

\section{Tratamento para Fim das Tarefas no Ambiente}

Após a finalização de todas as instâncias do programa, são armazenados em arquivo os resultados finais (tempo total na simulação do recurso, taxa de ocupação de cada domínio no recurso, taxa de ocupação de cada tarefa do domínio no recurso). Não existindo mais ocorrência de tarefas em nenhuma das filas de eventos no ambiente, o rdsim libera todas as células das listas criadas e encerra todos procedimentos da execução.

\subsubsection{Escalonamento dos Recursos}

O rdsim implementa o MTR-LS (Seção 3.1.1), o SVF-RR (Seção 3.2.1) e o WRR (Seção 3.3.1), aos quais os recursos definidos em tempo de construção do ambiente computacional serão submetidos. A política adotada a cada recurso é mantida estaticamente no Control até o final de uma execução do rdsim.

Para que uma mesma política pudesse ser adotada para diferentes recursos, o rdsim mantém estruturas de tabela para cada variável dependente do recurso. Cada entrada da tabela corresponde a um recurso existente no ambiente. A seguir, descrevemos a implementação dos escalonadores para apenas um recurso.

\section{Implementação do MTR-LS}

O ponto central da política do MTR-LS no rdsim é a lista de domínios ativos Token definida na Seção 5.4.1.

O rdsim implementa a rotina Monta_Listas_por_Dominio() apresentada na Figura 5.1, que efetua a montagem das listas de tarefas por domínio. Utilizando-se da rotina Insere_Fila_ Apropriada(), percorre a lista geral de tarefas no sistema e monta, para cada domínio ativo, uma fila de tarefas que contenham em sua primeira fase o recurso específico. 


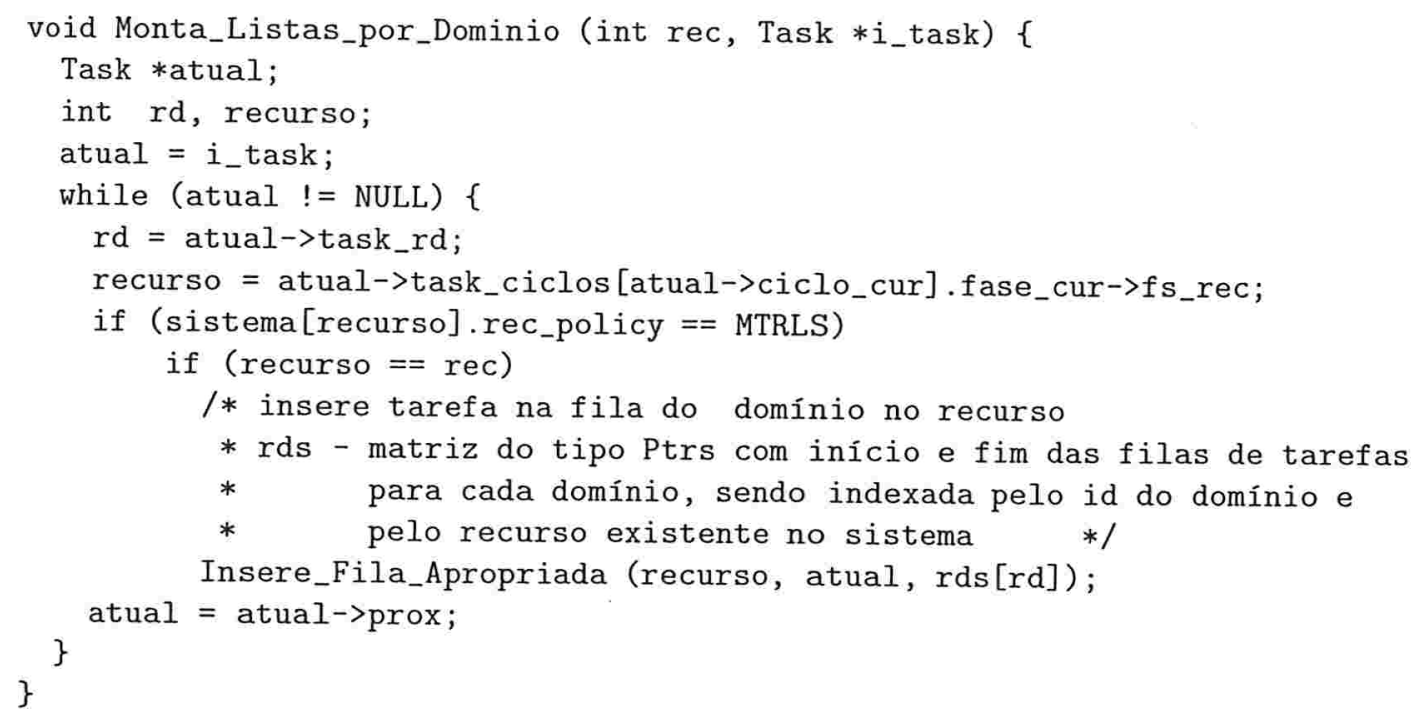

Figura 5.1: Implementação da Função Monta_Listas_por_Dominio para o MTR-LS.

Cada recurso que está sendo submetido ao MTR-LS, aciona a rotina Simula_Mtrls() exibida na Figura 5.2. Será executada enquanto houver tarefas no ambiente ou caso uma condição especial ocorrer, como referimo-nos na Seção 5.3.

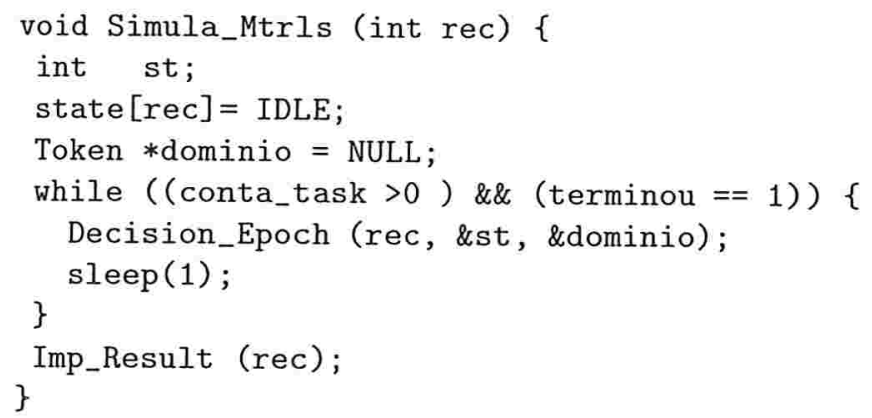

Figura 5.2: Implementação da Função Simula_Mtrls para o MTR-LS.

A rotina Decision_Epoch(), mostrada na Figura 5.3, será chamada no final do intervalo de preempção do recurso ou na expiração do quantum corrente. Uma variável estado é associada ao recurso. O estado do recurso é idle sempre que todas as tarefas dos domínios em Token estão executando ou requerendo outros recursos. Caso contrário, ou seja, quando existe algum domínio $D_{j}$ sendo executado, o estado do recurso é busy. Esta variável permite ou não a atualização dos tokens do domínio corrente. 


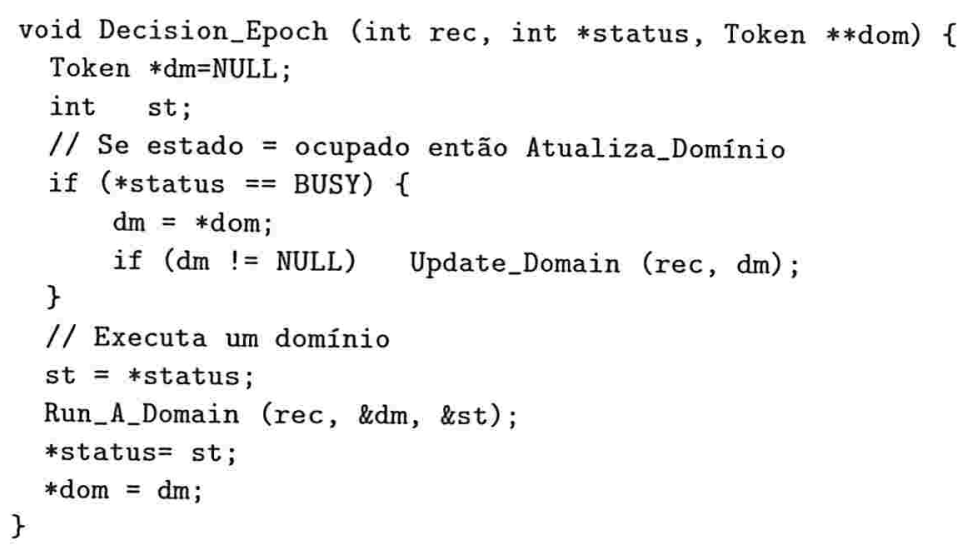

Figura 5.3: Implementação da Função Decision_Epoch para o MTR-LS.

Um domínio está pronto se existe pelo menos uma tarefa pertencente a ele na sua fila de prontos. A rotina Run_a_Domain(), apresentada na Figura 5.4, seleciona o próximo domínio pronto a executar no recurso e o coloca para ocupar o recurso, chamando a função Execute_Domain(). Sempre que um domínio inicia sua ocupação no recurso, o contador elapsed do recurso recebe o valor 0 . O elapsed registrará o tempo que foi utilizado pelo domínio para a próxima decision epoch. Quando não há um domínio pronto no instante corrente, o estado do recurso deve receber o valor idle.

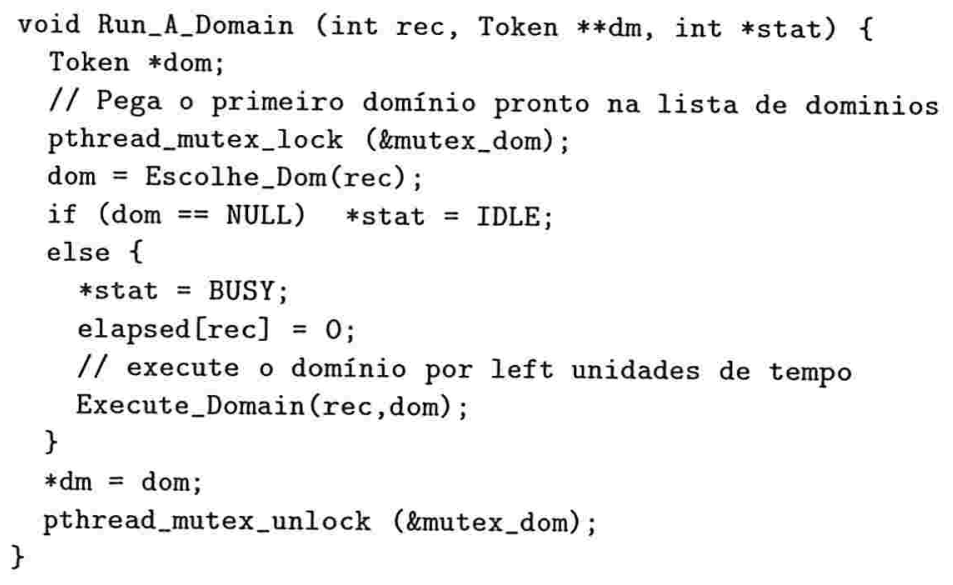

Figura 5.4: Implementação da Função Run_A_Domain para o MTR-LS.

A rotina Update_Domain() (Figura 5.5) será chamada sempre para atualizar o token do domínio corrente.

No índice correspondente ao recurso simulado, o vetor elapsed registra o tempo decorrido desde a última decision epoch. Caso a fração do ciclo de serviço do recurso para o domínio corrente, referente ao token corrente, não foi totalmente consumida, a função se encarrega de dividir o token corrente em dois, deixando a parte, left $_{k k}$, não atendida, na posição atual e 


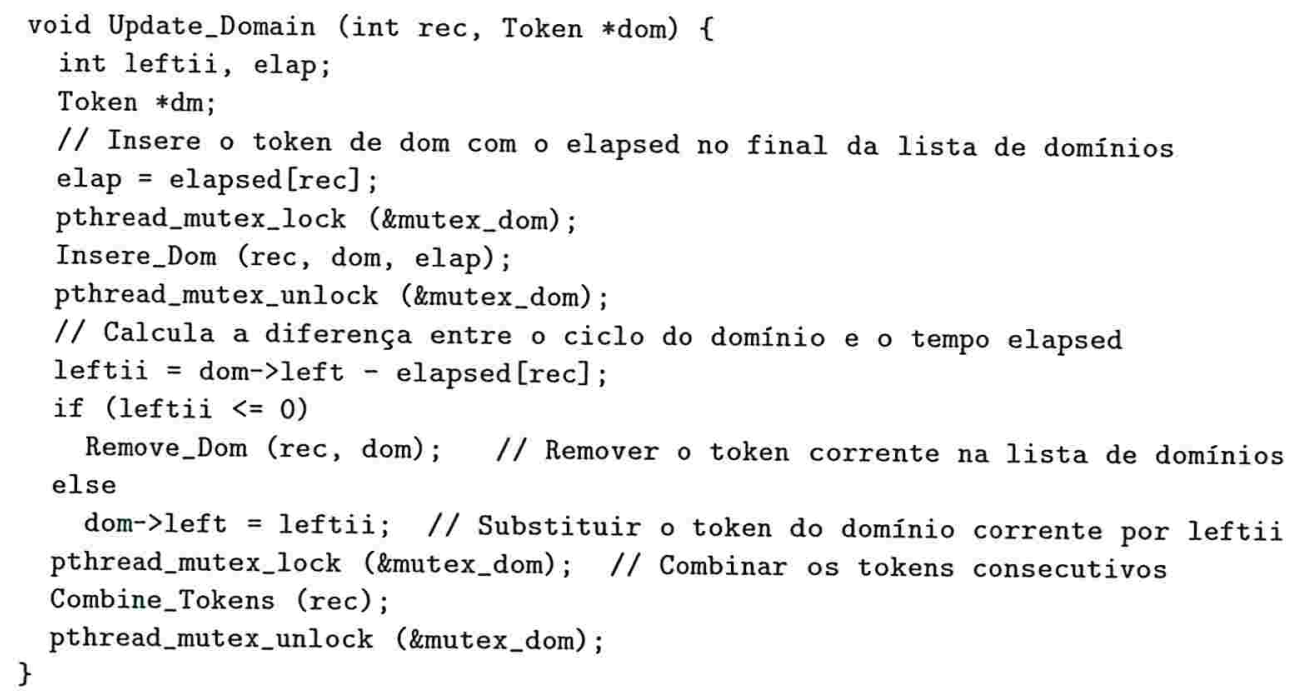

Figura 5.5: Implementação da Função Update_Domain para o MTR-LS.

colocando a porção já utilizada, left $t_{k}$, em um novo token no final da lista Token. Quando o domínio corrente recebeu sua cota completa, é movido o token inteiro da posição atual para o final da lista Token. Em qualquer caso, a soma do quantum de tempo dos dois tokens é iqual ao quantum de tempo do token original.

A Figura 5.6 apresenta a implementação da função Execute_Domain(). Execute_Domain() coloca o domínio corrente, $D_{j}$, para executar no recurso por, no máximo, left $t_{j}$ unidades de tempo. Realiza a simulação selecionando tarefas pertencentes ao $D_{j}$, efetuando o tratamento de distribuição de $l e f t_{j}$ entre estas tarefas, se responsabiliza pelo monitoramento da próxima fase da tarefa alocada ao recurso e verificação de fim de domínio. Cada domínio $D_{j}$ possui um ciclo de serviço corrente que será reiniciado para $\alpha_{i}$, a cada fim de ciclo de fração de serviço do domínio.

A função Escolhe_Dom() retorna um ponteiro para o primeiro domínio pronto na lista Token do recurso.

A rotina Insere_Dom() é responsável pela inserção do token que contenha em seu campo left o tempo registrado no vetor elapsed, no final da lista Token de domínios do recurso.

A rotina Remove_Dom() efetua a remoção do token corrente da lista Token de domínios do recurso.

Para que a lista Token não possua tokens consecutivos de um mesmo domínio, sempre que um domínio sofre uma atualização, o procedimento Combine_Tokens() examina os tokens adjacentes dessa última alteração e, caso houver dois de um mesmo domínio, são substituídos por um contendo a soma dos seus quanta. 


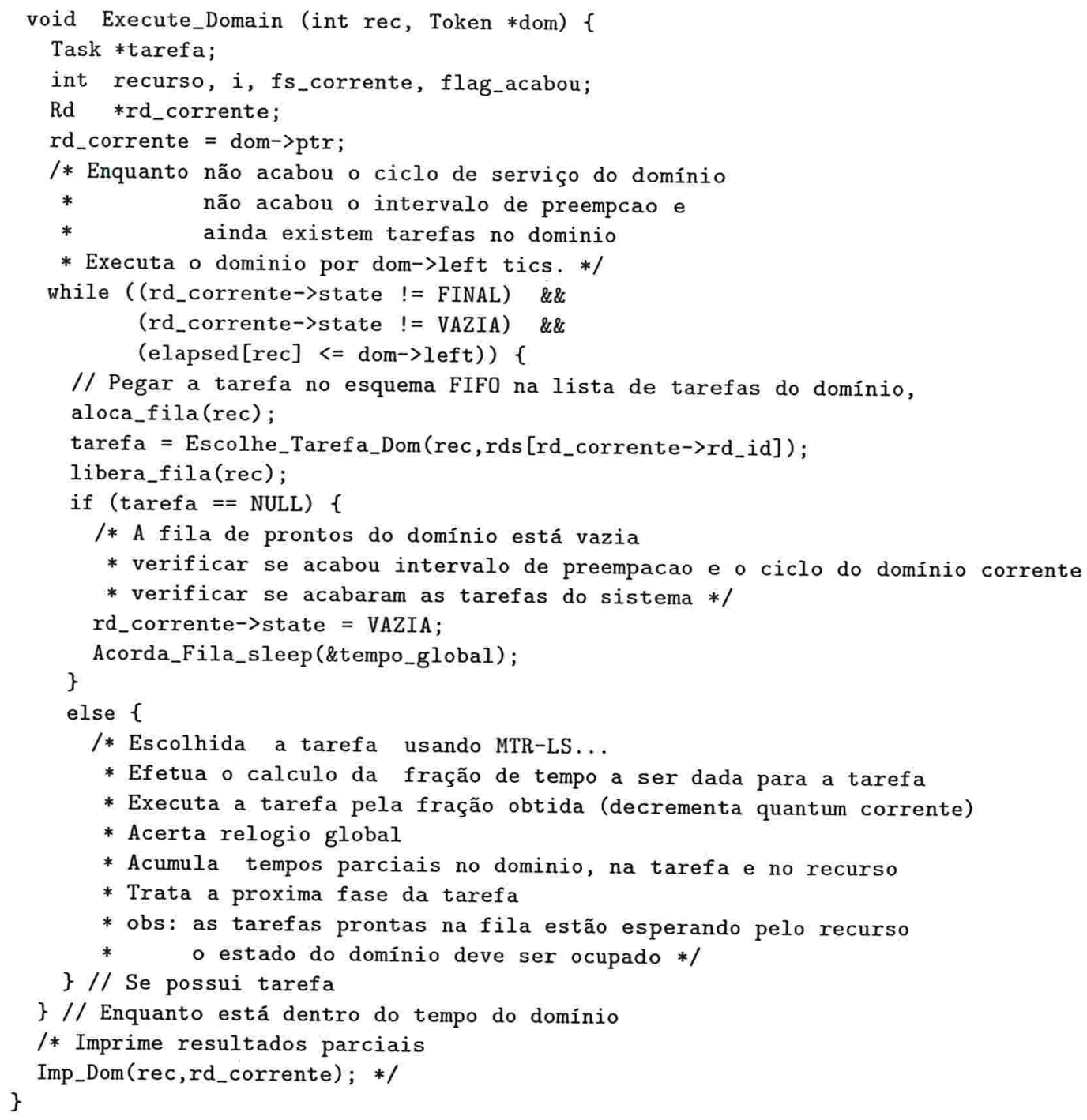

Figura 5.6: Implementação da Função Execute_Domain para o MTR-LS.

\section{Cálculo da fração de tempo de cada tarefa de uma reserva de domínio}

A fração de tempo a ser dada para cada tarefa é calculada a partir do conjunto de tarefas pertencentes ao domínio que é escolhido para ocupar o recurso.

A fração do ciclo do recurso para um token da lista Token das reservas de domínio deve ser distribuída para todas as tarefas pertencentes a fila de prontos do domínio. A distribuição feita é proporcional ao tempo da fase corrente de cada uma das tarefas no domínio.

Seja $x$ a reserva do ciclo de serviço do token da reserva de domínio em questão. Calcula-se a percentagem de $x$ que representa o tempo de cada tarefa em relação ao tempo total das 
tarefas na fila do domínio. O tempo a ser aferido para a tarefa será esta percentagem em relação ao $x$.

Exemplo: Seja 30 unidades de tempo, o ciclo de serviço do recurso $r$. Supondo que um token de uma reserva de domínio, possua a fração de $r$ correspondente a 10 unidades de tempo. Sejam $T_{1}$ e $T_{2}$, as tarefas prontas em $r$, pertencentes a este domínio. Os tempos das duas tarefas são 5 e 20 unidades de tempo, respectivamente. Calculamos a percentagem que representa cada tarefa em relação ao total do ciclo de serviço de $r$. Teremos $T_{1}$ utilizando $20 \%$ e $T_{2}, 80 \%$. Assim, o tempo a ser dado para $T_{1}$ será 2 unidades do tempo do ciclo deste token e para $T_{2}, 8$.

\section{Implementação do SVF-RR}

Quando é adotada a política SVF-RR(Seção 3.2.1)para gerenciamento de um recurso, será escolhida a tarefa na fila de prontas que está associada com a reserva de domínio que contém o token com o menor tempo virtual.

A Figura 5.7 apresenta alguns trechos da implementação da rotina Simula_SVFRR().

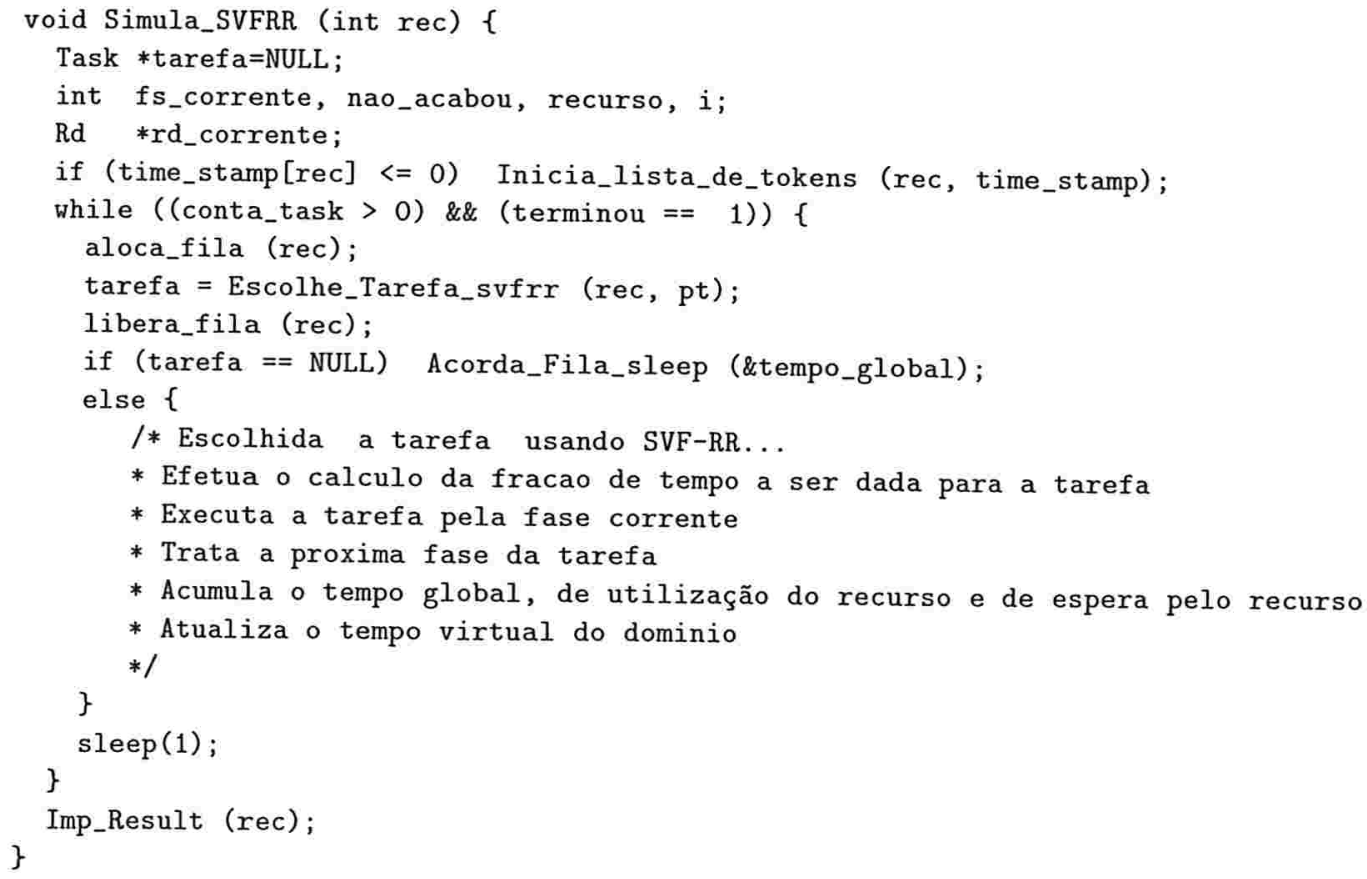

Figura 5.7: Implementação da Função Simula_SVFRR para o SVF-RR.

A idéia central do SVF-RR é computar uma representação de unidades discretas de tempo de serviço virtual ou timestamp, que marcam cada token das listas cíclicas de cada domínio em Rd. Inicialmente, timestamp recebe zero e é limitado ao valor $65.535^{13}$.

\footnotetext{
${ }^{13} \mathrm{O}$ tipo de dado, referente ao timestamp, unsigned int [Sch90] (Páginas 20-21) definido no padrão ANSI
} 
Quando o rdsim remove um domínio ou quando o contador timestamp contém o valor zero, é acionada a rotina Inicia_lista_de_tokens(), mostrada na Figura 5.8, onde a lista cíclica dos tokens de cada domínio em Rd é montada. Primeiramente, para cada domínio inicia-se o menor token (menor_token) e o primeiro token da lista cíclica fazendo-os receber o timestamp incrementado de um e os índices início e fim recebem o valor um. Os demais tokens da lista cíclica recebem o timestamp +1 até cobrir toda a fração do ciclo do recurso reservada para o domínio.

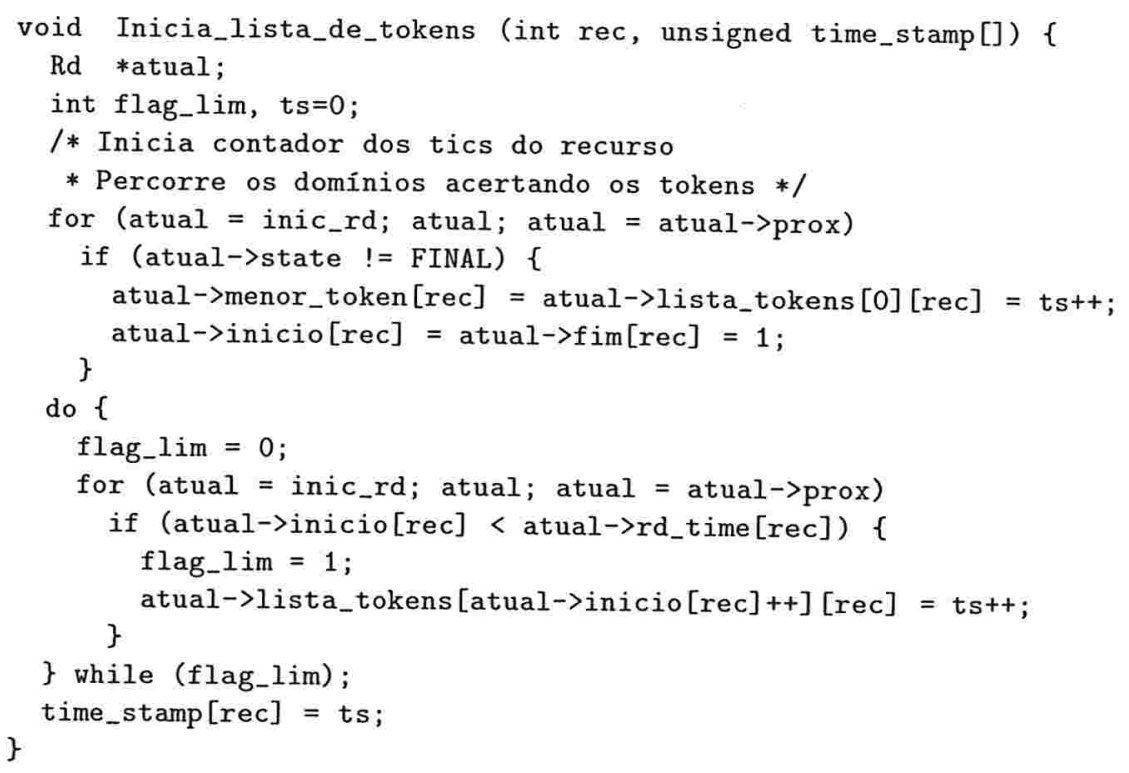

Figura 5.8: Implementação da Função Inicia_lista_de_tokens para o SVF-RR.

Ao término da fase de uma tarefa, acrescenta-se à lista cíclica de tokens do seu domínio mais um token com o contador timestamp corrente do recurso e atualiza-se o seu menor token, através da rotina Atualiza_Menor_Token(), que apresentamos a seguir na Figura 5.9.

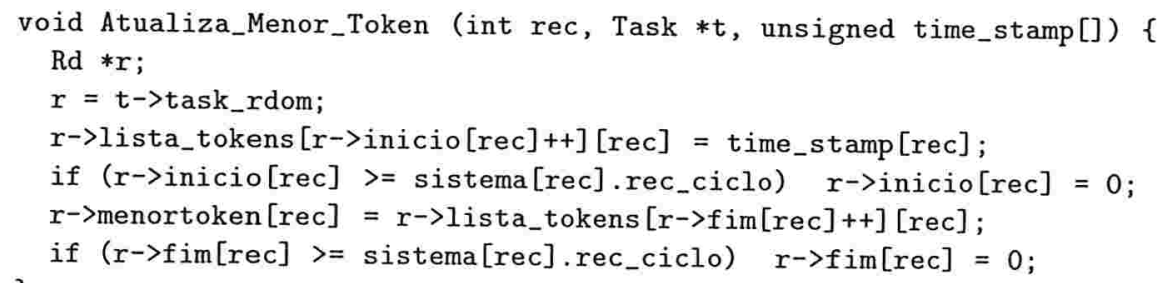

Figura 5.9: Implementação da Função Atualiza_Menor_Token para o SVF-RR.

Ao final de cada ciclo, a rotina Renova_Dominios() tem como objetivo reiniciar o tempo C possui a faixa mínima: 0 a 65.535. Ao incrementarmos o timestamp de 1, ocorre overflow e o conteúdo da variável será zero. 
de serviço de um ciclo do recurso simulado para todos domínios ativos.

Para selecionar a próxima tarefa a executar no recurso é chamada a rotina Escolhe_- Tarefa_svfrr(), implementada como na Figura 5.10. Percorre-se a lista de tarefas prontas no recurso e é escolhida a que tiver associada ao domínio com o menor timestamp no domínio.

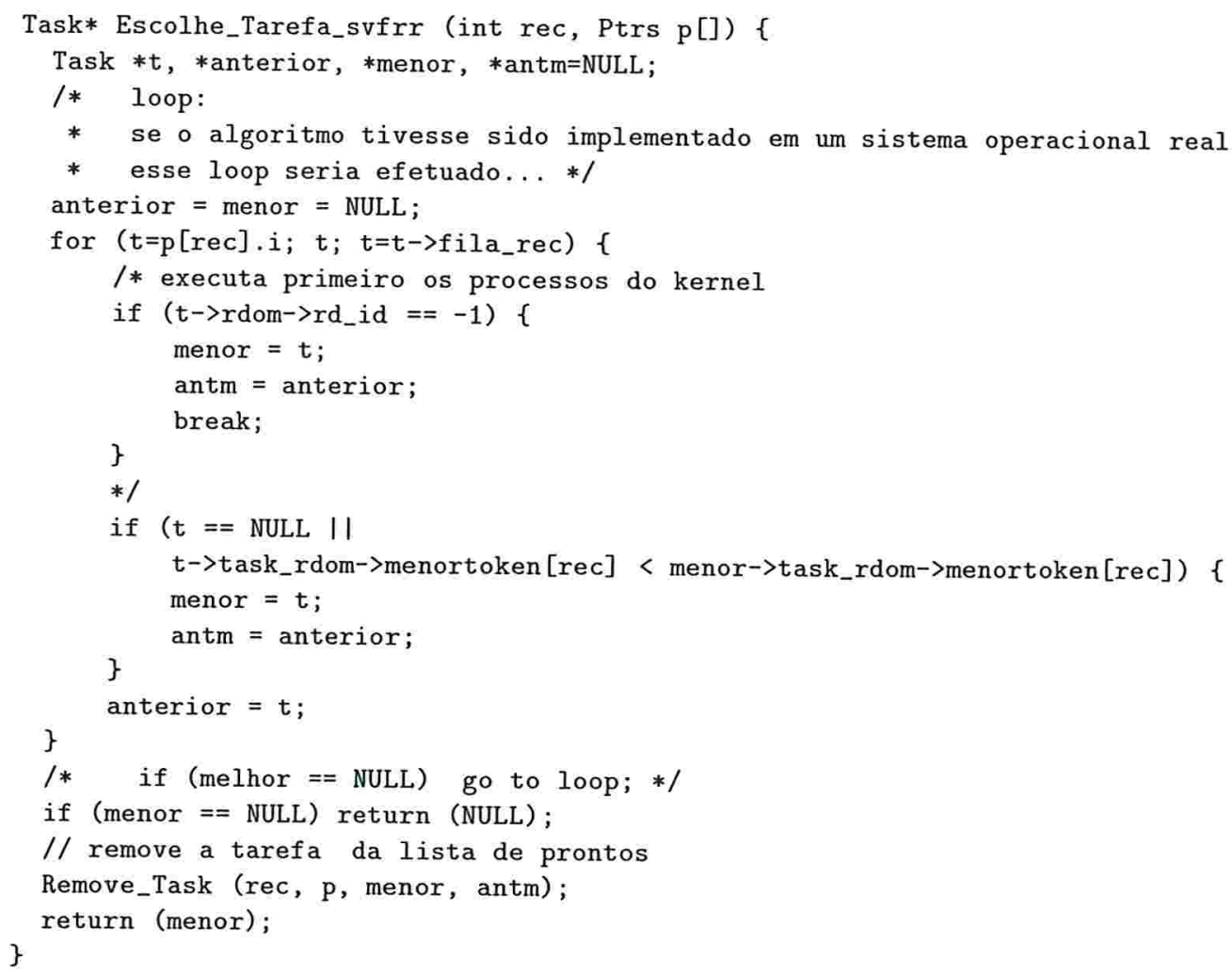

Figura 5.10: Implementação da Função Escolhe_Tarefa_svfrr para o SVF-RR.

\section{Implementação do WRR}

Para a política WRR(Seção 3.3.1), o rdsim implementa duas filas de tarefas prontas: a fila hi composta de cada tarefa pronta que possua em seu domínio o campo rec_time não-nulo e positivo e a fila lo composta de cada tarefa pronta que possua em seu domínio o campo rec_time nulo ou negativo. Cada reserva de domínio contém em sua estrutura um campo rec_time que corresponde à sua fração corrente do ciclo de serviço de cada recurso.

A cada ciclo de serviço do recurso e utilizando-se da rotina Escolhe_Tarefa_wrr() é selecionada a primeira tarefa na fila hi com o rec_time de seu domínio positivo.

É decrementado o campo rec_time com o tempo dispendido pela fase corrente da tarefa. Caso o campo rec_time ainda estiver positivo, a tarefa é removida do início da fila hi deste 
recurso e inserida no final da fila do recurso correspondente a sua próxima fase. Caso contrário, a tarefa não termina sua fase corrente. Atualiza-se a fase com o tempo restante e a tarefa é inserida na fila lo. Terminando o ciclo de serviço do recurso, reinicializa-se o campo rec_time de todos os domínios no ambiente e transfere-se todas as tarefas colocadas da fila lo para a fila hi.

A Figura 5.11 apresenta alguns trechos da implementação da rotina Simula_WRR().

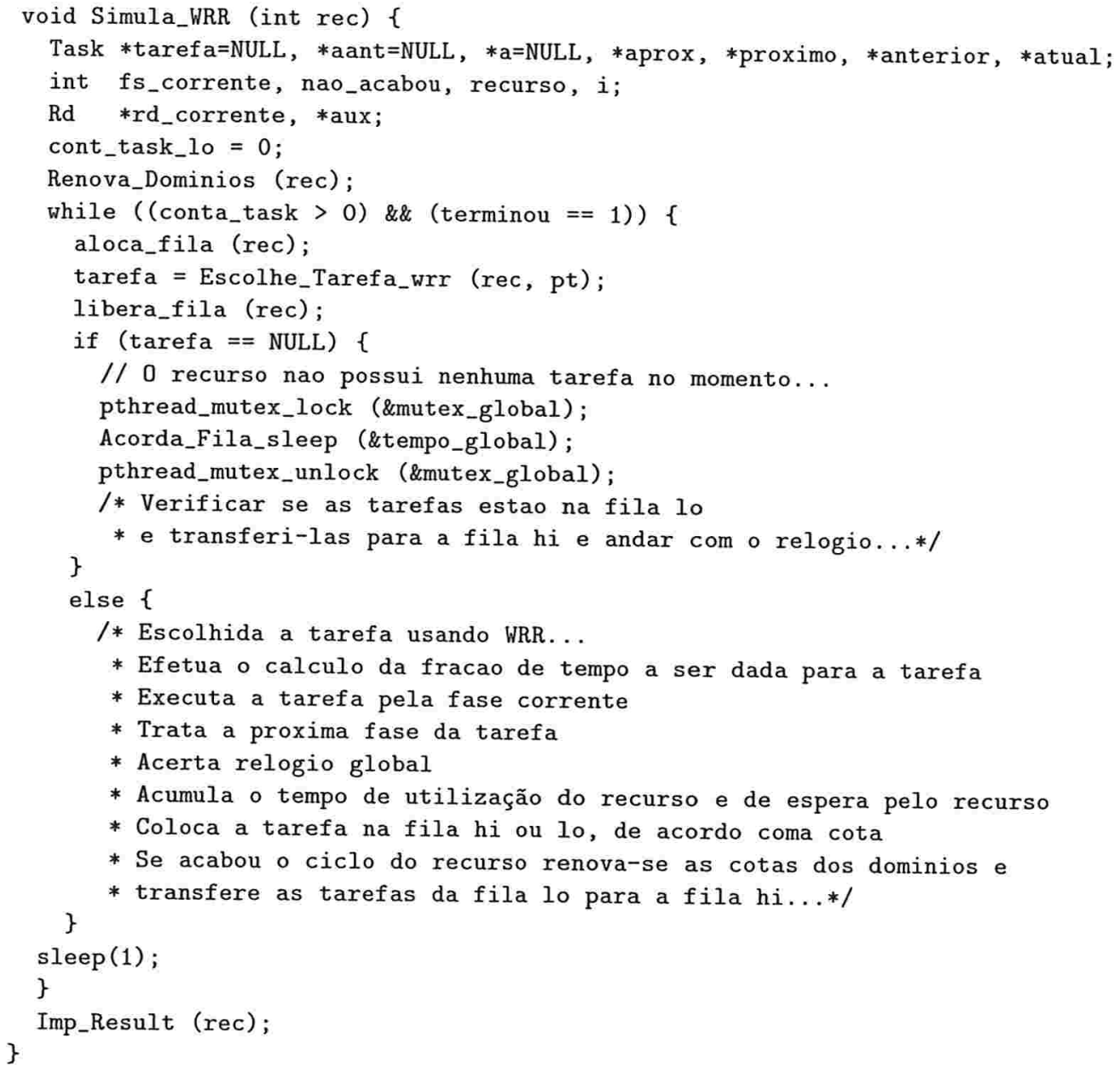

Figura 5.11: Implementação da Função Simula_WRR para o WRR. 


\subsection{Operacionalidade e Código Fonte}

As estruturas de dados do rdsim permitem que vários aspectos do sistema sejam analisados. As seguintes operações foram implementadas:

- Dado um recurso do ambiente computacional, obter:

$\Rightarrow$ Relatório completo sobre as especificações deste recurso.

$\Rightarrow$ Lista de tarefas no momento corrente deste recurso.

$\Rightarrow$ Estatísticas sobre a utilização do recurso.

- Dada uma reserva de domínio, obter:

$\Rightarrow$ Relatório completo sobre as especificações desta reserva de domínio.

$\Rightarrow$ Lista de tarefas no momento corrente nesta reserva de domínio.

$\Rightarrow$ Estatísticas do domínio sobre a sua utilização de cada recurso.

- Dada uma tarefa podemos obter:

$\Rightarrow$ Relatório completo sobre as especificações desta tarefa.

$\Rightarrow$ Sua reserva de domínio.

$\Rightarrow$ Estatísticas da tarefa sobre a sua utilização de cada recurso.

A implementação do rdsim [dCGN01] é simples, utilizando métodos tradicionais de manipulação de listas e filas. Sua estrutura flexível permite a inserção de novos algoritmos sem grandes alterações no restante do sistema. Está longe de ser um produto comercialmente aceitável. Ela apenas pretende validar a maioria das idéias deste trabalho de forma concreta, utilizando uma interface extremamente simples. 


\section{Capítulo 6}

\section{Análise de Desempenho dos Algoritmos de Escalonamento}

Neste capítulo analisamos, a partir de resultados obtidos da execução do procedimento rdsim [dCGN01], diferentes ambientes simulados de multiprogramação com várias classes de aplicações, submetendo os recursos às políticas de escalonamento estudadas.

\subsection{Introdução}

O problema de medição da eficácia dos algoritmos é complexo se pensarmos simultaneamente em todos aspectos envolvidos. Há itens ligados ao comportamento e ao desempenho das tarefas, quando estas estão associadas a alguma reserva de domínio, à escolha devida desta reserva de domínio, às características das tarefas existentes no cenário, às políticas designadas aos recursos existentes no sistema, etc.

Inicialmente, descrevemos nosso método de análise e apresentamos um conjunto de pequenos procedimentos práticos, um processo sistemático para a escolha de subconjuntos significativos de informações para a consolidação dos resultados em associação com as políticas dos escalonadores implementadas. Para realização dos experimentos e das simulações, desenvolvemos um conjunto de ferramentas para montagem dos cenários e utilizamos, particularmente, a ferramenta gnuplot, existente no ambiente Linux, na construção dos gráficos.

\subsection{Método de Análise}

O método consiste de quatro etapas. Na primeira delas, a partir dos objetivos traçados, descrevemos os cenários (que representam ambientes simulados de multiprogramação sobre os quais será realizado o estudo). Na segunda, escolhemos as variáveis e grupos de variáveis que utilizamos na obtenção de informações, no caso, as diferentes cargas a serem submetidas. 
$\mathrm{Na}$ terceira, realizamos um processo de seleção e transformação das informações obtidas na etapa anterior, armazenando-as em arquivos. Na quarta e última etapa, elaboramos gráficos comparativos. Através destes gráficos, discutimos a eficácia das políticas de escalonamento implementadas.

\subsubsection{Objetivo de Análise}

A definição do objetivo é fundamental para o processo de análise. Dela depende o tipo de informação a ser coletada, a forma de seleção, de transformação adequada da informação. Podemos querer analisar determinadas questões junto a um elemento do sistema ou a um conjunto de elementos. Por exemplo, analisar o tempo final de execução de uma tarefa utilizando determinado recurso, analisar a taxa de utilização efetiva de cada um dos recursos, diante de um cenário, pela comparação entre os três algoritmos de escalonamento simulados, investigar o comportamento de um conjunto de tarefas pertencente a apenas uma reserva de domínio ou a mais de uma, e quanto ao tipo das tarefas escolhidas.

O que buscamos é responder questões quanto à QoS obtida quando simulamos um conjunto de aplicações a serem executadas em um sistema utilizando reservas de domínios, diante das políticas de escalonamento estudadas. Como forma de se atingir esse objetivo, nos baseamos na análise diante da caracterização das reservas de domínios. Com a utilização das políticas de escalonamento de processos que se valem de reservas de domínios, elaboramos simulações que possibilitem a identificação do comportamento e desempenho diante das informações introduzidas.

\subsection{Ambiente e Premissas}

Com o objetivo definido, descrevemos as premissas iniciais e os cenários utilizados para análise.

\subsubsection{A Escolha e Descrição das Variáveis}

A escolha correta de cada variável na montagem do cenário é essencial para o entendimento do ambiente a ser avaliado. As unidades e escalas em que os valores das variáveis são expressos também são importantes para a manutenção das informações. Por exemplo, ao escolhermos o tempo do ciclo de serviço para um recurso, este deve ter sua ordem de grandeza compatível e coerente com as demais informações deste recurso e com as outras variáveis no ambiente.

Denominaremos variáveis estáticas aquelas que possuem valor fixo, ao longo dos experimentos. Elas representam informações que não sofrem alterações nos experimentos. Exemplos desse tipo de variável são as informações do ambiente computacional, tais como o nome de cada recurso no sistema e o tempo do ciclo de serviço de cada um. Denominaremos variáveis dinâmicas aquelas cujos valores são alterados durante as experimentações. Elas fornecem informações que variam em função do cenário a ser analisado. Exemplos dessas variáveis 
incluem a política a ser executada por um recurso, a cota de reserva de um recurso definida para um domínio e cada fase consumida pelas tarefas.

A descrição do cenário, pela definição do ambiente computacional (Seção 5.4), é composta do conjunto de reservas de domínios e do tipo de carga a que será submetido.

Para cada cenário experimentado, são definidas as seguintes variáveis:

\section{(a) $m$ : o número de domínios no sistema}

Analisamos ambientes com $m \geq 1$ domínios ativos. Como definimos na Seção 2.2.2, denominamos domínio ativo todo aquele que possui ao menos uma tarefa ao longo de um experimento.

No conjunto de reservas de domínios $\left\{D_{1}, D_{2}, \cdots, D_{m}\right\}$ sempre consideramos o domínio $D_{1}$ com alguma reserva dos recursos exclusiva para uso do "sistema operacional", com a percentagem entre $0 \%$ a $20 \%$. Isso porque um sistema operacional utiliza pequena parte dos ciclos de serviço de seus recursos no gerenciamento destes. Nas seções seguintes esta informação estará implícita, sendo omitida em todas as descrições dos experimentos.

\section{(b) $k$ : o número de recursos no sistema}

Simulamos ambientes computacionais com $k \geq 1$ recursos ativos. Chamamos de recurso ativo todo aquele que está sendo gerenciado por um dos algoritmos de escalonamento investigados. Em todos os testes os recursos não sendo avaliados são simulados utilizando o tratamento dado para as situações de bloqueio, descrito na Seção 5.5.2.

Avaliamos o comportamento de uma tarefa sob o ponto de vista de um recurso $r$, quando as tarefas no sistema alternam entre a utilização de $r$ e a utilização de outros não analisados. A tarefa é avaliada sob o ponto de vista de mais de um recurso, quando suas fases consomem frações dos ciclos de serviço de diferentes recursos sendo analisados.

\section{(c) n: o número de tarefas no sistema}

Cada experimento contém em seu cenário $n \geq 1$ tarefas.

A avaliação comportamental é feita em função do tempo de finalização de uma tarefa escolhida, que chamamos de tarefa de referência. O termo tempo significa o valor de um contador interno ao rdsim, que simula o relógio global referente à simulação de um cenário. A unidade de tempo é denominada tic.

Um conjunto de tarefas possui, pelo menos, a tarefa de referência. Uma tarefa possui em seus ciclos de execução uma ou mais fases, onde cada fase é formada por uma fração da duração do ciclo de serviço de um recurso, alternando com uma fase que utiliza o restante do ciclo em outros recursos do sistema. 
Cada tarefa pode pertencer a uma reserva de domínio pré-definida e existente no sistema ou não ter reserva explícita. Nestas circunstâncias, como apresentamos na Seção 5.4.1, o rdsim cria um novo domínio em tempo de execução. Uma tarefa pode utilizar um número arbitrário de recursos, porém em nossas simulações nos limitamos à abordagem de no máximo dois recursos ativos.

Os conjuntos de tarefas que compõem cada cenário podem ser formados por tarefas iguais, aleatórias e mistas.

* Conjunto de Tarefas Iguais

O conjunto de tarefas iguais utilizando apenas um recurso $r_{1}$ é definido em um cenário onde toda tarefa sendo simulada possui fases iguais e periódicas em $r_{1}$. Nos experimentos realizados, utilizamos tarefas com $10 \%, 40 \%$ e $70 \%$ do ciclo de serviço do recurso $r_{1}$, como apresentamos na Tabela 6.1 (a).

Para cenários com dois recursos $r_{1}$ e $r_{2}$, cada tarefa possui fases iguais e periódicas, ou seja, com tempo de chegada regular, nos recursos $r_{1}$ e $r_{2}$. Escolhemos três tipos delas, utilizando os recursos nas percentagens mostradas na Tabela 6.1 (b).

\begin{tabular}{|c|c|c|}
\hline \multicolumn{3}{|c|}{ (a) Recurso Específico } \\
\hline Tarefa & $r_{1}$ & outros \\
\hline$T_{1}$ & $10 \%$ & $90 \%$ \\
$T_{2}$ & $40 \%$ & $60 \%$ \\
$T_{3}$ & $70 \%$ & $30 \%$ \\
\hline
\end{tabular}

\begin{tabular}{|c|c|c|c|}
\hline \multicolumn{4}{|c|}{$(\mathrm{b})$ Vários Recursos } \\
\hline Tarefa & $r_{1}$ & $r_{2}$ & outros \\
\hline$T_{1}$ & $10 \%$ & $80 \%$ & $10 \%$ \\
$T_{2}$ & $40 \%$ & $40 \%$ & $20 \%$ \\
$T_{3}$ & $80 \%$ & $10 \%$ & $10 \%$ \\
\hline
\end{tabular}

Tabela 6.1: Tipos de Tarefas Iguais.

^ Conjunto de Tarefas Aleatórias

Para montagem de um conjunto de tarefas aleatórias e periódicas, foi implementado um programa [dCGN01] onde são solicitados os valores desejados para o número de tarefas a serem geradas, o número de ciclos e o número de fases em cada ciclo. Construímos um conjunto de tarefas periódicas utilizando em suas fases recursos do ambiente cuja ordem no consumo é aleatória e o seus respectivos tempos constantes, porém gerados aleatoriamente; normalizamos o resultado para abranger todo o ciclo de serviço do recurso.

O conjunto de tarefas aleatórias e aperiódicas, com tempo de chegada irregular, é definido em um cenário onde cada tarefa possui fases em recursos aleatórios e a duração das fases também é aleatória. Para montarmos os conjuntos destas tarefas, implementamos um procedimento semelhante ao mencionado no parágrafo anterior.

Como ilustramos na Tabela 6.2, construímos dois tipos de tarefas aperiódicas: um deles representado por tarefas $T_{a 1}$ que consomem em cada fase um recurso aleatório, dentre aqueles do ambiente, por tempos também gerados aleatoriamente; e outro, composto de tarefas $T_{a 2}$, 
onde cada ciclo é formado por uma fase aleatória em um recurso, alternando com uma fase em outro recurso, onde a sua duração é representada pela porção restante do ciclo de serviço de um dos recursos. Da mesma forma que para as tarefas iguais, os tempos nas fases são gerados cobrindo valores limitados pelo valor total do ciclo de serviço dos recursos.

\begin{tabular}{|c|c|c|}
\hline Tipo de Tarefa & $r_{1}$ & outros \\
\hline$T_{a 1}$ & $t_{x}$ & $t_{y}$ \\
$T_{a 2}$ & $t_{w}$ & $1-t_{w}$ \\
\hline
\end{tabular}

Tabela 6.2: Tarefas Aleatórias.

* Conjunto de Tarefas Mistas

\begin{tabular}{|rl|rl|}
\hline Tarefa de Referência & Tarefas Concorrentes \\
$r_{1}$ & $r_{2}$ & $r_{1}$ & $r_{2}$ \\
\hline $80 \%$ & $10 \%$ & $10 \%$ & $80 \%$ \\
$45 \%$ & $45 \%$ & $80 \%$ & $10 \%$ \\
$45 \%$ & $45 \%$ & $10 \%$ & $80 \%$ \\
$10 \%$ & $10 \%$ & $10 \%$ & $80 \%$ \\
\hline
\end{tabular}

Tabela 6.3: Tipos de Conjuntos de Tarefas com Carga Mista.

O conjunto de tarefas mistas é definido em cenários que possuem a tarefa de referência utilizando os recursos, nas proporções apresentadas na Tabela 6.3, bem como as demais concorrentes, iguais entre si, sobrecarregando um ou outro recurso.

\subsubsection{Limitações nos Experimentos}

É necessário se delimitar claramente quais resultados se deseja avaliar. Todos eles foram baseados em experimentos, analisando-se o comportamento da tarefa de referência e cobrindo diferentes cenários: em ambiente homogêneo, onde a carga do sistema é formada de tarefas periódicas ou aleatórias, em ambiente misto, sobrecarregando um recurso do sistema, em detrimento de outros. Outros experimentos foram baseados no tempo médio de utilização de um recurso.

Para que o comportamento da tarefa de referência não fosse alterado pela liberação de um recurso ou remoção de um domínio, em todos experimentos, procuramos ajustar os ciclos das tarefas concorrentes de modo que a escolhida finalizasse sua simulação de processamento antes do final de qualquer uma das demais no sistema.

Os experimentos foram realizados colocando sempre a tarefa de referência na reserva de domínio $D_{2}{ }^{1}$ e sendo sempre a primeira do conjunto delas no cenário. Quando estamos anal-

\footnotetext{
${ }^{1}$ Lembremos de que $D_{1}$ representa atividades do sistema operacional.
} 
isando um cenário onde temos tarefas que não possuem reserva explícita de domínio, conforme apresentamos na Seção 5.4.1, no instante da admissão de tais tarefas no sistema, atribuímos dinamicamente, para seu domínio, uma cota estática de $30 \%$ da porção não reservada de todos recursos definidos. Esta foi a percentagem designada por nos permitir simular de uma só vez um número considerável de tarefas com cota razoável dos recursos em seus domínios; o sistema só admite uma nova tarefa se e somente se tem uma porção não nula do ciclo de serviço dos recursos a serem utilizados.

Todos cenários foram submetidos aos três algoritmos de escalonamento estudados: o MTRLS, o SVF-RR e o WRR, descritos nas seções 3.1, 3.2 e 3.3, respectivamente. Quando a avaliação envolve mais de um recurso ativo, todos são submetidos ao mesmo algoritmo de escalonamento.

\subsection{Experimentos e Avaliações}

Os cenários experimentais e simulações são controlados e definidos a priori, de acordo com o objetivo da análise. Apresentamos a seguir algumas de nossas experimentações e avaliações separadas de acordo com o número de reservas de domínios presentes no cenário, com o número de tarefas e com usos dos recursos.

\subsubsection{Domínio, $n$ Tarefas e 1 Recurso:}

O ambiente foi construído como uma coleção de recursos estáticos onde definimos explicitamente apenas um domínio ativo $D_{2}$ que recebe como reserva toda fração do ciclo de serviço do recurso $r_{1}$ (sem considerar o domínio padrão, definido em 6.3.1).

Simulando cenários com apenas uma tarefa, independentemente da fração designada inicialmente para a reserva de domínio $D_{2}$, temos a distribuição da porção não reservada do ciclo de serviço dos recursos, na proporção de suas reservas pré-definidas, sendo disponibilizada uma cota extra entre os domínios ativos no sistema. Como temos apenas um domínio ativo, este recebe toda a cota e o comportamento e desempenho é o esperado; a tarefa independentemente de suas características não sofre nenhum atraso.

Posteriormente foi acrescentado ao cenário um número variado de tarefas pertencentes a esta única reserva de domínio $D_{2}$. Apresentamos na Tabela 6.4, o comportamento da tarefa de referência quando o conjunto é formado por dez tarefas iguais, utilizando-se apenas o recurso $r_{1}$. Os cenários $C_{1}, C_{2}$ e $C_{3}$ representam o tempo total de simulação da tarefa de referência quando são submetidos a cada algoritmo de escalonamento, nos quais as dez tarefas são do tipo $T_{1}, T_{2}$ e $T_{3}$, conforme definidos na Tabela 6.1 para um recurso específico, respectivamente.

Na Tabela 6.5 os cenários são compostos de dez tarefas aleatórias, geradas conforme mostramos na Tabela 6.2. No cenário $C_{a 1}$, temos o tempo total de execução quando todos recursos são aleatórios; e em $C_{a 2}$, a fração no uso do recurso é aleatória e o tempo nos demais representado pelo restante do seu ciclo de serviço.

Observamos nos experimentos que, utilizando o MTR-LS, podemos oferecer o recurso $r_{1}$ à 


\begin{tabular}{|c|c|c|c|}
\hline Cenário & MTR-LS & SVF-RR & WRR \\
\hline$C_{1}$ & $\mathbf{2 7 3}$ & $\mathbf{2 7 3}$ & 339 \\
$C_{2}$ & $\mathbf{3 6 2}$ & 930 & 1362 \\
$C_{3}$ & $\mathbf{5 6 3}$ & 1377 & 2727 \\
\hline
\end{tabular}

Tabela 6.4: Tempos para Tarefas Iguais utilizando um Recurso Específico.

\begin{tabular}{|c|c|c|c|}
\hline Cenário & MTR-LS & SVF-RR & WRR \\
\hline$C_{a 1}$ & $\mathbf{7 2 6}$ & 1006 & 1026 \\
$C_{a 2}$ & $\mathbf{8 9 7}$ & 942 & 1124 \\
\hline
\end{tabular}

Tabela 6.5: Tempos para Tarefas Aleatórias utilizando um Recurso Específico.

tarefa de referência, independentemente da sua necessidade pelas demais tarefas no sistema. Com a política MTR-LS o desempenho é melhor, pois a porção do ciclo de serviço do recurso $r_{1}$, designada para o único domínio no sistema $D_{2}$, que é de $80 \%$, é distribuída entre as dez tarefas presentes na fila de prontos de $r_{1}$. Portanto, a cada ciclo de serviço do recurso, todas tarefas são atendidas e se obtém progresso, garantindo serviço acumulado e atraso limitado.

Comprovando as considerações teóricas, no SVF-RR a escolha é feita em função do menor tempo virtual do domínio, ao qual as tarefas pertencem. Como elas pertencem ao mesmo domínio $D_{2}$, a escolha será sempre a primeira na fila de prontos do recurso $r_{1}$.

No WRR, após executar uma fase no recurso, a tarefa vai ao fim da fila e será atendida novamente depois de ser executada uma fase de todas tarefas no sistema, independentemente do ciclo de serviço do recurso $r_{1}$, o que ocorre semelhantemente quando utilizamos o Round Robin tradicional.

\subsubsection{Domínio, $n$ Tarefas e 2 Recursos:}

$\mathrm{O}$ ambiente foi constituído por um domínio $D_{2}$, com reserva estática que preenche toda cota disponível dos ciclos de serviço dos recursos $r_{1}$ e $r_{2}$.

Apresentamos na Tabela 6.6, os tempos totais de processamento obtidos pela tarefa de referência para os três cenários, cada um formado por dez tarefas iguais, como as definidas na Tabela 6.1 (b), e todas pertencentes ao domínio $D_{2}$.

\begin{tabular}{|c|c|c|c|}
\hline Cenário & MTR-LS & SVF-RR & WRR \\
\hline$C_{1}$ & $\mathbf{8 7 5}$ & 1461 & 1581 \\
$C_{2}$ & $\mathbf{7 3 2}$ & 1578 & 2142 \\
$C_{3}$ & $\mathbf{8 6 5}$ & 1602 & 2997 \\
\hline
\end{tabular}

Tabela 6.6: Tempos para Tarefas Iguais utilizando Dois Recursos. 
Verificamos que o desempenho da tarefa de referência é melhor quando utilizamos o MTRLS. Além disso, podemos observar que para os diferentes cenários $C_{1}, C_{2}$ e $C_{3}$, onde todas tiveram modificadas suas frações de uso dos recursos, o atraso no tempo de finalização da tarefa de referência não teve alteração significativa. A cada escolha, dentre as prontas nos recursos, é feita a redistribuição da cota da reserva de domínio $D_{2}$, entre todas, na fila de prontos de cada recurso. Por possuírem fases iguais, a porção atribuída a cada uma é uniforme, possibilitando um pequeno progresso para todas, a cada ciclo de serviço do recurso, o que reflete no total de atraso produzido.

Quando submetemos os recursos ao SVF-RR, a escolha sempre será a primeira na fila. O comportamento da tarefa de referência apresenta-se melhor em relação ao WRR, porque cada uma das tarefas cumpre toda sua fase no recurso, a cada ciclo de serviço dos recursos.

Utilizando o WRR, enquanto não se esgota a cota de um recurso reservada para o domínio $D_{2}$, o único no sistema, uma tarefa somente será atendida quando chegar na primeira posição da fila de prontos das que possuem reserva, neste ciclo do recurso. Como há várias tarefas consumindo a mesma reserva, esta se esgotando, leva todas não atendidas para a fila de prontos daquelas que não possuem reserva para este ciclo. Esta situação obriga o atendimento e a escolha da tarefa de referência somente após a execução de uma fase de todas as demais existentes no sistema.

Quando o cenário é composto por dez tarefas aleatórias no domínio $D_{2}$, os recursos e tempo das fases são gerados de forma aleatória. Na Tabela 6.7 temos em $C_{a 1}$ e $C_{a 2}$, os tempos para finalização da tarefa de referência quando as dez tarefas são dos tipos $T_{a 1}$ e $T_{a 2}$, conforme apresentamos na Tabela 6.2 , respectivamente.

\begin{tabular}{|c|c|c|c|}
\hline Cenário & MTR-LS & SVF-RR & WRR \\
\hline$C_{a 1}$ & 771 & $\mathbf{7 5 2}$ & 896 \\
$C_{a 2}$ & 997 & 1095 & $\mathbf{7 2 1}$ \\
\hline
\end{tabular}

Tabela 6.7: Tempos para Tarefas Aleatórias utilizando Dois Recursos.

Quando temos o conjunto de tarefas aleatórias na utilização dos recursos, a fração de tempo atribuída a cada fase pode não ser compatível com a cota reservada para o recurso no domínio $D_{2}$. No MTR-LS esta cota é distribuída em porcentagens distintas entre as tarefas na fila de prontos do recurso, podendo promover, como observamos na Tabela 6.7, um tempo de finalização da tarefa de referência maior do que quando utilizamos as outras políticas de escalonamento, onde isso não acorre.

\subsection{3 $m$ Domínios, $m$ Tarefas e 1 Recurso:}

O ambiente foi montado com $m$ reservas de domínios $D_{2}, \ldots, D_{m+1}$ definidas explicitamente, com cada uma recebendo como reserva $\frac{1}{m}$ da cota do ciclo de serviço do recurso $r_{1}$, tal que $\Sigma_{i=2}^{m+1} \frac{1}{m}+\alpha_{1}=1$, onde $\alpha_{1}$ representa a fração de reserva de $r_{1}$ para o domínio $D_{1}^{2}$ e

\footnotetext{
${ }^{2}$ Reserva para atividades do sistema.
} 
exatamente uma tarefa pertencente a cada reserva de domínio explícita no sistema.

As Figuras 6.1, 6.2, 6.3, 6.4 e 6.5 representam no eixo $x$, a percentagem do ciclo de serviço do recurso $r_{1}$ utilizada pelas tarefas e no eixo $y$, o tempo de finalização da tarefa de referência.

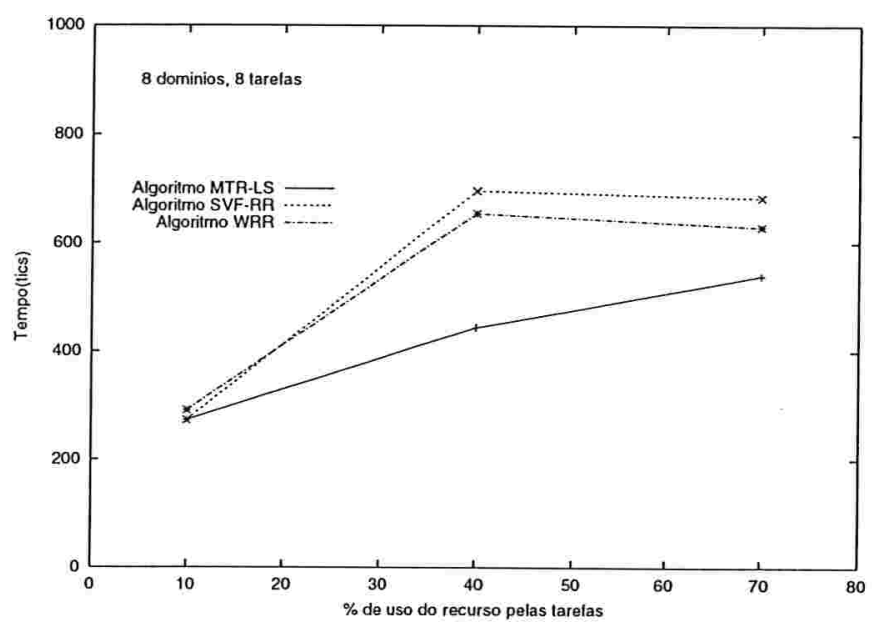

Figura 6.1: Tarefa de Referência para 8 Domínios e um Recurso.

Dentre os diversos experimentos efetuados, destacamos alguns que delineiam o comportamento da tarefa de referência, pertencente ao domínio $D_{2}$ :

No primeiro experimento, temos um ambiente montado com oito domínios $D_{2}, \ldots, D_{9}$ com reserva de $10 \%$ do recurso $r_{1}$, designada a cada um, e oito tarefas iguais, cada qual pertencendo a uma reserva de domínio própria.

Observamos na Figura 6.1 que, quando as oito tarefas no sistema consomem, a cada ciclo, mais que a cota do ciclo do recurso (10\%) designada ao domínio a que pertencem, o tempo para a finalização da tarefa de referência aumenta consideravelmente. Entretanto, com a utilização do escalonador MTR-LS, o desempenho é melhor; o tempo de espera da tarefa de referência está limitado no tamanho do ciclo de serviço do recurso. O SVF-RR e o WRR promovem resultados similares; ambos selecionam a próxima tarefa na fila de prontos.

No segundo experimento, apresentado na Figura 6.2, temos o comportamento da tarefa de referência, diante dos mesmos cenários do experimento anterior, formados, agora, por quatro tarefas iguais, cada qual pertencendo a uma reserva de domínio própria. Desta vez, temos um ambiente montado com quatro domínios $D_{2}, \ldots, D_{5}$, com reserva de $20 \%$ do recurso $r_{1}$ designada a cada um, preenchendo toda cota do ciclo de serviço do recurso ativo no sistema.

Para quatro tarefas, utilizando o dobro ou mais da cota do ciclo do recurso, o escalonador MTR-LS seleciona o primeiro domínio ativo na lista de domínios do sistema, escolhendo a única tarefa a ele pertencente. Ele utiliza toda a sua cota e leva o token $^{3}$ inteiro para o final

\footnotetext{
${ }^{3}$ Definido na Seção 3.1 .
} 


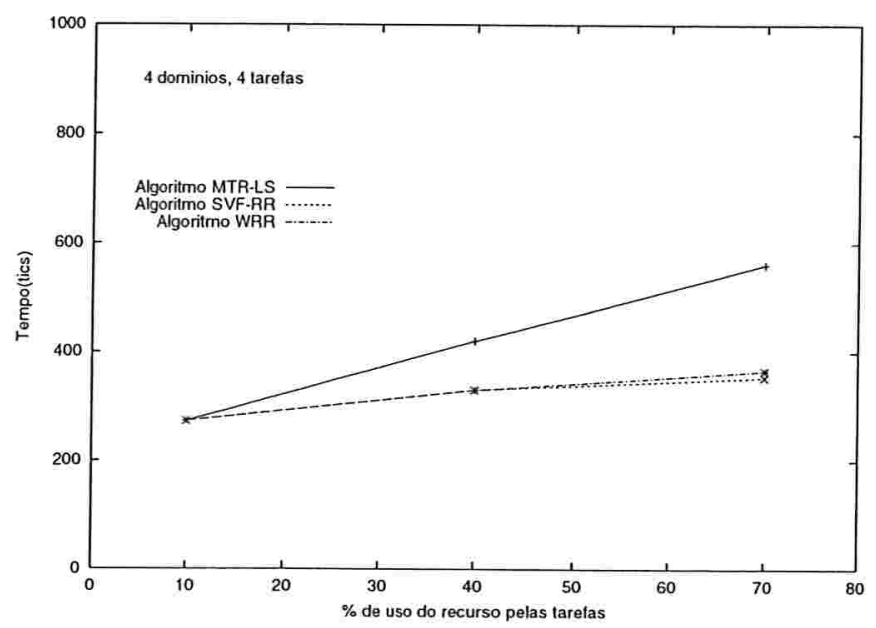

Figura 6.2: Tarefa de Referência para 4 Domínios e um Recurso.

da lista dos domínios. O escalonador deixa a tarefa esperando na mesma fase, enquanto que as outras cumprem seus tempos, no recurso, da mesma forma. Este fato provoca mais atraso do que no WRR, pois este leva a tarefa para a fila das que possuem cota dos recursos esgotada, transferindo-as para a fila de prontos, a cada início de ciclo.

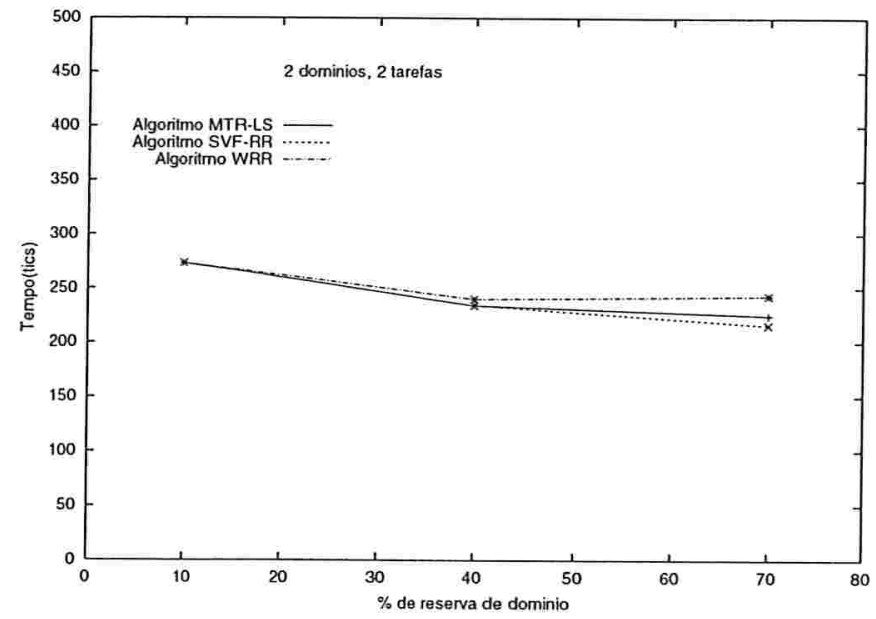

Figura 6.3: Tarefa de Referência para 2 Domínios e um Recurso.

No terceiro experimento, temos um ambiente montado com dois domínios, $D_{2}$ e $D_{3}$, com reserva de $40 \%$ do recurso $r_{1}$, designada a cada um, preenchendo toda cota restante do ciclo de serviço do recurso $r_{1}$ no sistema.

Apresentamos na Figura 6.3, os tempos de execução da tarefa de referência para os três conjuntos formados por duas tarefas iguais, cada qual pertencendo a uma reserva de domínio própria. Quando temos apenas duas tarefas no sistema, observamos que o tempo gasto em 
pouco é afetado, independentemente do algoritmo utilizado.

\begin{tabular}{|c|c|c|c|}
\hline$D_{1}$ & $D_{2}$ & $D_{3}$ & $D_{4}$ \\
\hline $20 \%$ & $5 \%$ & $70 \%$ & $5 \%$ \\
$20 \%$ & $10 \%$ & $35 \%$ & $35 \%$ \\
$20 \%$ & $20 \%$ & $40 \%$ & $20 \%$ \\
$20 \%$ & $35 \%$ & $10 \%$ & $35 \%$ \\
$20 \%$ & $40 \%$ & $20 \%$ & $20 \%$ \\
$20 \%$ & $70 \%$ & $5 \%$ & $5 \%$ \\
\hline
\end{tabular}

Tabela 6.8: Reserva dos Recursos para os Domínios no Sistema.

No quarto experimento, temos um ambiente montado com três reservas de domínios $D_{2}$, $D_{3}$ e $D_{4}$ e consideramos cota variada do ciclo de serviço de $r_{1}$, em cada um deles; sob o mesmo cenário, variamos as frações das reservas do recurso $r_{1}$ para os três domínios, com as percentagens mostradas na Tabela 6.8.

As Figuras 6.4 e 6.5 estão representando no eixo $x$, as percentagens do ciclo do recurso $r_{1}$

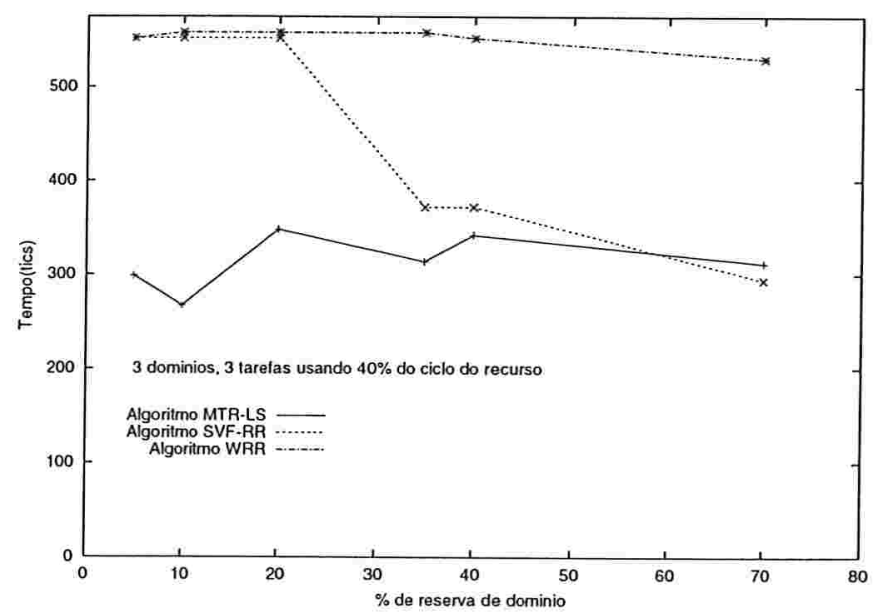

Figura 6.4: Tarefa de Referência utilizando $40 \%$ do Ciclo do Recurso.

reservadas para domínio $D_{2}$, constantes na segunda coluna da Tabela 6.8, para os conjuntos de tarefas formados por três tarefas iguais utilizando $40 \%$ e $70 \%$ do ciclo do recurso $r_{1}$, respectivamente, e no eixo $y$, o tempo da finalização da tarefa de referência.

Quando temos tarefas no sistema que gastam uma porcentagem maior da cota do ciclo do recurso, o WRR apresenta maior atraso em relação aos MTR-LS e SVF-RR. A tarefa demora mais para terminar pois, constantemente, vai para a fila de prontos das que possuem a cota de reserva do recurso esgotada.

Observamos, em diferentes testes, que quando a tarefa de referência pertence a um domínio com reserva menor que a duração de sua fase no recurso e as outras tarefas concorrentes 


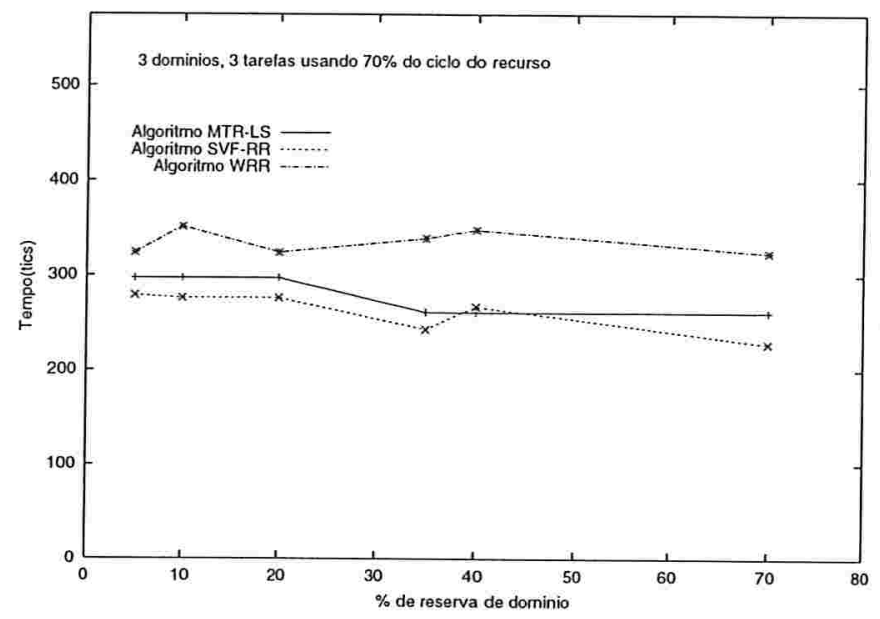

Figura 6.5: Tarefa de Referência utilizando $70 \%$ do Ciclo do Recurso.

pertencem a domínios recebendo mais reserva que a da tarefa de referência, os algoritmos MTR-LS e SVF-RR se revelam similares, enquanto que o WRR provoca sempre um maior atraso.

Quando aumentamos a fração do ciclo relativa ao domínio de cada uma delas, o desempenho depende da duração das fases das tarefas, em relação a esta fração e ao número de tarefas concorrentes no sistema. Na medida em que aumentamos a reserva de domínio para a tarefa de referência, em relação à das outras, a diferença do comportamento dos algoritmos e o tempo para atendimento desta tarefa diminuem.

\subsection{4 $m$ Domínios, $m$ Tarefas e 2 Recursos:}

Montando ambientes análogos aos definidos para " $m$ domínios, $m$ tarefas e 1 recurso" (definido na Página 152) simulamos cenários onde cada tarefa utiliza os recursos $r_{1}$ e $r_{2}$ e pertence a uma reserva de domínio explícita distinta.

\begin{tabular}{|c|c|c|c|}
\hline Cenários & $r_{1}$ & $r_{2}$ & outros \\
\hline$C_{1}$ & $10 \%$ & $80 \%$ & $10 \%$ \\
$C_{2}$ & $40 \%$ & $40 \%$ & $10 \%$ \\
$C_{3}$ & $10 \%$ & $10 \%$ & $80 \%$ \\
$C_{4}$ & $80 \%$ & $10 \%$ & $10 \%$ \\
$C_{5}$ & \multicolumn{3}{|c|}{ aleatórios } \\
\hline
\end{tabular}

Tabela 6.9: Cenários com Ciclos de Serviço em Dois Recursos.

Apresentamos cinco conjuntos de testes onde variamos a utilização dos recursos pelas tarefas no sistema. As Figuras 6.6, 6.7 e 6.8 estão representando no eixo $x$, cada um dos cinco 
cenários descritos na Tabela 6.9 e no eixo $y$, o tempo de finalização da tarefa de referência.

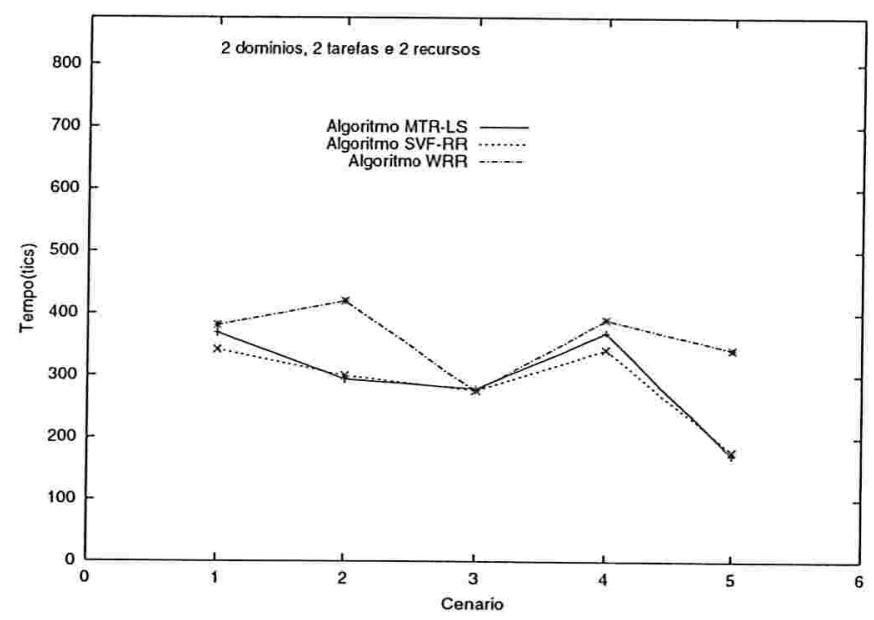

Figura 6.6: 2 Domínios, 2 Tarefas e 2 Recursos.

São cenários formados por 2, 4 e 8 tarefas iguais, cada qual pertencendo a reserva de domínio própria, para ambientes montados com 2, 4 e 8 domínios, cada qual com reserva de $40 \%, 20 \%$ e $10 \%$ dos recursos, preenchendo toda cota do ciclo de serviço dos recursos no sistema, respectivamente.

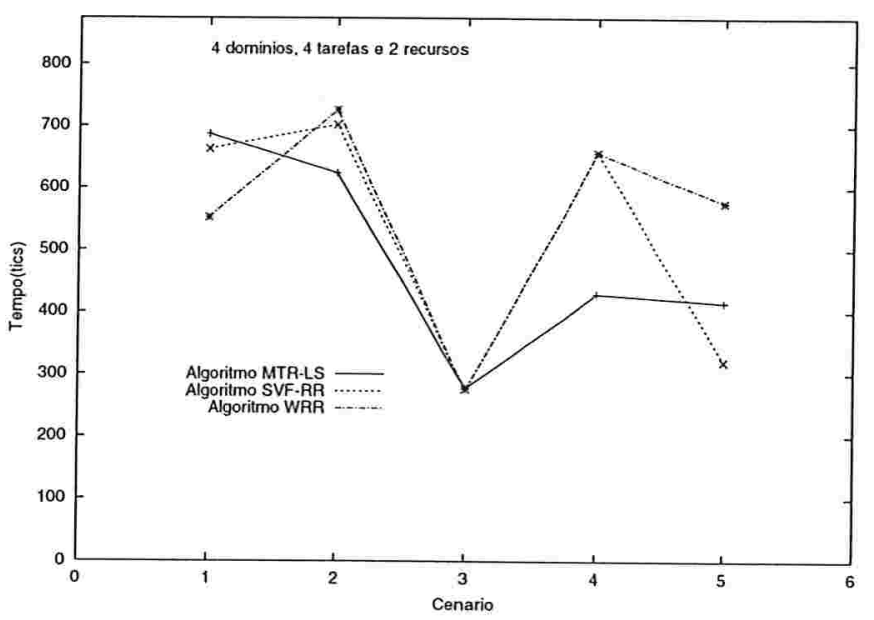

Figura 6.7: 4 Domínios, 4 Tarefas e 2 Recursos.

Os cenários $C_{1}$ e $C_{4}$ sempre apresentam desempenho similares, pois estamos colocando o mesmo algoritmo de escalonamento nos recursos ativos.

Para o cenário $C_{2}$, onde as tarefas consomem, praticamente, metade de um ciclo de serviço dos recursos, o tempo no final da tarefa de referência é menor, utilizando o MTR-LS. Evidencia- 
se o progresso obtido por ela, a cada ciclo de serviço, refletindo num menor tempo de atraso, em relação aos outros algoritmos.

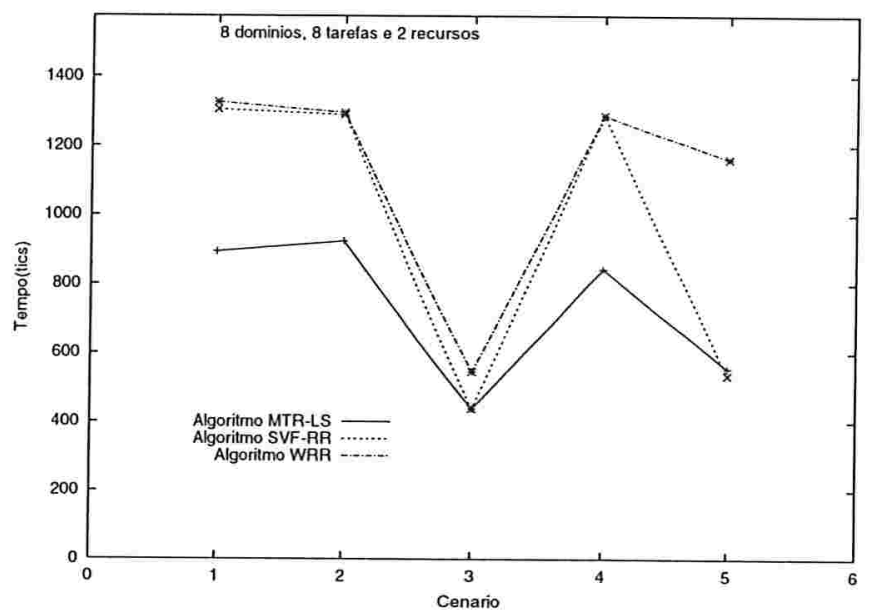

Figura 6.8: 8 Domínios, 8 Tarefas e 2 Recursos.

Para o cenário $C_{3}$, onde temos todas tarefas utilizando uma pequena fração do ciclo de serviço dos recursos, os tempos são similares e o atraso é pequeno, independentemente do número de tarefas no sistema.

Quanto ao cenário $C_{5}$, verificamos que para recursos gerados aleatoriamente, os algoritmos MTR-LS e SVF-RR revelam um desempenho melhor, pois a utilização acaba sendo compensada entre os recursos.

\subsection{5 $m$ Domínios, $m$ Tarefas sem reserva explícita e 2 Recursos:}

O ambiente foi montado com cenários contendo a tarefa de referência, convivendo com outras dez iguais, utilizando os recursos $r_{1}$ e $r_{2}$, de acordo com as percentagens apresentadas na Tabela 6.10; todas elas sem reserva de domínio explícita.

Devemos ressaltar que uma tarefa sem reserva explícita, entrando no sistema, cria sua própria reserva de domínio, que sobrevive enquanto a tarefa não termina. Este domínio recebe uma cota fixa (30\%) da porção não reservada do ciclo de serviço dos recursos do sistema. Como estamos considerando o cenário fechado, no instante inicial de sua simulação, cada tarefa que entra recebe, para seu domínio, um valor cada vez menor dos ciclos de serviço dos recursos definidos.

Observamos que o desempenho depende da cota de reserva de domínio da tarefa de referência. Se a cota não é suficiente, o desempenho do algoritmo analisado é prejudicado. Como ocorre diante do algoritmo MTR-LS, quando a tarefa de referência utiliza $10 \%$ do ciclo de serviço do recurso $r_{1}$ e $80 \%$ do recurso $r_{2}$ e contém em seu domínio, uma porção de, no máximo, $30 \%$ do ciclo de serviço de $r_{2}$. 


\begin{tabular}{|cc|cc|c|c|c|}
\hline \multicolumn{2}{|c|}{ Tarefa de } & \multicolumn{2}{|c|}{ Tarefas } & & & \\
Referência & \multicolumn{2}{|c|}{ Concorrentes } & MTR-LS & SVF-RR & WRR \\
$r_{1}$ & $r_{2}$ & $r_{1}$ & $r_{2}$ & & & \\
\hline $10 \%$ & $10 \%$ & $10 \%$ & $80 \%$ & $\mathbf{7 5 9}$ & 783 & 885 \\
$10 \%$ & $80 \%$ & $10 \%$ & $10 \%$ & 1740 & $\mathbf{6 2 4}$ & 690 \\
& & & & & & \\
$45 \%$ & $45 \%$ & $10 \%$ & $80 \%$ & $\mathbf{5 6 0}$ & 668 & 764 \\
$45 \%$ & $45 \%$ & $80 \%$ & $10 \%$ & 788 & $\mathbf{3 8 2}$ & 535 \\
& & & & & & \\
$80 \%$ & $10 \%$ & $10 \%$ & $80 \%$ & $\mathbf{5 3 1}$ & 540 & 669 \\
$10 \%$ & $80 \%$ & $80 \%$ & $10 \%$ & $\mathbf{6 6 9}$ & 876 & 885 \\
\hline
\end{tabular}

Tabela 6.10: Comportamento da Tarefa de Referência Sobrecarregando Um dos Recursos.

As tarefas concorrentes não interferem no comportamento da tarefa de referência de forma significativa; cada domínio utiliza sua porção de reserva dos recursos, independentemente dos outros domínios no sistema.

\subsection{6 $m$ Domínios, $m$ Tarefas ( $m-1$ sem reserva explícita) e 2 Recursos:}

$\mathrm{O}$ ambiente foi montado, inicialmente, com a reserva de domínio $D_{2}$ definida explicitamente; e apenas com a tarefa de referência pertencente a esta reserva. Neste cenário foram acrescentadas, uma a uma, tarefas iguais sem reserva explícita de domínio.

Apresentamos na Tabela 6.11, cinco conjuntos de testes, onde variamos a utilização dos recursos para todas tarefas no sistema.

\begin{tabular}{|c|lll|}
\hline Cenários & $r_{1}$ & $r_{2}$ & outros \\
\hline$a$ & $10 \%$ & $80 \%$ & $10 \%$ \\
$b$ & $45 \%$ & $45 \%$ & $10 \%$ \\
$c$ & $80 \%$ & $10 \%$ & $10 \%$ \\
$d$ & $10 \%$ & $10 \%$ & $80 \%$ \\
$e$ & \multicolumn{3}{|c}{ aleatórios } \\
\hline
\end{tabular}

Tabela 6.11: Tipos de Cenários Sobrecarregando o Sistema.

Para analisarmos o comportamento da tarefa de referência mediante um número variado de tarefas que utilizam muito cada um dos recursos, fixamos a cota das reservas dos recursos ativos em $10 \%$ para o domínio $D_{2}$.

As Figuras 6.9, 6.10, 6.11 e 6.12 apresentam os tempos de finalização da tarefa de referência, mediante um número crescente de tarefas concorrentes, utilizando os recursos, tal como descrito na Tabela 6.11, de acordo com os cenários $a, b, c$ e $d$, respectivamente. 


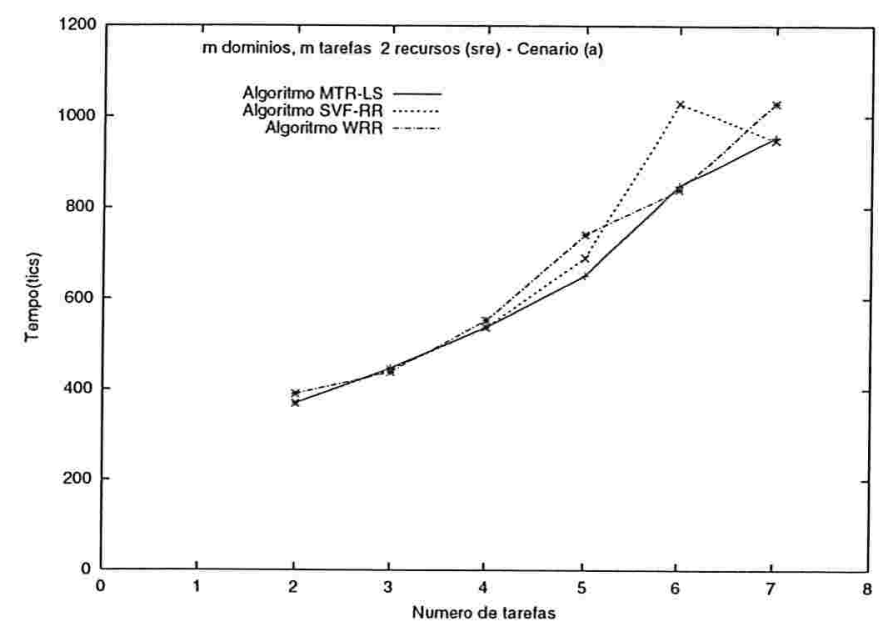

Figura 6.9: Cenário $a$ : Comportamento para Tarefas gastando $10 \%$ de $r_{1}$ e $80 \%$ de $r_{2}$.

Sabemos que cada tarefa concorrente inserida no sistema possui um valor menor do ciclo de serviço dos recursos designado para seu domínio, porém, mediante o cenário $a$, como podemos observar na Figura 6.9, com tarefas gastando pouco do recurso $r_{1}$, o comportamento dos algoritmos são similares.

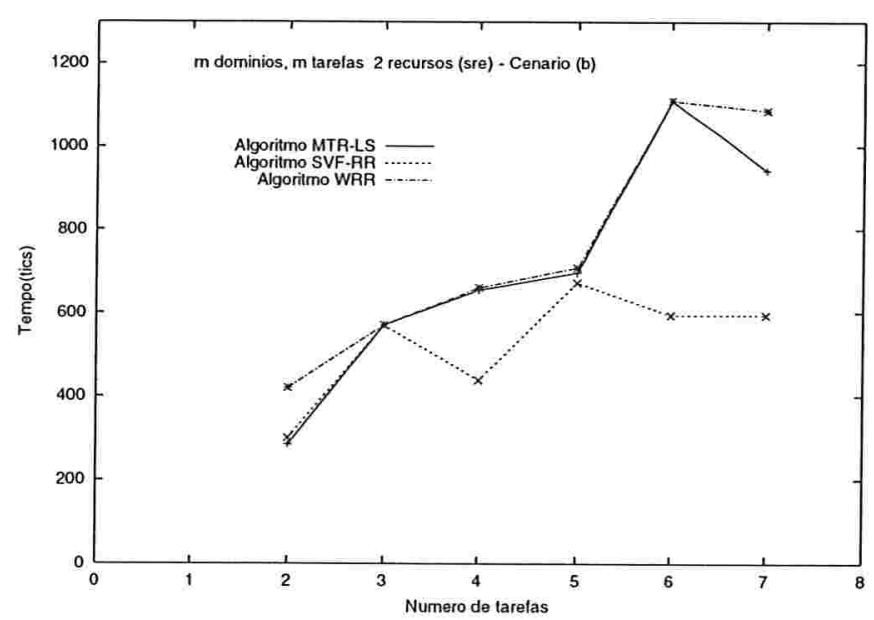

Figura 6.10: Cenário b: Comportamento para Tarefas gastando $45 \%$ de $r_{1}$ e $45 \%$ de $r_{2}$.

As Figuras 6.10 e 6.11 evidenciam que o escalonador SVF-RR provê um desempenho melhor. No cálculo do menor tempo virtual, é escolhida a tarefa que pertence ao domínio que possui mais reserva, no caso, aquela pertencente ao domínio $D_{2}$ - a tarefa de referência. 


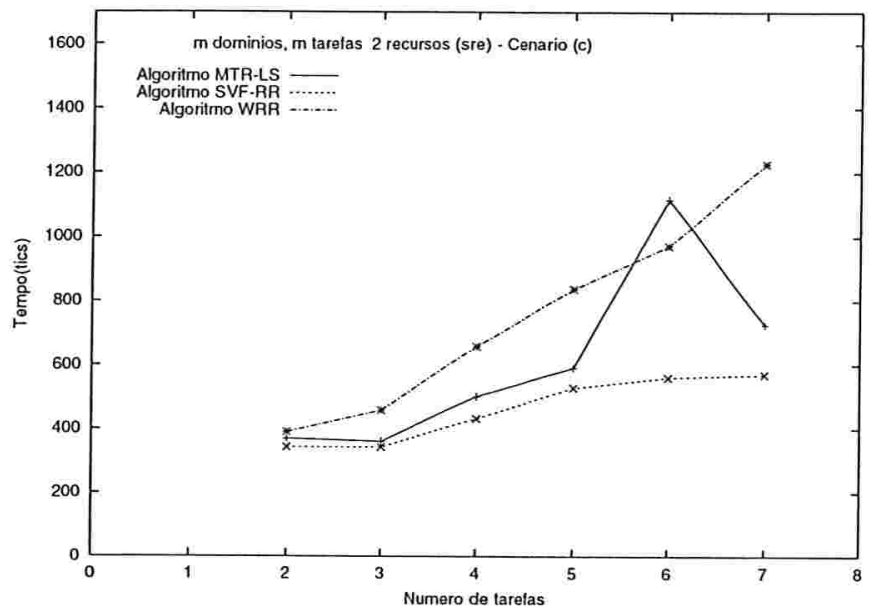

Figura 6.11: Cenário c: Comportamento para Tarefas gastando $80 \%$ de $r_{1}$ e $10 \%$ de $r_{2}$.

No MTR-LS o comportamento em média é bom; poderia ser melhor, porém é prejudicado porque o simulador rdsim não interrompe uma tarefa durante sua fase num recurso quando outra, com o token de seu domínio na frente, chega na fila de prontos do recurso.

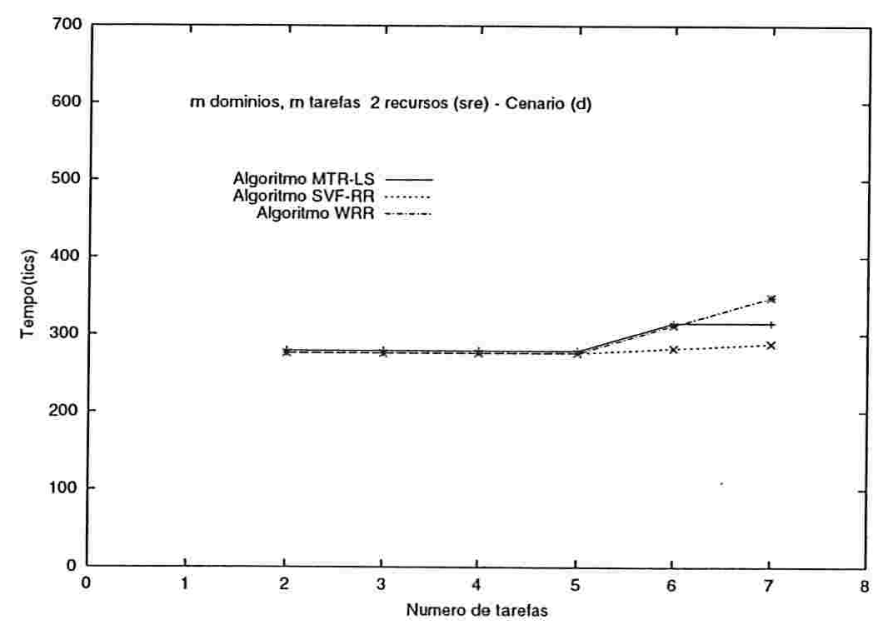

Figura 6.12: Cenário $d$ : Comportamento para Tarefas gastando $10 \%$ de $r_{1}$ e $10 \%$ de $r_{2}$.

Com tarefas que utilizam pequena taxa do ciclo de serviço dos recursos ativos observamos na Figura 6.12 que mesmo com o crescimento da carga no sistema, a tarefa de referência não sofre atraso significativo; resultado semelhante é obtido para os três algoritmos analisados.

Para o cenário $e$, com tarefas possuindo fases e recursos aleatórios (conforme se observa na Figura 6.13), o melhor desempenho está com a utilização da política MTR-LS. Quando um domínio possui a cota do ciclo de serviço de um recurso menor que a necessária para a sua tarefa, uma parte do seu token fica na frente do token do outro domínio. Assim, quando 


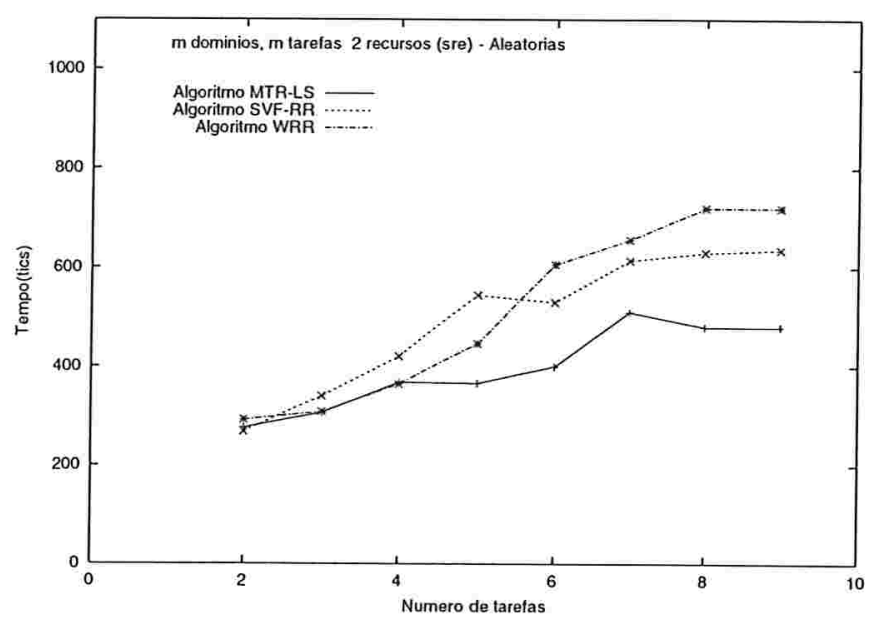

Figura 6.13: Cenário e: Comportamento para Tarefas Aleatórias.

o escalonador verifica a existência de tarefas no domínio da frente, após o atendimento de alguma outra tarefa no sistema, a de referência será novamente selecionada. O número de tarefas concorrentes não interfere no desempenho da tarefa de referência.

\subsection{7 $m$ Domínios, $n$ Tarefas, onde $m>1$ e $n>m$ :}

Ainda sob a perspectiva de uma análise comparativa e mediante os mesmos cenários, descritos na Tabela 6.9, acrescentamos uma tarefa à reserva de domínio da tarefa de referência. Analisamos o comportamento da tarefa de referência que disputa os ciclos de serviço dos recursos $r_{1}$ e $r_{2}$ com outra no mesmo domínio e com outras em domínios distintos.

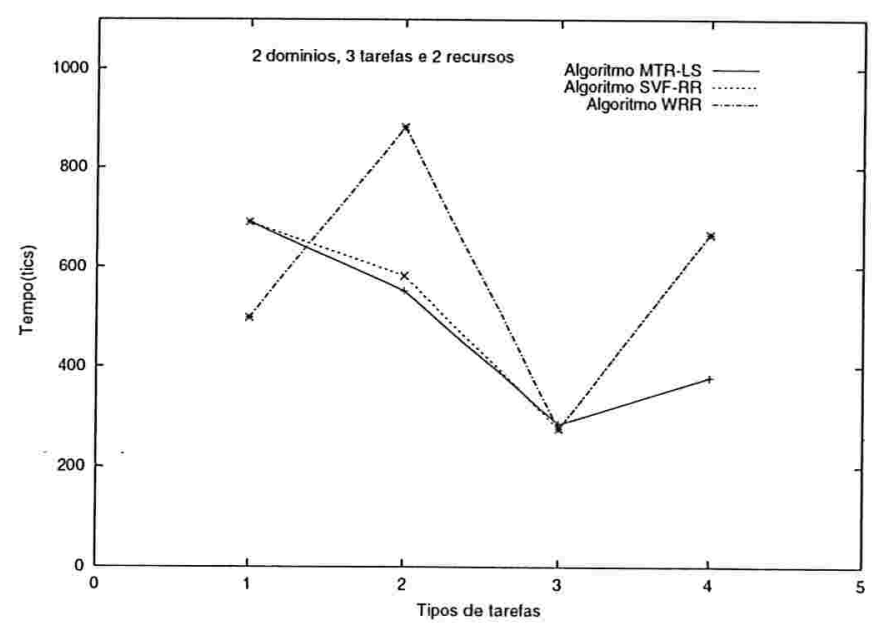

Figura 6.14: Comportamento para 3 Tarefas e 2 Domínios. 
Apresentamos, nas Figuras 6.14, 6.15 e 6.16, o tempo de finalização da tarefa de referência relativo aos quatro primeiros cenários, definidos na Tabela 6.9 , formados por 3,5 e 9 tarefas iguais, para ambientes montados com 2, 4 e 8 domínios, cada qual com reserva de $40 \%$, $20 \%$ e $10 \%$ dos recursos, preenchendo toda cota do ciclo de serviço dos recursos no sistema, respectivamente.

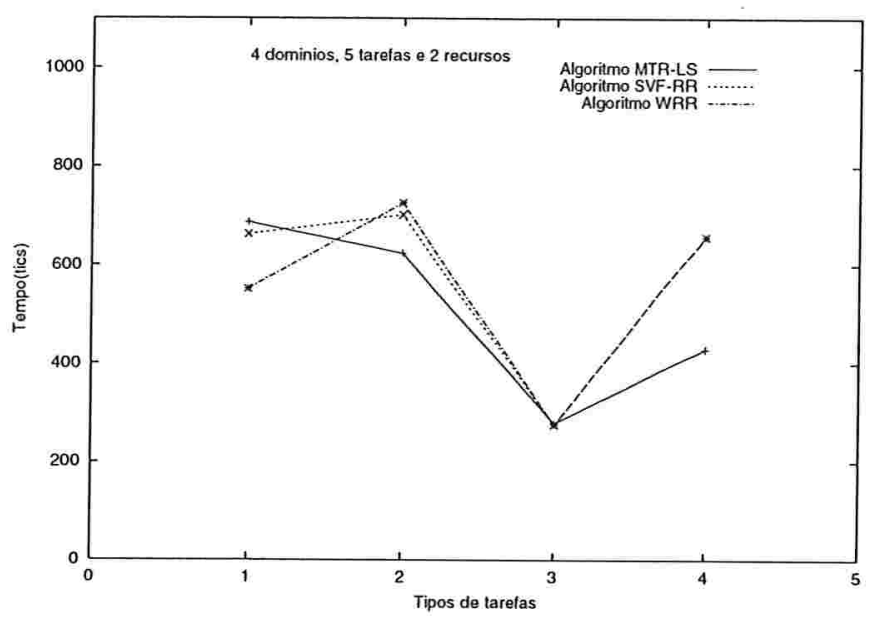

Figura 6.15: Comportamento para 5 Tarefas e 4 Domínios.

Quando adicionamos mais uma tarefa ao domínio da tarefa de referência, aos mesmos cenários apresentados anteriormente em " $m$ domínios, $m$ tarefas e 2 recursos" (Página 156), o tempo aumenta em média 50\%; o atendimento é feito distribuindo-se uma fração do tempo

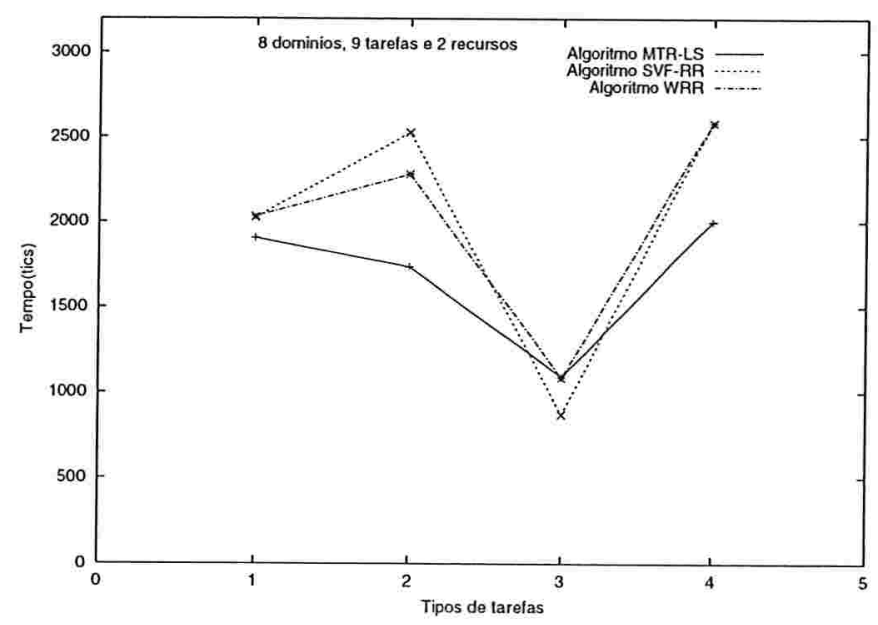

Figura 6.16: Comportamento para 9 Tarefas e 8 Domínios.

da porção do ciclo de serviço dos recursos do domínio $D_{2}$ a cada uma das duas.

No MTR-LS a tarefa é atendida, encaminhando-se para o final da fila de prontos do domínio 
e, dependendo da reserva de recurso do domínio, obtém-se bom desempenho.

No WRR a tarefa é atendida, dispendendo parte ou toda uma fração, indo para o final da fila de prontos, dentre todas no sistema.

No SVF-RR a próxima tarefa, com o menor tempo virtual no domínio, a ser atendida será a outra na fila de prontos, tendo desempenho similar ao WRR.

\subsubsection{Cenários Adicionais}

A análise de cenários onde o conjunto de tarefas no sistema é mista se baseia em três tipos de abordagem: (a) sobrecarregando o uso de um recurso; (b) variando a cota de reserva de um recurso e (c) analisando o tempo médio para o acesso a um recurso, diante dos diferentes algoritmos de escalonamento. Nestas abordagens, a tarefa de referência utiliza os recursos com frações diferenciadas das tarefas concorrentes.

\section{(a) Sobrecarregando um Recurso}

O ambiente foi constituído, inicialmente, por um domínio $D_{2}$ com reserva pré-definida e os recursos ativos $r_{1}$ e $r_{2}$.

Para investigarmos o escalonamento do recurso $r_{1}$, colocamos para executar, concorrentemente, a tarefa de referência e 8 tarefas iguais que utilizam muito o ciclo de serviço do recurso $r_{1}\left(80 \%\right.$ de $\left.r_{1}\right)$ e o restante $(20 \%)$ permanecem em situação de bloqueio. Cada tarefa concorrente possui sua própria reserva de domínio sem reserva explícita. A tarefa de referência alterna seu processamento entre $r_{1}$ e $r_{2}$, utilizando $10 \%$ de $r_{1}$ e $90 \%$ de $r_{2}$.

O mesmo cenário foi submetido ao rdsim, alterando a cada simulação a porção da reserva do recurso $r_{1}$ para o domínio $D_{2}$, e seus resultados são exibidos na Figura 6.17.

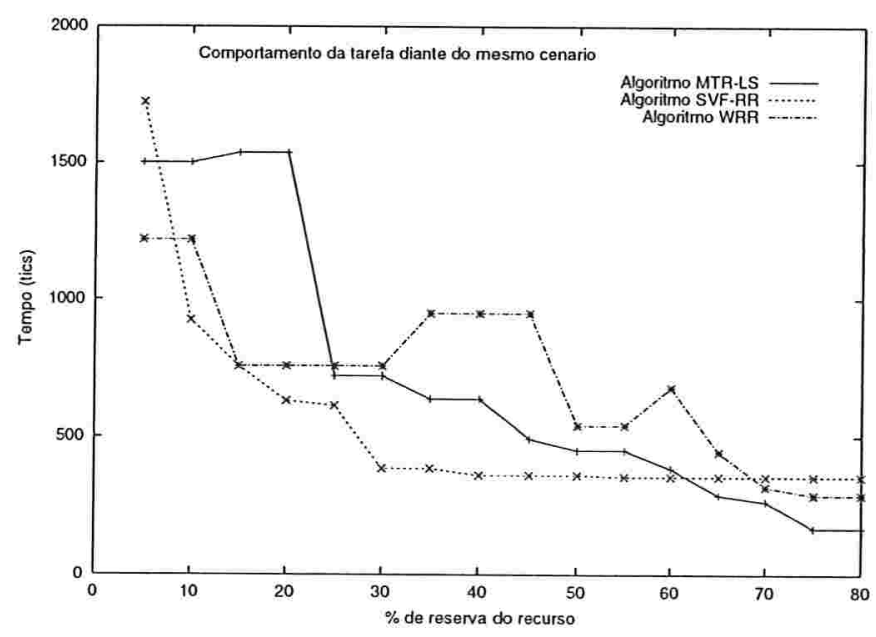

Figura 6.17: Tarefa de Referência e 8 Tarefas Concorrentes 
A tarefa de referência teve um desempenho melhor utilizando o WRR sob o mesmo cenário, quando sua reserva de domínio possuia uma fração entre $5 \%$ e $10 \%$ do ciclo de serviço de $r_{1}$. É evidente que, ao aumentarmos a porção da reserva do recurso $r_{1}$ para o domínio $D_{2}$, o desempenho da tarefa de referência melhora. Podemos observar a superioridade dos algoritmos MTR-LS e SVF-RR quando a cota da reserva de domínio supera a fração utilizada pelas fases da tarefa.

Para sobrecarregar o recurso $r_{1}$, foram colocadas para executar, disputando ciclos deste recurso, a tarefa de referência pertencente ao domínio $D_{2}$ e um número variado de tarefas concorrentes iguais sem reserva de domínio explícita.

As tarefas concorrentes alternam suas fases entre: $20 \%$ do ciclo do recurso $r_{1}$ e $15 \%$ do mesmo ciclo recebendo o tratamento para o caso de bloqueio. A tarefa de referência utiliza em cada fase, $10 \%$ do ciclo de $r_{1}, 80 \%$ do ciclo de $r_{1}$ em estado de bloqueio e $10 \%$ do ciclo de $r_{2}$, nesta ordem.

Acrescentamos a cada simulação uma tarefa concorrente, sobrecarregando o recurso $r_{1}$.

As Figuras 6.18, 6.19 e 6.20 apresentam no eixo $x$, o número de tarefas em cada cenário simulado, quando temos definida para o domínio $D_{2}$ uma cota de $10 \%, 20 \%$ e $30 \%$ dos ciclos dos recursos ativos $r_{1}$ e $r_{2}$, respectivamente. Observamos o comportamento de uma tarefa que alterna a utilização de dois recursos, disputando seus ciclos com tarefas iguais, que utilizam o recurso $r_{1}$ e dormem sempre.

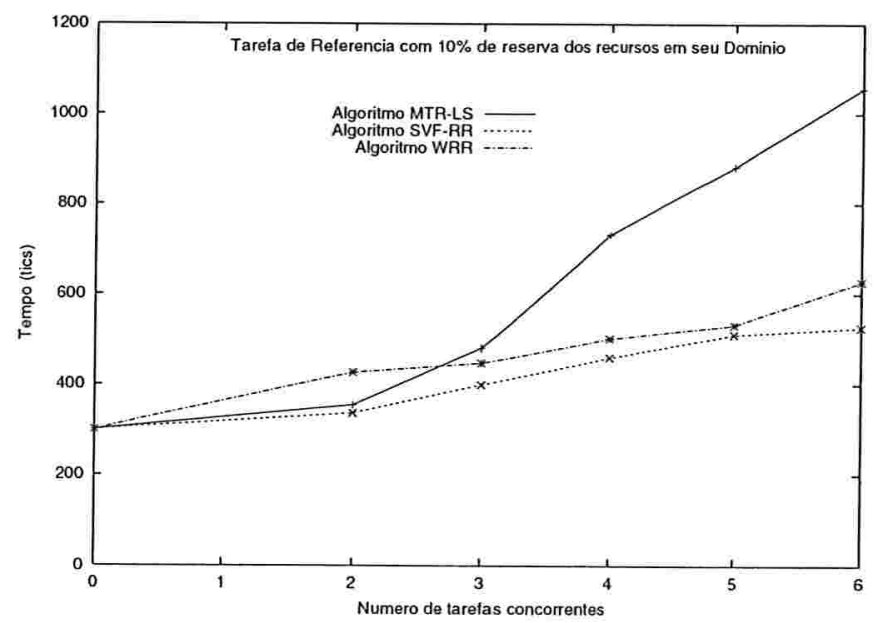

Figura 6.18: Comportamento da Tarefa de Referência para 10\% de Reserva dos Recursos em seu Domínio.

Com tarefas sendo executadas simultaneamente à tarefa de referência, e esta gastando menos que a fração reservada para seu domínio, constatamos que no MTR-LS, os tokens do domínio $D_{2}$ migram rapidamente para o início da lista dos domínios e são atendidos primeiro; as outras tarefas dormem sempre.

Também no SVF-RR, a tarefa de referência é a escolhida por ter em seu domínio o menor tempo virtual. 


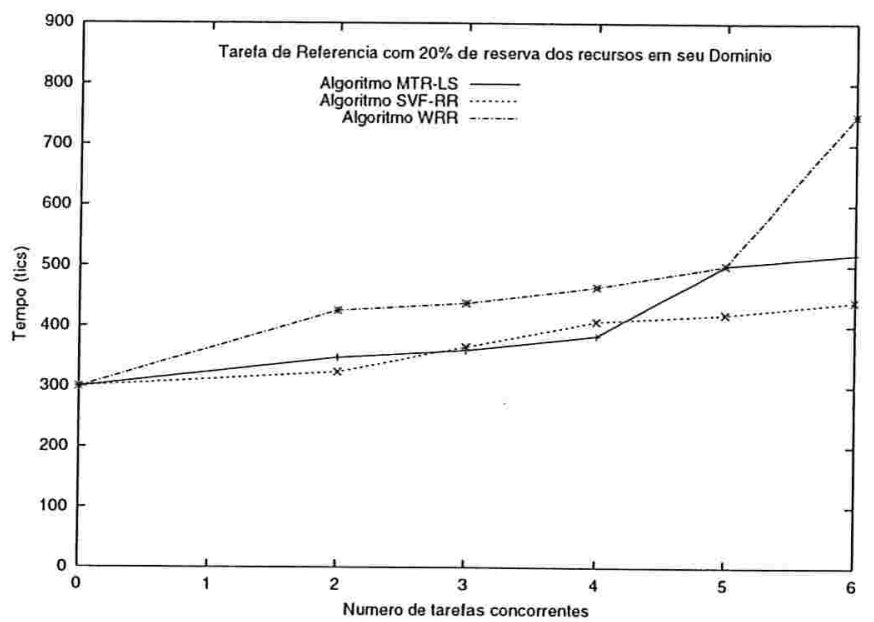

Figura 6.19: Comportamento da Tarefa de Referência para 20\% de Reserva dos Recursos em seu Domínio.

No WRR, a tarefa de referência também não apresenta grandes atrasos, pois na fila de prontos do recurso $r_{1}$ não encontramos sempre todas as tarefas concorrentes.

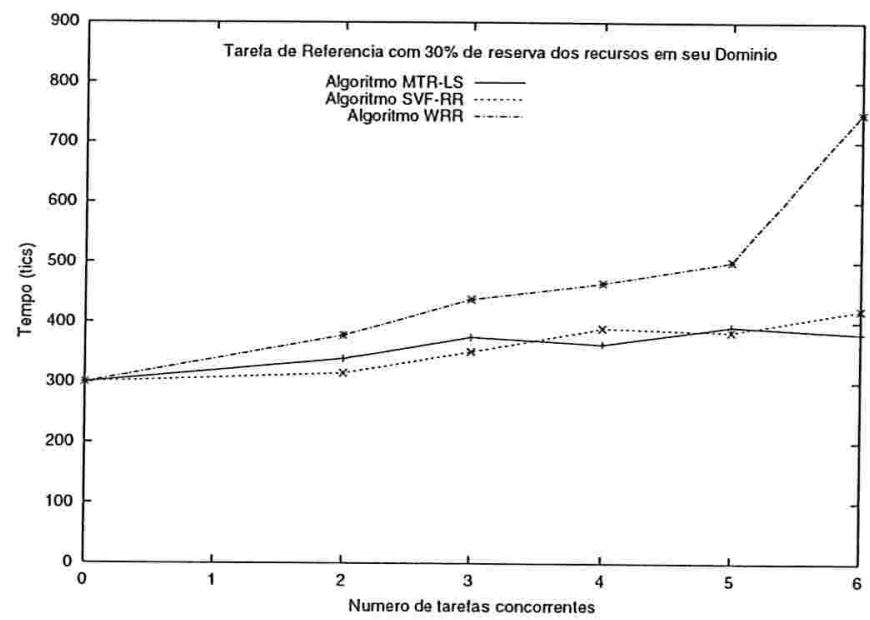

Figura 6.20: Comportamento da Tarefa de Referência para 30\% de Reserva dos Recursos em seu Domínio.

De modo geral, os algoritmos provêm um bom desempenho quando temos tarefas utilizando o recurso $r_{1}$ nos limites de sua reserva.

\section{(b) Variando a Cota de Reserva dos Recursos Ativos}

O cenário foi montado com dois domínios ativos, $D_{2}$ e $D_{3}$, e um conjunto de tarefas estático consumindo os ciclos de serviço dos recursos $r_{1}$ e $r_{2}$. 
Para analisarmos o desempenho da tarefa de referência mediante a variação da fração de reserva de um dos recursos ativos dos domínios $D_{2}$ e $D_{3}$, submetemos um conjunto de tarefas estático composto da tarefa de referência, utilizando $10 \%$ do ciclo de $r_{1}$ e $90 \%$ de $r_{2}$, pertencente ao domínio $D_{2}$, e de 8 tarefas concorrentes, utilizando $20 \%$ de $r_{1}$ e $80 \%$ de estado de bloqueio, pertencentes ao domínio $D_{3}$. Variamos, em cada um deles as cotas de reserva do recurso $r_{1}$ nos dois domínios ativos, de $5 \%$ a $80 \%$.

A Figura 6.21 representa, no eixo $x$, as reservas do recurso $r_{1}$ para o domínio $D_{2}$ e, no eixo $y$, o tempo da tarefa de referência no sistema.

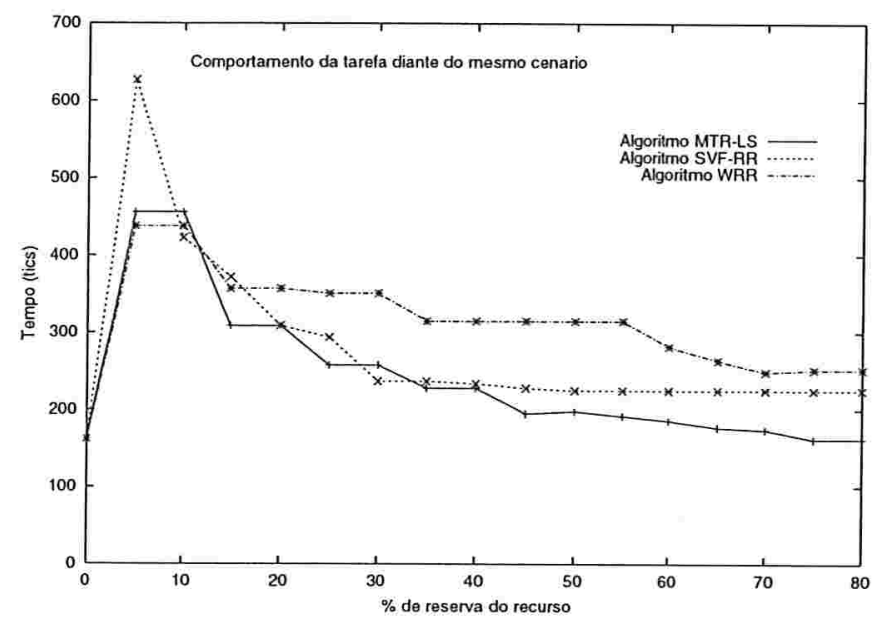

Figura 6.21: Tarefa de Referência sob Diferentes Reservas de $r_{1}$ em $D_{2}$.

Na medida em que a reserva do recurso $r_{1}$ em $D_{2}$ aumenta, a partir da reserva de $15 \%$, os algoritmos MTR-LS e SVF-RR escalonam a tarefa de referência antes das concorrentes. A explicação é que a tarefa de referência consome pouco do recurso $r_{1}$ e é a única em seu domínio. Assim, seus tokens tendem a migrar para o início da lista de domínios, enquanto que as outras são bloqueadas sempre. O tempo virtual do domínio $D_{2}$, onde temos a tarefa de referência, é menor, pois esta utiliza pouco do recurso $r_{1}$. Em outras palavras, estas políticas provêm um atraso limitado quando a tarefa não excede a sua reserva.

Para analisarmos o desempenho da tarefa de referência mediante a variação da fração da reserva dos dois recursos ativos em $D_{2}$ e $D_{3}$, submetemos um conjunto de tarefas estático composto da tarefa de referência utilizando $40 \%$ do ciclo de $r_{1}$ e $60 \%$ de $r_{2}$, pertencente ao domínio $D_{2}$, e de 10 tarefas iguais concorrentes utilizando $10 \%$ do ciclo de $r_{1}$ e $80 \%$ de $r_{2}$, pertencentes ao domínio $D_{3}$.

Diante de experimentações, utilizando o mesmo algoritmo de escalonamento para ambos recursos, os resultados apresentaram valores bem melhores para o MTR-LS quando a reserva do recurso $r_{1}$, do domínio $D_{2}$, variava de $75 \%$ a $55 \%$, enquanto que a reserva de $r_{2}$ variava de $5 \%$ a $25 \%$. Porém, para as outras frações de reservas designadas aos domínios, o desempenho da tarefa de referência foi extremamente ruim. Em relação aos outros algoritmos, o comportamento foi similar ao apresentado nesta seção. 


\begin{tabular}{|rc|cc|}
\hline \multicolumn{2}{|c|}{$D_{2}$} & \multicolumn{2}{c|}{$D_{3}$} \\
\hline$r_{1}$ & $r_{2}$ & $r_{1}$ & $r_{2}$ \\
\hline $75 \%$ & $5 \%$ & $5 \%$ & $95 \%$ \\
$70 \%$ & $10 \%$ & $10 \%$ & $90 \%$ \\
$65 \%$ & $15 \%$ & $15 \%$ & $85 \%$ \\
\multicolumn{2}{|c|}{$\vdots$} & \multicolumn{2}{|c}{$\vdots$} \\
$20 \%$ & $60 \%$ & $60 \%$ & $40 \%$ \\
$15 \%$ & $65 \%$ & $65 \%$ & $35 \%$ \\
$10 \%$ & $70 \%$ & $70 \%$ & $30 \%$ \\
$5 \%$ & $75 \%$ & $75 \%$ & $25 \%$ \\
\hline
\end{tabular}

Tabela 6.12: Reserva dos Recursos para os Domínios $D_{2}$ e $D_{3}$.

Para os experimentos apresentados aqui, colocamos o mesmo cenário diante dos três algoritmos de escalonamento para o recurso $r_{1}$ e o escalonador WRR para o recurso $r_{2}$. Variamos em cada um deles as cotas de reserva dos recursos $r_{1}$ e $r_{2}$ nos dois domínios ativos, conforme mostramos na Tabela 6.12.

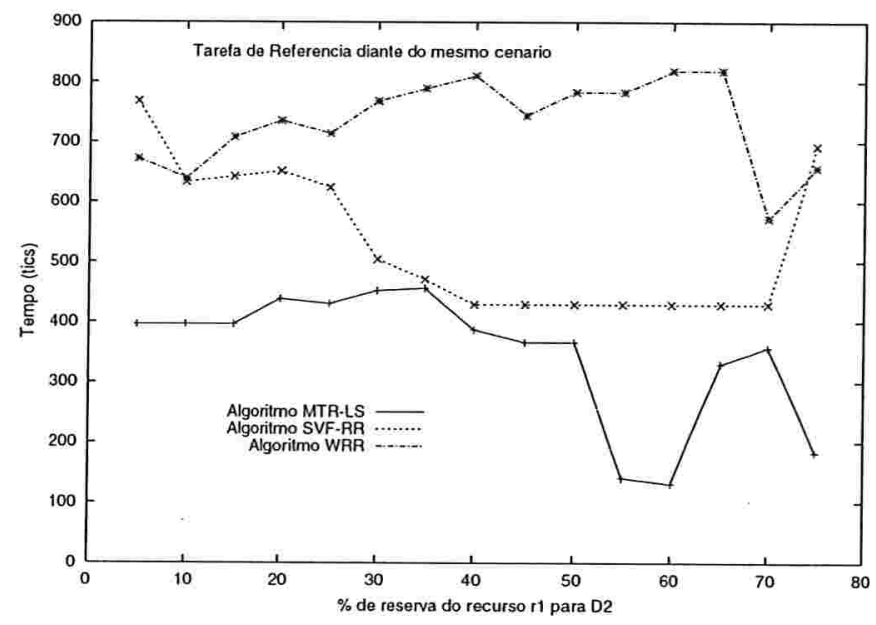

Figura 6.22: Tarefa de Referência sob Diferentes Reservas de $r_{1}$ e $r_{2}$ em $D_{2}$.

A Figura 6.22 representa no eixo $x$ as reservas do recurso $r_{1}$ para o domínio $D_{2}$ e no eixo $y$ o tempo da tarefa de referência no sistema.

Até a cota de $40 \%$, a tarefa de referência utiliza toda a reserva de $D_{2}$, pois é única em seu domínio, e ainda fica com um token no início da lista dos domínios, podendo ser atendida na próxima seleção feita pelo escalonador MTR-LS. Podemos observar que a variação das cotas do recurso $r_{2}$ pouco afeta seu desempenho. A tarefa de referência não volta imediatamente a utilizar o recurso no WRR, pois é colocada no final da fila de prontos, após as 10 tarefas concorrentes. 


\section{(c) Análise do Tempo Médio para o Acesso a um Recurso}

Este experimento foi construído no intuito de analisar o escalonamento de um recurso $r_{1}$ para uma tarefa rica na utilização do recurso $r_{2}$.

Consideramos o cenário onde temos a tarefa de referência, colocada no domínio $D_{2}$, que utiliza seguidamente, $20 \%$ do ciclo do recurso $r_{1}$ e $80 \%$ do recurso $r_{2}$, mais um número variado de tarefas iguais que utilizam $10 \%$ do recurso $r_{1}$ e o restante do ciclo permanecem bloqueadas. Fixamos o domínio $D_{2}$ com reserva de $40 \%$ de $r_{1}$ e $80 \%$ de $r_{2}$ e cada instância da tarefa concorrente executada em domínio separado, sem reserva explícita dos recursos.

Submetemos a tarefa de referência sozinha no sistema para obtermos o número de acessos ao recurso $r_{2}$ e os momentos de acesso ao mesmo. A partir destes dados, considerados ótimos e sem atraso, fomos acrescentando no sistema, uma a uma, as tarefas concorrentes e coletando as mesmas informações para a tarefa de referência.

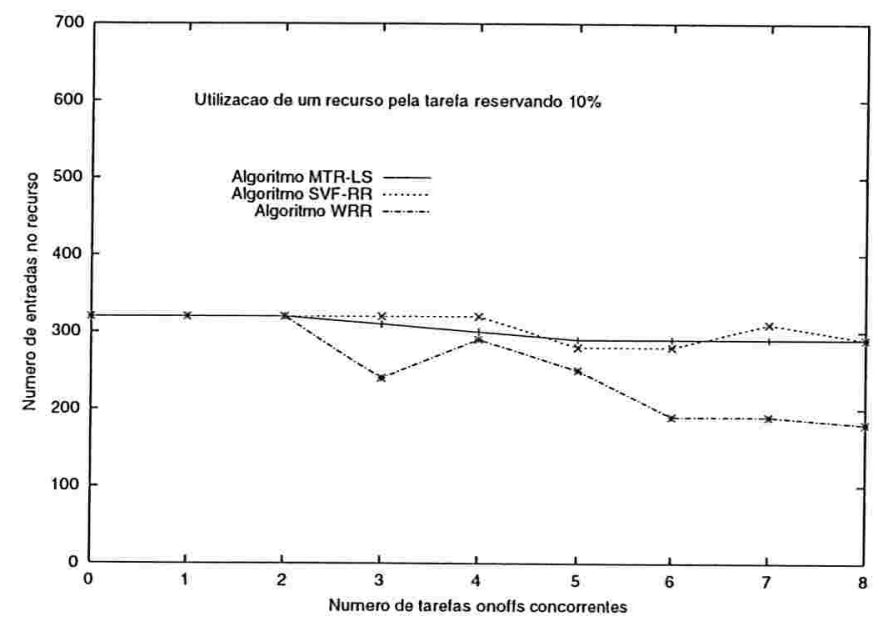

Figura 6.23: Tempos de Resposta cumpridos.

A Figura 6.23 representa no eixo $y$ o número médio de acessos ao recurso $r_{2}$, obtido pela tarefa de referência quando executada concorrentemente a um número variado de tarefas iguais.

Para os algoritmos MTR-LS e SVF-RR, a média de atraso é pequena e o número de entradas no recurso $r_{2}$, a cada intervalo de tempo é praticamente inalterado. No WRR, a tarefa de referência é sempre inserida ao final da fila de prontos do recurso $r_{1}$ e após as tarefas concorrentes. Assim, o throughput diminui à medida que aumentamos o número de tarefas concorrentes. Observamos em testes adicionais que quando aumentamos a reserva de recurso $r_{1}$ para a tarefa de referência, não obtemos melhora do resultado.

Na Figura 6.24, as tarefas concorrentes dispendem $10 \%$ a mais do ciclo no recurso $r_{1}$ e dormem $10 \%$ menos, para a mesma tarefa de referência.

Verificamos que o atraso ocorre de forma mais acentuada para os algoritmos MTR-LS e 


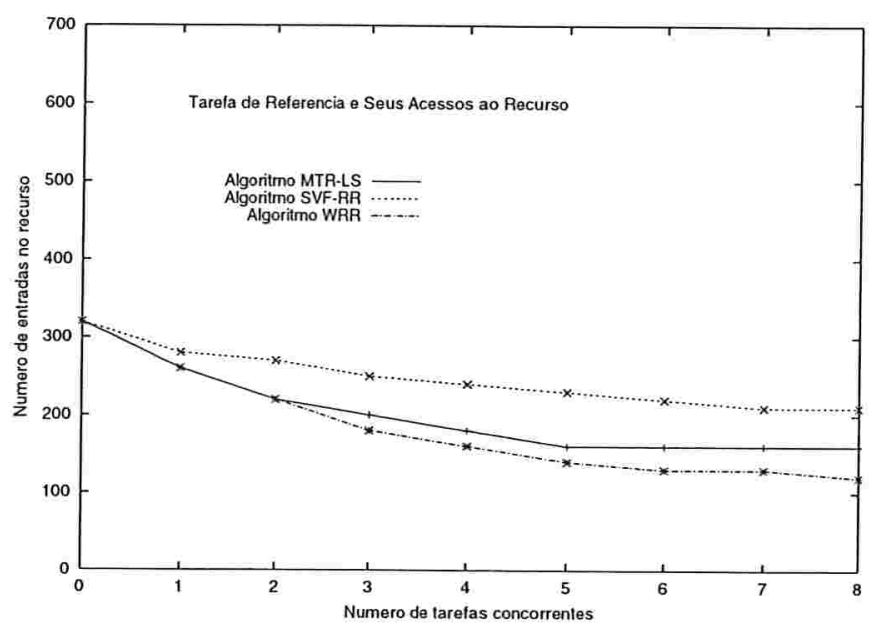

Figura 6.24: Tempos de Resposta cumpridos.

SVF-RR (relativamente ao experimento exibido na Figura 6.23). Porém, o progresso ocorre para todas tarefas no sistema, independentemente das suas necessidades pelos recursos.

\subsection{Conclusões}

Pela análise dos algoritmos utilizados e pelos resultados das experimentações apresentados, podemos constatar alguns benefícios das reservas de domínios:

* Quando as tarefas pertencem todas a uma mesma reserva de domínio, o desempenho depende da política de escalonamento do domínio;

* Os escalonadores de reservas de domínio preferem as tarefas que utilizam os recursos em porções pequenas de suas reservas;

* Mediante a sobrecarga de um recurso do sistema, os tempos de finalização das tarefas sofrem pouca alteração quando utilizamos o MTR-LS ou SVF-RR, em relação ao tempo quando sozinha no sistema, provendo QoS;

* Quando temos cenários possuindo carga mista, dependendo da política de distribuição das frações de reserva dos recursos, constatamos a superioridade dos algoritmos MTR-LS e SVF-RR;

* Verificamos que durante a simulação das tarefas, os atrasos não ultrapassaram limites estabelecidos. Caso a tarefa utilize algum recurso além da cota de processamento de sua reserva de domínio, esta sofrerá preempção, garantindo o acesso ao recurso por outra tarefa no sistema. Assim, a reserva de domínio previne que processos não monopolizem os recursos indefinidamente. 
Ressaltamos a importância da reserva de domínio ser bem definida para o bom desempenho das diversas aplicações no sistema. Quando temos distribuída a cota do ciclo de serviço do recurso, de maneira a satisfazer as tarefas no sistema, observamos que estas são atendidas com QoS, obtendo-se um bom desempenho, independentemente da necessidade dos recursos por elas requeridos. 


\section{Capítulo 7}

\section{Conclusões e Trabalhos Futuros}

Neste capítulo apresentamos as nossas considerações finais sobre o que foi realizado e os desafios encontrados no decorrer desta dissertação, comentando as conclusões deste trabalho e apresentando perspectivas sobre possíveis trabalhos futuros.

Com o crescimento da demanda de aplicações que envolvem intenso compartilhamento de recursos do ambiente computacional e da utilização de uma mesma plataforma para atender diferentes tipos delas, o controle e a gerência desses ambientes têm se tornado cada vez mais complexos.

Pesquisas na área de Sistemas Operacionais mostram que os sistema operacionais atuais não atendem adequadamente as demandas específicas das aplicações de tempo real, em razão do grande consumo de recursos geralmente impostos por elas, não oferecendo garantias de QoS. O desempenho de uma aplicação não depende só dela, mas do sistema operacional utilizado e de sua carga, como constatamos em nosso estudo de caso [dSVdCGN99b, dSVdCGN99c, dSVdCGN99a].

Diante desses fatos, nosso trabalho teve dois propósitos.

O primeiro propósito foi realizar uma pesquisa bibliográfica voltada à utilização e ao entendimento de alguns mecanismos de gerenciamento de recursos em sistemas multiprogramáveis, particularmente voltada ao estudo do problema da alocação apropriada dos recursos, que utilizam esquemas de gerenciamento baseados em reserva proporcional de recurso e que oferecem algumas garantias de QoS. O objeto de nosso estudo foi baseado em dois trabalhos de pesquisa. O primeiro diz respeito a um novo critério de QoS chamado serviço cumulativo. Discutimos a importância da garantia de serviço cumulativo para escalonadores tal que ofereça desempenho previsível para aplicações que requerem múltiplos recursos. O critério serviço cumulativo permite o relacionamento do total de serviço obtido por um processo sob uma política de escalonamento com o servico ideal que o processo teria acumulado executando em cada recurso se tivesse determinado uma fração de reserva de cada um destes. Uma política de escalonamento proporciona uma garantia de serviço cumulativo se o desempenho do sistema real difere do sistema ideal, no máximo, por uma constante. E refere-se também aos algoritmos de escalonamento: Move-to-Rear List Scheduling, Shortest Virtual 
Time First Round Robin e Weighted Round Robin Scheduling, que provêm as garantias de serviço cumulativo, justiça (compartilhamento do recurso proporcional) e atraso limitado. Detalhamos a política, a complexidade e as propriedades de cada um deles. que provêm as garantias de serviço cumulativo, justiça (compartilhamento do recurso proporcional) e atraso limitado. O segundo trabalho refere-se a uma das soluções apresentadas a abstração em sistemas operacionais chamada reserva de domínio [BGzS98] que permite um controle explícito sobre o aprovisionamento dos recursos do sistema pelas aplicações. Em geral, a cada reserva de domínio é designada uma certa fração de reserva de cada recurso (por exemplo, $25 \% \mathrm{CPU}$, $50 \% \mathrm{I} / \mathrm{O}$ ). Apresentamos o sistema operacional experimental Eclipse que utiliza a abstração reserva de dominio e estes escalonadores.

O segundo propósito foi o projeto e construção de um um ambiente para simulação de recursos baseado na proposta reserva de domínio, descrito no Capítulo 5, onde estas políticas foram implementadas com o intuito de simularmos escalonamentos em um modelo de sistema de reservas de domínios e avaliarmos e analisarmos o desempenho na utilização de reservas de domínios diante do comportamento de uma aplicação sob uma diversidade de cenários.

Comprovamos alguns benefícios da reserva de domínios e a funcionalidade das três políticas de escalonamento estudadas, através de simulações. Para tal, desenvolvemos o procedimento experimental rdsim. Realizamos testes comparativos entre os três algoritmos de escalonamento sob diferentes ambientes computacionais e cenários com diferentes tipos de tarefas. Vários conjuntos de experimentos foram realizados; os mais significativos estão documentados no Capítulo 6. Pudemos comprovar a eficácia das políticas de escalonamento que selecionam reserva de domínio para a alocação dos recursos diante da caracterização do ambiente, da descrição do cenário, da identificação da participação de cada reserva de domínio no sistema e da caracterização individual de cada recurso desse sistema.

\subsection{Desafios Enfrentados e As Soluções}

Um desafio foi encontrar um modo de investigarmos as três políticas de escalonamento baseadas em reserva de domínios. Acreditamos que a melhor estratégia seria a implementação das abstrações e dos algoritmos estudados no núcleo de um sistema operacional como o Linux, como elaborado em [Vie99]. Mas o escopo das alterações seria muito mais amplo que em [Vie99], exigindo um esforço de implementação além do pretendido neste trabalho. Assim, optamos por investigarmos o comportamento dos algoritmos através de simulações. Como discutido no Capítulo 5, desenvolvemos nosso próprio simulador, o rdsim.

Os resultados de uma análise podem ser avaliados e generalizados através de analogia; o desafio foi compreender como seria possível descobrir relacionamentos conclusivos entre as diferentes informações produzidas. Entendemos que isso passava por um processo de aprendizado e treino da visualização das informações e para tanto, desenvolvemos diversos conjuntos de experimentos onde saberíamos o que esperar. Variamos os dados dos três componentes de entrada para a ferramenta rdsim, cruzamos diferentes informações com disciplina, para encontrarmos cenários que seriam relevantes diante apenas de uma simulação, o que restringia bem 
o conjunto, principalmente para sobrecarregarmos o sistema. A técnica da análise explorativa é essencial quando se sabe pouco ou quase nada sobre o comportamento de um processo no sistema, qual reserva de domínio deve-se escolher para obter QoS; que QoS é um parâmetro do problema individualizado. Ela nos permite estudar um grande conjunto de informações através de um processo de tentativa e erro. A solução que encontramos para essa dificuldade foi seguirmos criteriosamente o método de análise que apresentamos no Capítulo 6.

\subsection{Sugestões e Pesquisas Futuras}

Podemos salientar e sugerir alguns assuntos que poderão ser abordados em futuros projetos:

- Melhoria da ferramenta rdsim, adicionando-se uma interface gráfica no rdsim para oferecer a comunicação com o usuário mais confortável e cooperativa. Com a implementação de janelas no rdsim pode-se gerar ambientes computacionais (recebendo as informações necessárias via teclado), pode-se escolher o algoritmo a ser simulado para cada recurso, pode-se apresentar os relatórios estatísticos, gráficos de escalonamento de tarefas, etc.

- A aplicação do rdsim como ferramenta de apoio didático dentro de uma disciplina do curso de Ciência da Computação.

Uma proposta de trabalho futuro seria acrescentar ao rdsim os componentes necessários para fazer dele uma ferramenta que possa ser utilizada como auxiliar no ensino de algoritmos de escalonamento de processos, semelhantemente ao simulador de escalonadores de tarefas de tempo-real [MKNB99], projeto desenvolvido e utilizado no DCCE - Unesp, campus de São José do Rio Preto. O rdsim pode ser estendido de forma a suportar abstrações e algoritmos clássicos, e assim permitir que o aluno experimente diretamente com algoritmos usualmente apresentados em livro texto. O rdsim permitiria então que o aluno simulasse seu conjunto de tarefas quando aplicado a vários algoritmos, fornecendo informações sobre o seu desempenho e comportamento no sistema.

- A avaliação de outros critérios na escolha de cenários de teste a fim de caracterizar integralmente uma indicação da melhor reserva de domínio.

- Permitir que os algoritmos simulados possam ser adaptados dinamicamente, permitindo que o escalonamento opere de acordo com a demanda.

Os algoritmos precisam ter a capacidade de se adaptar de forma automática a diferentes condições nas reservas de domínios. Se isto ocorrer de forma eficiente, tanto os recursos do sistema podem ser utilizados melhor, como a carga pode ter seu desempenho aprimorado. Com informação de controle podendo ser acessada durante a simulação podemos dinamicamente monitorar e alterar a situação de alguma reserva de domínio e assim melhorar o desempenho das tarefas que convivem no sistema em determinado instante. Um monitoramento dinâmico é uma solução para a redistribuição das reservas em tempo de execução. Quando algum atraso significante é obtido por uma tarefa no sistema, sua reserva pode ser aumentada ou vice-versa; 
se houver ociosidade entre os intervalos de preempção pode-se diminuir a cota de uma reserva de domínio. Um monitoramento das diversas tarefas no sistema, podendo-se decidir qual seria a melhor reserva de domínio a que ela deveria pertencer para obter o melhor desempenho.

- Estender reservas de domínios para sistemas distribuídos com múltiplos servidores e clientes, experimentando esquemas hierárquicos para reserva de domínios e investigando novos esquemas híbridos de escalonamento, combinando políticas baseadas em prioridades para reservas de domínios.

- Continuidade da pesquisa através da implementação dos algoritmos de escalonamento estudados em um sistema operacional como o Linux.

\subsection{Conclusão Final}

Acreditamos que a utilização da abstração reserva de domínio provê parâmetros de QoS esperados em sistemas sobrecarregados e particiona seus recursos pelas aplicações concorrentes. Reservas de domínios permitem que aplicações de tempo real possam co-existir com aplicações batch num mesmo sistema, sem prejuízo para nenhuma.

Através da escolha certa entre as reservas de domínios existentes no sistema, há como informar ao sistema a importância de uma aplicação e conseqüentemente, obter a Qualidade de Serviço desejada via reserva de domínios.

Esta dissertação está disponível no URL: www.ime.usp.br/dcc/posgrad/teses//. 


\section{Referências Bibliográficas}

[ADMC98] J. Almeida, M. Dabu, A. Manikutty, and P. Cao. Providing Differentiated Quality of Service in Web Hosting Services. In Proceedings of the Workshop on Internet Server Performance, June 1998.

$\left[\mathrm{BBD}^{+98}\right.$ M. Beck, H. Böhme, M. Dziadzka, U. Kunitz, R. Magnus, and D. Verworner. Linux Kernel Internals. Addison-Wesley, second edition, 1998.

$\left[\mathrm{BBG}^{+} 99 \mathrm{a}\right]$ J. Bruno, J. Brustoloni, E. Gabber, M. Mcshea, B. Özden, and A. Silberschatz. Disk Scheduling with Quality of Service Guarantees. In Proceedings of International Conference on Multimedia Computing and Systems. IEEE, June 1999.

[BBG $\left.{ }^{+} 99 \mathrm{~b}\right]$ J. Bruno, J. Brustoloni, E. Gabber, B. Özden, and A. Silberschatz. Retrofitting Quality of Service into a Time Sharing Operating System. In Proceedings of the USENIX 1999 Annual Technical Conference, Monterey, California, June 1999.

$\left[\mathrm{BBM}^{+} 99\right]$ J. Blanquer, J. Bruno, M. McShea, E. Gabber, B. Özden, A. Silberschatz, and A. Singh. Resource Management for Quality of Service in Eclipse/BSD. In Proceedings of FreeBSD 1999 Conference, Berkeley, California, October 1999.

[BDM99] G. Banga, P. Druschel, and J. Mogul. Resource Containers: A new facility for resource management in server systems. In Proceedings of the USENIX 3rd Symposium on Operating System Design and Implementation, New Orleans, LA, October 1999, February 1999.

[Ben96] R. Bentson. Inside Linux: A Look at Operating System Development. Specialized System Consultants, first edition, 1996.

[BGS] J. Brustoloni, E. Gabber, and A. Silberschatz. Signaled Receiver Processing. submitted for publication.

$\left[\mathrm{BGz}^{+}\right] \quad$ J. Bruno, E. Gabber, B. Özden, A. Silberschatz, M. McShea, J. Blanquer, and M. Kalia. Eclipse/BSD. http://www.bell-labs.com/what/eclipse. 
$\left[\mathrm{BGz}^{+} 97\right]$ J. Bruno, E. Gabber, B. Özden, H. Saran, and A. Silberschatz. Closedloop Packet Sources and Cumulative Service. Technical report, AT\&T Bell Laboratories, August 1997.

[BGzS97] J. Bruno, E. Gabber, B. Özden, and A. Silberschatz. Move-To-Rear List Scheduling: A New Scheduling Algorithm for Providing QoS Guarantees. In Proceedings of ACM Multimedia'97, Seattle, WA, November 1997. USENIX Association.

[BGzS98] J. Bruno, E. Gabber, B. Özden, and A. Silberschatz. The Eclipse Operating System: Providing Quality of Service via Reservation Domains. In Proceedings of the USENIX 1998 Annual Technical Conference, pages 235-246, New Orleans, Louisiana, June 1998. USENIX Association.

[BSD] FreeBSD. http://www.freebsd.org.

[BZ96a] Jon Bennett and Hui Zhang. Hierarchical Packet Fair Queueing Algorithms. In Proceedings of the SIGCOMM'96, ACM, August 1996.

[BZ96b] Jon Bennett and Hui Zhang. WF ${ }^{2} \mathrm{Q}$ : Worst-case Fair Weighted Fair Queueing. In Proceedings of the INFOCOM'96, pages 120-128, IEEE, San Francisco, March 1996.

[CDM97] R. Card, É. Dumas, and F. Mével. The Linux Kernel Book. John Wiley, 1997.

[CLR90] T. Cormen, C. Leiserson, and R. Rivest. Introduction to Algorithms. MIT Press. Cambridge, MA, 1990.

[Cru98] R. L. Cruz. Sched+: Efficient Management of Quality of Service Guarantees. In Proceedings of the IEEE INFOCOM, pages 198-211, San Francisco,March 1998, April 1998.

[CSKT91] S. Cheng, J. A. Stankovic, J. Kurose, and D. Towsley. Performance Evaluation of Two New Scheduling Algorithms for Real-Time Systems. pages 3:307-336. J. Real-Time Systems, 1991.

[CSR88] S. Cheng, J. A. Stankovic, and K. Ramamritham. Scheduling Algorithms for Hard Real-Time Systems: A Brief Survey. pages 150-173, 1988.

[dCGN01] M. do Carmo Garcia Noronha. rdsim: Simulador de Escalonadores. http://www.ime.usp.br/ carmo/rdsim, May 2001.

[Dij65] E. W. Dijkstra. Solution of a Problem in Concurrent Programming Control. Commun. of ACM, 1965.

[dSVdCGN99a] Dilma M. da Silva, Jorge E. Vieira, and M. do Carmo G. Noronha. Estudo de Caso: Desempenho Deficiente do Sistema Operacional Linux para Carga Mista de Aplicações. http://www.ime.usp.br/ dilma/smart/ws99, Fevereiro 1999. 
[dSVdCGN99b] Dilma M. da Silva, Jorge E. Vieira, and M. do Carmo G. Noronha. Estudo de Caso: Desempenho Deficiente do Sistema Operacional Linux para Carga Mista de Aplicações. Technical report, Instituto de Matemática e Estatística - USP, Maio 1999.

[dSVdCGN99c] Dilma M. da Silva, Jorge E. Vieira, and M. do Carmo G. Noronha. Estudo de Caso: Desempenho do SO Linux para Aplicações Multimidia em Tempo Real. In Proceedings of the Second Symposium of Real Time, pages 88-95, Salvador, BA, May 1999.

[FdSFoSdO00] Jean-Marie Farines, Joni da S. Fraga, and Rômulo S. de Oliveira. Sistemas de Tempo Real. Escola de Computação, 2000.

[FJ97] Eric Foster-Johnson. Graphical Applications with Tcl and Tk. Division of Henry Holt and Company, Inc, second edition, 1997.

[Fou] Free Software Foundation. GNU. http://www.gnu.org/fsf/.

[GGV96] Pawan Goyal, Xingang Guo, and Harrick M. Vin. A Hierarchical CPU Scheduler for Multimedia Operating Systems. In Proceedings of the Second Symposium on Operating Systems Design and Implementation, pages 107-121, Seattle, WA, October 1996. USENIX Association.

[GVC96] Pawan Goyal, Harrick M. Vin, and Haichen Cheng. Start-time Fair Queuing: A Scheduling Algorithm for Integrated Services Packet Switching Networks. In Proceedings of ACM SIGCOMM'96, Department of Computer Sciences, University of Texas at Austin, August 1996.

[GzS93] A. Goldberg, B. Özden, and A. Silberschatz. Virtual computers - a new paradigm for distributed operating systems. In Proceedings of the 6th IEEE Symposium on Paralled and Distributed Processing, pages 236-240, Dallas, Texas, December 1993.

[GzS94] A. Goldberg, B. Özden, and A. Silberschatz. Processor Scheduling In Virtual Computer Systems. In Proceedings of the 7th International Conference on Parallel and Distributed Computing Processing, October 1994.

[HP96] K. Husain and T. Parker. Linux Unleashed. Sams Publishing, second edition, 1996.

[JRR97] Michael B. Jones, Daniela Roşu, and M.-Cătălin Roşu. Cpu Reservations and Time Constraints: Efficient, Predictable Scheduling of Independent Activities. In Proceedings of the 16th ACM Symposium on Operating Systems Principles (SOSP), pages 198-211, Saint-Malo, France, October 1997.

[Kim] Myunggyu Kim. Ising Model Simulator. http://hana.etri.re.kr/ mgkim/tcltk.html. 
[Ler]

[LL73]

$\left[\mathrm{LMB}^{+} 96\right]$

[LMKQ96]

[MKNB99]

[MST93]

[MST94]

[NHNW93]

[NL96]

[NL97]

[Ous94]

$\begin{array}{llll}\text { X. Leroy. } & \text { The } & \text { LinuxThreads } & \text { library. } \\ \text { http://pauillac.inria.fr/ xleroy/linuxthreads/. } & & \end{array}$

C. L. Liu and James W. Layland. Scheduling Algorithms for Multiprogramming in a Hard-Real-Time Environment. Journal of the ACM, 20:46-61, January 1973.

I. Leslie, D. McAuley, R. Black, T. Roscoe, P. Braham, D. Evers, R. Fairbairns, and E. Hyden. The Design and Implementation of An Operating System to Support Distributed Multimedia Applications. IEEE Journal on Selected Areas in Communication, 14(7):1280-1297, September 1996.

S. Leffler, M. McKusick, M. Karels, and J. Quaterman. The Design and Implementation of the 4.4BSD UNIX Operating System. Addison-Wesley Publishing Company, 1996.

Aleardo Manacero, Rodrigo B. Kehdy, Viviane A Nabuco, and Luciana P.P. Bueno. Rtsim: Um Simulador de Escalonadores de Tarefas Aplicadas ao Ensino de Sistemas de Tempo-Real. In Proceedings of XIX Congresso Nacional da Sociedade Brasileira de Computação, pages 543-552, Rio de Janeiro, RJ, July 1999.

Clifford W. Mercer, Stefan Savage, and Hideyuki Tokuda. Processor Capacity Reserves: An Abstration for Managing Processor Usage. In Proceedings of the 4th Workshop on Workstation Operating Systems, October 1993.

Clifford W. Mercer, Stefan Savage, and Hideyuki Tokuda. Processor Capacity Reserves: Operating System Support for Multimedia Applications. In Proceedings of the IEEE International Conference on Multimedia Computing and Systems, May 1994.

Jason Nieh, James G. Hanko, J. Duane Northcutt, and Gerard A. Wall. SVR4 UNIX Scheduler Unacceptable for Multimedia Applications. In Proceedings of the Fourth International Workshop on Network and Operating Systems Support for Digital Audio and Video, pages 35-48, Lancaster, U. K., November 1993.

Jason Nieh and Monica S. Lam. The Design of Smart: A scheduler for Multimedia Applications. Technical report, Computer Systems Laboratory, Stanford University, June 1996.

Jason Nieh and Monica S. Lam. The Design, Implementation and Evaluation of Smart: A scheduler for Multimedia Applications. In Proceedings of the 16th ACM Symposium on Operating Systems Principles (SOSP, pages 184-197, Saint-Malo, France, October 1997.

John K. Ousterhout. Tcl and the Tk Toolkit. Addilson-Wesley Publishing Company, first edition, 1994. 
[per99] Tutorial of Perl/Tk. http://www.perl.com/pub/1999/10/perltk/index.html, 1999.

[PG93] A. K. Parekh and R. G. Gallager. A Generalized Processor Sharing Approach to Flow Control in Integrated Services Networks: The Single-Node Case. IEEE/ACM Transactions on Networking, 3:344-357, June 1993.

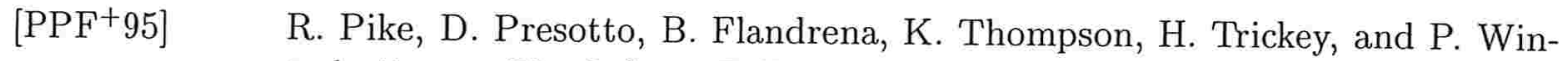
terbottom. Plan9 from Bell Labs. Journal of the USENIX Association, 3:221-254, 1995.

[RJM098] Raj Rajkumar, Kanaka Juvva, Anastacio Molano, and Shuichi Oikawa. Resourse Kernels: A Resource-Centric Approach to Real-Time and Multimedia Systems. In Proceedings of the SPIE/ACM Conference on Multimedia Computing and Networking, January 1998.

[RLLS97] Ragunathan Rajkumar, Chen Lee, John Lehoczky, and Dan Siewiorek. A Resource Allocation Model for QoS Management. Department of Computer Science, February 1997.

$\left[\mathrm{SAWJ}^{+}\right.$96] Ion Stoica, H. Abdel-Wahab, K. Jeffay, S. Baruah, J. Gehrke, and G. Plaxton. A Proportional Share Resource Allocation Algorithm for Real-Time, TimeShared Systems. In Proceedings of 17th Real-Time Systems Symposium, pages 288-299, IEEE, December 1996.

[SAWJ97] Ion Stoica, H. Abdel-Wahab, and K. Jeffay. On The Duality between Resource Reservation and Proportional Share Resource Allocation. In Proceedings of Multimedia Computing and Networking, February 1997.

[Sch90] Hebert Schildt. C - Completo e Total. McGraw-Hill, second edition, 1990.

[SG91] Klein Sha and J. Goodenough. Rate Monotonic Analysis for Real-Time Systems. In Foundations of Real-Time Computing: Scheduling and Resource Management, pages 129-155, Boston,MA. Kluwer Academic Publishers, 1991.

[SR88] J. Stankovic and K. Ramamritham. Tutorial on Hard Real-Time Systems. 1988.

[SR90] J. A. Stankovic and K. Ramamritham. What is Predictability for Real-Time Systems? The Journal of Real Time Systems, 2:247-254, 1990.

[SR93] J. Stankovic and K. Ramamritham. Advances in Real-Time Systems. In IEEE Computer Society Press, 1993.

[SR94] J. A. Stankovic and K. Ramamritham. Scheduling Algorithms and Operating Systems Support for Hard Real-Time Systems. In Proceedings of IEEE, volume 82 (1), pages 55-67, January 1994. 
[Tan92] Andrew S. Tanenbaum. Modern Operating Systems. Prentice-Hall, 1992.

[Tre99] Sam Tregar. gRMA v0.01a. http://www.tregar.com/gRMA, 1999.

[TW97] Andrew S. Tanenbaum and A. S. Woodhull. Operating Systems: Design and Implementation. Prentice-Hall, second edition, 1997.

[Vie99] Jorge E. Vieira. LINUX-SMART: Melhoria de Desempenho para Aplicações Real-Time Soft em Ambiente Linux. Dissertação de Mestrado. Instituto de Matemtática e Estatística - USP, Outubro 1999.

[WW94] Carl A. Waldspurger and W. E. Weihl. Lottery Scheduling: Flexible Proportional-Share Resource Management. In Proceedings of the First Symposium on Operating System Design and Implementation (OSDI), pages 1-11, Montrey, California, November 1994.

[WW95] Carl A. Waldspurger and William E. Weihl. Stride Scheduling: Deterministic Proportional-Share Resource Management. Technical report, TM-528. MIT Laboratory for Computer Science, Cambridge, Massachusetts, June 1995.

[zRS96] B. Özden, R. Rastogi, and A. Silberschatz. Fellini Continuous Media Storage Server. In Kluwer Academic Publishers, 1996. 